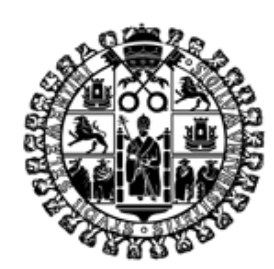

UNIVERSIDAD DE SALAMANCA

FACULTAD DE CIENCIAS SOCIALES

DEPARTAMENTO DE SOCIOLOGÍA Y COMUNICACIÓN

\title{
LAS ACTITUDES DE LOS RESIDENTES Y LAS RESIDENTES \\ HACIA EL REALOJO EN UNA COMUNIDAD URBANA \\ POBRE EN SAN JUAN: 2006-2007
}

Tesis presentada por Vivianna Margarita De Jesús Monge

para la obtención del grado de Doctora, bajo la dirección del Profesor Doctor Jorge Duany y la tutela del Profesor Doctor Pedro Cordero Quiñones

Salamanca, marzo de 2011 
APROBADO POR

\section{DIRECTOR}

Doctor Jorge Duany

TUTOR

Doctor Pedro Cordero Quiñones 
A los(as) residentes de la comunidad estudiada, por atenderme en sus hogares y dedicarme de su tiempo para poder realizar esta investigación.

Son un ejemplo a seguir por las demás comunidades en Puerto Rico, por su esfuerzo para mantenerse unidos(as), su perseverancia para permanecer en esa ubicación privilegiada en San Juan, su amor al pasado lleno de luchas y trabajo y su esperanza por un futuro mejor. 
Deseo expresar agradecimiento a mi padre Wilfredo, mi madre Rosa M. y mi hermano Wilfredo E., por inculcarme el amor al servicio público y el orgullo por nuestras raíces humildes.

Al Profesor Doctor Jorge Duany, por su apoyo y orientación durante la realización de esta investigación y ser un ejemplo a seguir en mi incursión en la Antropología.

Al Profesor Doctor Pedro Cordero Quiñones, Profesor Doctor Ángel Espina Barrio y la facultad del Departamento de Sociología y Comunicación de la

Universidad de Salamanca, por infundir en el estudiantado la dedicación a realizar estudios sobre Iberoamérica.

A los(as) residentes de la comunidad estudiada, por su participación en esta investigación.

Al personal de la corporación pública, por su ayuda y apoyo.

A María de Lourdes Javier Rivera, por su colaboración en la recopilación de datos, durante el trabajo de campo.

A mis familiares y amistades, por su apoyo, ánimo y consejos, durante la realización del doctorado. 
—La necesidá, doña. A mí misma, quién me 'biera dicho que yo diba llegar aquí. Yo que tenía hasta mi tierrita...

- Pueh nojotroh fuimoh de los primeroh. Casi no había gente y uno cogía la parte máh sequecita, ¿ve? Pero los que llegan ahora, fíjese, tienen que tirarse al agua, como quien dice: Pero, bueno, y... esa gente, ¿de dónde diantre habrán salío?

- A mí me dijeron que por ái por Isla Verde 'tan orbanisando y han sacao un montón de negros arrimaoh. Alo mejor son d'esoh.

José Luis González en "En el fondo del caño hay un negrito" 


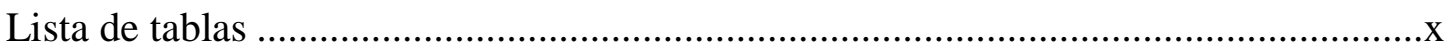

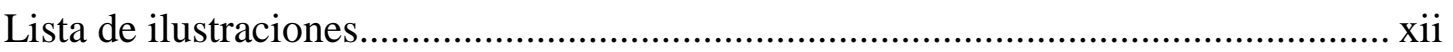

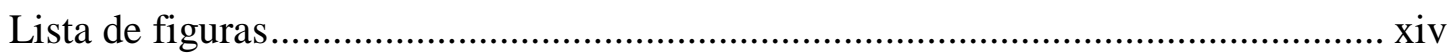

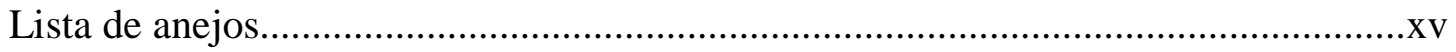

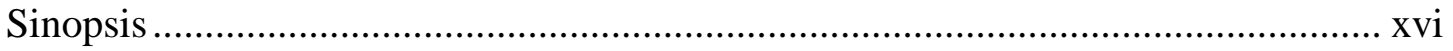

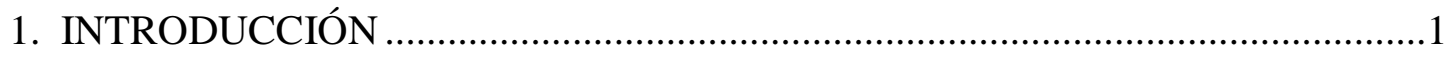

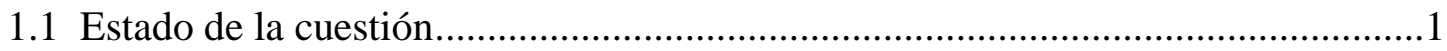

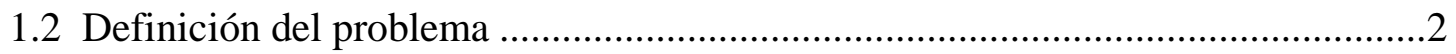

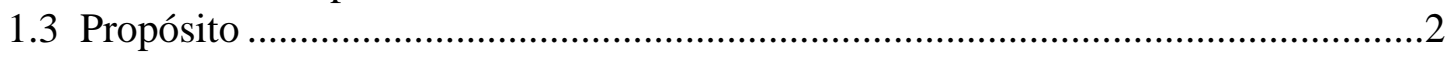

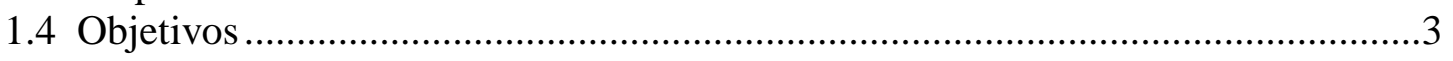

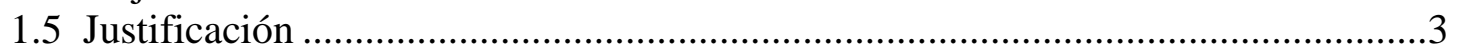

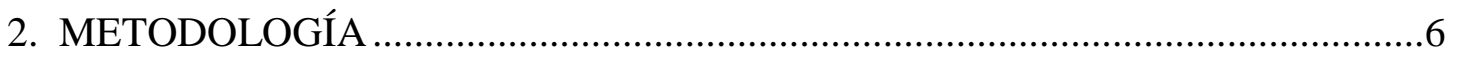

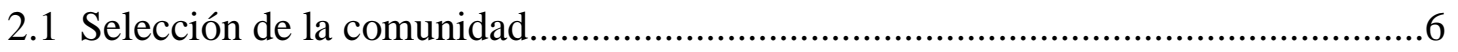

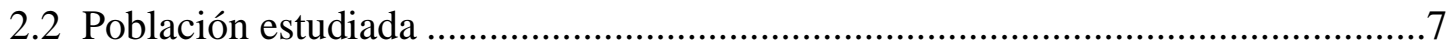

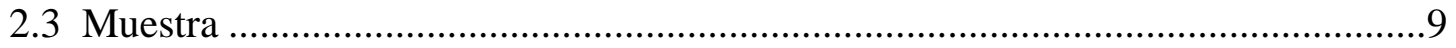

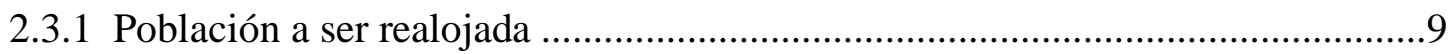

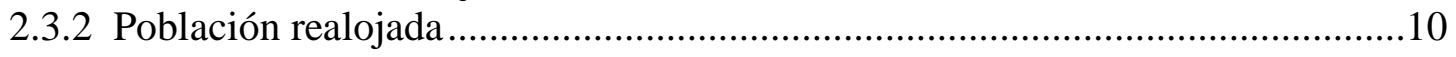

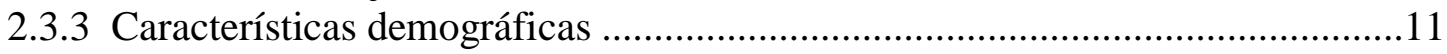

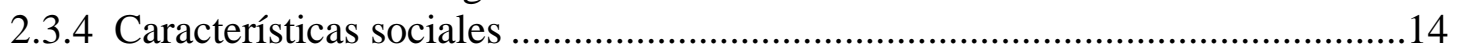

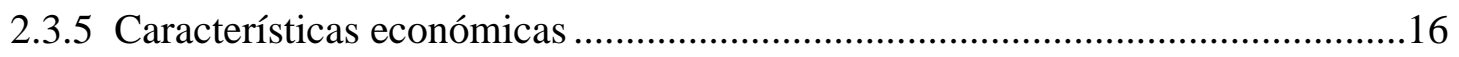

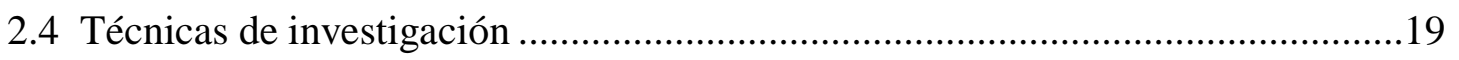

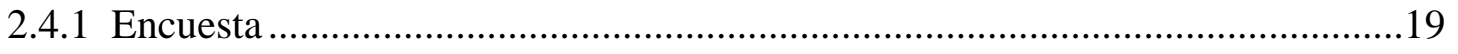

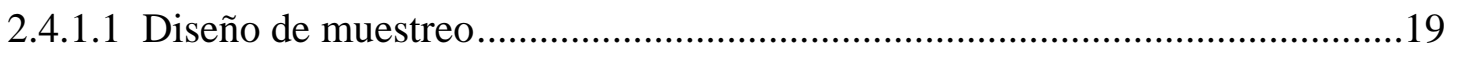

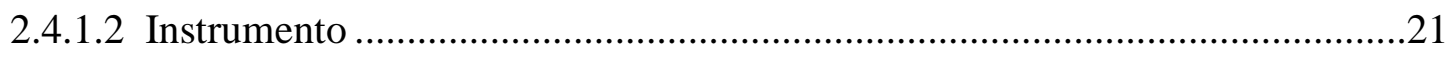

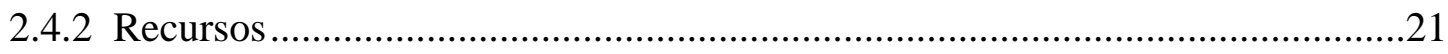

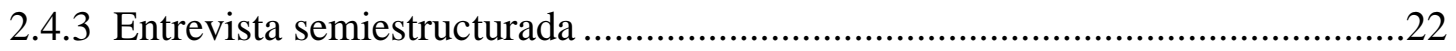

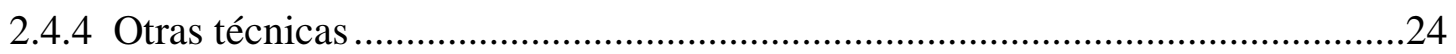

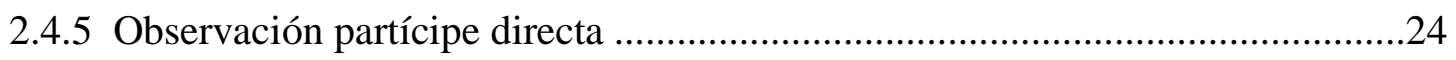

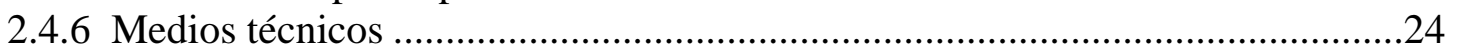

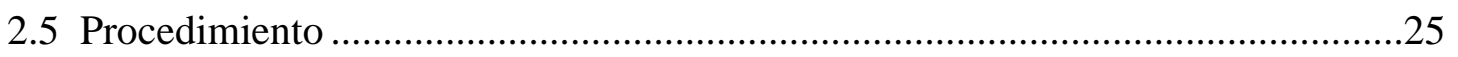

2.6 Reflexiones personales sobre la experiencia del trabajo de campo .......................27

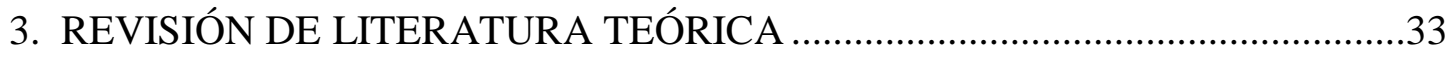

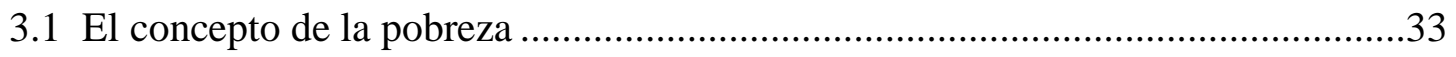

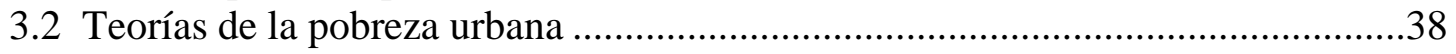

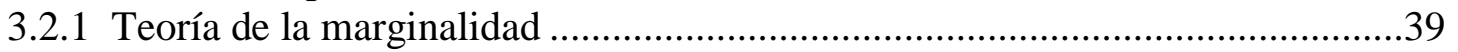

3.2.2 Teoría de la cultura de la pobreza ................................................................46

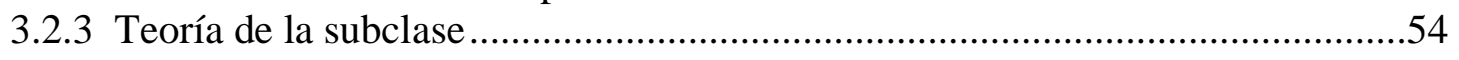

4. REVISIÓN DE LITERATURA ETNOGRÁFICA …..........................................63

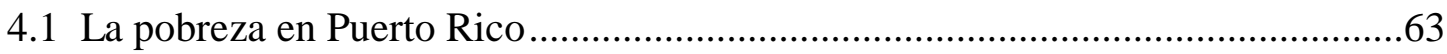

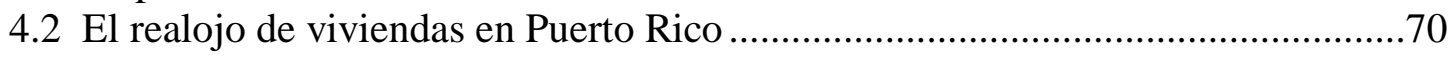

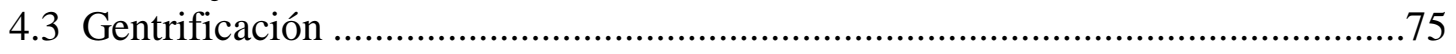

4.4 Diferencias entre arrabal, slum, shantytown, barrio y gueto ................................82 


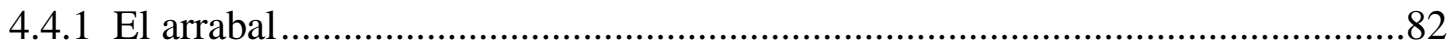

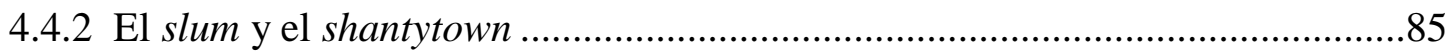

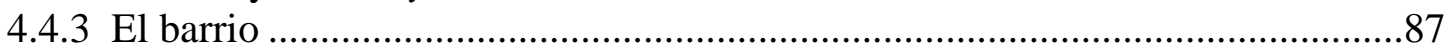

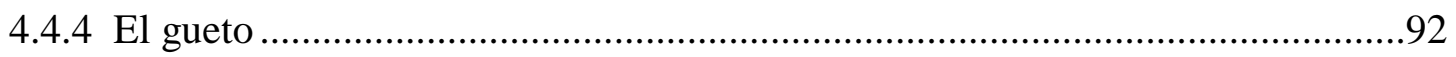

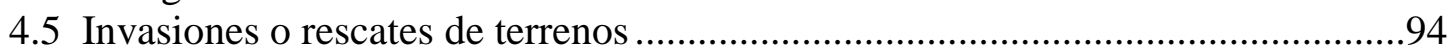

5. TRASFONDO HISTÓRICO Y SITUACIÓN ACTUAL DE LA

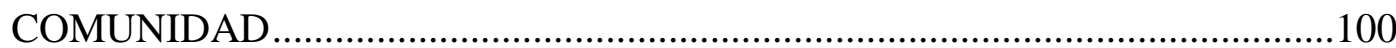

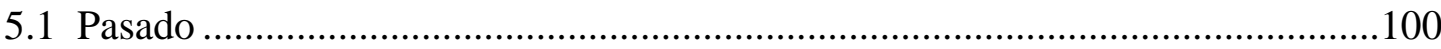

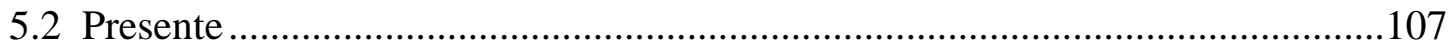

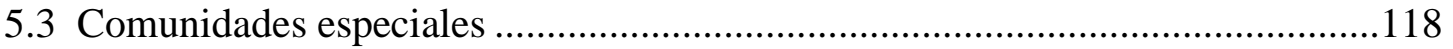

6. HALLAZGOS SOBRE ACTITUDES HACIA EL REALOJO ...........................123

6.1 Actitudes de los(as) residentes a ser realojados(as) y los(as) residentes

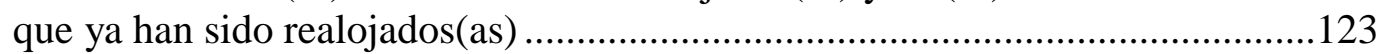

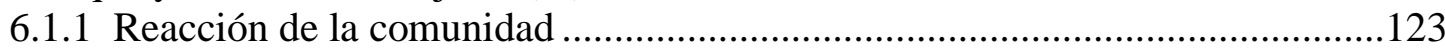

6.1.2 Comparación con otras comunidades donde han realojado o realojarán..........125

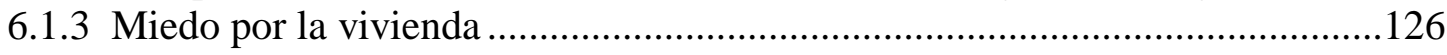

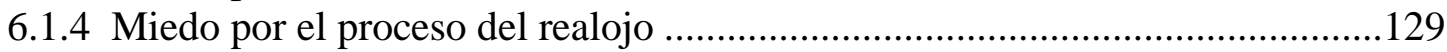

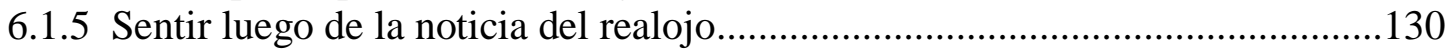

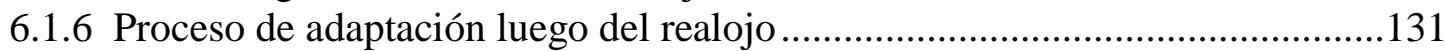

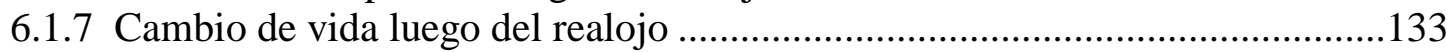

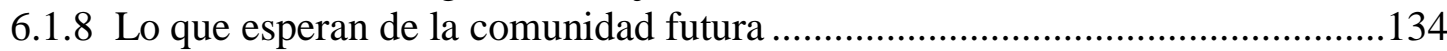

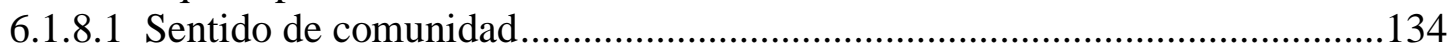

6.1.8.2 Lo que le faltaría o le falta a la comunidad................................................135

6.1.8.3 Lo que ganaría o ha ganado la comunidad...............................................136

6.1.9 Características de la comunidad deseada .....................................................138

6.1.10 Comentarios sobre los proyectos de vivienda por las personas

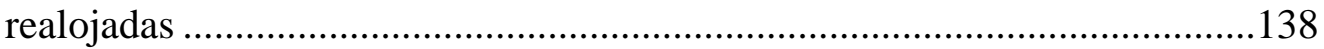

6.1.11 Aspectos que agradan y desagradan del proyecto de vivienda .....................140

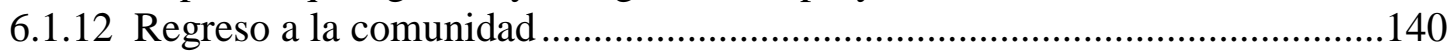

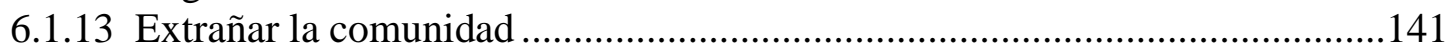

6.1.14 Comparación de su comunidad con el resto de San Juan ..............................142

6.1.15 Comparación de las actitudes hacia el realojo por género y edad ..................144

6.1.15.1 Actitudes hacia el realojo por género.......................................................144

6.1.15.2 Actitudes hacia el realojo por edad .......................................................... 145

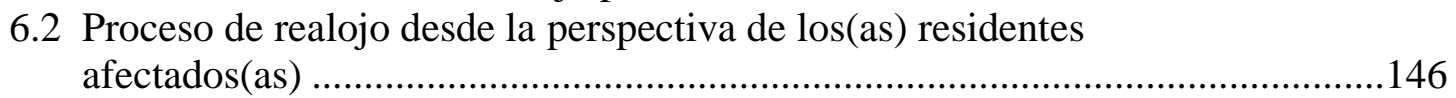

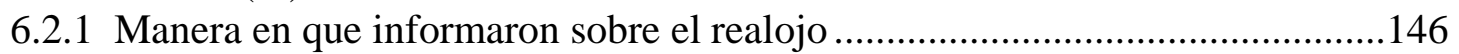

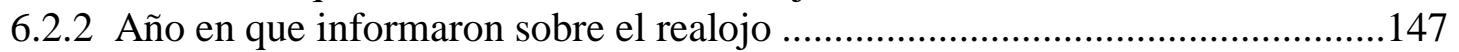

6.2.3 Agencia u organización que informó sobre el realojo ..................................147

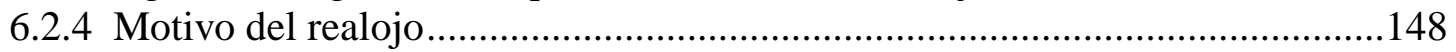

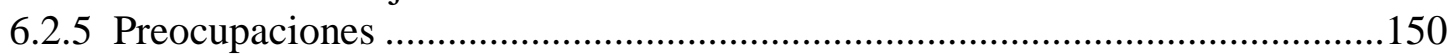

6.2.5.1 Preocupación por el realojo y percepción de la comunicación con la

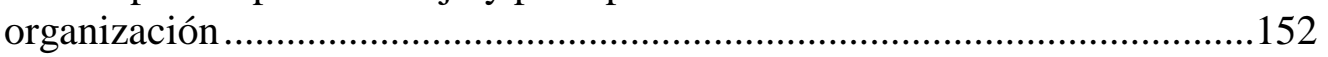

6.2.5.2 Preocupación por el realojo y años de estudio...........................................152

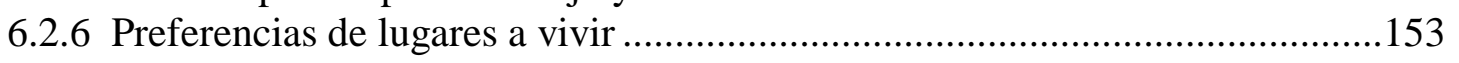

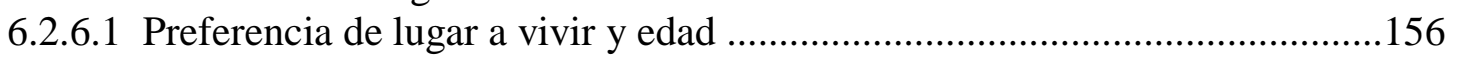

6.2.6.2 Preferencia de lugar a vivir y año de inicio de residencia en comunidad. 
6.2.6.3 Preferencia de lugar a vivir y percepción de los cambios ocurridos

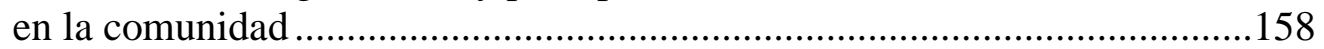

6.2.7 Experiencias pasadas de realojo y desalojo ..................................................158

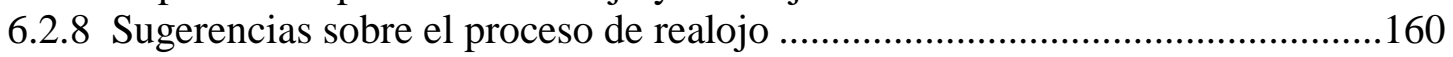

6.2.9 Percepción de la comunicación con la organización .....................................162

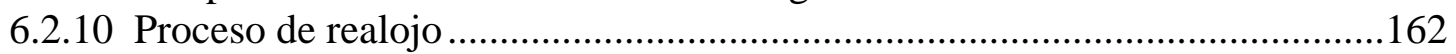

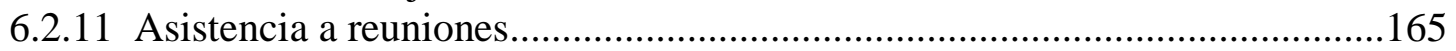

6.2.12 Sentirse preparados(as) para el proceso de realojo ....................................167

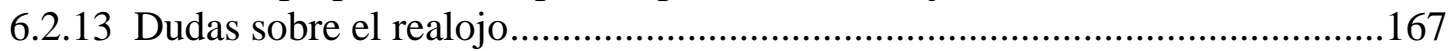

6.3 Diferencias entre el realojo voluntario y el forzado........................................170

6.4 Cambios ocurridos en la comunidad antes del proceso de realojo, desde la perspectiva de $\operatorname{los}(\mathrm{as})$ residentes que vivían en ésta .....................................172

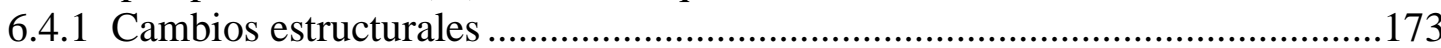

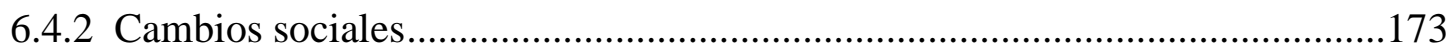

6.4.3 Percepción de cambios ocurridos en la comunidad .......................................176

6.5 Impacto socioeconómico del realojo en la comunidad .....................................177

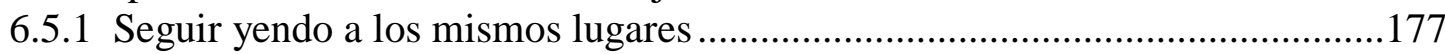

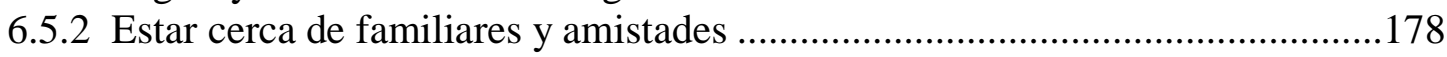

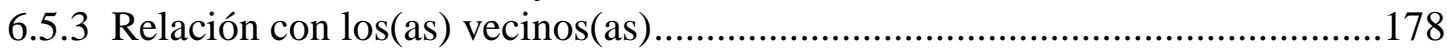

6.5.4 Contacto con sus pasados(as) vecinos(as) ....................................................180

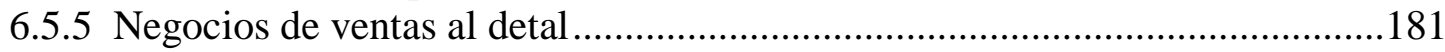

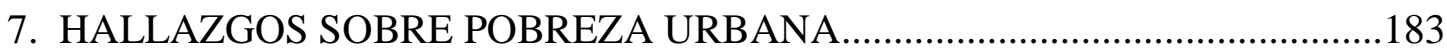

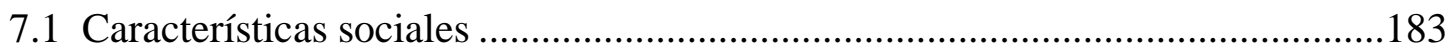

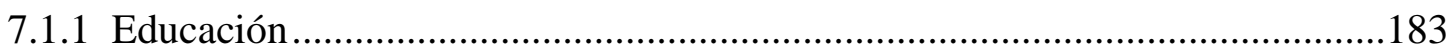

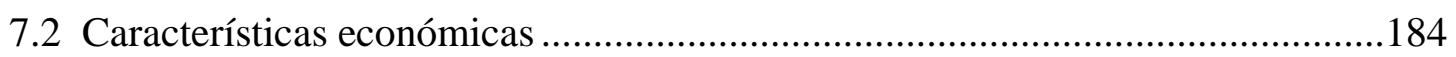

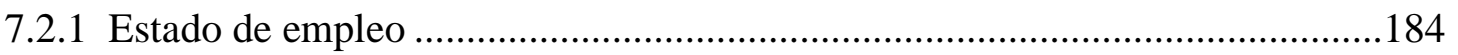

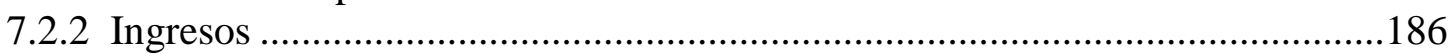

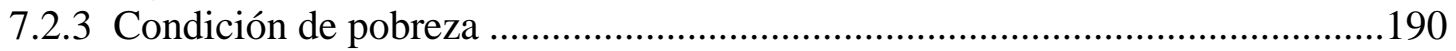

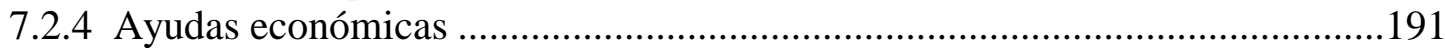

7.2.4.1 Condición de pobreza y ayudas económicas ...............................................194

7.2.4.2 Razones por las que reciben ayudas económicas......................................195

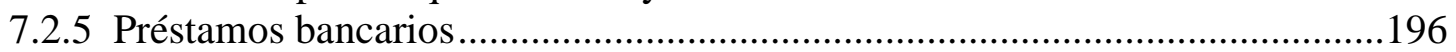

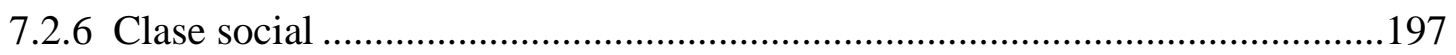

7.2.6.1 Clase social e ingreso mensual familiar...................................................197

7.3 Aspiraciones, pasatiempos y pertenencia a organización ..................................198

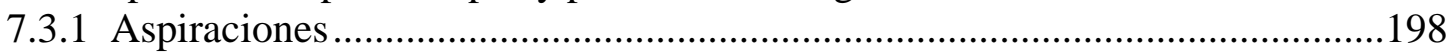

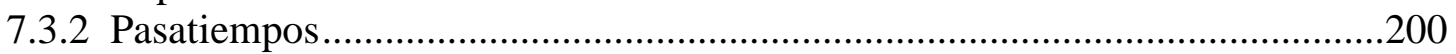

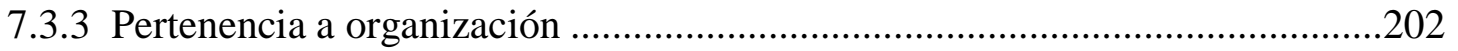

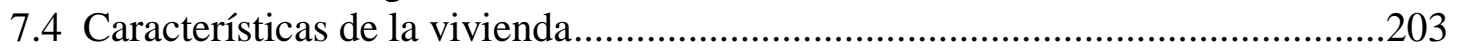

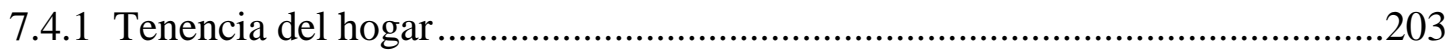

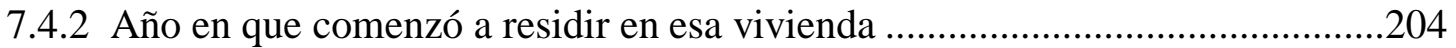

7.4.3 Año en que comenzó a residir en la comunidad ............................................206

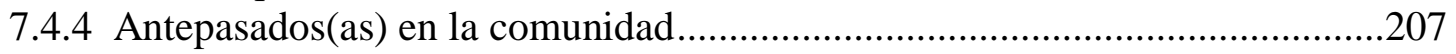

7.4.5 Aspectos que molestan de la comunidad......................................................209

7.4.6 Problemas sociales en la comunidad...............................................................214

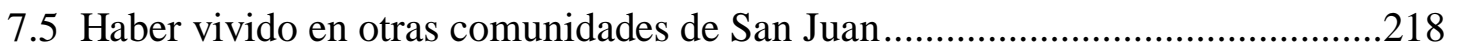

7.6 Parientes residiendo en la comunidad ............................................................218

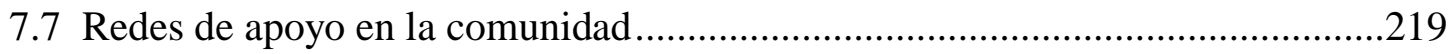

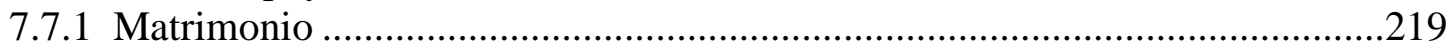




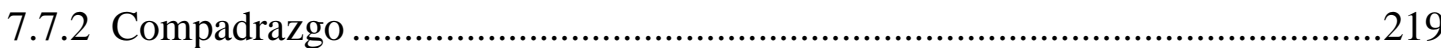

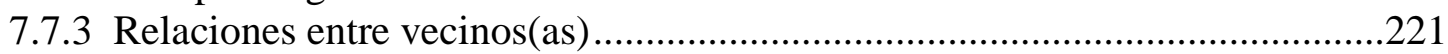

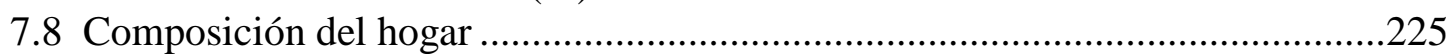

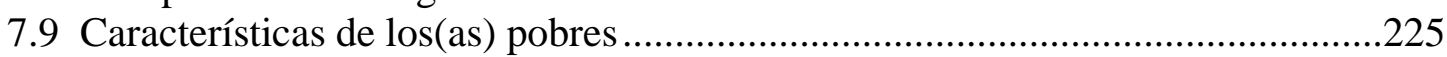

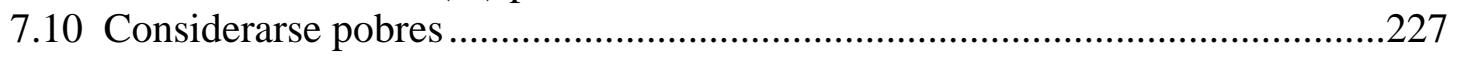

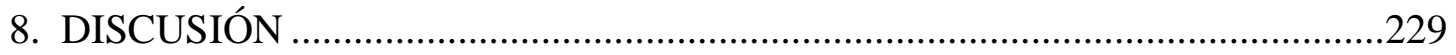

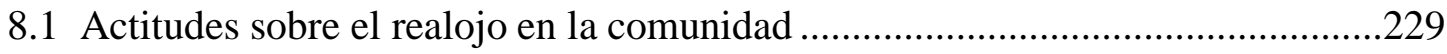

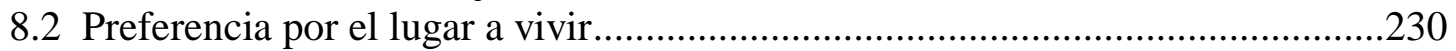

8.2.1 Renuencia a relocalización en residencial público .......................................233

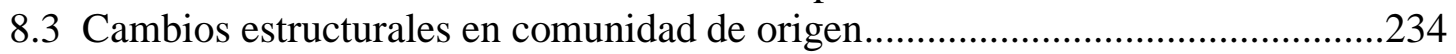

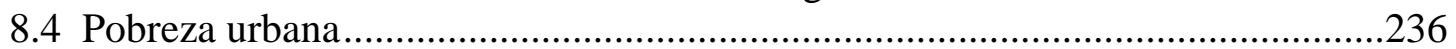

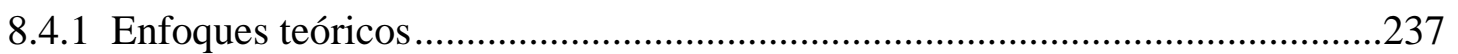

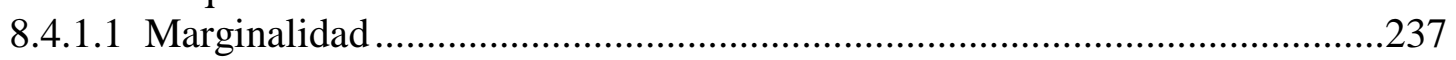

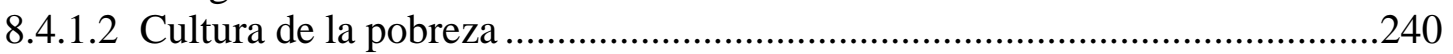

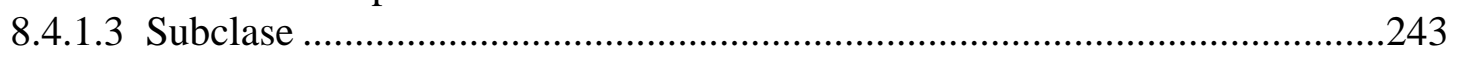

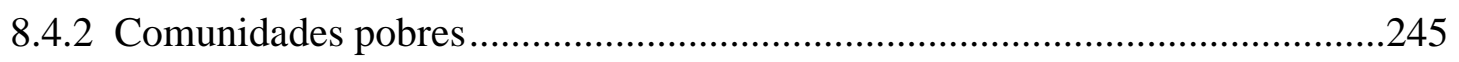

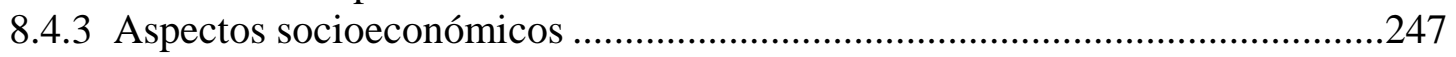

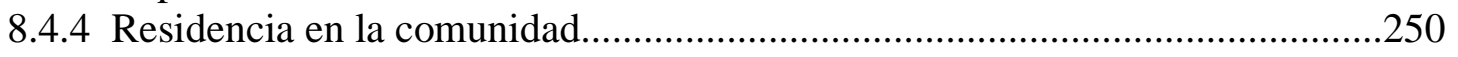

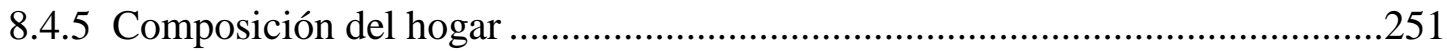

8.4.6 Lazos de parentesco, amistad, compadrazgo y ayuda mutua...........................252

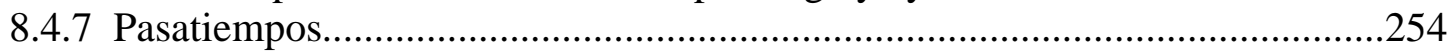

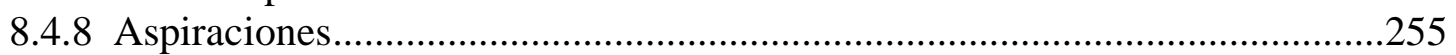

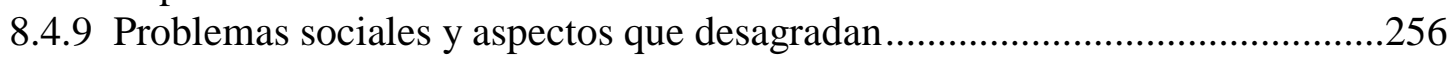

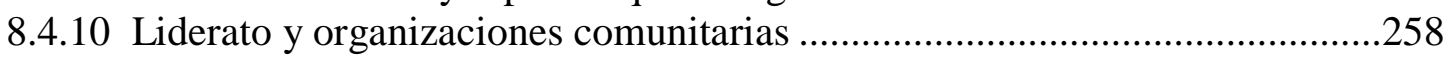

8.4.11 Política y relaciones con el gobierno .........................................................258

8.5 Impacto socioeconómico del realojo en la comunidad de origen y de

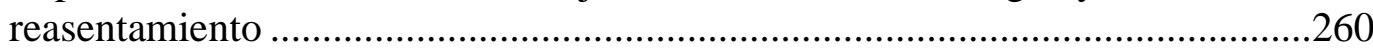

8.5.1 Lugares importantes para los(as) residentes afectados(as) por el realojo........261

8.5.2 Relaciones personales entre la comunidad de origen y de

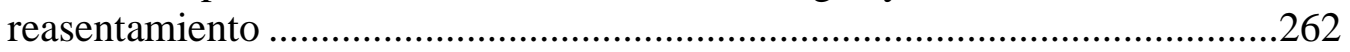

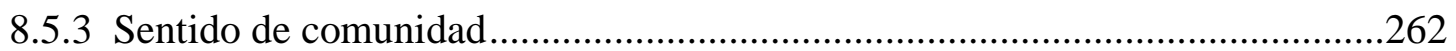

8.5.4 Adaptación en la comunidad de reasentamiento..........................................262

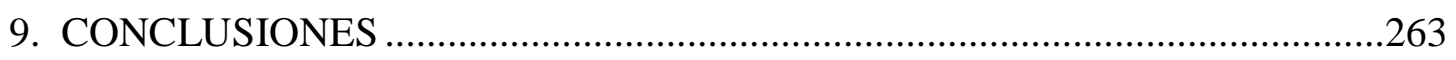

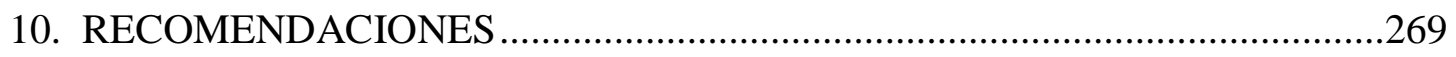

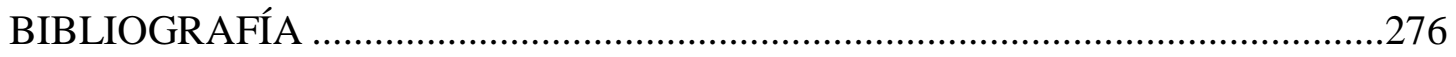

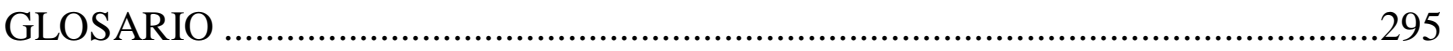

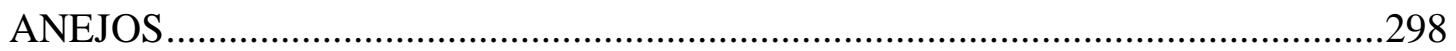




\section{Lista de tablas}

Título

Página

Tabla 2.1. Características demográficas de los(as) participantes del estudio y de la Encuesta de la Comunidad de Puerto Rico, 2006

Tabla 2.2. Características sociales de los(as) participantes del estudio y la Encuesta de la Comunidad de Puerto Rico, 2006 .14

Tabla 2.3. Características económicas de los(as) participantes del estudio y de la Encuesta de la Comunidad de Puerto Rico, 2006 .17

Tabla 6.1. Motivo del realojo, según los(as) residentes a ser realojados(as) y los(as) residentes realojados(as)

Tabla 6.2. Mayor preocupación sobre el proceso del realojo de los(as)

residentes a ser realojados(as) y los(as) residentes realojados(as)

Tabla 6.3. Preferencia en cuanto al nuevo lugar donde vivir de los(as) residentes a ser realojados(as) y los(as) residentes realojados(as).

Tabla 6.4. Sugerencias para mejorar el proceso de realojo de los(as) residentes a ser realojados(as) y los(as) residentes realojados(as)

Tabla 7.1. Años de estudio de los(as) residentes a ser realojados(as) y los(as) residentes realojados(as)

Tabla 7.2. Estado de empleo de los(as) residentes a ser realojados(as) y los(as) residentes realojados(as)

Tabla 7.3. Tipos de ingresos de los(as) residentes a ser realojados(as) y los(as) residentes realojados(as)

Tabla 7.4. Ingreso mensual familiar y mediana de los(as) residentes a ser realojados(as) y los(as) residentes realojados(as).

Tabla 7.5. Condición de pobreza de los(as) residentes a ser realojados(as) y $\operatorname{los}$ (as) residentes realojados(as)

Tabla 7.6. Ayudas económicas y sus tipos de los(as) residentes a ser realojados(as) y los(as) residentes realojados(as)

Tabla 7.7. Condición de pobreza y ayudas económicas de los(as) residentes a ser realojados(as) y los(as) residentes realojados(as)

Tabla 7.8. Razones por las que recibe ayudas económicas los(as) residentes a ser realojados(as) y los(as) residentes realojados(as). 
Tabla 7.9. Clase social e ingreso mensual familiar de los(as) residentes afectados(as) por el realojo

Tabla 7.10. Principales aspiraciones de los(as) residentes a ser realojados(as) (en orden descendente)

Tabla 7.11. Principales aspiraciones de los(as) residentes realojados(as)

(en orden descendente)

Tabla 7.12. Principales pasatiempos de los(as) residentes a ser realojados(as) (en orden descendente)

Tabla 7.13. Principales pasatiempos de los(as) residentes realojados(as) (en orden descendente)

Tabla 7.14. Características sobre vivienda de los(as) residentes a ser realojados(as) y los(as) residentes realojados(as).

Tabla 7.15. Antepasados(as) de los(as) residentes a ser realojados(as) y los(as) residentes realojados(as) en la comunidad

Tabla 7.16. Principales aspectos de la comunidad que le molestan a los(as) residentes a ser realojados(as) (en orden descendente)

Tabla 7.17. Principales aspectos de la comunidad que le molestan a los(as) residentes realojados(as) (en orden descendente)

Tabla 7.18. Principales problemas sociales presentes en la comunidad, según los(as) residentes a ser realojados(as) (en orden descendente)

Tabla 7.19. Principales problemas sociales presentes en la comunidad, según los(as) residentes realojados(as) (en orden descendente)

Tabla 7.20. Compadrazgo en la comunidad de los(as) residentes a ser realojados(as) y los(as) residentes realojados(as) en la comunidad

Tabla 7.21. Principales tipos de ayuda entre los(as) vecinos(as), según los(as) residentes a ser realojados(as) (en orden descendente)

Tabla 7.22. Principales tipos de ayuda entre los(as) vecinos(as), según los(as) residentes realojados(as) (en orden descendente).... 
Ilustración 2.1. Familiares frente a El Canario (década de 1950) 6

Ilustración 5.1. Camino en madera hacia casucha cerca de los terrenos del Puente de la Constitución en Santurce .100

Ilustración 5.2. Casas en pilotes sobre el agua en Tras Talleres .101

Ilustración 5.3. Vista aérea de la barriada Hoare en Santurce .102

Ilustración 5.4. Rancho en madera en un arrabal de Santurce .103

Ilustración 5.5. Familias desalojadas de un arrabal observando la demolición de sus casuchas .104

Ilustración 5.6. Inquilinos desocupando ranchones para mudarse hacia el caserío Llorens Torres

Ilustración 5.7. Alguaciles prestos a efectuar desahucio en terrenos de la sucesión Rexach. 106

Ilustración 5.8. Vivienda de madera ubicada en zona inundable del caño 108

Ilustración 5.9. Calle inundada en el sector bajo estudio. .108

Ilustración 5.10. Calle estrecha y sin aceras en la comunidad 109

Ilustración 5.11. Parte del caño contaminado con basura .110

Ilustración 5.12. Vista del caño y de salidero de aguas servidas .111

Ilustración 5.13. Vista desde la comunidad a la laguna....

Ilustración 5.14. Distribución de las comunidades especiales a través de Puerto Rico, 2008.

Ilustración 5.15. Distribución de las comunidades especiales a través de la región metropolitana de Puerto Rico, 2008

Ilustración 5.16. Distribución de las comunidades especiales a través del municipio de San Juan, Puerto Rico, 2008

Ilustración 6.1. Vista de la comunidad La Playita en la Laguna

Condado en Santurce

Ilustración 6.2. Área del caño donde antes había viviendas .128 
Ilustración 6.3. Agua estancada y desbordada del caño..........................................130

Ilustración 6.4. Uno de los proyectos de vivienda de la comunidad.........................136

Ilustración 6.5. Árboles y maleza donde antes había viviendas .............................141

Ilustración 6.6. Puente en construcción sobre el caño .............................................173

Ilustración 7.1. Desagüe y basura acumulada en el caño........................................211

Ilustración 7.2. Desagüe de aguas servidas al caño ...............................................213

Ilustración 7.3. Mujer sin hogar, con pertenencias frente a vivienda, ubicada en la avenida principal que cruza la comunidad estudiada .............216 
Título

Página

Figura 6.1. Percepción de la comunicación con la organización por mayor preocupación sobre el realojo de los(as) residentes afectados(as) ........152

Figura 6.2. Nivel educativo por mayor preocupación sobre el realojo de los(as) residentes afectados(as)

Figura 6.3. Grupos de edad por preferencia de lugar a vivir de los(as) residentes afectados(as)

Figura 6.4. Mediana del año de inicio de residencia en comunidad por preferencia de lugar a vivir de los(as) residentes afectados(as).

Figura 6.5. Percepción de los cambios ocurridos en la comunidad por preferencia de lugar a vivir de los(as) residentes afectados(as) 
Anejo A. Carta del 17 de octubre de 2006, solicitando permiso a organización comunitaria para realizar estudio en su comunidad

Anejo B. Carta del 14 de noviembre de 2006, solicitando permiso a corporación pública para realizar estudio en su comunidad .300

Anejo C. Carta informativa a líderes comunitarios(as) sobre visita a su comunidad para realizar entrevistas

Anejo CH. Carta informativa entregada a residentes sobre visita a su comunidad (primer formato).

Anejo D. Carta informativa entregada a residentes sobre visita a su comunidad (segundo formato)

Anejo E. Carta de presentación entregada a los(as) participantes del estudio .304

Anejo F. Hoja de consentimiento entregada a los(as) participantes del estudio .305

Anejo G. Cuestionario para la población a ser realojada. .306

Anejo H. Cuestionario para la población realojada .314

Anejo I. Preguntas guías a población a ser realojada. .322

Anejo J. Preguntas guías a población realojada

Anejo K. Diseño factorial 2 × 2 × 2, utilizado para la selección de los(as) participantes a entrevistar .328

Anejo L. Umbrales de pobreza del 2007, preparados por el Negociado Federal del Censo 


\section{Sinopsis}

Introducción: Las actitudes de los(as) residentes hacia el realojo de sus viviendas han sido muy poco estudiadas. Objetivos: 1) conocer las actitudes de los(as) residentes afectados(as) por el realojo; 2) describir el proceso de realojo; 3) examinar la diferencia entre el realojo voluntario y el forzado; 4) evaluar los cambios ocurridos en la comunidad antes del realojo; 5) examinar el impacto socioeconómico del realojo en la comunidad; y 6) revaluar el debate teórico de la antropología, en torno a la pobreza urbana. Metodología: La comunidad estudiada está localizada en la zona urbana de San Juan, Puerto Rico. La muestra está compuesta por 90 jefes(as) de hogar a ser realojados(as) y 21 jefes(as) de hogar realojados(as). El método principal de investigación es la etnografía y las técnicas de investigación son encuesta con muestreo aleatorio, entrevista semiestructurada y observación partícipe directa. Hallazgos: Las actitudes de los(as) residentes afectados(as) por el realojo de sus viviendas son mayormente miedo, resignación, impotencia, desconfianza, suspicacia e incertidumbre. De manera general, los(as) residentes querían ser realojados(as) a una casa igual o mejor que la que tenían: propia, unifamiliar, terrera, individual y de concreto. Las objeciones a ser realojados(as) a proyectos de vivienda son cumplir con reglamento, vivir en un apartamento y tener que pagar. La pobreza es un grave problema social en la comunidad, que aqueja a la gran mayoría de los(as) residentes, por tener bajos ingresos y bajo nivel educativo y vivir en zonas degradadas y marginales al caño contaminado, entre otras cualidades. Conclusiones: Sus ingresos bajos, falta de empleo y poder político y dependencia del gobierno contribuyen a tener miedo y desconfianza y sentir impotencia y resignación, sobre su futuro como comunidad.

Palabras claves: actitudes, realojo, pobreza, Puerto Rico 


\section{Introducción}

\subsection{Estado de la cuestión}

Las actitudes de los(as) residentes hacia el realojo en las comunidades pobres de San Juan han sido muy poco estudiadas en los últimos años. Los trabajos existentes tratan este tema desde la perspectiva antropológica para comunidades que fueron desalojadas a mediados del siglo pasado (Safa, 1980 y Ramírez, 1976).

Según el Censo de Población y Vivienda del 2000, que incluye la edad y la condición de pobreza entre sus variables estudiadas, esta comunidad está en una zona que cae dentro de una cantidad específica de divisiones censales (U.S. Census Bureau, 2003a). Al analizar los datos por condición de pobreza de esos sectores censales, hay 20.509 personas que para el 1999 obtuvieron ingresos por debajo del nivel de pobreza, de una población total de 30.147 personas, a quienes se les determinó el nivel de pobreza, o sea, todas las personas, con excepción de los(as) internos(as) en instituciones, en alojamiento de grupo militares y en domicilios universitarios (U.S. Census Bureau, 2003b). Por lo tanto, la tasa de pobreza de la población en los sectores censales que cubren el área donde está la comunidad es de un alarmante 68,0\%. Cabe destacar que el sector censal con la tasa más baja tiene $57,6 \%$ y el sector censal con la tasa más alta tiene $85,9 \%$. O sea, en el 2000, más de la mitad, como mínimo, de sus residentes tenía ingresos que los calificaron como pobres. Estas tasas de pobreza son mayores a la tasa de pobreza de la población total de Puerto Rico, la cual es 48,2\% para ese mismo año. Entonces, es preocupante el alto porcentaje de personas que en el 2000 residía en la comunidad estudiada y recibieron ingresos en 1999 por debajo del nivel de pobreza establecido. 


\subsection{Definición del problema}

En el caso de Puerto Rico, la Autoridad de Carreteras del Departamento de Transportación y Obras Públicas señaló en 1989 en su Manual de orientación y realojo en proyectos con participación federal:

Una de las inevitables consecuencias del programa de construcción de carreteras en una nación progresista es el realojo necesario de un pequeño grupo de la población para el bienestar de la mayoría. Es la política de nuestro Gobierno que las personas desplazadas reciban un tratamiento justo y humano, evitando así las inconveniencias creadas por la obra pública a realizarse (p. 1). Entonces, al comparar los términos desahucio, expropiación, desalojo y realojo, sólo en la última a las personas desplazadas se les provee de una vivienda y es el interés primordial de este estudio. Es importante distinguir estos términos porque son mencionados por los(as) residentes de la comunidad estudiada, ya sea porque conocen que en el pasado han expropiado, desahuciado y realojado personas. Debido a que uno de los objetivos principales de las organizaciones comunitarias y de la corporación pública que planifica el dragado del caño y otros proyectos es mantener la comunidad, entiéndase mantener a los(as) residentes viviendo en esa localidad, lo que planifican es realojar a las personas que residen en zonas inundables a las orillas del caño y otras áreas. Además, el que estos términos sean mencionados por algunos(as) residentes entrevistados(as) indistintivamente es preocupante porque denota confusión en lo que sospechan que podría pasar más adelante con ellos(as) y sus familias.

\subsection{Propósito}

En este estudio etnográfico, me interesó conocer las actitudes de los(as) residentes hacia el realojo en una comunidad urbana y pobre en San Juan, Puerto 
Rico. Tuve el deseo de conocer cuál es la postura que adoptan las personas y sus estados de ánimos manifestados ante el proceso de realojo de sus viviendas, desde dos perspectivas distintas, a saber, la de las personas que serán realojadas y la de las personas que ya fueron realojadas y residen en los nuevos proyectos de vivienda en la comunidad.

\subsection{Objetivos}

1. Conocer las actitudes de los(as) residentes a ser realojados(as) y los(as) residentes que ya han sido realojados(as).

2. Describir el proceso de realojo, desde la perspectiva de los(as) residentes afectados(as).

3. Examinar las posibles diferencias entre los realojos voluntarios y los forzados.

4. Evaluar los cambios ocurridos en la comunidad antes del proceso de realojo, desde la perspectiva de los(as) residentes que vivían en ésta.

5. Examinar el impacto socioeconómico del realojo en la comunidad.

6. Revaluar el debate teórico de la antropología, en torno a los aspectos sociales y culturales de la pobreza urbana.

\subsection{Justificación}

Este estudio antropológico sobre las actitudes de las personas a ser realojadas y ya realojadas en una comunidad pobre en San Juan sería de los primeros en realizarse en el siglo XXI, después de los llevados a cabo a finales de los años sesenta del siglo XX. Aún cuando el tema se trabajó intensamente en esa década, la situación socioeconómica y ambiental de la zona estudiada ha cambiado drásticamente. Un cambio demográfico ocurrido en esta comunidad fue la llegada, a finales del siglo XX, de un grupo poblacional nuevo. Los(as) inmigrantes procedentes de la República Dominicana se establecieron en esta zona urbana de San Juan, a la cual todavía siguen 
llegando personas procedentes de ese país. Por otro lado, en las últimas décadas, se ha visto un aumento en la venta y abuso de drogas ilegales. Además de los(as) residentes usuarios(as) de estas sustancias no controladas, la comunidad recibe personas no residentes que van exclusivamente a comprar drogas ilegales. También hay un número considerable de personas sin hogar que deambulan por sus calles. Muchas de estas personas son usuarias de drogas ilegales. Además, en esta comunidad ha habido un deterioro ecológico que ha afectado la zona de mangles, que bordea el caño, uno de los cuerpos de agua más contaminados del país. El establecimiento de viviendas en los manglares, a mitad del siglo XX, impactó negativamente el ecosistema. No solamente el terreno fue secado por relleno de basura para construir viviendas improvisadas, también se fue degradando con la descarga de aguas usadas no tratadas al cuerpo de agua. Todavía, hay áreas que no tienen alcantarillado sanitario.

Este trabajo de investigación incluye técnicas de investigación cualitativa y cuantitativa, utilizando la etnografía como método principal de investigación. Este estudio sería único en las investigaciones contemporáneas sobre Puerto Rico y de alto grado de innovación desde el punto de vista metodológico. También podría contribuir a actualizar un viejo debate teórico, aún pertinente, sobre las comunidades urbanas pobres y otros sectores urbanos marginales. De esta manera, este estudio ayudará a repensar diferentes teorías que intentan explicar la pobreza y marginalidad, que no sólo han tenido un impacto académico, sino también en la formulación de políticas públicas en las últimas décadas.

El análisis de las actitudes de los(as) residentes hacia el realojo podría contribuir al desarrollo de políticas públicas adecuadas a sus necesidades particulares, específicamente lo concerniente al proceso de cambio de residencia. Por ejemplo, hay que seguir estudiando con minucioso detalle su adaptación a la nueva comunidad. 
Específicamente en el proceso de seleccionar una residencia, abandonar su residencia anterior y reiniciar sus vidas en una diferente en una área distinta. También se beneficiarían la planificación, ejecución y funcionamiento de servicios ofrecidos, al saber cuál es su modo de pensar hacia el realojo de sus viviendas porque las instituciones públicas y privadas tendrían más información al momento de tomar decisiones respecto a los servicios diseñados para este subgrupo poblacional.

Además, un estudio antropológico aportaría a ampliar los conocimientos existentes sobre realojo, renovación urbana y pobreza en Puerto Rico. De esta manera, aumentarían los conocimientos sobre esta situación tan importante, además de los pocos trabajos ya publicados, pero enfocados en el Trabajo Social y Demografía. Asimismo, es importante conocer las actitudes de los(as) residentes hacia el realojo desde una perspectiva antropológica porque permite a los(as) residentes entrevistados(as) afectados(as) por el realojo de viviendas expresarse sin tener que únicamente encajonar sus respuestas al verse obligados(as) a seleccionar una de varias opciones para contestar una pregunta en una encuesta. Por medio de la técnica de entrevista profunda, los(as) personas afectadas(as) directamente por el realojo pudieron abundar sus respuestas y expresarse libremente y así pude conocer de cerca lo que piensan los(as) residentes sobre el realojo de sus viviendas en una comunidad en particular del municipio de San Juan, Puerto Rico. Además, la Antropología, específicamente la Antropología Urbana, provee un marco teórico conceptual para explicar el comportamiento de las personas de zona urbana, en particular, los(as) residentes de comunidades pobres en zonas urbanas. 


\section{Metodología}

\subsection{Selección de la comunidad}

Para este estudio etnográfico, seleccioné esta comunidad porque representaba la población residente actualmente en viviendas candidatas al realojo por estar en zonas aledañas al caño contaminado, el cual será dragado en el futuro cercano, y en proyectos de viviendas diseñados para realojar a familias. Además, elegí este sector sanjuanero por el vínculo emocional y afectivo que tengo hacia él. En esa comunidad, se criaron mi madre, mi abuela materna, mi abuelo materno y mis tíos abuelos y tías abuelas. Aunque ya no viven allí porque se han mudado o han fallecido, siempre está el grato recuerdo de aquella comunidad, donde humilde y honradamente formaron sus familias y las mantuvieron económicamente con el funcionamiento de dos “colmados" (pequeños negocios de venta de alimentos): Monge's Grocery y El Canario (véase la Ilustración 2.1). También persiste en la memoria de algunas personas que todavía viven en esa comunidad, el apellido de mi familia materna, y se emocionan cuando se acuerdan de ellos(as).

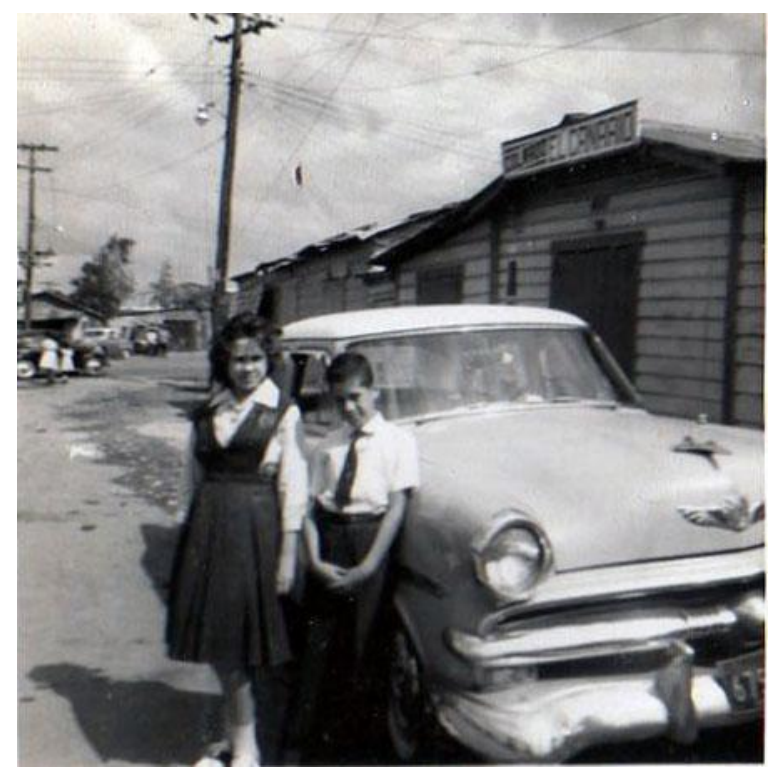

Ilustración 2.1. Familiares frente a El Canario (década de 1950) 


\subsection{Población estudiada}

En este estudio, la comunidad realmente está compuesta por nueve comunidades distintas. Debido a que éstas tienen en común el caño, al estar ubicadas en sus orillas, son consideradas como una en esta investigación. Por otro lado, la ley que creó la corporación pública para su desarrollo económico, incluyendo el dragado del caño, incluye estas nueve comunidades en todos sus proyectos. Además, últimamente se les llama "comunidades del caño" y la directiva de la organización comunitaria que agrupa a los(as) representantes de las 12 organizaciones de las nueve comunidades está de acuerdo en considerarlas como una sola. Cada comunidad es muy particular en su formación, aunque la mayoría de las nueve comunidades fueron originalmente áreas rescatadas al mangle de las orillas del norte y sur del caño, a partir de la década de 1930. También las circunstancias en que se formaron son una característica que las diferencia, como es el caso de una comunidad que se formó por la necesidad de personas por vivienda luego del paso devastador en 1932 de un huracán, cuyo nombre se tomó para identificar dicha comunidad. Por otro lado, otra comunidad se formó durante la década de 1930, cuando una empresa privada dedicada a la extracción, procesamiento y venta de piedra comenzó en el área a transformar el terreno. Así las familias de los(as) trabajadores de la cantera tomaron pedazos de terreno, según se eliminaban los cerros de piedras.

Según los datos del Censo de Población y Vivienda del 2000, en esta comunidad había 30.190 habitantes. En cuanto a las viviendas en la comunidad, había para ese año censal 12.307 unidades de viviendas, de las cuales el 88,9\% (10.944) estaban ocupadas (US Census Bureau, 2003b). Por definición del Censo, unidad de vivienda ocupada es igual a hogar (US Census Bureau, 2003a). Entonces, puedo deducir que en el 2000 había 10.944 jefes y jefas de hogar. Como han pasado 7 años 
desde que se realizó ese censo poblacional, estos números han cambiado y la situación poblacional es diferente a la encontrada en el 2000, sobre todo por los proyectos de realojo que se han dado en el pasado, que posiblemente implicaron un cambio de comunidad para las personas afectadas, y por la llegada de inmigrantes, especialmente de la República Dominicana. Además, no todas las personas que residen en la comunidad estudiada han sido ni serán realojadas porque viven en áreas fuera de peligro, como lo puede ser el caño contaminado, o en áreas donde hay hacinamiento de viviendas, el cual puede causar retraso en la llegada de vehículos de emergencia y rescate (bomberos y ambulancia) y la propagación rápida de incendios entre las viviendas, según me han informado varios(as) residentes.

La población estudiada está compuesta por dos grupos principales de personas. Uno de ellos está formado por las personas que aún residen en las riberas de un caño contaminado y en otras zonas aledañas y que serán realojadas en un futuro. Respecto a ese caño, hace 80 años fueron ciénagas, desecadas por inmigrantes de la zona rural de Puerto Rico que no encontraron tierra firme donde vivir. Hoy en día, el caño sigue albergando una de las poblaciones más pobres de todo el país. La otra subpoblación está compuesta por las personas que residían en las riberas del caño contaminado y en otras zonas aledañas y que fueron realojadas de sus hogares. Ambos grupos residen en una comunidad urbana pobre en el municipio de San Juan, la capital de Puerto Rico.

El realojo es planificado y llevado a cabo en estas comunidades de San Juan, Puerto Rico, por organizaciones comunitarias que desarrollan sus proyectos de vivienda y por agencias gubernamentales. Como están las personas que ya han sido realojadas y las que todavía están en espera de serlo, en este estudio hay dos muestras. A ambas muestras, les administré una encuesta (basada en un cuestionario); y, a las 
personas que dispusieron del tiempo y desearon voluntariamente participar, les hice entrevistas semiestructuradas.

\subsection{Muestra}

Debido a que me interesó conocer las actitudes hacia el realojo de sus viviendas, entendí que el jefe o la jefa del hogar es la persona que más conoce sobre el proceso de realojo, incluyendo tramitar los documentos, elegir la vivienda y planificar la mudanza, además de tomar decisiones determinantes sobre el futuro de sus familias; igualmente, son las personas que fueron informadas sobre el proceso de realojo de sus viviendas. Por lo tanto, son los jefes y las jefas de los hogares afectados por el realojo, las personas que conformaron el marco de la muestra. En este estudio, definí el concepto de jefatura del hogar como la persona encargada del mismo, ya sea porque es el(la) dueño(a) o el(la) inquilino(a) de la vivienda. En los casos, en que había una pareja en el hogar, por matrimonio o convivencia, ellos(as) determinaron quién contestaría el cuestionario. Las personas conformaron dos muestras aleatorias, específicamente los jefes y las jefas de los hogares. Debido a que el proceso de realojo depende, en parte, de asuntos presupuestarios y administrativos, y avanza según sea permitido por varios factores, como el progreso en el desarrollo de viviendas y el avance en el proceso de orientación a las familias afectadas, el número total de personas realojadas y a ser realojadas ha cambiado.

2.3.1 Población a ser realojada. En cuanto a la población a ser realojada, se distingue el motivo del realojo y la organización encargada de la planificación del realojo, a saber, la organización comunitaria, la agencia gubernamental y la corporación pública que persigue el desarrollo urbano, social y económico de las comunidades aledañas al caño contaminado y la rehabilitación ambiental del caño que une dos cuerpos de agua, la bahía y la laguna, el cual es límite municipal entre San 
Juan y otro municipio. De esta subpoblación de personas que serán realojadas, casi todas viven en una zona de 50 metros desde la orilla del caño y sólo algunas viven en áreas donde en el futuro se construirá algún proyecto de infraestructura.

Es difícil estimar una cantidad total de personas que serán realojadas porque las cifras podrían variar en el momento de la realización de los distintos proyectos. Por ejemplo, según las entrevistas informales realizadas durante el trabajo de campo, en la ejecución de los proyectos, como el del dragado del caño contaminado, los(as) líderes comunitarios(as), quienes también son residentes, y miembros de las organizaciones comunitarias, indican que al eliminar una vivienda, la vivienda contigua podría verse afectada porque está muy cerca a otra y para poderle eliminar la vivienda identificada, podría ser que eliminen la contigua para que la maquinaria pueda tener espacio. Sin embargo, la corporación pública que planifica el dragado del caño y coordina proyectos de infraestructura y desarrollo socioeconómico, estima que aproximadamente 600 viviendas se afectarán por el dragado y otras 1.000 se afectarán por arreglos a la infraestructura en el futuro. Sólo las personas que serán realojadas por el dragado han sido informadas porque es una gran prioridad para esta corporación y las organizaciones comunitarias proveerles una vivienda segura, fuera de áreas inundables y libres de contaminantes.

2.3.2 Población realojada. En cuanto a la población ya realojada, se distingue el motivo y la organización, encargada de la planificación del realojo, a saber, la organización comunitaria y la agencia gubernamental, encargada del desarrollo de proyectos de infraestructura. Es difícil señalar una cantidad total de personas realojadas porque en el momento se están realizando distintos proyectos de vivienda y la cantidad de personas realojadas aumentará. Por ejemplo, según las entrevistas informales realizadas durante el trabajo de campo, actualmente hay un 
proyecto de vivienda listo para que los(as) residentes se muden, quienes están tomando una serie de talleres de capacitación.

Un representante de la corporación pública, que planifica el desarrollo de las comunidades aledañas al caño contaminado, indicó que ya han realojado familias de cerca de 300 viviendas por varios motivos y a cargo de agencias gubernamentales, por ejemplo. Estas familias pueden estar viviendo en la misma comunidad o fuera, ya sea en Puerto Rico o en otro país.

Sobre la subpoblación de personas que fueron realojadas, muchas familias viven en proyectos de viviendas, diseñados por la misma organización comunitaria y algunas familias viven en otras partes de Puerto Rico porque así lo prefirieron, cuando la agencia del gobierno que desarrolla proyectos de infraestructura o la organización comunitaria les presentó varias opciones de vivienda o le dieron en dinero el valor de su propiedad por tasación. Sin embargo, en este estudio sólo entrevisté a personas que han sido realojadas en proyectos de vivienda para poder realizar el diseño de muestreo aleatorio.

2.3.3 Características demográficas. Para evaluar la representatividad de la muestra, realicé una comparación con la población total de Puerto Rico del $2006^{1}$, específicamente las personas de 22 años y más ya que ésa era la edad mínima para la muestra. La muestra de este estudio está compuesta por 111 personas, de las cuales 90 son personas a ser realojadas y 21 son personas que fueron realojadas. Al examinar sus características demográficas, encontré que la muestra tiene una estructura de edad un poco más vieja que la población total de Puerto Rico (véase la Tabla 2.1). Tanto en la muestra como en la población total, poco más de la mitad es del género femenino.

\footnotetext{
${ }^{1}$ La muestra de este estudio es comparada con la población total, calculada a base de la Encuesta de la Comunidad de Puerto Rico del 2006, en vez de la población de la comunidad estudiada porque dicha fuente no incluye alguna variable geográfica que permita seleccionar alguna división política (municipio) o censal (sector censal).
} 
Tabla 2.1

Características demográficas de los(as) participantes del estudio y de la Encuesta de la Comunidad de Puerto Rico, 2006

Característica

Muestra Población Total de Puerto Rico*

Edad

Menos de 30

6,3

16,7

30 a 39

12,6

19,5

40 a 49

18,0

20,0

50 a 59

27,0

17,3

60 a 69

22,5

13,5

70 a 79

9,9

8,3

80 y más

3,6

4,8

Total

100,0

100,0

(111)

(2.678.192)

Mediana

55

46

Género

Masculino

43,2

46,4

Femenino

56,8

53,6

Total

100,0

100,0

(111)

(2.678.192)

Raza

Blanco(a)

22,5

75,2

(tabla continúa) 


\section{Indio(a)}

Jaba(ao)

Negro(a)

Trigueño(a)

Moreno(a)

Otras

Total
5,4

1,8

8,1

8,3

36,0

2,7

$23,4 * *$

$16,5^{* * *}$

100,0

100,0

Fuentes: Participantes de la tesis doctoral: Actitudes de los(as) residentes hacia el realojo en una comunidad urbana pobre en San Juan: 2006-2007 y Negociado Federal del Censo. (2007). Encuesta de la Comunidad del 2006, Muestra de Microdatos para Uso Público: Puerto Rico [Base de datos]. Washington, DC, EE.UU.: Autor. Tabulaciones producidas por la autora.

* Los datos de la muestra de la Encuesta de la Comunidad de Puerto Rico del 2007 se ponderaron para obtener los estimados de la población total de Puerto Rico para el mismo año. Para propósitos comparativos, seleccioné la población total de 22 años y más, por ser la edad mínima de la muestra de esta investigación.

** La categoría Otras incluye no sabe, mezcla, mezcla blanco y prieto, mezcla blanco y moreno, mezcla blanco y trigueño, de todo, prieto(a), mestizo(a), latino(a) y clara.

*** La categoría Otras incluye asiático(a), indio(a) americano(a), nativo(a) de Alaska, nativo(a) de Hawai u otras islas del Pacífico, asiático(a), alguna otra raza o dos o más razas combinadas.

Respecto a la característica de raza, poco más de una tercera parte de la muestra se consideró trigueña. Debido a que las categorías utilizadas en este estudio son diferentes a las utilizadas por el Negociado Federal del Censo (U.S. Census Bureau, en inglés), agencia de los Estados Unidos de América encargada de llevar a cabo el censo y encuestas de población en Puerto Rico, la comparación es limitada. 
Por dicha razón, sólo son comparables tres categorías (blanco(a), negro(a) y otras). Según los datos de dicha agencia, tres cuartas partes de la población total son blancas (véase la Tabla 2.1).

2.3.4 Características sociales. En cuanto a la educación, casi el 30\% alcanzó algún grado del nivel secundario (véase Tabla 2.2). Al comparar con la población total, hallé que las categorías de nivel secundario y universidad son las de mayor porcentaje, siendo $31,5 \%$ y $41,5 \%$, respectivamente. Sin embargo, en la población total, el porcentaje de personas con algún grado universitario duplica el de la muestra. Por otro lado, en la muestra hay 2 veces el porcentaje de personas que no tiene ningún año de estudio que en la población total. En cuanto al estado marital, la muestra y la población total coincidieron en las categorías de mayor porcentaje, a saber, casado(a), divorciado(a) y nunca casado(a) y en la categoría de menor porcentaje, la cual es $\operatorname{separado}(a)$

\section{Tabla 2.2}

Características sociales de los(as) participantes del estudio y la Encuesta de la Comunidad de Puerto Rico, 2006

Característica Muestra Población Total de Puerto Rico*

Educación

Ningún

Nivel elemental

21,6

Nivel intermedio

19,8

10,6

Nivel secundario

29,7

31,5

(tabla continúa) 
Universidad

Total

Mediana

Estado marital

Casado(a) actualmente

Convivencia

Viudo(a)

Divorciado(a)

Separado(a)

Nunca casado(a)

Total

Lugar de nacimiento

Puerto Rico

Otro país

Total

Otro país

República Dominicana

Estados Unidos
85,0

10,0
100,0

(111)

82,0

18,0

41,5

100,0

(2.678.192)

10

37,8

49,0

14,4

14,4

8,4

13,0

4,4

25,2

100,0

(2.678.192)

(111)

90,5

9,5

100,0

(2.678.192)

54,8

(tabla continúa) 


\begin{tabular}{lcc} 
Característica & Muestra & Población Total de Puerto Rico* \\
& & \\
Colombia & 5,0 & 2,7 \\
Total & 100,0 & 100,0 \\
& $(20)$ & $(149.223)$ \\
\hline
\end{tabular}

Respecto al lugar de nacimiento, el porcentaje de la población total que nació en Puerto Rico es mayor que el correspondiente para la muestra, siendo 90,5\% y $82,0 \%$, respectivamente (véase Tabla 2.2). Del grupo de personas de la muestra que indicó haber nacido fuera de Puerto Rico, el 85,0\% nació en la República Dominicana, siendo el doble del porcentaje de las personas de la población total (42,5\%). Otra categoría es Estados Unidos, donde el 54,8\% de las personas de la población total indicó haber nacido en ese país, en comparación con el 10,0\% reportado por la muestra.

2.3.5 Características económicas. Poco más de la mitad de la muestra tiene alguna ocupación de servicios (véase Tabla 2.3). A esa categoría, le sigue en importancia relativa, la categoría de ventas y oficina con un 16,2\%. La categoría de menor porcentaje es producción, transportación y movimiento de material $(8,1 \%)$. Al comparar con la población total, hallé diferencias porque la categoría con mayor porcentaje es gerenciales y profesionales $(28,0 \%)$, siendo más del doble a la correspondiente a la muestra $(10,8 \%)$. La muestra y población total coincidieron en que la segunda categoría de mayor porcentaje es ventas y oficina. 
Tabla 2.3

Características económicas de los(as) participantes del estudio y de la Encuesta de la Comunidad de Puerto Rico, 2006

Característica

Muestra Población total de Puerto Rico*

Ocupación

Gerenciales y profesionales

10,8

28,0

Servicios

54,1

20,1

Ventas y oficina

16,2

27,1

Construcción, extracción

reparación y mantenimiento

10,8

11,4

Producción, transportación

y movimiento de material

8,1

13,3

Total

100,0

100,0

(37)

$(1.477 .087)^{* *}$

Ingreso familiar mensual***

Menos de \$500,00

$\$ 500,00$ a $\$ 999,00$

38,7

$\$ 1.000,00$ a $\$ 1.499,00$

13,5

$\$ 1.500,00$ a $\$ 1.999,00$

7,2

$\$ 2.000,00$ a $\$ 2.499,00$

\$2.500,00 o más

8,1

No dijo

1,1

(tabla continúa) 
Total

Condición de pobreza

Bajo el nivel de pobreza

Sobre el nivel de pobreza

Total
100,0

$\$ 700,00$

** No incluye las personas desempleadas que nunca trabajaron, militares y personas con ocupaciones en la agricultura, pesca y silvicultura.

*** La variable ingreso familiar mensual no puede ser comparada porque la muestra de la población de la Encuesta de la Comunidad no incluye dicha variable, sino ingreso personal total en los pasados 12 meses.

**** Condición de pobreza fue determinada para todas las personas, excepto las personas institucionalizadas, en alojamientos de grupos militares, en dormitorios universitarios e individuos no relacionados menores de 15 años.

Tres quintas partes de la muestra reportó recibir mensualmente US\$999,00 o menos. Las categorías con menor porcentaje corresponden a las de mayor ingreso, a saber, $\$ 1.500,00$ a $\$ 1.999,00$ y $\$ 2.000,00$ a $\$ 2.499,00$, con $7,2 \%$ cada una. La mediana de ingreso familiar mensual es $\$ 700,00$. O sea, la mitad de la muestra reportó $\$ 700,00$ o menos y la otra mitad reportó $\$ 700,00$ o más. En cuanto a la condición de pobreza, cerca del $80 \%$ de la muestra recibe ingresos que están por debajo del nivel de pobreza, según los umbrales de pobreza preparados por el Negociado Federal del 
Censo para el año $2007^{2}$. Es importante señalar que el porcentaje de personas de la muestra clasificadas como pobres es el doble de la correspondiente en la población total de Puerto Rico para el 2006.

\subsection{Técnicas de investigación}

\subsubsection{Encuesta}

2.4.1.1 Diseño de muestreo. Para esta subpoblación, el tipo de muestreo es aleatorio. A base de la revisión de documentos realizada en la corporación pública que coordina el dragado y otros proyectos de infraestructura y de entrevistas informales realizadas a los(as) líderes comunitarios(as) y personal de algunas organizaciones comunitarias, hay cerca de 730 viviendas de personas afectadas por el realojo, ya sea porque serán realojadas en el futuro o porque ya lo fueron. Entonces, dividí 730 entre 146 y resultó 5. El intervalo de muestreo es 5. Apliqué este cálculo a cada una de las muestras. En cuanto a la muestra de personas a ser realojadas, el total es 560 y dividido entre 112, resulta en 5. Sobre la muestra de personas ya realojadas, el total es 170 viviendas, entre apartamentos y viviendas de propiedad horizontal, y dividido entre 34 , resulta en 5.

Durante la recopilación de datos, me encontré con diversas situaciones que afectaron el tamaño de la muestra. Las cantidades de viviendas afectadas por el realojo, ofrecidas por la organización comunitaria y la corporación pública, fueron calculadas antes de la realización de uno de los proyectos de vivienda, construidos para personas realojadas. También algunas familias fueron realojadas por la construcción de un puente, por parte de una agencia gubernamental. Por lo tanto, cuando fui a realizar la encuesta y las entrevistas me encontré con que había menos viviendas de lo esperado, ya que fueron deshabitadas por las familias realojadas;

\footnotetext{
${ }^{2}$ Para determinar si la persona y su familia recibe ingresos por debajo del nivel de pobreza, comparé su ingreso familiar mensual al umbral determinado para la cantidad de personas viviendo en ese hogar, cantidad de menores de 18 años y edad del jefe(a) del hogar (U.S. Census Bureau, 2008c).
} 
algunas fueron destruidas y otras permanecen allí. Entonces, dividí 601 entre 120 y resultó 5 . El intervalo de muestreo es 5 . Nuevamente, apliqué este cálculo a cada una de las muestras.

En cuanto la muestra de las personas a ser realojadas, el total es 431 y dividido entre 86 , resulta en 5 . Sobre la muestra de las personas ya realojadas, el total es 170 y dividido entre 34 , resulta en 5 . De esta manera, la muestra que se afectó fue la correspondiente a las personas a ser realojadas. Sin embargo, no pude alcanzar la meta de tener una muestra total de 120 porque tuve dificultades al realizar la encuesta y entrevistas semiestructuradas para la muestra de personas ya realojadas. Durante la recopilación de datos en un proyecto de vivienda, construido para las personas realojadas, una líder comunitaria y residente en el mismo prohibió mi trabajo de investigación y mi asistente y yo tuvimos que cesar. Al final de la recopilación de datos, obtuve una muestra total de 111 , incluyendo 90 personas a ser realojadas y 21 personas ya realojadas.

Como ya expliqué, administré el cuestionario a 1 de cada 5 viviendas. Si en la vivienda número 5, no había alguien o su jefe(a) no deseaba participar, el método de reemplazo fue seleccionar la próxima vivienda donde alguien estuviera disponible y deseara participar voluntariamente, para luego volver a contar 5 viviendas y escoger la próxima. Escogí este método porque la cantidad de viviendas afectadas por el dragado y otros proyectos es baja, al igual que la cantidad de viviendas en proyectos comunitarios, y muchas calles son cortas. Además, en la zona de dragado, que va desde la orilla del caño hasta 50 metros tierra adentro, en la franja que divide las viviendas a ser realojadas y las viviendas no afectadas por dicho proceso, no está muy clara la identificación de las mismas. Por lo tanto, me limité a las viviendas que estaban más abajo de la línea divisoria hasta la orilla del caño. 
2.4.1.2 Instrumento. En cuanto al cuestionario (véase Anejos G y H), antes de comenzar la fase de recopilación de datos, realicé una preprueba con residentes afectados(as) por el realojo para mejorar el instrumento y asegurarme que fuera entendible para todos(as). En la preprueba, administré el cuestionario y realicé la entrevista semiestructurada, simulando una situación real. También les pregunté a las personas que participaron de la preprueba si entendieron las preguntas y si podían mejorarse. Además, aproveché para tomar el tiempo de duración. Diseñé dos cuestionarios diferentes, uno para cada una de las muestras. Ambos cuestionarios tienen preguntas en común que servirán para comparar las muestras y conocer similitudes y diferencias entre las personas a ser realojadas y las ya realojadas. Además, ambos cuestionarios tienen preguntas sociodemográficas para conocer las características generales de la población bajo estudio. Este cuestionario incluye características demográficas (edad, género, lugar de nacimiento), sociales (estado marital, grado escolar o universitario y estado de empleo) y económicas (ingresos y ayudas económicas). También incluí preguntas para explorar si hay discrepancias entre el censo de población y vivienda realizado en el 2002 por una firma de consultores con la colaboración de los(as) residentes que trabajaron como entrevistadores(as). Las variables a comparar entre este estudio y dicho censo son tiempo de residencia en comunidad y vivienda, tenencia de la vivienda, aspectos que agradan y desagradan de la comunidad y preferencia por el nuevo lugar a vivir, entre otras. El tiempo de duración dependió de, entre otros aspectos, la presencia de distracciones en el hogar y compromisos de la persona entrevistada.

2.4.2 Recursos. Durante la realización de la encuesta, contraté los servicios de una asistente de investigación, estudiante doctoral en filosofía e historia del arte en la Universidad de Salamanca. Su labor fue encuestar a ambas muestras. Una semana 
antes de su incorporación al trabajo de campo, la adiestré sobre la metodología de estudio y la encuesta, como técnica de investigación cuantitativa.

2.4.3 Entrevista semiestructurada. En las entrevistas semiestructuradas individuales, pregunté sobre sus actitudes hacia el realojo, en particular, cómo se sintió la persona cuando le dijeron que sería realojada, cómo han sido los preparativos, cómo compara el proceso de realojo con las situaciones vividas en otras comunidades en el pasado y en el presente y cómo describiría al realojo, si como voluntario o forzado.

Para este tipo de entrevista, había preparado una hoja de consentimiento informado (véase Anejo F) para que la persona la firmara antes de proceder a hacer las preguntas. Sin embargo, en la preprueba y en el comienzo de la recopilación de datos, tuve dificultades para que las personas firmaran la hoja de consentimiento. Por ejemplo, algunas personas, luego de llenar el cuestionario de la encuesta, no quisieron continuar con la entrevista semiestructurada por no firmar dicha hoja. Por lo tanto, decidí no exigirles que firmaran la hoja de consentimiento y resultó eficientemente porque la respuesta de las personas a participar sin dicha hoja fue mayor que si la tuviera. En cuanto a las personas que participaron en las entrevistas semiestructuradas, grabé las mismas con una grabadora de voz digital, siempre y cuando las personas así lo permitieran. Sin embargo, desde el principio hasta la mitad de la recopilación de datos, también tuve dificultades para continuar la entrevista por el temor de algunas personas de grabar su voz. Por lo tanto, decidí escribir las respuestas de las preguntas de la entrevista semiestructurada.

Estimaba que al final de la fase de recopilación de datos tendría un total de 32 entrevistas semiestructuradas (16 a personas a ser realojadas y 16 a personas ya realojadas). Para seleccionar a las personas a entrevistar, tomé en consideración las 
variables independientes: edad, género y educación. Por ejemplo, traté de tener la misma cantidad de adultos(as) (menores de 60 años) y viejos(as) (60 años y más), de mujeres y hombres y de personas con menos de décimo grado de escolaridad y personas con décimo grado o más (como mínimo algún grado de escuela superior). Para esto, llevé a cabo un diseño factorial, el cual presenta todas las combinaciones de todas las categorías de las variables independientes (Bernard, 2006). El diseño factorial de este estudio es $2 \times 2 \times 2$ porque son 3 variables con 2 categorías cada una. $\mathrm{Al}$ combinarlas, tendría 8 condiciones a buscar en personas voluntarias para realizar las entrevistas semiestructuradas (véase Anejo K). Busqué tener 2 entrevistas para cada una de las condiciones para ambas muestras. De esta manera, tendría 16 entrevistas para cada una de las muestras. Debido a que tuve que cesar la recopilación de datos en uno de los proyectos de viviendas de personas realojadas, sólo pude realizar 4 entrevistas semiestructuradas de la muestra de personas ya realojadas. En cuanto a la muestra de personas a ser realojadas, sólo me faltaron por realizar 2 entrevistas para lograr la cuota establecida. De esta manera, al finalizar la recopilación de datos, entrevisté a 14 personas por ser realojadas y a 4 personas ya realojadas, para un gran total de 18 entrevistas semiestructuradas.

En cuanto a la guía de preguntas, la misma consta de 25 preguntas abiertas (véase Anejos I y J). Antes de comenzar la fase de recopilación de datos, realicé una preprueba con residentes afectados(as) por el realojo para hacer los cambios necesarios. El tiempo de duración dependió, entre otros aspectos, de la presencia de distracciones en el hogar, compromisos de la persona entrevistada y el tiempo requerido por la persona para recordar y relatar su experiencia. 
2.4.4 Otras técnicas. En cuanto a los materiales para el análisis, éstos incluyeron los resultados de la encuesta con cuestionarios, que incluye preguntas abiertas y cerradas, las entrevistas semiestructuradas individuales y las notas tomadas, escribiendo en el momento (claves y frases) que luego profundicé y la observación participante directa. Luego, tabulé los datos. Analicé cuantitativamente los resultados de la encuesta con el programa de ordenador, Paquete Estadístico para las Ciencias Sociales (o S.P.S.S., Statistical Package for the Social Sciences, según sus siglas en inglés), utilizando tablas de frecuencia, tablas cruzadas, medidas descriptivas, como mediana, y gráficas.

2.4.5 Observación partícipe directa. Respecto a la técnica de observación partícipe directa, estuve presente en la comunidad durante un período de un año y un mes y compartí con los(as) residentes en todo lo que me fue permitido por la población, ya fueran actividades ordinarias o extraordinarias. De esta manera, obtuve datos a través de un contacto directo y continuo en situaciones cotidianas. Realicé un muestreo de eventos para hacer observación partícipe, a saber, reuniones públicas, organizadas por la comunidad, organización comunitaria y/o corporación pública, y actividades sociales (de índole familiar y/o comunal), organizadas por los(as) residentes. Estas observaciones las llevé a cabo desde la oficina central del proyecto ambiental y comunitario de la corporación pública. Esta oficina estaba localizada en una avenida principal que cruza de norte a sur a la comunidad y es perpendicular al curso del caño.

2.4.6 Medios técnicos. Utilicé una grabadora digital de voz para registrar las entrevistas, con previa autorización (verbal, debido a la renuencia de algunas personas de firmar la hoja de consentimiento) de los(as) participantes de este estudio. También usé una cámara fotográfica para tomar imágenes de las viviendas y de la comunidad y 
sus alrededores. Finalmente, utilicé un ordenador portátil con el Paquete Estadístico para las Ciencias Sociales.

\subsection{Procedimiento}

Antes de realizar el trabajo de campo, establecí un acuerdo de colaboración con la gerencia de la corporación pública que persigue el desarrollo urbano, social y económico y la rehabilitación ambiental del caño, para poder usar sus facilidades y ofrecer mis servicios voluntarios a cambio. De esta manera, los(as) residentes de la comunidad que fueron a la oficina y yo nos conocimos mejor y pudimos establecer relaciones informales. En retribución, brindé mi apoyo en las tareas administrativas en las que pude cooperar. Fue en esta oficina donde tuve la oportunidad de conocer más sobre los proyectos a cargo de la corporación pública y pude participar en varias actividades planificadas por la corporación. Además, me presenté ante las organizaciones comunitarias para informarles de mi proyecto de investigación y ofrecerles mis servicios voluntarios, en el caso de que les pudiera ayudar en algo. Luego, regresé para dejarles saber del inicio de la fase de recopilación de datos y les solicité su cooperación para poder realizar la misma.

Para lograr acceso a las personas incluidas en las muestras, coordiné las visitas a sus comunidades con los(as) líderes comunitarios(as), a quienes les informé sobre la intención de mi estudio. Además, debido a que en la comunidad hay varios puntos de distribución de drogas ilegales (se le llama punto de drogas, al lugar donde venden las drogas ilegales), unos más pequeños que otros, fue importante comunicarme con los(as) líderes, quienes también son residentes, para que me informaran más sobre esa y otras particularidades de su comunidad. Por las experiencias pasadas de algunos(as) residentes, en las que personas mienten sobre su identidad e intenciones, deseé evitar que mi visita causara confusión y por eso fue importante trabajar como voluntaria en 
la corporación, informar a los(as) líderes de mi estudio y visitar la comunidad antes de ir a entrevistar. En esta comunidad, la organización comunitaria y la corporación pública han advertido de la presencia de personas inescrupulosas que engañan para comprar viviendas a bajo precio para obtener beneficios de los proyectos planificados. Además, por la presencia del narcotráfico en el vecindario, siempre está el miedo de que confundan a una con una agente de la policía o que me vea afectada por algún incidente criminal. Por ejemplo, durante un ejercicio de observación partícipe, como a las 2:00 de la tarde en un día de semana, cerca de 5 jóvenes con armas largas estaban en una calle en posición de vigilancia, parece que a la espera de algo. Me sorprendió ver las armas tan temprano en el día y en manos de personas tan jóvenes.

Antes de la visita para realizar la encuesta y las entrevistas semiestructuradas y según las sugerencias de algunos(as) líderes, entregué casa por casa una hoja donde informé el propósito de mi estudio y la posibilidad de que esa vivienda fuera seleccionada al azar para participar de la encuesta (véase Anejos CH y D). Para entrevistar, visité la comunidad de lunes a domingo de 10:00 a 20:00 con el propósito de aumentar la posibilidad de encontrar personas en sus hogares. En la visita, me presenté a los(as) residentes seleccionados(as) al azar para dejarles saber mi propósito de la entrevista y de lo que consistía, en este caso, un cuestionario de ocho páginas que duraría cerca de treinta minutos. A los(as) residentes seleccionados aleatoriamente e interesados(as) en participar, les entregué una carta de presentación (véase Anejo E), justo antes de llevar a cabo la entrevista. Al finalizar el cuestionario, les pregunté si deseaba seguir comentando sobre el mismo tema en una segunda parte, que consistía en más preguntas abiertas. Si la persona aceptaba, le preguntaría si tenía tiempo de realizarla en el momento. 


\subsection{Reflexiones personales sobre la experiencia del trabajo de campo}

Durante el periodo en que estuve en la comunidad bajo estudio, entendí las preocupaciones que tienen muchos(as) residentes en cuanto a sus hogares, como las inundaciones. Durante los meses en que realicé las entrevistas, en varias ocasiones tuve que cesarlas temporalmente y abandonar en auto la comunidad por el riesgo que corría de no poder salir de allí. Uno de los peligros que trae las inundaciones es el posible daño a la salud de los(as) residentes porque se combina el agua de lluvia con el agua contaminada del caño y las aguas servidas. Otra de las consecuencias de las inundaciones es el daño a los muebles y equipos electrónicos en los hogares afectados. Como son personas de escasos recursos en su mayoría, es más difícil para ellas recuperar lo perdido.

Por otro lado, en algunos sectores de la comunidad, anduve por caminos muy estrechos y entendí la preocupación de algunos(as) residentes de la posibilidad de que los servicios de emergencia, como ambulancias y bomberos, no puedan llegar con facilidad y rapidez, debido a la estrechez de los caminos. También caminé por lugares peligrosos por la presencia de varios puntos de distribución de drogas ilegales. Si me sentía incómoda, quizás más incómodos(as) podrían estar muchos(as) residentes, quienes tienen que caminar por el área con mayor frecuencia con que yo lo hacía.

Durante la investigación de campo, confronté problemas metodológicos, como la resistencia de algunos(as) líderes comunitarios(as) a que hiciera entrevistas. Debido a que en el pasado algunos(as) estudiantes graduados(as) que han hecho sus investigaciones en la comunidad, no han regresado para presentar sus hallazgos, luego de presentarme ante los(as) líderes comunitarios(as), muy pocos(as) mostraron desconfianza ante mi intención de hacer un estudio sobre las actitudes de los(as) residentes hacia el realojo de viviendas. Esta resistencia llegó al punto de planificar la 
creación de un contrato entre la agrupación de los(as) líderes y esta servidora. Este contrato estipularía mi compromiso de regresar a la comunidad para presentar y/o entregar los hallazgos de mi estudio. Aunque el contrato no llegó a materializarse, me mantengo firme en mi deseo y obligación de reportar los hallazgos de esta investigación, una vez sean presentados en la defensa de la tesis doctoral. Entiendo que al finalizar el trabajo de campo, y con ello la recopilación de datos, la actitud de los(as) líderes comunitarios(as) que me mostraron desconfianza en octubre del 2006 ha cambiado a una de cordialidad y hasta amistad. Para lograr el cambio de actitud, siempre demostré mi compromiso con la comunidad y mi estudio al ser responsable y puntual en las citas acordadas para visitar los distintos sectores de la comunidad, respetuosa con los(as) residentes y accesible para responder preguntas sobre el estudio.

Otro problema metodológico confrontado fue la desconfianza de algunos(as) informantes, reflejada en el rechazo a firmar las hojas de consentimiento informado y a grabar las entrevistas. En la preprueba de los instrumentos, sólo una persona firmó la hoja de consentimiento y anticipé que tendría dificultades en la fase de recopilación de datos, específicamente para realizar las entrevistas semiestructuradas. Resolví no usar la hoja de consentimiento para tratar alcanzar la meta de entrevistar una cantidad específica de personas. Una vez superado este problema, me topé con la situación de que algunas personas no querían que grabara la entrevista. Por lo tanto, opté por escribir las respuestas a las preguntas de la entrevista semiestructurada. Entiendo que posiblemente la desconfianza por firmar la hoja y a grabar la entrevista se deba a varios factores, como la residencia en la comunidad de personas indocumentadas, procedentes de la República Dominicana, en su mayoría. Pienso que otro factor podría ser el posible vínculo de algunas personas con la distribución de drogas ilegales, luego 
de sospechar que había entrevistado a un encargado de un punto de drogas. Otra causa puede ser la duda por parte de algunos(as) residentes sobre mi identidad y propósito de mi estudio al no conocer a toda la población de la comunidad. Durante el trabajo de campo, al caminar por las calles de la comunidad, en muchas ocasiones, me preguntaron quién era y qué hacía allí. También algunas personas pensaron que trabajaba en el gobierno porque al verme con documentos en mano (instrumentos de recopilación de datos) me hacían comentarios, como un residente que me dijo: "Ya yo llené esos papeles", quizás refiriéndose a documentos relacionados al realojo. Le dije que no trabajaba en el gobierno y me reiteró: "Ya dije lo que tenía que decir". Otra persona me gritó: "De aquí no me voy. Nadie me saca. Esta casa es mía. Yo trabajo a mi edad".

Los problemas prácticos encontrados durante la realización de este estudio sugieren que la aprensión prevaleciente en la comunidad se debe en parte a las malas experiencias vividas en el pasado, donde las promesas no se cumplen, ya sea por parte del gobierno en cuanto a alguna petición hecha o por parte del estudiantado que ha realizado su investigación y/o práctica allí y no ha regresado. En cuanto al estudiantado, se espera que la atención recibida por parte de los(as) participantes en sus estudios sea reciprocada con la entrega de los resultados. Después que las personas participaron en las investigaciones, desean conocer qué encontraron en cuanto a su comunidad, sobre todo, los(as) líderes, quienes en ocasiones no se enteran por completo de lo que piensan sus residentes. También algunos resultados de los estudios realizados han causado controversia, como pasó con una investigación de estudiantes de Trabajo Social, quienes generalizaron un hallazgo a base de la respuesta de una persona, según informado por líderes y personal de la corporación pública. 
Su relación con el gobierno municipal y estatal en las pasadas seis décadas ha marcado la actitud de los(as) residentes hacia las personas que entren a la comunidad, especialmente los(as) representantes de partidos políticos, quienes desde la mitad del siglo pasado han visitado las casas y caminado por sus calles con la supuesta intención de conocer las condiciones de vida y problemas de sus residentes. Algunas personas mayores recuerdan a la primera alcaldesa de San Juan (1946-1968), Felisa Rincón de Gautier (“doña Fela”), quien, según ellas, visitaba la comunidad y ayudaba a los(as) residentes para que tuvieran una vivienda estable, como asistir a rellenar el terreno y "levantar las casas sobre zocos". También han tenido experiencias con actuales funcionarios(as) públicos(as). Sobre un funcionario en particular, una residente de la comunidad dijo que él ha faltado el respeto de los(as) residentes en reuniones. Por otro lado, en un taller de adiestramiento a miembros de base comunitaria, celebrado en abril del 2007, este funcionario aprovechó para informar a los(as) residentes sobre distintas situaciones en varias comunidades de San Juan:

En el sector de no le voy a permitir a nadie que coja títulos. Están traqueteando en ARPE [Administración de Reglamentos y Permisos]. Tengo los títulos de listos y se los voy a dar a sus dueños. Se inventaron corporaciones para botarlos del barrio. Estoy cansado del invento y del engaño. Ustedes se tienen que organizar. Me enteré que en $\$ le están haciendo unas patrañas. A no sacan la gente. El escándalo más grande se va a formar en Ni que los otros del barrio ni los de afuera los engañe. No tuve que sacar a nadie en Hill Brothers para ponerlo bonito. El delito que se cometió en $\amalg$ no pasará en El_ dragado vale 200 millones, pero para dragar no hay que sacar gente. No entreguen 
escrituras ni títulos. No hay derecho. Que no te digan ahora 'tu casa es mía'. No lo vamos a permitir.

Por otro lado, el recelo presente en la comunidad ante la visita de personas no residentes puede deberse a las experiencias vividas en torno al realojo de sus viviendas. Durante la realización de las entrevistas, al preguntarles cuándo fueron informadas del posible realojo de su vivienda, muchas personas comentaron que desde hace años se comenta o escuchan sobre eso. Como la inmensa mayoría de las personas saben que las viviendas fueron construidas originalmente en humedades, a las orillas del caño, el terreno pertenecía al gobierno de Puerto Rico, por lo que la amenaza del desalojo está presente desde hace más de seis décadas. Entonces, cada familia ha recibido en su hogar a varios representantes del gobierno, durante todos estos años, para comentar, preguntar y/o informar sobre la vivienda y el realojo de la misma.

De manera general, fue una grata experiencia el realizar el trabajo de campo en dicha comunidad. La inmensa mayoría de las personas que me recibieron en sus hogares fueron muy atentas y serviciales conmigo. A pesar de la desconfianza hacia desconocidos(as) que prevalece en el país en estos tiempos, muchas personas me invitaron a entrar a sus hogares y hasta me ofrecieron bebidas para refrescarme por el calor que hizo en esos días. Algunos(as) residentes ya han participado en otros estudios porque a esa comunidad han ido y siguen yendo estudiantes de distintas disciplinas, como Trabajo Social y Enfermería, a hacer sus prácticas y realizar investigaciones, a veces con pocos beneficios inmediatos para la comunidad. No obstante, muchas personas me recibieron sin problemas, aunque quizás acostumbradas al procedimiento de una entrevista, especialmente al formato de preguntas cerradas. 
Cuando entendía que era oportuno, para crear un ambiente de mayor confianza, a algunos(as) residentes les relaté que mi familia materna es originaria de la comunidad y fue agradable escuchar que las personas mayores de edad recordaban a mi abuelo y tíos(as) abuelos(as). Espero haber aportado modestamente al desarrollo de la comunidad por medio de mi trabajo voluntario, realizado durante los primeros meses del trabajo de campo, en la corporación pública. También espero contribuir al progreso de la comunidad con esta investigación. 


\section{Revisión de literatura teórica}

\subsection{El concepto de pobreza}

La revisión bibliográfica de este estudio sobre las actitudes de los(as) residentes hacia el realojo de sus viviendas en una comunidad pobre en la capital de Puerto Rico se limita a los trabajos publicados sobre los temas de pobreza en general; pobreza urbana; realojo de viviendas; gentrificación; distinción entre barrio, slum, arrabal y gueto; y las invasiones o rescates de terreno. Esta revisión de literatura incluye definición de conceptos, teorías principales y su desarrollo y metodologías utilizadas, además de las limitaciones y críticas a las mismas. También la literatura revisada contiene las publicaciones sobre dichos temas en Puerto Rico y otros países, como Estados Unidos, España, México y Argentina, y desde varias disciplinas, como antropología, sociología, demografía, economía, trabajo social, leyes, planificación y geografía.

La pobreza es un problema social que ha afectado a todos los países del mundo desde hace mucho tiempo, pero durante la mitad del siglo pasado se le ha prestado más atención sistemática. Ésta puede abordarse de diferentes maneras, dependiendo de la situación socioeconómica de la población, país o región en particular, de los datos disponibles y del propósito con que se desea investigar. A pesar de la variedad de los estados de pobreza, las limitaciones impuestas a la existencia de los seres humanos, la negación de la oportunidad para desarrollar sus potencialidades y el ser víctimas de la explotación de los poderosos son elementos comunes que le imparten a la pobreza un carácter universal (Ramírez, 1970).

En el estudio de la pobreza, se destaca Amartya Sen (1993), quien analiza y critica los conceptos y medidas de pobreza y los procesos de identificación de los pobres y la agregación de los mismos. Para medir la pobreza, Sen (1993: 19-20) 
diferencia la identificación de los(as) pobres y la agregación de las características de su pobreza: "Para identificar a los pobres, dado un conjunto de necesidades básicas es posible utilizar por lo menos dos métodos. Uno consiste simplemente en determinar el conjunto de personas cuya canasta de consumo actual deja insatisfecha alguna necesidad básica. A éste se le puede llamar el método del ingreso, el primer paso consiste en calcular el ingreso mínimo, o la línea de pobreza, en el cual todas las necesidades mínimas específicas se satisfacen. El siguiente paso es identificar aquellos cuyo ingreso actual está por debajo de dicha línea de pobreza”. El otro método es el directo, el cual "identifica a aquellos cuyo consumo real no satisface las convicciones aceptadas sobre necesidades mínimas" (Sen, 1993: 21). En la segunda operación, la de agregación considera las brechas de ingreso, que son "el déficit de ingresos de una persona cuyas percepciones están por debajo de la línea” (Sen, 1993: 24).

“La pobreza se entiende [...] como la imposibilidad de alcanzar un estándar o nivel de vida, comúnmente aceptado como mínimo, por no contar con acceso a los recursos necesarios para ello" (Consejo de Desarrollo Estratégico para Puerto Rico, 1993: 202). Esta definición de la pobreza considera el alcanzar ciertos niveles relativos para la satisfacción de las necesidades materiales e inmateriales. El Consejo de Desarrollo Estratégico para Puerto Rico (1993: 202) señala: “Estas últimas tienen que ver con la calidad de vida, la participación en los procesos decisorios y las instituciones de la sociedad, la calidad y funcionalidad de la educación, la realización a través del trabajo, la identidad cultural, el grado de libertad efectiva que se disfruta, la calidad de la vida familiar y la calidad del medio ambiente".

En su análisis sobre desarrollo político y pobreza en Puerto Rico, Morales (1993: 352) señala: "La pobreza resulta ser un problema de carencia de medios 
adecuados para incorporar al proceso político las soluciones que hagan posible que los pobres dejen de ser pobres y que logren que los ricos sean menos ricos. Pobreza, para mí, no es otra cosa que una indigencia total de poder político que impide que los intereses de los grupos indigentes se vean adecuadamente representados en el proceso de decisión y que, por lo tanto, imposibilita el que esos grupos satisfagan las metas y objetivos que se trazan para sí mismos, tanto individual como colectivamente".

Más adelante, el autor añade que las clases indigentes en el país no pueden mejorar su situación socioeconómica porque no tienen poder político por su endeble condición socioeconómica, siendo víctimas de un círculo vicioso. Morales (1993: 361) recomienda que protesten los(as) pobres, que expongan sus intereses y problemas y que luchen para lograr que se satisfagan, obligando a actuar al gobierno: "si los gobiernos no han podido o no han querido satisfacer las necesidades de los pobres, deberán los pobres actuar positivamente para completar la acción del gobierno".

La pobreza puede verse en términos absolutos y relativos. Lok-Dessallien (2000) define estos conceptos, entre otros más, y presenta varios indicadores usados en el análisis de este problema social. La pobreza absoluta se define como la subsistencia por debajo condiciones de vida mínimas y socialmente aceptables, usualmente establecidas sobre la base de requisitos nutricionales y otros bienes esenciales. Por otro lado, la pobreza relativa compara los segmentos más bajos de la población con los segmentos superiores, usualmente medida en ciertas percentilas de ingreso, por ejemplo, en quintilas. Se añade que dentro de la llamada pobreza absoluta, los países generalmente distinguen entre indigencia o pobreza primaria y pobreza secundaria (a veces referida como pobreza extrema). La indigencia se refiere a aquellos que no tienen acceso o los recursos básicos para la supervivencia humana, 
mientras que la pobreza secundaria se refiere a los grados de privación por encima de ese umbral de pobreza. Lok-Dessallien señala que algunas personas que trabajan en torno al desarrollo de algún sector le dan mayor prioridad a reducir la pobreza absoluta por la urgencia asociada con la hambruna, malnutrición y otras aflicciones.

Por otro lado, la pobreza puede dividirse en crónica y episódica (Lichter \& Crowley, 2002). La primera se puede causar por oportunidades limitadas de trabajo, educación, habilidades y destrezas de trabajo y por discriminación; las personas están mucho tiempo y es difícil salir de esta situación. Este tipo de pobreza se considera como intratable y difícil de erradicar. La pobreza episódica es de corta duración, no es tan difícil para salir de este estado y habitualmente ocurre durante eventos críticos en el ciclo vital, como viudez y retiro.

Además, Lok-Dessallien (2000) sugiere que la pobreza puede abordarse desde una perspectiva objetiva o subjetiva. La perspectiva objetiva (algunas veces referida como acercamiento de bienestar) involucra juicios normativos, como qué constituye la pobreza y qué es lo que se requiere para sacar a las personas de ese estado emprobecido. Por otro lado, la perspectiva subjetiva enfatiza en el individuo y cuánto valora los bienes y servicios. Sin embargo, no siempre los individuos juzgan lo mejor para ellos. Por ejemplo, todos los individuos valoran el consumo de alimentos y algunos les dan un mayor valor a ciertos tipos de comida o cantidades de comida que no son las mejores para el bienestar físico. Estas dos perspectivas se aproximan al fenómeno desde diferentes ángulos y no se les puede categorizar como buenas o malas.

Debido a que gran parte de la literatura sobre la pobreza, en cuanto a conceptos, metodologías, tendencias y hallazgos ha sido publicada por los Estados Unidos, es importante destacar sobre el marco conceptual y metodológico utilizado 
por el Negociado del Censo de ese país. Una de las críticas a la metodología del Negociado del Censo al medir la pobreza es que su criterio principal es el ingreso de la persona o de la familia. Uno de los métodos se llama línea de pobreza o método de ingreso, por establecer un umbral específico, al cual se compara el ingreso individual o familiar y, si está por debajo, se considera como pobre a la persona o la familia.

Sobre tomar el ingreso solamente para medir la pobreza, Ramírez (1970) considera que no es suficiente y que se deben incluir otros criterios para complementarlo, como escolaridad, ocupación y zona de residencia.

Sin embargo, varias instituciones han realizado observaciones y recomendaciones sobre esta definición de pobreza. Primero, según Dalaker (2001), la medida oficial de pobreza no muestra cómo los impuestos, los beneficios que no son en efectivo y los gastos relacionados al trabajo afectan al bienestar de las personas. Segundo, en 1995 un panel de la Academia Nacional de Ciencias observó que esta medida oficial tampoco muestra cómo los cambios en política en esas áreas afectan a los(as) pobres. Tercero, este panel notó que la medida oficial de pobreza no tomó en consideración cómo el costo de bienes básicos (como comida y vivienda) ha cambiado relativo a otros bienes desde principios de la década de 1960, cuando se desarrolló la medida oficial de pobreza. Cuarto, no refleja que los costos varían geográficamente. Quinto, este panel de la Academia Nacional de Ciencias señaló que éstos no computan correctamente el aumento en gastos y las economías a escala que ocurren a medida que el tamaño de la familia aumenta. Y sexto, esta definición de pobreza es establecida en función de los estándares norteamericanos de bienestar (Vélez, 1995b). Por el contrario, esta definición de pobreza, también tiene sus ventajas. Algunas de ellas son 1) que es una medida objetiva, basada en el concepto de medición de línea de pobreza, el cual es bastante usado en muchos países y a través 
del tiempo; 2) luego de establecer los umbrales de pobreza, es fácil establecer si la persona es pobre o no, ya que simplemente se compara el ingreso de la familia con el umbral, y si el primero es menor que el segundo, entonces se califica como pobre; 3) los umbrales de pobreza son actualizados anualmente de acuerdo a la inflación, usando el Índice de Precios del Consumidor; y 4) es usada como criterio de elegibilidad por algunos programas sociales que proveen asistencia a las personas pobres.

En conclusión, los trabajos sobre la pobreza en general han contribuido significativamente al análisis de este problema y de las características de las personas, cuyos ingresos están por debajo del nivel de pobreza. Especialmente, estos estudios han aportado particularmente en su definición, medición y relación con otros conceptos, como desarrollo y desigualdad. Sin embargo, quedan pendientes problemas de investigación, como la medición del efecto de crisis económicas (nacionales y/o mundiales) sobre la población ya empobrecida y el posible aumento de la probabilidad de ser clasificadas como pobres las personas no clasificadas de esa manera anteriormente. Otro problema de investigación sería el de cómo mecanismos contra el desplazamiento urbano (gentrificación), como un fideicomiso de la tierra, podrían contribuir a la reducción de la pobreza. Entonces, quedan pendientes por estudiar otros factores que influyen sobre la pobreza y podrían llevar a modificar su definición y medición.

\subsection{Teorías de la pobreza urbana}

En el análisis del problema de la pobreza, se destacan los estudios sobre la pobreza urbana, particularmente los que presentan diversos conceptos y teorías para explicar este fenómeno social. Vilagrasa (2000) señala que, a partir de los trabajos sociológicos de la Escuela de Ecología Urbana de Chicago, el supuesto básico es que 
la ciudad (particularmente durante las primeras décadas del siglo pasado) se convirtió en punto de llegada de inmigrantes que fueron adaptándose a las normas de convivencia urbanas y acogiéndose a las oportunidades que les ofrece la ciudad, desde condiciones inicialmente precarias. De la misma manera, Ramírez (1977) señala que el proceso mundial de urbanización, la migración de los(as) residentes de la zona rural, su incorporación a la vida de la ciudad y la subsiguiente expansión de las barriadas de clase baja dentro de la ciudad y sus alrededores presentan problemas teóricos y prácticos que preocupan a $\operatorname{los}($ as) científicos(as) sociales, los(as) planificadores(as) y los(as) políticos(as).

Sobre el tema de la pobreza, se destacan los trabajos de investigación de la Escuela de Chicago, de donde surgieron teorías que explicaban este problema social que todavía persiste, sobre todo en la comunidad estudiada en esta tesis. Las teorías más relevantes sobre el problema de pobreza urbana, que se han utilizado en Puerto Rico por los(as) investigadores(as), son la cultura de la pobreza de Oscar Lewis, la marginalidad de Robert Ezra Park y Everet Stonequist y la subclase (underclass en inglés) de William Julius Wilson, los cuales usaré para tratar el tema principal de esta investigación, las actitudes de los(as) residentes hacia el realojo de sus viviendas en una comunidad urbana y pobre de San Juan. Posiblemente, debido a las condiciones de vida en esta comunidad, entre sus residentes se destaquen algunas actitudes hacia el realojo de sus viviendas, como resultado de su condición socioeconómica.

3.2.1 Teoría de la marginalidad. Según Colón Reyes (2006: 122), el concepto de marginalidad "se utilizó para referirse a la situación marginal creada por las aglomeraciones urbanas, producto de la industrialización acelerada de 1950”. De igual manera, Gravano (2005: 87) lo define “como un fenómeno emergente del rápido crecimiento poblacional de las urbes, consecuencia del proceso acelerado de 
urbanización provocado por los flujos migratorios, refiriéndose a conglomerados de viviendas precarias y la ocupación ilegal de terrenos fiscales y privados".

Asimismo, Monreal (1996: 88) señala que la marginalidad descansa sobre la creencia de que "debido a la rápida urbanización, las ciudades se han visto invadidas por hordas de campesinos, que son vistos como desarraigados, desorientados, incapaces de adaptarse a un supuesto estilo de vida urbano y deseosos de volver a sus pueblos de origen". Estos inmigrantes se aislaron en enclaves con características rurales como mecanismo de autodefensa, sin aprovechar lo que les ofrecía la sociedad urbana. La teoría de la marginalidad señala que "en estos enclaves se desarrollan todos los síntomas de desorganización social: desestructuración familiar, anomia, crimen, violencia, promiscuidad..." (Monreal, 1996: 88).

El concepto de la marginalidad se ha ampliado últimamente para referirse a todos los grupos, cuya participación activa en las instituciones dentro de una sociedad es restringida, por lo que no influyen en la toma de decisiones o en los beneficios del desarrollo económico (Ramírez, 1977). La marginalidad no indica separación o estar fuera del sistema, sino ser parte de un sistema desigual más amplio, sin tener completa participación (Ramírez, 1977).

Las teorías sobre marginalidad se elaboraron cuando se pudo constatar que el proceso de industrialización no solucionaba los problemas sociales y económicos por no ser capaz de absorber a los(as) desocupados(as) urbanos(as) y a los(as) migrantes rurales que llegaban a las ciudades (Colón Reyes, 2006). Con nombres que reflejaban las teorías e ideologías, los barrios de la pobreza fueron nombrados desde las ciencias sociales (Gravano, 2005). "Para el barrio bajo de la metrópoli sirvió la teoría del slum [arrabal], y para el barrio bajo del Tercer Mundo, la teoría de la marginalidad" (Gravano, 2005: 87). En la teoría de la marginalidad, los barrios pobres fueron 
indicadores de la indeseabilidad dominante en la ciudad. Para la década del 50 del siglo pasado, los barrios pobres fueron la marca de la extensión de asentamientos irregulares precarios e ilegales (de propiedad privada o fiscal), construidos con material de desecho por los(as) propios(as) pobladores(as), quienes son migrantes expulsados(as) del campo y llegaron a las grandes urbes, en busca de trabajo o atraídos(as) por las condiciones de vida urbanas (Gravano, 2005).

Entonces, hay distintos tipos de marginalidad, como la marginalidad social, marginalidad urbana, marginalidad económica y marginalidad política. Sobre la marginalidad social, Ramírez (1977: 3) señala que puede analizarse en distintos niveles institucionales: "Se puede examinar en términos de la participación de los marginados en el proceso de crecimiento económico y del sistema de mercado, en su acceso a las instituciones públicas, en su aceptación o rechazo de las ideologías y los valores que prevalecen en la sociedad, así como por su participación en el proceso político".

Por su parte, Perlman (1976) señala que la marginalidad es caracterizada por la desorganización interna de las comunidades y el aislamiento externo. Sobre la marginalidad urbana, Gravano (2005: 86) la define como quedar excluido(a) del cumplimiento de los derechos que se derivan de vivir en la ciudad, incluyendo "el derecho a la vivienda, a una vida digna, a usar los servicios que la ciudad debe brindar para todos, como ámbito socializado de la producción humana". Añade el autor que los(as) marginados(as) "quedan al margen del derecho al uso digno de la ciudad y sus servicios, por el lugar que habitan: el barrio bajo (énfasis del autor)” (p. 87). Muy relacionado a este tipo de marginalidad, está la marginalidad residencial. Perlman la define como la marginalidad que se produce por la residencia en asentamientos ilegales, caracterizados por la ausencia de equipamientos urbanos y el aislamiento 
físico con respecto al resto de la sociedad. Castells (1986) menciona que el origen de la marginalidad urbana está en el Estado, al aplicar distintas políticas a los diferentes grupos sociales y en el abuso de esta actitud de segregación residencial/espacial por distintas fuerzas económicas. Para Castells, son las condiciones de la urbanización y no la ausencia de industrialización o el tipo de industrialización existente, las que originan la marginalidad urbana. Por lo tanto, "la marginalidad urbana es la consecuencia de la crisis de un sistema urbano incapaz de responder a las necesidades de una mayoría de la población, en cuanto a viviendas y a equipamientos" (Monreal, 1996: 93).

En cuanto a la marginalidad económica, Gravano (2005) la define cuando las personas quedan fuera del sistema de empleo y coberturas sociales. Perlman (1976) indica que este tipo de marginalidad hace referencia a los(as) desempleados(as), subempleados(as) o definitivamente desenganchados(as) del mercado de trabajo y a aquellos(as) cuyo nivel de ingresos no les permite el acceso a las estructuras de consumo. Además, Perlman señala que en la marginalidad económica, los rasgos serían el parasitismo de los(as) marginados(as) y la ausencia de una cultura del trabajo que valore el esfuerzo y la superación. Monreal (1996: 94) la define como aquella que “considera marginales a todos aquellos individuos y grupos que no están imbricados en el mercado de trabajo urbano ni poseen el suficiente poder adquisitivo para vincularse a las estructuras de consumo de la sociedad". Entonces, al vincular la marginalidad urbana con la situación laboral, Monreal (1996) resalta que la segunda no es la única fuente de la primera, ya que dentro de la población marginada están los "lumpen" ("individuos situados permanentemente al margen de las formas dominantes de producción económica e intercambio" [Giddens, 2004]), los(as) trabajadores(as) informales, los(as) desempleados(as), las prostitutas, los(as) 
criminales y una población trabajadora formal, estable y relativamente bien remunerada, que pertenece al funcionariado (conjunto de personas que desempeñan empleos públicos, según la Real Academia Española, 2001) o a los(as) trabajadores(as) industriales "tradicionales" y que comparte comunidades, barrios, escasez de servicios, alquileres excesivos, protestas y asociaciones en un mismo espacio urbano.

Sobre la marginalidad política, Perlman (1976) la define como la población que desconoce y no participa en procesos políticos por apatía y, como el radicalismo, que lleva a motines esporádicos y violentos. Al respecto, Monreal (1996) indica, que para los(as) pobres de la población urbana, el barrio es la base principal desde la que expresan sus quejas y privaciones y donde se concentran sus luchas por las deficiencias que sufre, en cuanto a servicios básicos, como agua, electricidad y transportación, o la ilegalidad de los asentamientos. Esto lleva a que sus residentes se unan en sus reivindicaciones ante el gobierno.

Colón Reyes (2006) señala que los(as) marginados(as) son un grupo particular de los sectores pobres, compuesto por otros tres grupos, a saber, los colonos que trabajan la tierra, pero no la poseen; los muy pequeños propietarios, como comerciantes y contratistas; y la clase obrera agrícola, industrial y del área de servicios que recibe el salario mínimo o por debajo del mismo. Específicamente, sobre los(as) marginados(as), la autora señala que hay "diferentes niveles de exclusión del sistema económico dominante que viven por debajo o apenas en el nivel de sobrevivencia: desempleados, subempleados, miserables, mendigos, menores abandonados, adictos a drogas, prostitutas, deambulantes hambrientos y lumpen" (p. 96). 
Sin embargo, la teoría de la marginalidad ha sido criticada. Monreal (1996) destaca las críticas que ha recibido la teoría de la marginalidad, en particular sobre la composición heterogénea de la población marginada. Monreal (1996: 90) menciona que "ninguna de estas características son exclusivas de los marginados y muchos de los marginados no poseen tales rasgos". Monreal (1996) entra en detalles sobre lo encontrado en el estudio de Perlman:

Los marginados muestran un fuerte asociacionismo voluntario, estrechos lazos de amistad y parentesco, confianza y ayuda mutua; están adaptados al medio urbano y pocos desean regresar a sus lugares de origen; tienen un amplio contacto y conocimiento de las noticias locales y nacionales; desean trabajar, aspiran a obtener buenos puestos de trabajo y están abiertos a la innovación. Los marginados están integrados en el sistema económico, y realizan los trabajos peor remunerados, más inestables y de menor cualificación, pero no es correcto identificar con una posición de marginalidad el bajo nivel educativo, la precariedad en el empleo y los escasos ingresos; en todo caso, afirma Perlman, sería una marginalidad de la explotación y la exclusión, más que de la estrechez de miras y la ausencia de motivación (p. 90).

Un fenómeno mostrado por el estudio sobre pobreza urbana y política en Rio de Janeiro de Perlman fue que la población socialmente marginada no es la protagonista principal de los asentamientos pobres porque en las comunidades pobres había personas empleadas en trabajos estables y con pautas sociales y culturales integradas (Monreal, 1996). Otro fenómeno encontrado es la heterogeneidad de los asentamientos y comunidades de los(as) pobres, en cuanto a niveles de educación, estructura ocupacional, procedencia y tiempo de residencia (Monreal, 1996). 
Según Del Pilar y Udasco (2004), la noción de marginalidad continúa siendo usada, a pesar de preguntas sobre su solidez, y añaden que las críticas han sido en gran parte ignoradas. Debido a que el concepto de marginalidad surgió cuando Park describió como hombre marginal al que estaba en el margen entre su cultura nativa y la del país anfitrión (Del Pilar \& Udasco, 2004), surgió la confusión de si ser un hombre marginal significa estar en una situación marginal, tener rasgos de personalidad marginal o ambas (Dickie-Clark, 1966). Las primeras críticas hacia la teoría en la década de 1940 y principios de la década de 1950 parecen proveer evidencia de dicha confusión, surgiendo dudas sobre quiénes eran y quiénes no eran hombres marginales (Dickie-Clark, 1966). Por otro lado, luego de realizar una revisión de literatura en las disciplinas de psicología y sociología sobre la marginalidad, Del Pilar y Udasco encontraron que esta teoría había sido criticada por ser poco precisa, vaga y especulativa, carente de apoyo empírico, sin definición clara, aplicada indiscriminadamente a un rango asombrosamente ancho de escenarios y ha habido un fracaso en hacer una distinción entre la situación marginal y la personalidad marginal, resultando en una confusión del concepto de marginalidad. Particularmente, sobre la metodología de esta teoría, Del Pilar y Udasco señalaron que los intentos por operacionalizar la definición de marginalidad como patológica y la posterior prueba de las hipótesis fallaron, para encontrar resultados significativos. Además, una línea de criticismo sobre marginalidad se ha enfocado en la influencia negativa de este concepto imperfecto con respecto a los grupos que quiere caracterizar; por ejemplo, Park y Stonequist escribieron que miembros de grupos raciales minoritarios nunca podrían ser completamente americanizados (Del Pilar \& Udasco, 2004). Del Pilar y Udasco concluyen que la marginalidad carece de validez de construcción porque no hay acuerdo en la literatura de las ciencias sociales sobre el significado del concepto 
de marginalidad y, como concepto científico, la marginalidad no puede funcionar si éste tiene múltiples niveles de significado.

3.2.2 Teoría de la cultura de la pobreza. El concepto de la cultura de la pobreza fue desarrollado inicialmente por Oscar Lewis en 1959 en su libro Antropología de la pobreza: Cinco familias. Como señala Lewis (1985) en ese libro, su propósito era aportar a la comprensión de la cultura de la pobreza en el México contemporáneo y a la comprensión de la vida cotidiana de la clase baja en general, en tanto que los(as) pobres de todo el mundo tienen una cultura en común. En este trabajo, Lewis (1985) señala que la pobreza crea una subcultura por sí misma al ser un factor que afecta la participación en la esfera de la cultura nacional ${ }^{3}$. Añade que se puede hablar de una cultura de la pobreza porque tiene sus propias modalidades y consecuencias distintivas psicológicas y sociales para sus miembros. "La cultura de la pobreza rebasa los límites de lo regional, de lo rural y urbano, y aun de lo nacional" (Lewis, 1985: 17). Al mismo tiempo, según Lewis "la cultura de la pobreza se refiere sólo a cierto estilo de vida compartido por los pobres en determinados contextos históricos y sociales" (Lewis, 1983: LI). Estos contextos son "la etapa inicial de libre empresa del capitalismo y es genérica de esta misma etapa, y que es también endémica en los regímenes coloniales" (Lewis, 1983: LIII).

Según Lewis (1983), el objetivo de su estudio de otro arrabal puertorriqueño, La Vida, era someter a prueba el concepto de la cultura de la pobreza en distintos contextos nacionales. Como antropólogo, señala Lewis que ha tratado de comprender la pobreza y sus rasgos coexistentes como una cultura o como una subcultura, para ser más preciso, como un modelo de vida que se transmite de generación en generación sobre bases familiares. El tipo de estudio utilizado por Lewis es intensivo, la historia

\footnotetext{
${ }^{3}$ Oscar Lewis (1983) indica que utiliza "cultura de la pobreza" como forma abreviada del término "subcultura de la pobreza".
} 
de vida de una sola familia extendida, cuyos objetivos principales fueron contribuir a la comprensión de la vida en los barrios pobres de San Juan y comprobar y refinar el concepto de la cultura de la pobreza, mediante una comparación de los datos de México y Puerto Rico. Según Lewis, al estudiar una sola familia extendida se puede conocer a los individuos, la vida familiar, la vida de la clase baja en general y la historia y cultura en que viven. Por lo tanto, la unidad de análisis seleccionada es la familia Ríos. Sobre esta familia, Lewis subraya que no es una familia puertorriqueña típica, pero que representa el estilo de vida dominante en un barrio puertorriqueño. Sobre su historia, el autor añade que "pone de manifiesto, en forma dolorosa y dramática, las terribles condiciones de pobreza y patología social que existían en escala masiva en Puerto Rico antes de la década de 1940 y que aún persisten en los barrios pobres. Los relatos autobiográficos de los individuos nacidos entre 1900 y 1930 revelan un cuadro de desquiciamiento familiar, violencia, brutalidad, desprecio a la vida, falta de amor, de educación, de servicios médicos —en suma, un cuadro de increíbles privaciones cuyos efectos no pueden ser erradicados en una sola generación" (p. XIV).

Entre las características de la cultura de la pobreza, destaca la falta de participación e integración efectivas de los(as) pobres en las instituciones principales de la sociedad general (Lewis, 1983). Lewis señala que esta falta de participación "se deriva de una serie de factores, como la falta de recursos económicos, la segregación y la discriminación, el temor, la suspicacia o la apatía, y la invención de soluciones locales a los problemas. Sin embargo, la 'participación' en algunas instituciones de la sociedad general — no elimina por sí misma las características de la cultura de la pobreza. En el caso de un sistema de asistencia pública- que escasamente permite la supervivencia, tanto la pobreza misma como la desesperanza se perpetúan más bien 
que se eliminan" (p. XLVIII). Sobre las personas que viven en la cultura de la pobreza, el autor señala que "su nivel de alfabetización y educación es bajo, generalmente no se afilian a sindicatos ni partidos políticos, no participan en las instituciones nacionales de bienestar social y no hacen uso de los bancos, hospitales, tiendas, museos o galerías de arte. Mantienen una actitud crítica ante algunas de las instituciones fundamentales de las clases dominantes, odian a la policía, desconfían del gobierno y de quienes ocupan altas posiciones, y ven con cinismo incluso a la iglesia" (p. XLVIII-XLIX).

Respecto a la cultura de la pobreza a nivel de la comunidad local, Lewis (1983) menciona que tendrá condiciones habitacionales deficientes, hacinamiento y un mínimo de organización fuera de la familia nuclear y extendida. Añade que en los barrios pobres aparecen agrupaciones informales o asociaciones voluntarias sólo ocasional y transitoriamente. También puede haber cierto sentido de comunidad y espíritu de cuerpo entre los(as) habitantes de los barrios pobres, a pesar del nivel generalmente bajo de organización. En cuanto al nivel de la familia, los rasgos principales de la cultura de la pobreza son las uniones libres o matrimonios consensuales, la incidencia relativamente alta de abandono de mujeres e hijos(as) y la tendencia a la familia centrada en torno a la mujer o la madre.

Las características de la cultura de la pobreza al nivel del individuo incluyen "un fuerte sentimiento de marginalidad, impotencia, dependencia e inferioridad" (Lewis, 1983: L). Otros rasgos distintivos son "la falta de control de sus impulsos, la orientación temporal dirigida primordialmente hacia el presente, la capacidad relativamente reducida de aplazar la realización de los deseos o de planear para el futuro, la resignación y el fatalismo" (p. L) y bajo nivel de aspiración. Además, las personas "en la cultura de la pobreza son provincianos, viven en función de su 
ambiente inmediato y poseen un escaso sentido histórico. Sólo saben de sus propios problemas, su propia situación local, su propio vecindario, su propio estilo de vida" (pp. L-LI).

Por otro lado, las personas dejan de pertenecer a la cultura de la pobreza, aunque sigan siendo desesperadamente pobres, cuando adquieran conciencia de clase, se afilien a organizaciones sindicales o adapten un enfoque internacionalista del mundo. Por lo tanto, la base psicológica y social de la cultura de la pobreza quedará destruida por cualquier movimiento pacifista, revolucionario o religioso, que organice y dé esperanzas a los(as) pobres y fomente con efectividad la solidaridad y el sentido de identificación con grupos más amplios (Lewis, 1983).

Sobre los distintos contextos históricos y sociales en los que se podría o no desarrollar la cultura de la pobreza, Lewis (1983) indica que no surge en las sociedades primitivas y en las sociedades de castas. Por otro lado, tiende a declinar en las sociedades socialistas, fascistas o capitalistas avanzadas, características por un Estado de bienestar. El autor sospecha "que la cultura de la pobreza se desarrolla en la etapa inicial de libre empresa del capitalismo y es genérica de esta misma etapa, y que es también endémica en los regímenes coloniales" (p. LIII). Aun cuando no se logre abolir la pobreza misma, las revoluciones logran con frecuencia abolir algunas de las características básicas de la cultura de la pobreza, al efectuar cambios estructurales básicos en la sociedad, al redistribuir la riqueza, al organizar a los(as) pobres y al dotar de un sentido de participación, de poder y de liderazgo.

En su discusión sobre la marginalidad, Colón Reyes (2005) señala que el antropólogo Oscar Lewis utilizó el término de marginalidad para referirse a las características culturales, valores y organización familiar de los(as) pobres. Para 
Perlman (1976), sería una marginalidad cultural, por la cultura tradicional o rural de los(as) marginados(as) y por los rasgos de la cultura de la pobreza de Lewis.

El concepto de la cultura de la pobreza fue popularizada por técnicos(as), investigadores(as) y académicos(as) en Estados Unidos, durante la década del 60 del siglo pasado. Monreal (1996: 31) plantea "que su popularidad se debió a que en parte fue un mecanismo para justificar y legitimar la desigualdad y la miseria en los países del Centro, a la vez que encubría ideológicamente las contradicciones que las sociedades engendran". Añade la autora que las teorías que culpabilizaban a los(as) pobres de su pobreza eran un buen marco para justificar la desigualdad; de esa manera, investigadores(as) académicos(as) daban una cobertura aparentemente científica, neutral y objetiva a la desigualdad: "La teoría de la cultura de la pobreza ha sido aplicada de diferentes formas y en diferentes contextos, pero todas estas aplicaciones comparten el intento de explicar la desigualdad social y la pobreza como un resultado de las deficiencias internas de los grupos que las sufren, es decir, como causadas por su cultura o psicología" (Monreal, 1996: 36).

Más allá de la academia, la cultura de la pobreza influyó en los programas gubernamentales creados a partir de que fuera declarada la Guerra contra la Pobreza por Lyndon B. Johnson, entonces presidente de los Estados Unidos, en 1964, y en las políticas asistenciales de John F. Kennedy, anterior presidente de ese mismo país (Monreal, 1996). Estas políticas asistenciales insistieron en el sistema de educación, en los incentivos para la motivación, en la construcción de viviendas y en los subsidios económicos, y acordaron que la meta fundamental del gobierno de los Estados Unidos en su lucha contra la pobreza debía ser el establecimiento de una familia negra o puertorriqueña nuclear de tipo angloamericano de clase media. El concepto de la cultura de la pobreza fue empleado extensamente por Michael 
Harrington en 1961 en su libro The Other America, el cual desempeñó un importante papel en el comienzo de la campaña nacional contra la pobreza en los Estados Unidos (Lewis, 1983). Por la relación sociopolítica con los Estados Unidos, estas políticas se extendieron en Puerto Rico.

La incidencia en el 2000 de las familias encabezadas por mujeres sin esposo presente en Puerto Rico, según Oficina de la Gobernadora, Junta de Planificación y Oficina de la Procuradora de las Mujeres (2004), era de 268.476, siendo el 26,7\% de los hogares de familia. Este porcentaje aumentó 3,5 puntos porcentuales desde el 1990, cuando la incidencia era de 23,2\% (205.508 hogares con jefas). También aumentó la cantidad de hogares de familia encabezadas por mujeres sin esposo presente que tenían hijos(as) propios(as) menores de 18 años (104.005 en 1990 a 131.584 en 2000). Según el U.S. Census Bureau (2003b), en el 2000 había 159.205 hogares encabezados por mujeres con ingresos por debajo del nivel de pobreza, siendo el $66,7 \%$ del total de los hogares encabezados por mujeres sin esposo presente.

En Puerto Rico, durante las décadas 60 y 70 del siglo pasado, investigadores(as) sociales realizaron estudios sociológicos y económicos, desde la perspectiva de la cultura de la pobreza. Por ejemplo, Walker (1970: 3), en su reflexión sociológica sobre el problema de la pobreza, escribió: “[H]a quedado demostrado por un gran número de científicos sociales que el ser pobre en términos económicos va a menudo acompañado por una pobreza en aspiraciones, una pobreza en actitudes y en fe hacia el futuro. En su gran mayoría los pobres se han resignado ya a ser pobres. Resignación que con frecuencia conduce hacia una enajenación social entre aquellos que se resignan".

Añade el autor que por sí solos(as) los(as) pobres no pueden romper con el círculo vicioso de la pobreza porque carecen de la educación, las destrezas, confianza 
en sí mismos(as) y hasta del espíritu combativo necesario para romper con este círculo vicioso. Siete años más tarde, Walker (1977), en su análisis de la pobreza desde una perspectiva psicosocial, indica que la falta de esperanza y el pesimismo de un alto número de pobres están justificadas hasta cierto punto porque estas personas han recibido poca atención del gobierno. Walker añade que la falta de confianza al personal del gobierno lleva a un retiro total de toda posible participación aún dentro de la misma subcultura donde viven.

En 1973, Pérez de Jesús, en su estudio sobre el desarrollo económico, la sobrepoblación y la desigualdad en Puerto Rico, señala que en vista del estudio de Oscar Lewis y otros más, es razonable afirmar que una parte considerable de la población está atrapada en un círculo vicioso de pobreza extrema, baja escolaridad, bajo nivel de destreza, desempleo en masa, muy bajos ingresos, alta fecundidad y un grado considerable de desorganización social y patología psicológica. Además, un estudio sobre los factores que determinan la pobreza en Puerto Rico, realizado por Cantero, Rodríguez y Alverio (1978), presenta como factor la alta probabilidad de que una familia pobre afecte directamente a sus descendientes, al éstos(as) adquirir las mismas características que tenían sus antepasados(as). Los autores explican este factor, mencionando que generalmente la condición de pobreza no le permite a una familia educar a sus hijos(as) social ni académicamente, de tal forma que éstos(as) puedan desarrollar sus capacidades innatas y logren salir de la condición en que estaban sus padres. Basados en datos censales del 1970, Cantero, Rodríguez y Alverio señalaron que casi el $60 \%$ de las familias en Puerto Rico vivían bajo el nivel de pobreza y que en muchos casos habitaban en un ambiente de privación material, crimen, vicio, codicia y deseo de salir de allí, entre otras características. Añaden que ése es el ambiente al que se refería Oscar Lewis al describir la cultura de la pobreza, 
"ya que (generalizando) los pobres tienden a compartir un mismo sistema de valores que los lleva a mirar la vida de una forma muy parecida" (p. 10).

Aunque encaminado a la comprensión de la falta de participación que tienen los(as) pobres de la zona urbana en las instituciones de la sociedad más amplia, el enfoque de la cultura de la pobreza es discutible, muy criticado e inadecuado (Ramírez, 1977). Gravano (2005: 84-85) destaca dos aspectos de la crítica a la tesis de Lewis: “[P]or un lado, a su determinismo cultural extremo que llega a considerar imposible la transformación de los hábitos negativos de la cultura de la pobreza, y por el otro, al hecho de no haber visualizado que las relaciones de ayuda mutua y reciprocidad que destacó sólo en la unidad doméstica se extendían a nivel de las barriadas".

Desde el punto de vista teórico, la cultura de la pobreza es criticada por ser un conglomerado de características heterogéneas y sin jerarquizar, donde no se analiza cómo cada elemento o factor actúa y porque confunde las características, causas y efectos de la pobreza (Monreal, 1996). También la teoría es criticada por ser etnocentrista, al guiarse por los valores de la clase media blanca norteamericana para identificar todo aquello que es diferente como malo, desorganizado y apático (Monreal, 1996). Según Monreal (1996: 38), “los pobres se perciben como opuestos al comportamiento de las clases medias en un sistema social de dominación y subordinación, donde, en vez de la tendencia a la discusión, las diferencias de clase en el comportamiento se exageran al afirmarse en términos de oposiciones polares. La gente de clase media es pacífica; los pobres no”.

Entonces, el argumento de Lewis ha tenido implicaciones políticas en Puerto Rico, al aplicarse sus hallazgos en la creación de programas para la reducción de la pobreza, en particular, que los(as) pobres tienen cierto estilo de vida que se transmite 
de generación en generación. De los programas de Estados Unidos aplicados en Puerto Rico, están los subsidios económicos para atender las necesidades de alimentación, vivienda y empleo; como el programa de Asistencia Nutricional (P.A.N.), el Programa de Rehabilitación Económica y Social, Programa de Ayuda Temporal para Familias Necesitadas y el Programa de Sección 8 (Departamento de la Familia, 2007b y Departamento de Vivienda, 2008b).

3.2.3 Teoría de la subclase. "Tras más de veinte años de silencio, muchas de las características dadas a los pobres por Lewis, surgirán otra vez con un nuevo nombre: la teoría de la nueva pobreza, la subclase o la 'underclass' (énfasis de la autora)" (Monreal, 1996: 41). Sobre el concepto de subclase, Monreal (1996) y Vilagrasa (2000) presentan dos orígenes distintos. Myrdal (1962) definió under-class (luego se popularizó underclass) como un nuevo grupo social fundamentalmente situado en la periferia o en los márgenes del mercado del trabajo. Añade otras características, incluyendo su baja formación cultural y ocupacional, su frecuente localización en las áreas degradadas de las ciudades, su asociación con los sin techo, el hacinamiento provocado por los proyectos de renovación urbana, su desorganización política y su escasa participación social (Vilagrasa, 2000). Por otro lado, según Monreal (1996: 70), “el debate actual se abrió en 1977 con un artículo en la revista Time, donde este grupo social no se identificaba tanto con la pobreza como con las drogas, el crimen, los embarazos prematuros y extramatrimoniales de adolescentes, el alto desempleo, la delincuencia juvenil, el desmembramiento familiar, la decadencia urbana... Esta subclase, como el concepto de la cultura de la pobreza, no se ligaba totalmente a la pobreza material, pero sí a los varones jóvenes y a las minorías étnicas". 
En su libro The truly disadvantaged: The inner city, the underclass, and public policy (publicado en 1987), William Julius Wilson comenzó a elaborar el concepto, distinguiéndolo de otras significaciones, que podían ser semejantes al de lumpen proletariado marxista. Wilson (1987) afirmó que términos neutrales como "clase baja" o "clase trabajadora" no evocaban las recientes transformaciones en la estructura ocupacional de las ciudades norteamericanas que originaban esta creciente concentración de pobreza.

Basándose en estadísticas vitales y datos censales de los Estados Unidos, Wilson (1987) se propuso describir los crecientes problemas urbanos sociales en el interior de la ciudad, como el crimen, embarazos en adolescentes y dependencia del bienestar social, explicar su aumento y sugerir una agenda pública comprensiva que vaya más allá de los asuntos de raza para confrontar los problemas más fundamentales, asociados a cambios en una sociedad industrial avanzada. Al referirse al concepto de subclase, Wilson (1987: 7-8) señala que los guetos de hoy son habitados casi exclusivamente por los segmentos más desaventajados de la comunidad urbana negra, que forman un grupo heterogéneo de familias e individuos y son la corriente principal (mainstream, en inglés) del sistema ocupacional estadounidense. Incluidos en este grupo, están los individuos que carecen de adiestramiento y destrezas y experimentan desempleo por un largo periodo de tiempo o no son miembros de la fuerza laboral; individuos que están involucrados en el crimen callejero y otras formas de comportamiento aberrante; y familias que experimentan periodos largos de pobreza y/o dependencia del bienestar social.

En su concepción, el término subclase sugiere que han ocurrido cambios en los guetos (ghettos, en inglés) y que los grupos que se han quedado son colectivamente diferentes de aquellos que vivieron en esos vecindarios en años 
anteriores. Los grupos de familias dependientes del bienestar social por mucho tiempo y los criminales de la calle han vivido e interactuado en la misma comunidad deprimida y son parte de la población que, con el éxodo de segmentos de la clase trabajadora y la clase media, se han aislado socialmente de los patrones y normas de comportamiento de la corriente principal (Wilson, 1987: 49): el comportamiento de los(as) profesionales negros(as) de clase media del interior de la ciudad, seguido por el aumento en número de negros(as) de clase trabajadora, han dejado atrás una concentración mucho más alta de los segmentos más desaventajados de la población urbana negra, la población a la cual se refiere cuando habla de la subclase del gueto. Los vecindarios del interior de la ciudad industrial estadounidense han pasado por una profunda transformación social en los últimos años, reflejado no solamente en las tasas crecientes de problemas sociales (incluyendo crimen, desempleo, nacimientos fuera del matrimonio, familias encabezadas por mujer y dependencia al bienestar público), sino también en la cambiante estructura económica de clase de los guetos (Wilson, 1987).

El éxodo del la clase media de muchos guetos, según Wilson, removió un importante amortiguador social que podría desviar el impacto del desempleo prolongado y creciente que plagó los vecindarios del interior de la ciudad en la década del 1970 y principios de la década del 1980, creado por las recesiones académicas y el crecimiento económico desigual. Añade el autor que la presencia de estas familias durante esos periodos provee modelos a seguir que ayuden a mantener viva la percepción de que la educación es crucial, que el empleo estable es una alternativa viable al bienestar público y que la estabilidad familiar es la norma, no la excepción.

Wilson apunta que estas comunidades están plagadas de desempleo masivo, desobediencia abierta y flagrante a las leyes y escuelas de bajo desempeño, por lo que 
tienden a ser evitadas por los(as) que no son de allí. Como consecuencia, los(as) residentes de esas áreas, ya sean mujeres y niños(as) de familias que reciben el bienestar público o criminales agresivos(as) de la calle, se han aislado socialmente de los patrones de comportamiento de la corriente principal de la sociedad (mainstream, en inglés).

Sobre el aislamiento social, Wilson lo define y lo compara con la cultura de la pobreza. El autor define el primer concepto como la falta de contacto o interacción sostenida con individuos e instituciones que representan la corriente principal de la sociedad. Añade que no sólo implica que el contacto entre grupos de distintas clases y/o razas está ausente o se ha vuelto intermitente, pero la naturaleza de este contacto agrava los efectos de vivir en área con alta concentración de pobreza. Por otro lado, Wilson indica que la cultura de la pobreza implica que los valores y actitudes básicas de la subcultura del gueto fueron internalizados $y$, por ello, influyen el comportamiento. Al comparar el aislamiento social y la cultura de la pobreza, Wilson subraya que, aunque ambos conceptos enfatizan la asociación entre la aparición de ciertos rasgos culturales y la estructura de necesidades y oportunidades, la cultura de la pobreza, contrario al aislamiento social, le da un fuerte énfasis al carácter autónomo de los rasgos culturales una vez surjan. El concepto de aislamiento social no significa que los rasgos culturales son irrelevantes en el entendimiento del comportamiento en áreas de pobreza altamente concentradas y resalta el hecho de que la cultura es una respuesta a las necesidades y oportunidades socialmente estructuradas. Por lo tanto, el aislamiento social enlaza un comportamiento específico del gueto con los problemas de la organización de la sociedad. Los conceptos de amortiguador social, aislamiento social y efectos de concentración (concentración desproporcionada de los segmentos más desaventajados de la población negra urbana, como resultado de la 
transformación social del interior de la ciudad) describen los mecanismos sociales e institucionales que agravan los patrones de problemas sociales, originalmente causados por la subyugación racial, pero se han fortalecido en años recientes la transformación de clases en el interior de la ciudad y cambios en la economía urbana.

Wilson concluye que el acercamiento más realista a los problemas de la pobreza concentrada en el interior de la ciudad es proveer a los individuos y familias de la subclase del gueto con recursos que promuevan la movilidad social. El autor señala que, a medida que mejoren los recursos económicos y educativos, estas personas posiblemente seguirán el camino de pasados(as) residentes del gueto y se moverán a vecindarios más seguros o deseados. Los problemas de los(as) verdaderamente desaventajados(as) podrían requerir soluciones no raciales, como empleo a tiempo completo, crecimiento económico balanceado y educación y adiestramiento; por lo tanto, podrían ser tratados con una combinación de política macroeconómica, estrategias de mercado laboral y programas de adiestramientos. Añade Wilson que todavía muchas familias podrían requerir apoyo en los ingresos y/o servicios sociales, como cuido de niños(as).

Otra conclusión a la que llega Wilson es que los problemas sociales del interior de la ciudad (desempleo, crimen, embarazos en adolescentes, nacimientos fuera del matrimonio, familias encabezadas por mujer y dependencia al bienestar público) deberían analizarse no como aberraciones culturales, sino como síntomas de desigualdad de raza y clase. Añade que los cambios en las situaciones sociales y económicas de la subclase del gueto llevarán a cambios en las normas culturales y patrones de comportamiento. Además, en cuanto al creciente aislamiento social y la concentración de pobreza en el interior de la ciudad que han hecho a los guetos 
vulnerables a fluctuaciones en la economía, Wilson señala que indudablemente influyen en las actitudes, valores y aspiraciones.

El concepto de subclase de Wilson tiene implícitas tres perspectivas teóricas diferentes de la pobreza, según Monreal (1996). La primera es la de la Escuela de Chicago en sus aspectos ecológicos, reflejada en la insistencia en las condiciones ambientales como factores de reproducción de esta nueva pobreza urbana, como el aislamiento geográfico y cultural de los valores dominantes de la sociedad norteamericana y la concentración de la población negra en áreas cada vez más deprimidas del centro de la ciudad. La segunda perspectiva recuerda a la teoría sobre la cultura de la pobreza por desarrollar la subclase como una cultura, aunque presentada como una forma de adaptación a constreñimientos estructurales, más que como una forma de vida. La tercera perspectiva presentada por la autora es la concepción materialista porque, para Wilson, "la subclase es producto del cambio en los mercados de trabajo urbanos, de la desindustrialización y la terciarización de la economía en las grandes ciudades" (Monreal, 1996: 73).

Por otro lado, Colón Reyes (2005) menciona el concepto subclase y señala que es el nombre utilizado en las últimas décadas en Estados Unidos para referirse al sector de excluidos y que dicho nombre sustituye los antiguos conceptos de la cultura de la pobreza y marginalidad. Sobre dicha comparación, la autora profundiza su señalamiento e indica que "aún con las grandes diferencias existentes entre estos conceptos, todos realmente se refieren e intentan explicar el mismo sector poblacional, que vive bajo niveles de pobreza permanente, generados por la estructura y que encara los problemas más serios de supervivencia” (p. 127). Al respecto, Castells (1981) y Perlman (1976) señalan que el problema es que se considera que los(as) marginados(as) son un grupo que, a causa de vivir en determinados espacios, 
automáticamente adquieren un estilo de vida que incluye rasgos políticos, sociales, económicos y culturales; es decir, la teoría de la marginalidad, como el gueto en la Escuela de Chicago o la teoría de la subclase en la actualidad, llevan implícita una visión ecológica cultural de la ciudad.

Entre las críticas al concepto de subclase está que "Wilson sigue utilizando y reproduciendo un concepto de cultura homogéneamente compartido, inamovible, acabado y unificador" (Monreal, 1996: 74). Otra crítica relacionada con la anterior es que se caracteriza a los(as) nuevos(as) pobres urbanos(as) "como agentes pasivos, que viven aisladamente y sobreviven mediante el Estado asistencial” (p. 74). La tercera crítica es la concerniente a la metodología utilizada por Wilson, ya que se cuestiona si las fuentes de datos censales son las adecuadas para estudiar los cambios en la estructura social y en los valores y normas del gueto, además de la ausencia de datos etnográficos. Además, se critica a Wilson por negar la importancia del sistema racial de los Estados Unidos, como causa primordial en la reproducción de la nueva pobreza entre los(as) afroamericanos(as), y sustituirlo por la estructura de clases (Monreal, 1996).

Por otro lado, una de las consecuencias del trabajo de Wilson ha sido un regreso a las tesis que recalcan el mercado de trabajo en la comprensión de la pobreza urbana, alejándose de las visiones más periodísticas y políticamente conservadoras, de énfasis en los rasgos psicológicos de los individuos pertenecientes a la subclase (Vilagrasa, 2000). En la actualidad, según Small y Newman (2001), el término underclass y el debate, si era una clase separada, han sido abandonados gradualmente. Por las implicaciones negativas del término, Wilson lo abandonó oficialmente, prefiriendo el término "pobres del gueto". Este cambio representaba una desviación sutil de una designación de clases a una de individuos. 
Las teorías de la pobreza urbana reseñadas anteriormente en esta investigación (teoría de la marginalidad, teoría de la cultura de la pobreza y teoría de la subclase) han aportado a la comprensión de este problema social, aunque una de ella ya no esté vigente en la actualidad (teoría de la cultura de la pobreza). Cada teoría está relacionada con la otra y muchos(as) autores(as) hacen mención de las similitudes entre algunas de ellas. También cada teoría ha sido utilizada para entender el problema de la pobreza en la ciudad y justificar programas de erradicación de la misma. En el caso de Puerto Rico, la teoría más utilizada fue la cultura de la pobreza, posiblemente, porque Lewis se basó en una familia puertorriqueña para comprobar su teoría. Varios estudios en la segunda mitad del siglo pasado se fundamentaron en su enfoque para explicar este fenómeno que todavía existe en este país. Aunque cada teoría es distinta por haber sido creada en diferentes contextos históricos, todas coinciden en describir a las personas que viven en la pobreza, de acuerdo con ciertos rasgos comunes, como la falta de participación activa y efectiva en las instituciones sociales o participación restringida en las mismas, políticamente no están organizados(as) y/o no tienen participación, viven en áreas degradadas y deficientes, el desempleo y subempleo y baja formación cultural, ocupacional y educativa.

Debido a que la comunidad estudiada se formó originalmente por la llegada de migrantes rurales, ha sido clasificada como barrio pobre, inicialmente fue un asentamiento legal y por que posiblemente residen personas desempleadas y/o subempleadas, la teoría de la marginalidad es pertinente. Como las actitudes de las personas podrían estar relacionadas a sus características, como individuos y comunidad, la teoría de la cultura de la pobreza apunta al comportamiento y actitudes de los(as) pobres en el entorno urbano. Por otro lado, por ser una comunidad, donde hay residentes que viven o han vivido en pobreza, personas que dependen o han 
dependido del bienestar público, individuos con niveles bajos de educación y residentes desempleados(as) o que lo han estado, la teoría de la subclase está relacionada con este tema de investigación. Como parte de los objetivos, se pretende revaluar el debate de estas teorías antes presentadas. También se compararán los resultados con las hipótesis derivadas de las teorías de la pobreza urbana.

En resumen, el problema de la pobreza implica la insatisfacción de necesidad y el no acceso a recursos. Entonces, la alimentación adecuada, vestimenta, vivienda, educación y salud se ven afectadas por vivir en la pobreza. De acuerdo a las causas de la pobreza que se planteen, son las soluciones planteadas para aliviarla, que lleva a una variedad de teorías desarrolladas para explicar el surgimiento y/o existencia de la pobreza urbana. 


\section{Revisión de literatura etnográfica}

\subsection{La pobreza en Puerto Rico}

Además de las investigaciones realizadas para entender el problema de la pobreza en general y de los estudios que han planteado conceptos y teorías para explicar la pobreza urbana, están los trabajos realizados en Puerto Rico para conocer más sobre este problema en el país. En el análisis del problema de la pobreza en Puerto Rico, se han identificado los factores, tendencias en el tiempo, percepciones y características socioeconómicas y demográficas de las personas que son vulnerables a ser pobres y de posibles causas para el desarrollo y/o continuación de la pobreza.

Varios trabajos publicados difieren en cuanto a la causa de la pobreza y de la desigualdad, la cual se enfoca en la distribución de ingreso y necesidades básicas dentro de un grupo poblacional. La Junta de Planificación de Puerto Rico (1971: 8) presenta varias razones para explicar la desigualdad, ya que este trabajo considera "la pobreza como un nivel de privación de bienes y servicios (materiales y sociales) que impide a las personas vivir en unas condiciones de vida y unos niveles de bienestar social que la misma sociedad considera adecuadas". Al respecto, la Junta señala: "La privación que caracteriza a la pobreza es una de bienes, servicios y oportunidades que son compartidos por los sectores sociales de la población que goza de unas condiciones confortables, afluentes y opulentas. Esta diferenciación cuando es amplia refleja una situación de desigualdad en la distribución de la riqueza material o ingresos monetarios” (Junta de Planificación de Puerto Rico, 1971: 8).

Por otro lado, las dos razones para explicar la desigualdad que aparecen en el trabajo de la Junta de Planificación (1971) son planteadas por Harvey S. Perloff y Hernan Miller. La razón de Perloff es que "los factores que contribuyen a la desigualdad o concentración de ingreso son las siguientes: la alta concentración de 
propiedad de las fincas más grandes y más productivas, las plantaciones e industrias manufactureras, las altas tasas de ganancias en determinadas industrias, las grandes ganancias de los intermediarios envueltos en la distribución, las altas tasas de interés, la falta de oportunidades educativas adecuadas especialmente para los niños de las familias de bajo ingreso, impuestos altos en bienes de consumo y jornales bajos" (p. 9).

La otra razón, la de Miller, atribuye la desigualdad del ingreso en Puerto Rico a la presencia de un grupo grande de subprivilegiados formado mayormente de obreros agrícolas con jornales bajos, trabajadores urbanos no diestros y una clase media que vive razonablemente bien. La Junta de Planificación (1971: 9) añade una tercera explicación: "El desarrollo económico de Puerto Rico no ha ido acompañado de medidas vigorosas para redistribuir los ingresos generados en el proceso y su orientación al uso del capital intensivo en la manufactura y el abandono y decadencia en el sector agrícola ha reducido el número de empleos disponibles y la oferta de empleos requiere unos altos niveles de destreza y escolaridad que gran parte de la población carece”.

Duggal (1979), en su artículo sobre la pobreza en Puerto Rico, determina que este problema parece estar más relacionado con desempleo y sueldos bajos que otros factores misceláneos. El autor señala que la situación de desempleo empeoró con el progreso de la industrialización con las masivas inversiones extranjeras a partir de la década de 1970 y añade que la industrialización no fue capaz de absorber los migrantes rurales desempleados(as) que vinieron a las ciudades, causando pobreza. Además, las compañías "extranjeras" (procedentes de EE.UU.) generalmente se localizan en Puerto Rico para producir para exportar, sin considerar las necesidades de la economía local, manteniendo sueldos bajos. 
Otro indicador utilizado para estudiar la pobreza es el ingreso per cápita. Al respecto, en su análisis de los aspectos económicos de la pobreza en Puerto Rico, Silva (1993) señala que los altos ingresos per cápita de los centros urbanos más populares en el país engañan en cierto modo por la presencia de áreas de pobreza extrema, los arrabales urbanos. Añade el autor que "allí son normales la vivienda deteriorada e inadecuada, el hacinamiento, el bajo nivel educativo, la escasez de empleos regulares, la alta incidencia de enfermedades y un alto grado de dependencia de bienestar público" (pp. 370-1).

Por otro lado, los trabajos económicos de Sotomayor (1998, 2002) y Sotomayor y Kicinski $(1997,1999)$ argumentan que la pobreza y la desigualdad se deben a la falta de empleo. Sobre el argumento de que la pobreza y la desigualdad se deben a la falta de empleo, Sotomayor (1998) señala que los bajos niveles de salarios actuales en Puerto Rico llevarían a suponer que la población empobrecida trabaja, pero no hace lo suficiente para cruzar la línea de pobreza. Añade que la pobreza parece más el resultado de la ausencia de actividad económica que de bajos salarios. Dada la composición demográfica de la familia puertorriqueña, los hogares donde el jefe o la jefa trabaja son la minoría del total de la población empobrecida. Este trabajo concluye que, mientras la mayoría de la población pobre en países en desarrollo tiene salarios bajos, en Puerto Rico se debe mayormente a que un alto porcentaje de la población no trabaja, mientras que los hogares con jefes(as) que trabajan parecen escapar de la pobreza. Sotomayor y Kicinski (1997, 1999) indicaron que los problemas de pobreza y desigualdad tienen como fuente principal la escasez de empleo, y las mejoras en el mercado de trabajo no lograron impactar favorablemente los niveles de pobreza y desigualdad, ya que éstas no afectaron la posición económica de las familias marginadas. Sobre la escasez de empleo, indicaron que ésta es la 
fuente principal de la pobreza y la desigualdad en Puerto Rico. Añadieron que se estima que la gravedad de ambos problemas disminuyó durante el periodo comprendido entre los años 1969 y 1989, y que el factor que impulsó estos cambios fue el alza en los pagos de transferencia. En otro estudio, Sotomayor (2002) encuentra que el empleo es el primer determinante de pobreza en el país, específicamente la escasez del mismo. Concluye Sotomayor al señalar que la pobreza en el país es producto de la combinación de dos factores relacionados. El primer factor es la alta incidencia del fenómeno entre familias encabezadas por una persona económicamente inactiva o desempleada y el segundo factor es el estado de empleo de las cabezas de familia (desempleado(a) o económicamente inactivo(a)) (Sotomayor, 2002).

Los trabajos económicos tomaron como metodología el análisis de los índices de pobreza y desigualdad, la cual descompone o desglosa la medición de pobreza en contribuciones por grupos de interés, y con los datos de varios censos de población se analizó estadísticamente el ingreso promedio por ciertas variables, como edad y sexo del jefe o jefa del hogar y región (urbana o rural).

También se han realizado investigaciones sobre la pobreza y sus tendencias en el tiempo. En 1964, Miller analizó la pobreza en Puerto Rico con los datos censales de 1960. El autor encontró que, en la categoría de ingreso en el año anterior (1959) correspondiente a $\$ 1.000,00$ a $\$ 1.500,00$, una alta proporción, en comparación con las categorías más bajas de ingreso, proviene del desempleo, subempleo y falta de educación y adiestramiento por jefes(as) de familias urbanas.

Otro estudio realizado en Puerto Rico por Cantero, Rodríguez y Alverio (1979), con los datos censales del 1970, encontró que la escolaridad, índice de ruralidad e índice de desempleo están relacionados con el índice de pobreza. Los autores partieron del supuesto que el desempleo influye en el que las personas reciban 
ingresos que no le permitan satisfacer todas sus necesidades básicas. Añaden que "al estar las personas desempleadas no tendrán una fuente de ingresos fijos y tendrán que estar dependiendo, casi exclusivamente, de ayudas gubernamentales para poder satisfacer algunas de sus necesidades básicas” (p. 7).

En 1979, se publicó una investigación sobre la pobreza en Puerto Rico, donde se presentaron por primera vez tablas sobre la condición de pobreza en 1970. Rivera (1979) señala que la pobreza es un ejemplo claro de las desigualdades, las cuales se materializan por la estratificación. En 1989, se publicó otra investigación sobre los factores asociados a la pobreza en Puerto Rico para 1970 y 1980, según los censos de población. Paravisini (1989) describe la pobreza como un problema que atenta contra la salud física, mental y social de los individuos y contra la estabilidad del país. Finalmente, Vélez (1995b) realizó otra investigación sobre la población bajo el nivel de pobreza y sus características demográficas y socioeconómicas, con los datos del Censo de Población y Vivienda del 1990. La autora señala que el porcentaje de personas bajo el nivel de pobreza en Puerto Rico (58\%) es aproximadamente 5 veces más alto que el de los Estados Unidos (13\%) para 1990.

Estas últimas tres investigaciones se realizaron con la misma fuente de datos, pero de diferentes años censales sobre la pobreza en Puerto Rico. Sin embargo, unas eran más de tipo descriptivo y otras eran más de tipo explicativo, con análisis de correlación. Estos trabajos enriquecen la literatura proveyendo un análisis de la condición de pobreza cada 10 años, para cuando se realiza el censo decenal de población y vivienda.

García (2002) realizó un estudio exploratorio-descriptivo desde el Trabajo Social para conocer las percepciones de pobreza de los(as) residentes de dos comunidades de San Juan, una pobre y otra de clase media. El investigador halló que 
el $84,8 \%$ de los(as) participantes percibe la pobreza como falta de recursos económicos. Se les preguntó cómo reconocer una comunidad pobre y el 71,2\% señaló que por el deterioro de sus casas. Otras respuestas fueron la falta de servicios de infraestructura (66,7\%), higiene y limpieza (51,5\%). También el autor se interesó en conocer si percibían que vivir en caseríos, residenciales públicos, barriadas y barrios era un indicador de pobreza y halló que el 36,4\% de los(as) participantes indicó que no era un indicador y el 30,3\% señaló que sólo a veces. También se les preguntó cómo eran percibidas las personas pobres y las respuestas principales fueron el área de residencia $(57,6 \%)$, forma de vestir $(53,0 \%)$, actitudes $(47,0 \%)$ y el modo de hablar $(31,8 \%)$.

García (2002: 180) señaló que "la constatación de la relevancia del área de residencia ubica una percepción de pobreza mayormente visual, o sea, la pobreza no se puede esconder, se ve". Concluyó el autor que "el impacto de la pobreza fue percibido como devastador al considerarlos como excluidos social, económica y mayormente en el campo de lo político" (p. 186). Al respecto, Ramírez (1970) recomienda que se fomente una genuina participación de los(as) pobres en el proceso de intentar erradicar la pobreza, basada en el convencimiento de que sus puntos de vista son indispensables en todo proceso de cambio. De la misma manera, en su estudio sobre la pobreza en Puerto Rico, Walker (1970: 7) señala que "la única alternativa para auténticamente resolver el problema de la pobreza es dándole participación en tantas actividades sociales como sea posible" a los(as) pobres. Añade que hay que dejarles sentir que son útiles y que tienen una contribución que hacer a la sociedad puertorriqueña. Recomienda Walker que se les provea una oportunidad igual para educarse y luego dejarles competir de igual a igual. 
En conclusión, los trabajos sobre la pobreza en Puerto Rico han contribuido significativamente en la identificación y análisis de este problema y de las características demográficas y socioeconómicas de las personas, cuyos ingresos están por debajo del nivel de pobreza y de las personas que son propensas a ser pobres. Estos estudios han aportado grandemente en la acumulación de información sobre las tendencias de la pobreza en el tiempo y sobre las posibles causas que perpetúan este problema en la sociedad.

Sin embargo, los estudios sobre la pobreza en Puerto Rico tienen varias limitaciones, como la fuente de datos utilizada por los trabajos realizados desde la demografía y la economía, la cual es el censo poblacional y de vivienda. Debido a que el censo se realiza cada 10 años, desde el 2005, se lleva a cabo la Encuesta de la Comunidad, para tener datos actualizados sobre las características de la población y vivienda de los(as) residentes en este país. Entonces, son muy pocos los estudios sobre este problema que han tomado los datos de esta encuesta anual. Por otro lado, aunque tomaran esta encuesta para realizar la investigación sobre la pobreza, la limitación que surge es la medición de la variable pobreza, la cual es calculada en y para los Estados Unidos y no es modificada para ajustarse a la situación socioeconómica particular de Puerto Rico ni para cualquiera de los 50 estados, al momento de hacer la encuesta. También otra limitación que tienen estos estudios es que no están actualizados y hace falta tener información reciente sobre las características de los(as) pobres y las causas de la pobreza; por ejemplo, un estudio de la década del 1970 menciona a la presencia de los obreros agrícolas y trabajadores no diestros como la razón para explicar la desigualdad en ingreso, cuando posiblemente la presencia de estos dos grupos es mucho menor en la actualidad, por el cambio de la economía a una de servicios. Además, ya que varios estudios mencionaron a la 
participación del(a) pobre como mecanismo para reducir la pobreza, la limitación es la falta de elaboración sobre dicha alternativa, como cuáles son los efectos, cómo medir la participación y qué es la participación. Por ejemplo, sería interesante explorar si sólo los(as) líderes comunitarios(as) participan activamente, por qué los(as) demás residentes no se movilizan y cuáles son los impedimentos que tienen que superar los(as) pobres para poder participar en la formulación y enmiendas a leyes que les afecta directamente, por ejemplo.

\subsection{El realojo de viviendas en Puerto Rico}

Debido a que el tema de investigación son las actitudes de los(as) residentes hacia el realojo de sus viviendas en una comunidad pobre y urbana de San Juan de Puerto Rico, también he revisado la literatura existente sobre el realojo de viviendas en el país. El realojo de viviendas ha sido estudiado en el país desde la década del 50 del siglo XX. Los principales estudios sobre este tema son Familias del arrabal por Helen I. Safa (1980); El arrabal y la política por Rafael I. Ramírez (1976) y Slums, projects, and people por Kurt W. Back (1962). Estas investigaciones tratan sobre la eliminación de arrabales y el desalojo de sus residentes, quienes en su mayoría fueron reubicados en caseríos, los cuales son proyectos de vivienda pública, durante las décadas del 50 y 60 del siglo pasado en el área de San Juan, Puerto Rico. Los trabajos de Safa (1980) y Ramírez (1976) son estudios etnográficos, donde utilizaron las técnicas de observación partícipe y entrevistas con informantes, entre otras. Además, ambos estudios contrastan sus hallazgos con los planteados de Oscar Lewis sobre la cultura de la pobreza $(1961,1972,1982$ y 2002). Aunque los trabajos de Ramírez y Safa fueron sus respectivas tesis doctorales en Antropología, la investigación de Safa fue basada en un estudio auspiciado por la Administración de Renovación Urbana y Vivienda. Por otro lado, el estudio de Back (1962) fue solicitado por el Departamento 
de Vivienda de Puerto Rico y auspiciado por el Centro de Investigaciones Sociales de la Universidad de Puerto Rico. Este trabajo fue un estudio transversal, basado en una encuesta de seis grupos distintos, a saber, residentes en arrabales, cuya eliminación no ha sido planificada; residentes en arrabales, cuya eliminación ha comenzado, pero no ha progresado más allá de la encuesta inicial; residentes en arrabales, cuya eliminación comenzó y parte ya ha sido arrasada; residentes de proyectos de vivienda pública; residentes de arrabales que fueron eliminados para construir proyectos de vivienda y prefirieron vivir en otro arrabal; y pasados(as) residentes de proyectos de vivienda. Estos tres estudios se llevaron a cabo justo en el momento cuando el gobierno estatal ejecutaba el proyecto de renovación urbana que incluía la eliminación de arrabales. Como menciona Ramírez (1976: 55), "la respuesta del gobierno a los problemas de vecindad fue el recomendar la relocalización de las familias en viviendas públicas y de bajo costo”.

La Ley Núm. 88 del 22 de junio de 1957 creó las agencias Corporación de Renovación Urbana y Vivienda y la Administración de Renovación Urbana y Vivienda, con el propósito de responder mejor a los objetivos y metas del gobierno estatal para solucionar el problema de la vivienda (Cotto Morales, 2006). Su política pública incluía el impulso de programas de eliminación de arrabales y rehabilitación urbana; el fomento de la construcción de viviendas a bajo costo por la empresa privada; la promoción de la creación de cooperativas para la construcción de proyectos de viviendas colectiva e individuales y el desarrollo de diferentes tipos de vivienda y solares para venta o alquiler bajo un plan liberal de pagos. Estas agencias fueron disueltas por medio de la derogación de la ley en 1991.

Aunque los estudios tratan sobre el realojo de viviendas a caseríos, cada investigación tiene un interés distinto, por lo que obtienen resultados 
complementarios. Mientras que Ramírez (1976: 6) estaba interesado en "comprender la posición de los habitantes de arrabales y caseríos de Puerto Rico, a través de su participación en el proceso político y la integración, o marginalidad en el sistema social más amplio", Safa (1980: 17) estaba interesada en cómo los patrones económicos, familiares y de comunidad "promueven u obstaculizan el desarrollo de la conciencia de clase y la solidaridad de clase entre los pobres de zona urbana". Por otro lado, Back (1962) señala que el propósito de su encuesta fue entender el proceso de realojo para saber la reacción individual al cambio social. Entonces, sólo el estudio de Back se enfoca en el proceso psicosocial de realojo, mientras que Ramírez (1976) y Safa (1980) relacionan el realojo de viviendas con la participación política y conciencia social, respectivamente.

Tanto Ramírez (1976) como Safa (1980) cuestionan las premisas teóricas de la cultura de la pobreza según Oscar Lewis. Lewis (1982) estableció que la cultura de la pobreza se caracterizaba por la falta de participación e integración efectivas en las principales instituciones, tales como sindicatos y partidos políticos; desconfianza en el gobierno; fuerte sentimiento de marginalidad, impotencia, dependencia e inferioridad, resignación y fatalismo, y orientación temporal dirigida primordialmente hacia el presente. En relación a la teoría de la cultura de la pobreza, Ramírez (1976: 2) señala: "El modo de la cultura de la pobreza, con su énfasis en ideas y valores transmitidos de una generación a otra, es inadecuado para entender la integración o marginalidad de los pobres de zona urbana en la sociedad más amplia”.

Ramírez (1976: 10-11) añade: "Los datos sobre la participación política muestran que contrariamente a lo que expresa Lewis, los individuos en la muestra no están enajenados de las cuestiones políticas. Aun cuando los asuntos políticos no constituían la preocupación principal de la gente en Cataño, excepto por la minoría, 
esta situación no puede interpretarse como falta de información o de interés en los asuntos políticos”.

De la misma manera, Safa (1980) encontró poca evidencia de la desesperanza y apatía que según Lewis caracteriza a la cultura de la pobreza. Los(as) residentes de la comunidad estudiada por Safa eran "extraordinariamente positivistas y creen con firmeza en el valor del trabajo, en el ahorro y en la iniciativa individual. Aun las familias más pobres aspiran a un futuro mejor para ellos y sus hijos” (p. 55). Además, su investigación desmiente: "La opinión de muchos científicos sociales y del público en general de que los pobres son gente homogénea, atropellada, desorganizada y apática. Por el contrario, este estudio recalca el ingenio y el optimismo de las familias del arrabal y su capacidad para responder a condiciones socioeconómicas cambiantes" (p. 18-19).

Aunque Ramírez (1976) entrevistó a los(as) residentes de caseríos y arrabales, los estudios de Safa (1980) y Back (1962) cubren los aspectos de vivir en el arrabal, previo al realojo, y las nuevas condiciones de vida en los caseríos, luego del realojo. En el 1969 (10 años después de haber investigado originalmente el arrabal - ya desaparecido), Safa regresó para ver qué había sucedido con las familias del arrabal que había conocido y que en ese año vivían en proyectos de vivienda pública (caseríos), urbanizaciones privadas y cooperativas de vivienda. Safa (1980: 21) encontró que "la relocalización en la vivienda pública aumenta, pues, la dependencia de los pobres respecto del gobierno y disminuye sus posibilidades de movilidad ascendente". La autora concluye que "la relocalización de los residentes del arrabal mediante la renovación urbana también ha obstaculizado la formación de un sentido de conciencia de clase" (p. 111). 
Cotto Morales (2006) señala que el gobierno de Puerto Rico desarrolló un programa de vivienda pública urbana, aprovechando los programas federales que aplicaban a Puerto Rico por ser un territorio no incorporado de los Estados Unidos. Añade la autora que "los residentes de algunas de las barriadas populares se resistieron a abandonar sus viviendas y mudarse a los caseríos porque les quitaba el derecho a poseer una vivienda convirtiéndolos en inquilinos del gobierno" (p. 28). Sin embargo, esta política pública de renovación urbana, que incluía a los residenciales públicos o caseríos, las urbanizaciones de bajo costo y otras formas de vivienda pública, llegó a su límite a fines de la década del 60 del siglo pasado. En la actualidad, Puerto Rico tiene 55,414 unidades de vivienda pública en 322 residenciales subsidiados por el gobierno federal. Particularmente, San Juan tiene 18,503 unidades de vivienda en 56 residenciales públicos (Administración de Vivienda Pública, 2008).

Como señala Back (1962), la eliminación y realojo de los arrabales son vistos por los(as) afectados(as) como pérdida de hogar y exposición a los peligros de una nueva manera de vivir. Back preguntó sobre las preferencias para vivir y la mayoría contestó que una casa ideal sería de concreto, unifamiliar, de al menos tres dormitorios, cocina aparte y calle pavimentada que lleve a la casa. En cuanto a las actitudes hacia moverse a vivienda pública, dos terceras partes de los(as) residentes de los arrabales querían mudarse y dos terceras partes de los(as) residentes de vivienda pública querían permanecer viviendo ahí. Las objeciones más presentadas por los(as) participantes del estudio para vivir en proyectos de vivienda pública fueron pagar alquiler y vivir en apartamentos.

En conclusión, los trabajos realizados sobre el realojo de viviendas en Puerto Rico han aportado al conocimiento de este tema desde la década del 50 del siglo XX. Es pertinente mencionar que relacionar el realojo de viviendas con la pobreza y la 
formación de comunidades marginadas ha sido muy importante para poder entender el proceso por el que pasan las familias pobres en el cambio de residencia y sus consecuencias en los ámbitos sociales, económicos y psicológicos. Aunque estos estudios fueron realizados hace varias décadas, éstos permiten entender el proceso por el que han pasado miles de personas pobres en Puerto Rico. Y, aunque ya no se construyen proyectos de vivienda pública en este país, el gobierno estatal sigue implantando proyectos de renovación urbana que han implicado el desalojo de miles de personas de sus hogares.

No obstante, los estudios sobre el realojo de viviendas en Puerto Rico tienen la limitación de que fueron hechos entre las décadas de 1960 y 1980, cuando se realojaban en caseríos, los cuales ya no se construyen en Puerto Rico, por lo que hay falta de trabajos más recientes que investiguen dicho tema. Entonces, debido a que dichos estudios fueron publicados hace varias décadas, éstos no incluyeron la teoría de pobreza urbana más reciente, la cual es la teoría de la subclase de William J. Wilson de 1987, para explicar sus resultados o debatir la teoría.

\subsection{Gentrificación}

Otro fenómeno asociado al realojo de viviendas es el desplazamiento de sus residentes originales o más antiguos(as) por otros(as) habitantes, usualmente de ingresos superiores. Monreal (1996: 65) la define como "la penetración del capital comercial y de servicios o profesionales de clases medias en espacios urbanos antes ocupados residencialmente por comunidades de sectores populares". De la misma manera, Sargatal (2000) señala que el fenómeno de gentrificación es una "serie de mejoras físicas o materiales y cambios inmateriales - económicos, sociales y culturales- que tienen lugar en algunos centros urbanos viejos, los cuales experimentan una apreciable elevación de su estatus" (para 1). Además, "se 
caracteriza normalmente por la ocupación de los centros de las ciudades por una parte de la clase media, de elevados ingresos, que desplazan a los habitantes de clase baja, de menores ingresos, que vivían en el centro urbano. El desplazamiento va acompañado de inversiones y mejoras tanto en las viviendas, que son renovadas o rehabilitadas, como en toda el área afectada: comercios, equipamientos y servicios" (para 2-3). La gentrificación (gentrification, en inglés) también es llamada elitización, gentilización, aburguesamiento, aristocratización, elitización residencial y recualificación social (García Herrera, 2001).

La gentrificación ha sido estudiada desde la década 60 del siglo pasado, desde las disciplinas de sociología, geografía, antropología y planificación, entre otras. Estos estudios coinciden que el término gentrificación fue acuñado por Ruth Glass en 1964, donde Glass compara este proceso con un viejo hábito propio de la gentry, la clase media-alta inglesa de las áreas rurales, que solía mantener una vivienda en la ciudad además de su residencia en el campo, hecho parecido al que se observaba en Londres en la década del 60 del siglo XX (Van Weesep, 1994). Además de Londres, en ciudades como Madrid, Barcelona, Santa Cruz de Tenerife, Toronto, Washington, D.C., Columbus, Ohio, Nueva York, Tampa, Filadelfia, San Francisco, Chicago y San Juan se ha estudiado la gentrificación.

De igual manera, Sieber (1987) realizó un estudio sobre un vecindario de la ciudad de Nueva York en la década del 70 del siglo pasado. El autor señala que los gentrificadores eran profesionales de clase media, cuyas acciones transformaron el vecindario de acuerdo a la imagen de su clase. Añade que centrándose en los temas de renovación, limpieza y purificación, su ideología impactó en muchas áreas de la vida comunitaria. Como consecuencia del mejoramiento al vecindario, aumentó el valor de 
las propiedades y se aceleró el desalojo de los(as) antiguos(as) residentes del vecindario (Sieber, 1987).

En cuanto a las relaciones entre los(as) antiguos(as) residentes y los(as) recién llegados(as), Sieber (1987) indica que hubo resistencia y cólera y los(as) recién llegados(as) eran vistos(as) como arrogantes en sus intentos por imponer su voluntad en el vecindario. El valor de las propiedades se duplicaba cada ciertos años y se convirtió en el incentivo para los(as) antiguos(as) residentes de vender y mudarse a los suburbios. El autor señala que el desalojo nunca fue un asunto político principal por el aspecto voluntario de muchas partidas de los(as) antiguos(as) residentes, restringiendo las posibilidades de una resistencia colectiva en contra de la gentrificación.

Por otro lado, en Toronto, Caulfield (1992) realizó un estudio sobre la gentrificación y la familia, donde la primera parece ser una forma de vivienda apropiada para la crianza de niños(as) por personas de clase media de la zona urbana. El autor concluye que la proximidad a empleos en el centro urbano o servicios de ocio no fue tomada en cuenta como una decisión para vivir en el centro de la ciudad, sino como una ventaja resultante de vivir en el casco urbano.

Este proceso es de gran importancia en esta investigación por su relación con la renovación urbana. Al respecto, García Herrera (2001) señala: "Durante las tres últimas décadas del siglo XX las ciudades del mundo desarrollado han experimentado un creciente proceso de transformación de determinados sectores de sus áreas centrales provocando su revitalización funcional y el cambio en la composición social de sus habitantes. Esta transformación ha afectado, en gran medida, a los barrios populares de antigua formación y con un importante deterioro de sus edificaciones, 
mediante intervenciones dirigidas tanto a la rehabilitación como a la construcción de nuevos edificios" (para 1).

Sargatal (2001) realizó un estudio de caso sobre la gentrificación e inmigración en el barrio El Raval en Barcelona. Según Sargatal, "los cascos antiguos de muchas ciudades experimentan actualmente procesos conflictivos por un lado, se establecen en ellos inmigrantes procedentes en su mayoría de los llamados países poco desarrollados o en vías de desarrollo; por otro lado, determinados sectores de las clases altas trasladan allí su residencia, atraídos por su centralidad; este proceso es conocido como gentrificación" (para 1).

En el caso específico de El Raval, la autora indica que a mediados de la década del 50 del siglo XX llegaron al centro urbano inmigrantes del campo por la crisis provocada por la falta de medios económicos. En la ciudad, ya no existía oferta nueva de vivienda y se acomodaron en alojamiento barato, pero en malas condiciones. Esta situación llevó a la formación de barrios marginales de autoconstrucción en la periferia urbana, la degradación del barrio y frecuentemente el tráfico de drogas. Se aprovecharon de los preparativos de las Olimpiadas en Barcelona en 1992, para planificar la renovación urbana del barrio. Concluye la autora: "Las distintas situaciones en el mismo barrio posibilitarán la coexistencia — ¿o se tratará de una simple coexistencia? - entre los gentrificadores, la población residente tradicional y los inmigrantes extranjeros. Los poderes públicos han de procurar evitar la formación de pequeños guetos dentro del mismo barrio. Creemos que la riqueza cultural del Raval radica en la variedad de situaciones en tan poco espacio" (para 42).

En un estudio sobre gentrificación y los cambios producidos en el mercado de vivienda en varios barrios de Santa Cruz de Tenerife, García Herrera (2003) encontró que el resultado de un proyecto de remodelación urbana en la zona fue una "probable 
disminución del suelo, un prolongado proceso de deterioro y abandono de los edificios, el forzado desalojo de los residentes tradicionales" (para 35). Añade la autora que este proyecto "implicaba la expropiación del parque inmobiliario con objeto de sustituir, con el frente marítimo, el uso residencial por el terciario (comercial y administrativo), posteriormente las nuevas viviendas a construir se ubicarían en la zona alta" (para 15). Sin embargo, la incompleta ejecución del plan de remodelación creó un largo periodo de más de tres décadas, de escasa actividad inmobiliaria, en el que el deterioro y el abandono se apoderaron de los inmuebles de la zona, que se convirtió en un espacio de marginalidad.

Sobre la relación entre gentrificación y grupos minoritarios, Boyd (2005) realizó un estudio en Chicago para examinar cómo los(as) defensores(as) negros(as) de la gentrificación entienden el proceso y sus implicaciones para sus vecindarios. Boyd encontró que la gentrificación tiene distintos significados para los(as) afroamericanos(as). Para algunos(as) residentes, la gentrificación hará al vecindario más atractivo a inversionistas residenciales y comerciales, por lo que aumentará la calidad de vida. También al atraer a negros(as) de clase media, se espera evitar el desplazamiento racial por blancos(as) y mantener el área como un vecindario africanoamericano. Para otros(as) residentes, la gentrificación negra, como cualquier otra, amenaza con desplazar a los(as) residentes de más tiempo. Entonces, Boyd argumenta que los(as) proponentes de la gentrificación negra ven a los(as) inversionistas de clase media como una estrategia para elevar la raza ("uplifting the race, en inglés", p. 269). El autor abunda que, al promover la presencia de clase media negra, los(as) defensores(as) de la gentrificación esperan prevenir un futuro desplazamiento comunitario por los(as) blancos(as). 
Otro estudio sobre la relación entre la gentrificación y grupos minoritarios fue el de Cahill (2007), quien trató las experiencias de gentrificación desde la perspectiva de las jóvenes mujeres de color ("women of color", en inglés) de clase trabajadora. Esta investigación encontró que sólo la presencia de personas blancas en el vecindario es amenazante. Las ansiedades sobre cambios en el vecindario son proyectadas en los cuerpos blancos (“white bodies", en inglés) que representan no sólo la vanguardia de la gentrificación, sino la exclusión potencial de las mujeres (p. 209). Sobre el desalojo, el autor indica que éste ha sido experimentado de diversas maneras, como ofreciendo vivienda pública, parientes realojados(as) temporalmente que nunca regresan a sus casas, experiencias personales de ser hostigados(as) por el(la) propietario(a), duplicando las familias en pequeños apartamentos y viendo amistades desplazados(as). Para entender el proceso desde la perspectiva de los(as) residentes, se puede pensar en el apego a un lugar y la pérdida de redes ricas en capital social. Sobre el apego al lugar, Cahill indica que éste describe un sentido de seguridad y el significado de un lugar para las conexiones sociales, especialmente cuando se está inmerso(a) por mucho tiempo y donde uno(a) puede aprender nuevos roles sociales, como cuando se crece. Sobre el desalojo, añade Cahill que éste es experimentado como un proceso donde se borran los signos de herencia personal y cultural. Esta sensación de borrar la historia personal es acompañada por sentimientos de ansiedad y cólera.

Según Sargatal (2000), "el desplazamiento puede tener lugar bajo distintas formas: a través de la rehabilitación de las viviendas ocupadas por grupos populares, reclasificados como residencias de alto nivel; el abandono involuntario del barrio por parte de habitantes con ingresos limitados (familias numerosas, ancianos, etc.), que no pueden pagar los crecientes impuestos sobre la propiedad, fruto de la política 
gubernamental local; la imposibilidad por parte de jóvenes emancipados, originarios del barrio, de pagar una vivienda en este; la emigración de residentes por la desaparición de instituciones sociales, económicas, religiosas e incluso por la pérdida de amistades en el barrio" (para 15). Como consecuencias de la gentrificación sobre las comunidades desplazadas, Monreal (1996) señala que la erosión de la base económica local, al eliminar los(as) pequeños(as) comerciantes, desestructura y fragmenta comunidades populares histórica y culturalmente moldeadas, destruye el asociacionismo comunitario y rompe las redes de ayuda mutua y solidaridad entre vecinos(as), entre otras.

Los estudios sobre la gentrificación, en particular los estudios de caso, han aportado significativamente en el entendimiento de este fenómeno en distintas ciudades de diversos países. Estas investigaciones se complementan porque cada una trata un aspecto singular de la gentrificación, como la reacción de los(as) antiguos(as) residentes a este proceso, los intereses y características de los(as) gentrificadores(as) y cambios físicos y sociales de las comunidades. Entonces, estos estudios realizados desde las ciencias sociales con distintas metodologías han coincidido en la definición del fenómeno de gentrificación y han investigado interesantes ángulos del mismo.

Sin embargo, los trabajos sobre la gentrificación tienen varias limitaciones, ya que quedan asuntos por estudiar, como la compra-venta de viviendas y negocios a personas que no son de la comunidad, por lo que son ajenas a su historia y quienes podrían tener intereses distintos a los de la comunidad, siendo posiblemente más del tipo individual (particular). Otros asuntos pendientes por investigar son si los(as) residentes entienden el problema de gentrificación, si creen que su comunidad está en amenaza de desaparecer, si tienen conocimiento de algún interés por parte el gobierno y/o empresa privada por los terrenos que habitan y si se han movilizado para prevenir 
o detener el proceso de gentrificación y mantener la comunidad en su sitio. Además, falta conocer si hay diferencias en las características de los(as) residentes sobre su opinión de la gentrificación; por ejemplo, si las personas de más edad tenderían a estar en contra del desplazamiento urbano porque son personas que posiblemente llevan más años residiendo y han visto desarrollar a su comunidad. También se puede explorar la eficacia de algunos mecanismos para evitar el desplazamiento, como un fideicomiso de la tierra, y cuáles son los obstáculos a los cuales se enfrentan dichos mecanismos.

\subsection{Diferencias entre arrabal, slum, shantytown, barrio y gueto}

4.4.1 El arrabal. También en la literatura de pobreza en general y pobreza urbana, se destacan varios conceptos para hacer referencia a las comunidades pobres y sus particularidades geográficas y económicas. Safa (1980) describe la comunidad estudiada en 1959 como arrabal. Safa define arrabal como el modo principal de residencia de los(as) puertorriqueños(as) pobres de la zona urbana y está localizado a lo largo de terrenos públicos marginales. Añade que "las casuchas del arrabal son, desde el principio, infraestructuras inadecuadas; la mayor parte se ha construido de forma bastante endeble, con los materiales que tienen a la mano, y por trabajadores diestros, generalmente el dueño y sus amigos. [...] Los arrabales se encuentran con frecuencia en las ciudades pre-industriales de áreas en vías de desarrollo, donde todavía existe terreno público marginal en la periferia urbana" (p. 16). La autora indica que "debido a su localización en terreno marginal, el arrabal está apartado tanto física como socialmente del resto del área metropolitana” (p. 25). También Safa describe así la comunidad para finales de la década del 60 del siglo pasado, cuando regresó para ver qué había pasado con las familias que había conocido personalmente: "Los residentes del arrabal están privados de muchos servicios esenciales, tales como 
el recogido de basura, un sistema de alcantarillado, alumbrado en las calles y calles pavimentadas. Tampoco existen en el barrio servicios médicos, escuelas o iglesias. Pequeñas tiendas locales venden una variedad limitada de productos enlatados y otros artículos no perecederos, en tanto que los cafetines constituyen un lugar de reunión favorito de los hombres" (p. 26).

Añade Safa (1980: 27) que la comunidad estudiada no era autosuficiente, como resultado de la "segregación de clase, muy dependiente de los recursos y servicios que presta la comunidad metropolitana mayor". Safa compara los arrabales en Puerto Rico con los asentamientos urbanos no regulados de América Latina, señalando que los primeros dependen de la comunidad urbana más amplia en mayor medida que los segundos porque éstos “por lo general cuentan con una variedad más amplia de negocios pequeños y otras facilidades que sirven a la comunidad de invasores" (p. 27).

Stevens (1985) señala que la formación de los asentamientos no regulados en tierras baldías dentro y en los alrededores de las grandes ciudades es uno de los fenómenos más espectaculares en países de crecimiento rápido en América Latina. "Se les llama de maneras diversas: arrabales en Puerto Rico y la República Dominicana, barriadas o pueblos jóvenes en Perú, callampas en Chile, colonias proletarias en Argentina" (Stevens, 1985: 155), favelas en Brasil, villas miserias en otros países, colonias proletarias o vecindades en México.

Stevens (1985) presenta una primera definición de arrabal, a base de la Ley Núm. 264 del 1945 del Estado Libre Asociado de Puerto Rico: "Los arrabales son aquellas secciones urbanas o suburbanas integradas por viviendas $\mathrm{u}$ otras edificaciones antihigiénicas e inseguras. Zonas que por la insalubridad de los terrenos, por aglomeración de las edificaciones, o por el número excesivo de las mismas en 
relación con la capacidad del área en que están ubicadas o por concurrencia de cualquiera de los factores antes enumerados, son peligrosas, perjudiciales o contrarias a la seguridad, a la salud, bienestar y moralidad de la comunidad en general”.

Por su parte, Ramírez (1977) realizó su investigación sobre la participación política de los(as) pobres en Cataño, Puerto Rico. Ramírez define y describe los términos arrabal, asentamientos no regulados y barrios pobres. Ramírez señala que es arrabal es el nombre oficial en Puerto Rico para los asentamientos no regulados y es donde vive gran parte de los(as) pobres de zona urbana. El desarrollo de los arrabales ha seguido el patrón de otras ciudades latinoamericanas, ubicándose en manglares, colinas y cerca de los ríos. Además de la ubicación de arrabales en tierra pública, ocasionalmente se invade la tierra privada. Otra característica de los arrabales puertorriqueños es que tienden a ser lugares de residencia permanentes para muchos(as) de los(as) habitantes, por lo que tratan de mejorar sus casas para fijar su residencia. "Su interés por permanecer en los arrabales está en pugna con el programa de renovación urbana, que intenta despejar el área de las estructuras y mudar los residentes a viviendas públicas, o de bajo costo en otras vecindades" (Ramírez, 1977: 13-14).

Ramírez señala que los caseríos presentan condiciones semejantes a la del arrabal, como pobreza, desempleo, subempleo y niveles bajos de educación, a pesar que los caseríos ofrecen facilidades de vivienda superiores. El autor propone que "la solución para los problemas de la privación social y económica no es mudar a la gente de los arrabales a los caseríos. Debido a ésto, algunos de los caseríos están adquiriendo las características asociadas a los 'ghettos' de las grandes ciudades industriales de Estados Unidos" (p. 14). 
La Ley 264 define arrabales en términos de sus características físicas, más que por la legalidad de su ocupación. Por lo tanto, esta definición incluye arrabales que fueron asentamientos no regulados en terrenos públicos.

Luego, Stevens compara los arrabales al final de su periodo de estudio (19901970), con los asentamientos no regulados latinoamericanos y señala que los primeros son vecindarios permanentes. "Ya no son los vecindarios dinámicos, de casuchas en expansión de las primeras décadas; son, más bien, vecindarios de clase baja, decentes y urbanizadas" (Stevens, 1985: 156).

Sobre los tipos de vivienda y los vecindarios de trabajadores de las primeras décadas del siglo XX, Stevens (1985) indica: "En cada vecindario dominaba uno de tres tipos de vivienda: casas de vecindad o apartamentos alquilados; parcelas pequeñas arrendadas legalmente en las cuales la persona construía su propia casa (o apartamentos de alquiler); y parcelas en terrenos públicos ocupados ilegalmente y en los cuales construían sus propias casas. Los vecindarios en donde predominaban los dos últimos tipos de vivienda se conocieron como 'arrabales'” (p. 157).

En su estudio sobre los rescates de terreno en Puerto Rico, Cotto Morales (2006) señala que antes del 1968, la forma de ocupación de tierras más común en el país era la ilegal gradual, en la que familias individuales iban haciendo comunidad en el transcurso de los años. Añade la autora que este tipo de ocupación dio origen a los arrabales que caracterizaron las ciudades en Puerto Rico para las décadas del 30 y 40 del siglo XX. Entonces, una vez la gente ocupa el terreno, lo divide en solares y fabrica sus casas de acuerdo a los recursos de cada familia (madera, cartón y latas), se forma la barriada (Ramírez, 1977).

4.4.2 El slum y el shantytown. Stevens (1985) añade a la discusión de arrabal, los términos en inglés slum y shantytown (o shanty town), mencionados en la 
literatura sobre pobreza urbana y su aplicación por agencias del gobierno en Puerto Rico. Stevens traduce slum como zona urbana en deterioro y shantytown como arrabal. Según el autor, "la connotación específica puertorriqueña de zona urbana en deterioro (slum) fue aplicada primeramente por oficiales del gobierno a los vecindarios de trabajadores de los años treinta y siempre en relación a programas federales de erradicación de arrabales. La primera vez que un barrio bajo se le declaró legalmente 'arrabal' surgieron serias protestas de partes de las familias de residentes, ya que esta declaración significaba una casi segura eliminación de vecindario por la Autoridad de la Vivienda. A mediados de los años cincuenta, 'arrabal' era un nombre que le daba a vecindarios de clase baja, y que no significaba eliminación necesariamente" (p. 157).

Según Gravano (2005: 48), “el slum es el ejemplo más típico de este acotamiento espacial, social y cultural. Esta palabra mayormente ha sido traducida al español como ‘barrio bajo’ y es definida como la zona de peores condiciones físicas de la ciudad. Pero principalmente se la concibe como un lugar donde se desarrolla un orden moral y social particular. Es el área donde, además de pobreza y malas condiciones físicas, se concentra — de acuerdo con esta visión- un verdadero desorden social y moral (énfasis del autor). No se le debe confundir, entonces, con el barrio pobre ni con el ghetto".

Siguiendo con el término slum, Stevens (1985) menciona que Safa objetaba el uso del término slum para arrabal, por definir ese término como áreas de estructuras anteriormente adecuadas y que se encuentran deterioradas, sin mantenimiento y convertidas en casa de vecindad. Por lo tanto, Safa utiliza shanty town para definir el área residencial de estructuras débiles, construidas con materiales provisionales y por mano de obra no diestra. 
Sobre los shantytowns, Stevens (1985) señala que "shanty town” es un término aceptable para traducir el concepto arrabal. Evita los problemas de utilizar "slum" o "squatter settlement" - aunque la mayoría de los(as) residentes en arrabales de San Juan son "squatters" (colonos, rescatadores, invasores). Sin embargo, "shanty town" no describe los arrabales de los años ' 70 muy bien. Muchas de las estructuras que originalmente eran débiles e inadecuadas han sido transformadas por sus dueños en estructuras sólidas (p. 158). En su estudio sobre San Juan, Stevens (1985: 189) finaliza señalando que "la calidad del arrabal, en términos generales, la villa miseria (énfasis del autor) de los 1930 y 1940 es ahora, un vecindario de clase baja trabajadora grandemente mejorado y en vías de continuar mejorando".

4.4.3 El barrio. Para Colón Reyes (2006: 228), "los llamados barrios de pobres, los arrabales, las vecindades" nacieron cuando en las décadas del 40 y 50 llegaron a las zonas urbanas personas empujadas por la falta de empleo en el campo. "Se alojaron en las áreas residenciales deterioradas, construyeron sus comunidades donde pudieron, a orillas del mar, del río o del mangle, en las tierras de nadie, todavía no reclamadas por la ciudad” (Colón Reyes, 2006: 228).

Según Colón Reyes, existen diferentes categorías de barrios pobres, teniendo en común los problemas de falta de vivienda y pobreza. El término barrio pobre puede ser aplicado a un área dentro de la ciudad que se ha deteriorado a través de los años y el área donde se construyeron viviendas bajo los estándares deseables o casas de vecindad para personas de bajos ingresos. Según la autora, “otro tipo de barrio pobre es aquel que se estableció en terrenos de propiedad privada y por tanto, de apropiación ilegal, en terrenos no regulados, generalmente localizados en las afueras de la ciudad y en tierras marginales. [...] En este caso la gente ocupó el terreno, lo dividió en solares, generalmente mal planificados, y fabricó sus casas de acuerdo con 
sus recursos” (p. 229). Ramírez (1977: 11) también hace mención de los barios pobres: "Se acostumbra aplicar el término de barrio pobre a un área dentro de la ciudad que se ha deteriorado a través de los años, o donde alguna vez se construyeron viviendas sub-estándares o casas de vecindad para acomodar las poblaciones de ingresos bajos". Además, indica que los barrios pobres se llaman distinto en América Latina, como callejones en La Paz, casas de vecindad en México, conventillo en Buenos Aires y zaguanes en San Juan. Sobre las características de los barrios pobres, el autor señala que éstos son clasificados como áreas de deterioro físico y desorganización social, en donde la mayoría de los(as) residentes son inquilinos(as) de caseros(as) que viven fuera del área. Añade que "casi todos los criterios utilizados para clasificar un área como barrio pobre, se basan en los estándares y valores de clase media formulados en muchas de las metas y reglamentos relacionados con los programas de renovación urbana” (p. 10). Generalmente, se definen los barrios pobres como vecindades urbanas caracterizadas por bajos ingresos, hacinamiento, condiciones de vivienda subestándares, educación inferior, niveles de destreza limitados, problemas de higiene e inadecuados servicios públicos (Hunter, 1964). Al comparar los asentamientos no regulados y los barrios, Ramírez (1977: 12) señala que "las casas y el área adyacente en las comunidades de invasores, en lugar de deteriorarse con el tiempo se mejoran constantemente de acuerdo a los recursos y las aspiraciones de sus dueños. Mientras más vieja sea la barriada, más diversificada y estratificada será su composición”. Por su parte, Stevens (1985), al referirse a todas las áreas de viviendas de clase baja, usa indistintamente los términos: barrios obreros, barrio bajo y barrio pobre.

En su trabajo sobre los barrios populares desde su fundación hasta comienzos del siglo XX, Quiles (2005) aborda las relaciones entre el barrio y la ciudad. El autor 
señala que el "arrabal, en Puerto Rico, es una versión del barrio popular de la ciudad industrial donde predomina el hacinamiento y la precariedad de servicios e infraestructura" (p. 1). Según Quiles (2003: 14), "sus barrios, localizados en los márgenes de las ciudades, en los intersticios de poca utilidad para el capital inmobiliario, son con frecuencia convertidos por ellos mismos en terrenos adecuados que se incorporan a las áreas urbanas. Se convierten en fronteras que marcan la dirección del desarrollo urbano o definen rutas de circulación que posibilitan la conexión entre partes de la ciudad. Sus comunidades, muchas veces construidas con recursos propios, son importantes como espacios de reproducción, de interacción social y como territorios desde los cuales consolidar las bases de su identidad para generar y ejercer poder en y sobre su cotidianidad".

En su análisis de los barrios formados a mitad del siglo XVIII en San Juan, Quiles (2003: 40) señala que éstos están en continuo desarrollo como las ciudades, pero sus cambios son “impuestos desde afuera según las necesidades del mercado inmobiliario y las regulaciones gubernamentales". Los barrios están más propensos a ser eliminados cuando surgen proyectos de cambio, por su construcción frágil y su existencia, a veces ilegal, en lugares ajenos. Por lo tanto, los barrios "son tolerados hasta que surgen usos más 'adecuados' para el desarrollo de la ciudad” (Quiles, 2003: 40). Y sus residentes son una población móvil que debe ajustar sus requerimientos a las necesidades de los grupos dominantes.

Sobre los barrios de San Juan a finales del siglo XIX, Quiles (2003) escribe:

Los barrios fueron la propuesta de los pobres que necesitaban vivir cerca de los lugares en donde había trabajo, pero no podían pagar el alquiler de una vivienda, ni adquirir un terreno donde construir legalmente, y por lo tanto alquilaban los terrenos o los ocupaban legalmente. [...] Faltos de 
infraestructura básica y servicios, los propios pobladores tuvieron que asumir la construcción dentro de una precariedad extrema. En los barrios construidos por la propia población el entorno se crea a partir del manejo de las condiciones ambientales, tanto del entorno natural como el de la propia ciudad de la que se quiere ser parte, de modo que adquieren su forma a partir de las necesidades y demandas de la vida cotidiana, las urgencias de la sobrevivencia, la disponibilidad de recursos y su capacidad de manejo de la tecnología (p. 148).

Estos barrios en San Juan del siglo XIX, al no tener propiedad de los terrenos donde están ubicados, son siempre asentamientos precarios y frágiles, sujetos a cambios sobre los que tienen poco o ningún control (Quiles, 2003). Por otra parte, Gravano (2003: 12) realizó "un estudio antropológico sobre el barrio como espacio simbólico-ideológico y referente de identidades sociales urbanas [...] mediante un análisis comparativo de la realidad barrial contemporánea en diferentes contextos urbanos de la Región Metropolitana de Buenos Aires”. Al analizar la noción de barrio, a base de las categorizaciones entre los ámbitos académicos de gestión y de amplios sectores en la vida cotidiana, Gravano señala que: "el barrio puede aparecer como apropiación de la acepción arquitectónica, urbanística y espacial, como opuesto al centro de la ciudad, como opuesto al conjunto de 'tugurios' o villas miseria, o como antípoda de la parte 'moderna' de cualquier ciudad. A la vez, al centro de la ciudad también se lo suele llamar barrio, lo mismo que a la villa miseria y al complejo de apartamentos" (p. 15).

Sobre la formación del barrio, Gravano indica que "el barrio es una consecuencia de la apropiación desigual del excedente urbano, concretada en el proceso de segregación. Su constitución histórica se dio como una consecuencia de la 
división del trabajo, ligada específicamente a la reproducción material de las clases trabajadoras urbanas (activas o en reserva)" (p. 254).

En cuanto a los valores más repetitivos simbolizados por el barrio, está el ideal de la vida urbana digna, de relaciones comunitarias, afectivamente positivas. Además, el barrio aparece como símbolo de bases populares, de integración social y cohesión, de inocencia, orden, tradición y autenticidad y pertenencia. Entonces, Gravano, por medio de su análisis, indica la diferencia entre barrio y villas, presentada por los(as) habitantes de las comunidades estudiadas en Buenos Aires. Para los(as) ocupantes de esas tierras, el barrio tiene orden y una disposición del espacio organizada según partes urbanas, con calles, plazas y espacios con destino comunitario y público, contrario a la villa, que sería un mero aglomerado de viviendas separadas apenas por un pasillo.

En su análisis de cómo ha sido abordado el barrio en el conjunto de la teoría social, Gravano señala los diversos problemas sociales que otros estudios han relacionado con el barrio: "Independientemente de estas tomas de partido respecto de las causas de los problemas, lo que se constata es la existencia plena de los mismos en los barrios de la ciudad, enunciados como desempleo, pobreza, comportamientos de grupos conflictivos, droga, delincuencia, 'falta de aprovechamiento de las oportunidades económicas', deserción escolar, deterioro del medio ambiente, economía informal y problemas étnicos” (p. 112). La segregación, pobreza y deshumanización de la vida social son considerados consecuencias de la complejidad social de los tiempos modernos y característicos propios de la ciudad industrial. De esta perspectiva, explica Gravano (2003), el barrio es asociado al slum (barrio bajo) por ser el primero un recipiente de viviendas donde se hacinan las clases trabajadoras 
urbanas y aquellos sectores sociales que no tienen un empleo formal. También es relacionado al ghetto por la presencia de minorías étnicas.

Al analizar los enfoques de lo barrial en los estudios sobre el urbanismo, Gravano (2005) presenta los conceptos slum y ghetto. Alrededor de las unidades de análisis (ghetto y slum), se entorna la teoría social urbana por varias décadas. El autor indica que las "identidades y comportamientos no normales (énfasis del autor) se concentraban o emergían en el slum (barrio bajo, pobre) y en ghetto (barrio con residencia de minorías étnicas), que en gran medida coincidían” (p. 46). Gravano (2005) se refiere con "identidades y comportamientos" no normales a que el barrio bajo aparece como un problema urbano por la concentración de desajuste y pobreza. Finalmente, Gravano (2005: 49) indica que a partir de la década del 50 del siglo XX, se fortalece la idea: "Eliminación (énfasis del autor) del barrio bajo de las grandes ciudades latinoamericanas, como único 'remedio' para la vida 'sana' dentro de éstas. De más está decir, que cuatro décadas después, los slum gozan de muy buena salud tanto en las ciudades del capitalismo central como del periférico".

4.4.4 El gueto. El término ghetto fue utilizado por la Escuela de Chicago para nombrar las áreas urbanas donde residían los pobres (Monreal, 1996). Sobre este tema, la monografía más importante es The Ghetto de Louis Wirth (1928). El ghetto (o gueto, en español) es un "área natural de la ciudad entendida como barrio que no ha sido conscientemente diseñado o planificado por los urbanistas, sino que simplemente crece de manera espontánea y natural como un organismo vivo" (Monreal, 1996: 22). También el gueto es el lugar donde la segregación ha lanzado a ciertos grupos étnicos y raciales, los cuales defienden su cultura amenazada por la cultura dominante. Monreal (1996: 22) señala que "para Park, como para Wirth, el gueto no es sólo un hecho físico: es también un estado de mente (énfasis de la autora) concebido como 
una cultura, porque la historia del gueto representa la hostilidad y la violencia, los conflictos a los que ha dado el lugar el vivir juntas dos culturas".

En su libro sobre la antropología y la pobreza urbana, Monreal (1996) critica a la Escuela de Chicago. Su primera crítica a esta Escuela es que "parece como si cualquier cosa que no estuviera en conformidad con los principios de la sociedad convencional se presentase como un asunto de desorganización" (p. 26). Por tanto, el origen inmigrante de los(as) residentes de los guetos y la defensa de sus valores étnicos los(as) hacía compartir características con la pobreza indigna, las cuales son comportamientos, valores extraños y psicología considerados teóricamente anómalos y vinculados a la degradación y la desviación sociales, relacionados al crimen, la pereza e inestabilidad residencial. La segunda crítica que hace la autora a la Escuela de Chicago es que ésta nunca vinculó al gueto con la situación económica y política de la ciudad de Chicago de la década del 20 del siglo XX.

En resumen, el gueto es la segregación residencial de grupos étnicos y raciales, vinculada a problemas sociales, como la pobreza y el crimen. En el caso de Puerto Rico, Ramírez (1970) utiliza este término, eliminando el elemento racial y étnico y enfatizando en las condiciones de vida y problemas sociales existentes en esas áreas. Según Ramírez, existe la segregación física de los grupos más necesitados, además de la diferenciación social y económica en la sociedad puertorriqueña. Por tanto, en los grandes centros urbanos han surgido áreas donde la gran mayoría de sus residentes son pobres. Los caseríos y los arrabales son presentados por Ramírez como ejemplos de "guetos" por las condiciones sociales prevalecientes que limitan aún más a las pocas oportunidades de mejoramiento económico y social. Sin embargo, la concentración de las minorías étnicas y raciales en centros urbanos segregados y pobres no es tan aguda en Puerto Rico como en Estados Unidos. 


\subsection{Invasiones o rescates de terrenos}

Como señalé anteriormente, muchas comunidades pobres y urbanas, especialmente en América Latina y el Caribe, se formaron a partir de los rescates de terrenos. En Puerto Rico, los rescates de terreno han sido respuestas populares a la escasez de vivienda. Estas respuestas han sido a veces espontáneas y a veces organizadas. En su estudio sobre los rescates de terreno en Puerto Rico, Cotto Morales (2006: 10) señala: "La invasión o el rescate es una forma ilegal de adquirir un terreno y se caracterizan por ser una acción colectiva, comunitaria e inmediata. Esta forma de asentamiento se inauguró en Puerto Rico en 1968 por pobladores urbanos, hijos e hijas de los migrantes campesinos que conformaron las barriadas obreras y los arrabales en las décadas de los años 20 y 30 del pasado siglo. Aunque estos pobladores constituían la segunda generación en la ciudad, no habían accedido a un espacio físico ni ocupacional propio. En las décadas de 1970 y 1980, los pobladores de las invasiones de terreno adoptaron el término 'rescatadores' para definir su identidad”. Según Colón Reyes (2006), la necesidad de viviendas para los sectores pobres explotó entre 1968 y 1976, cuando hubo 118 rescates de terrenos públicos y privados (Colón Reyes, 2006 y Cotto Morales, 2006).

Aunque muchas personas se apropiaron ilegalmente de terrenos privados y públicos, durante los años 1940 al 1960, no hubo reacción estatal negativa al establecimiento de esos asentamientos por varias razones. Según Colón Reyes (2006), de esta forma el gobierno no tenía que suministrar viviendas a las familias que no poseían los recursos mínimos. La segunda razón es que, aunque se apropiaron ilegalmente de terrenos de propiedad privada, constituían tierra marginal de baja productividad y valor. Y la tercera razón es que las autoridades gubernamentales 
alentaron la ocupación de las tierras, alquilando los solares por 1 dólar anual, y les proveyeron agua potable y energía eléctrica.

A partir de 1968, ocurrieron rescates de terrenos bien cotizados de propiedad privada y gubernamental, en su mayoría. Sin embargo, la reacción del gobierno fue violenta, al punto del enfrentamiento con agentes de la Policía de Puerto Rico (Colón Reyes, 2006). Por ejemplo, “durante la primera semana de agosto [de 1971], oficiales de la CRUV [Corporación de Renovación Urbana y Vivienda], con respaldo policíaco, arrasaron una gran cantidad de comunidades, entre ellas: Villa Carrera en Canóvanas, Villa Libertad y Villa Pui en Trujillo Alto, Villa Plata en Dorado y Villa Albizu en Juncos. Se quemaron todas las estructuras y la Policía entró armada, excepto en Villa Plata. Se informó que los policías golpearon a hombres, mujeres y niños. Ninguna de las comunidades había recibido una orden de desahucio de los tribunales. Los residentes de Villa Albizu en Juncos informaron que la furia policíaca fue tal que comenzaron a destruir casa con gente adentro" (Cotto Morales, 2006).

Cotto Morales (2006) describe a los(as) rescatadores(as) de terreno como habitantes de los centros urbanos de Puerto Rico o Nueva York, pertenecientes a diferentes fracciones de las clases trabajadoras, como empleados(as), subempleados(as) o desempleados(as), recipientes de ayudas gubernamentales, sostienen actividades económicas informales y justifican la ocupación de tierras baldías y terrenos de la periferia como un acto motivado por la necesidad. Concluye la autora que la aparición y legitimación de nuevos actores sociales, como los pobres sin vivienda, fue un legado cultural del movimiento social de los rescates. También surgieron procesos novedosos para la vida política puertorriqueña, como la formación de organismos regionales de sectores populares que denotan la presencia de alianzas y 
el apoyo de múltiples sectores no partidistas (y también partidistas), profesionales, sectores educativos y religiosos.

Desde las perspectivas legal y judicial, Corretjer Hernández (2001) trata el tema de las invasiones de terreno, presentando decisiones del Tribunal Supremo de Puerto Rico, leyes y artículos del Código Civil y del Código Penal de Puerto Rico. Desde esas perspectivas, Corretjer Hernández señala que "el invasor o rescatador de terrenos que entra en propiedad privada es poseedor de mala fe, ya que conoce que no es el dueño y entra a ejercer actos de dominio sobre el bien, sin el consentimiento del dueño" (para 26). Dependiendo del tiempo que dure el(la) invasor(a) en la propiedad, será la acción legal a tomar. Para lograr el desalojo de la propiedad de una persona que lleve más de un año y en contra de la voluntad del dueño o poseedor anterior, este último pierde la posesión sobre la propiedad y requerirá una acción específica, como reivindicación, injuction o desahucio en precario. Por otro lado, si han transcurrido 30 años de la posesión ininterrumpida, el(la) invasor(a) puede adquirir por prescripción extraordinaria o por usucapión la posesión del inmueble. Sin embargo, el autor indica que "en cualquier momento antes que se consolide su dominio está el invasor sujeto a la acción del dueño para recobrar su posesión" (para 27). Añade el autor que si la propiedad invadida pertenece al Estado Libre Asociado de Puerto Rico, no se puede adquirir por usucapión o prescripción extraordinaria.

Los estudios sobre la invasión o rescates de terrenos han aportado significativamente en el entendimiento de este fenómeno en Puerto Rico, desde las perspectivas de las ciencias sociales y la legal/judicial. Estos estudios se complementan porque tratan diferentes aspectos sobre esta forma de adquirir terrenos para establecer residencias, como la descripción de las características de los(as) rescatadores(as), el procedimiento judicial para efectuar el desalojo y las 
circunstancias sociales que llevaron a que se dieran los rescates de terrenos. No obstante, es muy poca la literatura que se ha publicado sobre los rescates de terreno en Puerto Rico, cuando este fenómeno es tan controversial por haber personas sin vivienda y quizás sin el poder adquisitivo para obtener una por posible alto nivel de pobreza y por la ocupación ilegal de terrenos privados y públicos.

La literatura en sociología y antropología urbana ha presentado desde la década del 20 del siglo pasado distintos términos para comunidades formadas en la zona urbana y caracterizadas mayormente por ser pobres. Conceptos como ghetto, slum, arrabal, shantytown, asentamiento no regulado, barrio, barrio pobre y vecindad fueron creados por teóricos(as) y usados por investigadores(as) para describir y analizar sus comunidades de estudio. También varios(as) investigadores(as) han aludido a términos usados en otros países para referirse al mismo tipo de comunidad pobre. En la literatura, se encuentran términos extranjeros, como ghetto y slum, concebidos en Italia y los Estados Unidos, respectivamente. Algunos(as) investigadores(as) los utilizan en inglés, aunque sus investigaciones están redactadas en español, y otros(as) investigadores(as) presentan su versión en español, como gueto para ghetto y barrio bajo para slum. Aunque en la academia, se escuchan estos términos en las disciplinas de antropología, sociología y planificación, en la actualidad en Puerto Rico ya no se aplican popularmente esos conceptos, con la excepción de comunidad pobre, comunidad especial (refiriéndose al programa gubernamental que atiende las comunidades pobres en Puerto Rico), barrio (o barriada) y caserío. Por lo menos, en la comunidad estudiada en esta investigación, decir arrabal podría resultar ofensivo, según informara una empleada de la corporación pública que lleva a cabo la planificación del dragado del caño. Además, durante el trabajo de campo nunca escuché las palabras arrabal, slum, ghetto, 
shantytown, vecindad, asentamientos ni villas para referirse al área bajo estudio. Sólo escuché comunidad y barrio. Los términos utilizados para describir a las comunidades urbanas pobres en Puerto Rico mayormente son arrabal, caserío y barrio, en referencia a las investigaciones realizadas antes de la década del 80 del siglo pasado, en el campo de antropología urbana.

De manera general, los estudios realizados sobre la pobreza urbana han aportado significativamente a las disciplinas de antropología, sociología y planificación, al presentar términos nuevos y aplicarlos a las distintas comunidades estudiadas en Estados Unidos y Puerto Rico. Debido a que las comunidades han cambiado, junto a las teorías urbanas, la aplicación de estos términos dependerá de las características de la comunidad a estudiar, además de su ubicación geográfica y cultura.

No obstante, la mayoría de los estudios sobre pobreza urbana fueron realizados en el siglo pasado, cuando las condiciones de vivienda, en general, eran distintas, ya que en la actualidad muchas de las características mencionadas para describir algún concepto, como el arrabal, ya no existen. Por ejemplo, un material común de construcción es el cemento (permanente y duradero). Además, muchas comunidades pobres tienen la mayoría de los servicios esenciales y hasta los no esenciales, como cable televisión. También, aunque originalmente surgieron en tierras marginales, las comunidades, como la de este estudio, están ubicadas en zonas altamente privilegiadas y deseadas por los(as) inversionistas locales y extranjeros(as), por estar cerca de cuerpos de agua, vías principales de transportación, oficinas gubernamentales y privadas y zonas turísticas. Por lo tanto, recomiendo la revisión de las definiciones de los conceptos utilizados en la pobreza urbana, para identificar comunidades pobres y evaluar cuáles se mantienen vigentes en la actualidad. 
En conjunto, la bibliografía sobre la pobreza incluye ensayos que postulan conceptos y teorías para explicar este problema social; investigaciones que tratan un tipo de pobreza, como la pobreza urbana; trabajos que describen el perfil de las personas pobres y sus condiciones de vida en comunidades específicas; estudios sobre la pobreza en general; e investigaciones que tratan este problema en alguna comunidad, ciudad o país en particular. Además, muchos de estos trabajos sobre la pobreza están relacionados con otros fenómenos sociales, como la gentrificación y el realojo de viviendas en comunidades urbanas y pobres. Esta literatura ha aportado significativamente al entendimiento de este problema en la sociedad contemporánea. No obstante, aún quedan varias lagunas en el conocimiento, tales como explorar si la teoría de subclase de William J. Wilson podría explicar el problema de pobreza en Puerto Rico, por ser la teoría más reciente desarrollada, describir las actitudes de los(as) residentes hacia las situaciones que se enfrentan, como el realojo de sus viviendas, cambios en su comunidad y la amenaza de la gentrificación y presentar un estudio de caso que actualice la literatura sobre una comunidad pobre y urbana, donde realojarán a una cantidad significativa de sus residentes por vivir en áreas degradadas, con los objetivos de proveerles calidad de vida, mejores condiciones de vivienda y disfrute para todos(as) sus residentes de áreas comunes aledañas al caño. La presente investigación pretende contribuir a llenar esos vacíos. 


\section{Trasfondo histórico y situación actual de la comunidad}

\subsection{Pasado}

El sector donde está ubicada la comunidad estudiada fue el primer asentamiento extramuros de San Juan, en la península de Santurce, debido a la falta de espacio dentro de la ciudad amurallada, que obligó a buscar alternativas de expansión. Este asentamiento fue fundado en el siglo XVIII, aunque es habitado desde el siglo XVI (Quiles, 2003).

Sepúlveda y Carbonell (1987) describen este sector “como una península de costas cenagosas dominada por cinco colinas (p. 20)", donde las ciénagas pobladas de densos mangles "determinaban gran parte del proceso de ocupación de terrenos (p. 20)". Añaden que estas colinas, que tenían mejor vista y drenaje, estaban ocupadas por propietarios privados. Los sectores menos elevados estuvieron cubiertos por ciénagas y bosques de mangle hasta las primeras décadas del siglo $\mathrm{XX}$, cuando estas tierras marginales fueron ocupadas por un inmenso sistema de arrabales (Sepúlveda \& Carbonell, 1987). La mayor parte de las viviendas eran pequeñas estructuras de madera, cartón, zinc y latas de metal, construidas por los propios residentes (véase la Ilustración 5.1).

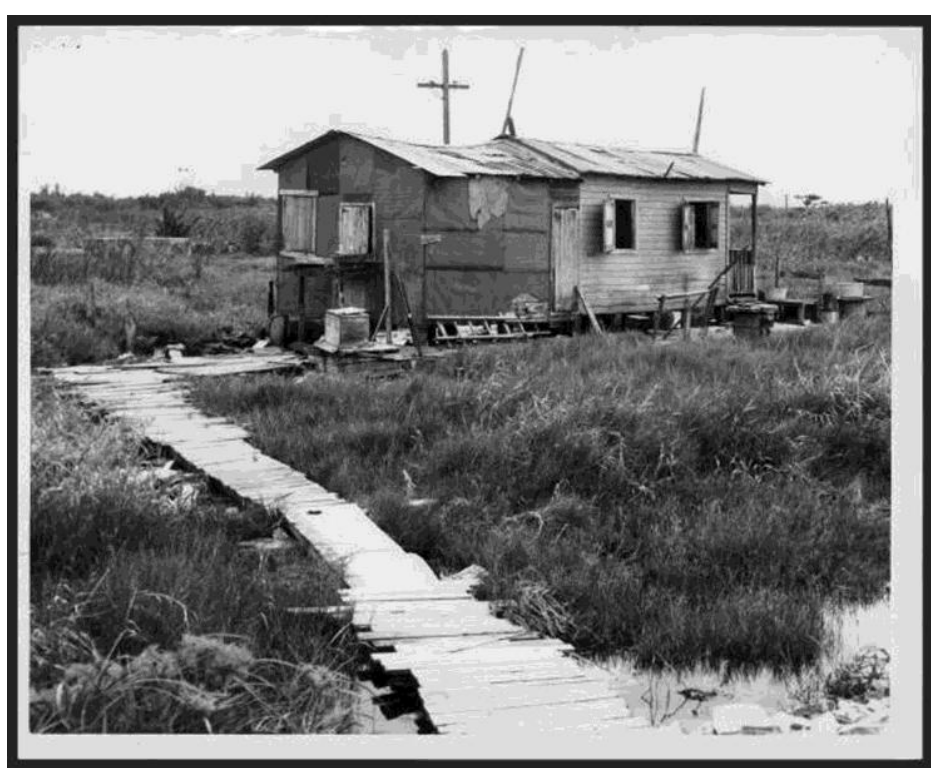

Ilustración 5.1. Camino en madera hacia casucha cerca de los terrenos del Puente de la Constitución en Santurce. 1953. Foto por Teodoro Torres. Proyecto de Digitalización de la Colección de Fotos del Periódico El Mundo, Universidad de Puerto Rico, Recinto de Río 
La comunidad estudiada, en particular, se formó a partir de la década de 1930, cuando a la ciudad de San Juan llegaron miles de migrantes rurales buscando trabajo. Según Safa (1980), la gran concentración de actividades económicas en la capital fue el atractivo para que personas de la zona rural vinieran buscando empleos y otras comodidades urbanas. Añade que la migración masiva comenzó durante la depresión de la década de 1930, junto al estancamiento de la agricultura y al crecimiento desmesurado de la zona urbana. Hacia 1935, los primeros inmigrantes que llegaron a San Juan se concentraron en tierras pantanosas o en propiedades ribereñas inadecuadas para uso residencial o comercial (véase la Ilustración 5.2). Por otro lado, Stevens (1985: 169) señala que "los huracanes San Felipe (1928) y San Ciprián (1932) impulsaron a las familias de bajos recursos, tanto rurales como urbanas, a reubicarse en los manglares de las tierras públicas". Añade que "ciertamente los huracanes no causaron las invasiones - la causa se encuentra en las desastrosas condiciones socio-económicas en que se encontraba la Isla a través de los años treinta y cuarenta-, no obstante tuvieron una influencia estimulante y significativa (p. 170)”.

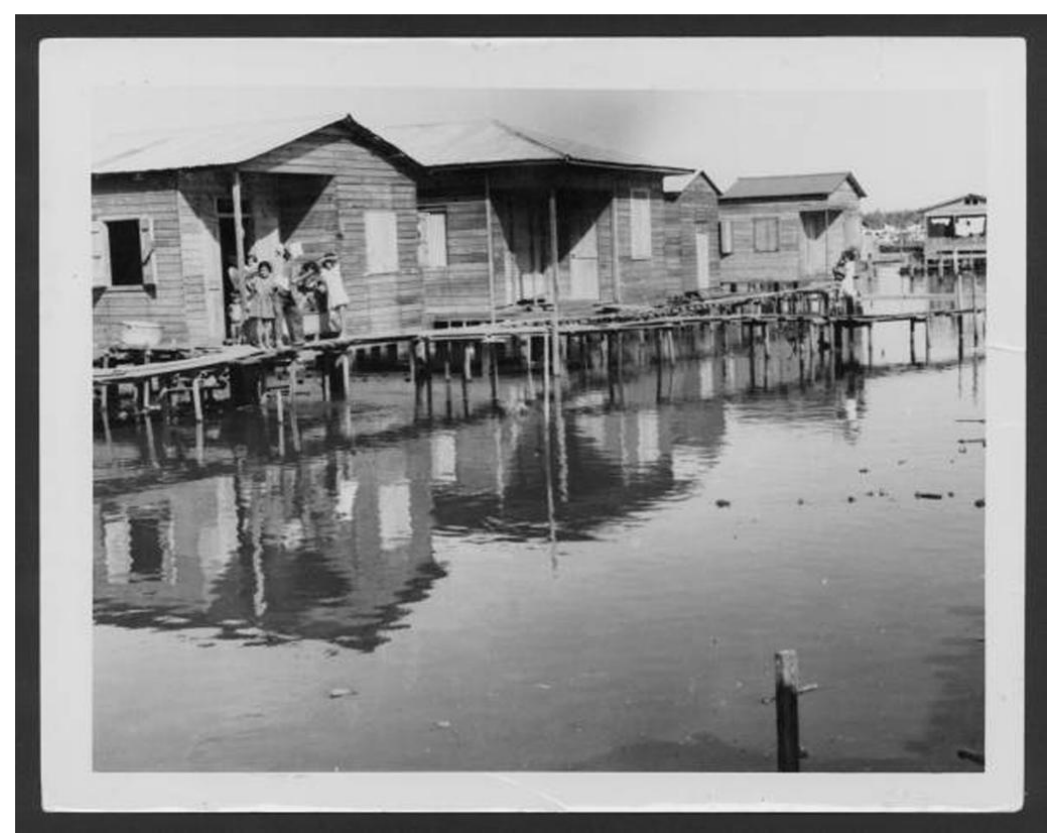

Ilustración 5.2. Casas en pilotes sobre el agua en Tras Talleres. 1939. Proyecto de Digitalización de la Colección de Fotos del Periódico El Mundo, Universidad de Puerto Rico, Recinto de Río Piedras. 
Sepúlveda y Carbonell (1987) coinciden con Safa (1989) en que, entre las décadas de 1930 y 1950, el modelo económico agrario de Puerto Rico, basado en la exportación de caña de azúcar, se deterioró considerablemente. Añaden que "la emigración de las zonas rurales se hizo mayor, mientras que la incipiente industrialización concentrada en las áreas urbanas confrontó serios problemas de absorción de la fuerza de trabajo. En este periodo, los arrabales del municipio de San Juan alcanzaron su máxima expansión física como áreas pauperizadas. [...] Es durante este periodo cuando se ocupan por primera vez las áreas marginales cubiertas por los antiguos bosques de mangle que habían contenido la expansión del tejido urbano en la periferia sur y este de Santurce” (p. 38) (véase la Ilustración 5.3).

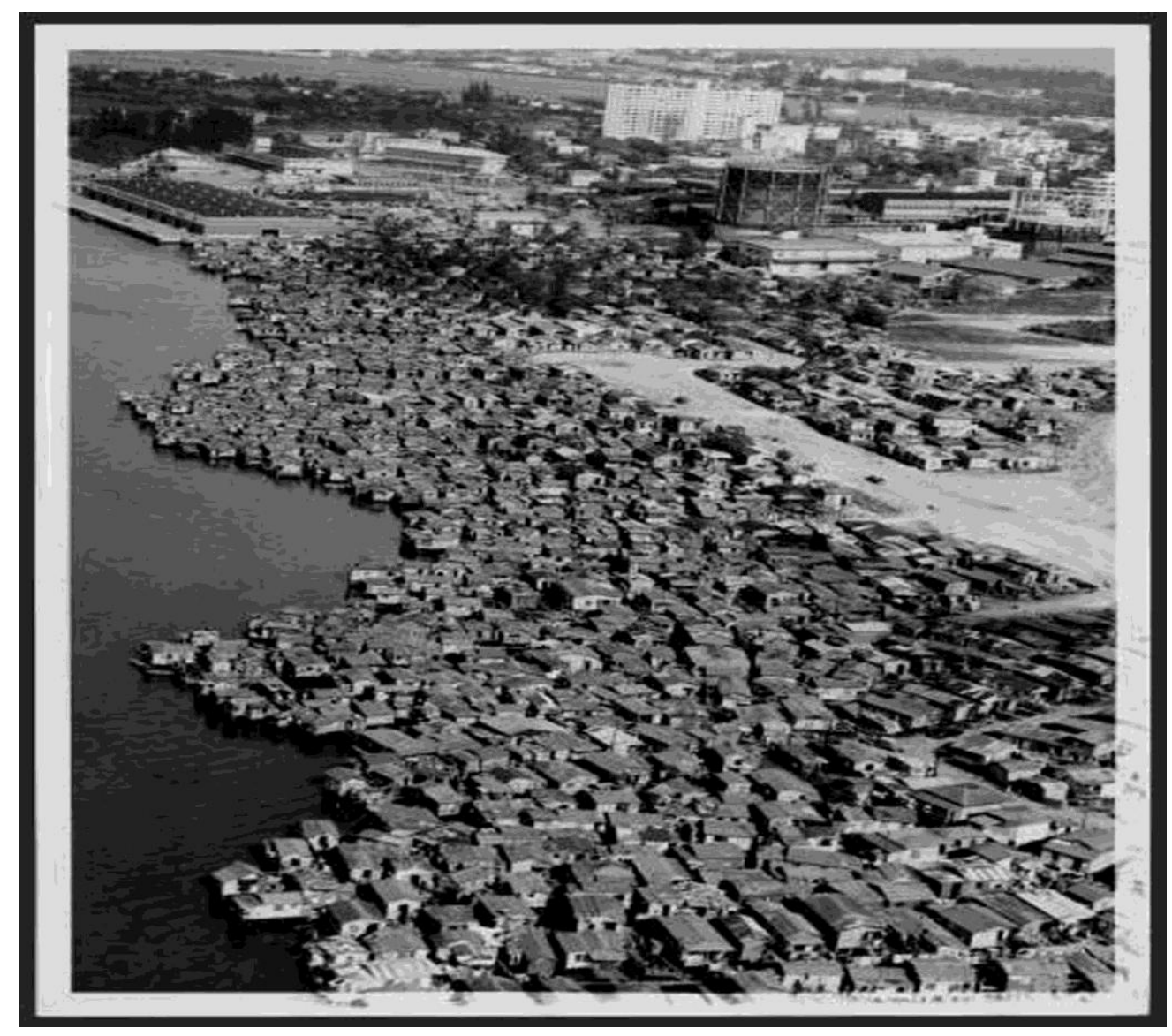

Ilustración 5.3. Vista aérea de la barriada Hoare en Santurce. 1953. Foto por Luis de Casenave. Proyecto de Digitalización de la Colección de Fotos del Periódico El Mundo, Universidad de Puerto Rico, Recinto de Río Piedras. 
Debido a que la mayoría de los inmigrantes que vinieron a San Juan eran personas de escasos recursos, una vez localizados en el sector, tuvieron que secar y rellenar el terreno pantanoso, por ejemplo, con cocos, llantas de autos, basura, arena, tierra y piedras y construir su vivienda con todo tipo de material asequible. Según algunos(as) residentes actuales de la comunidad, se llevaba el material a rellenar con carretillas y/o con camiones. También contó un residente que ocasionalmente se les pagaba a personas para que sacaran el babote del caño, como se le llama localmente al fango del manglar, con cubos para poder echar el nuevo material. "La diversidad de materiales y la inventiva de los constructores, que utilizan todo material disponible en la construcción de una vivienda, son un tributo a los recursos de la gente pobre que necesita un hogar” (Ramírez, 1976: 11) (véase la Ilustración 5.4).

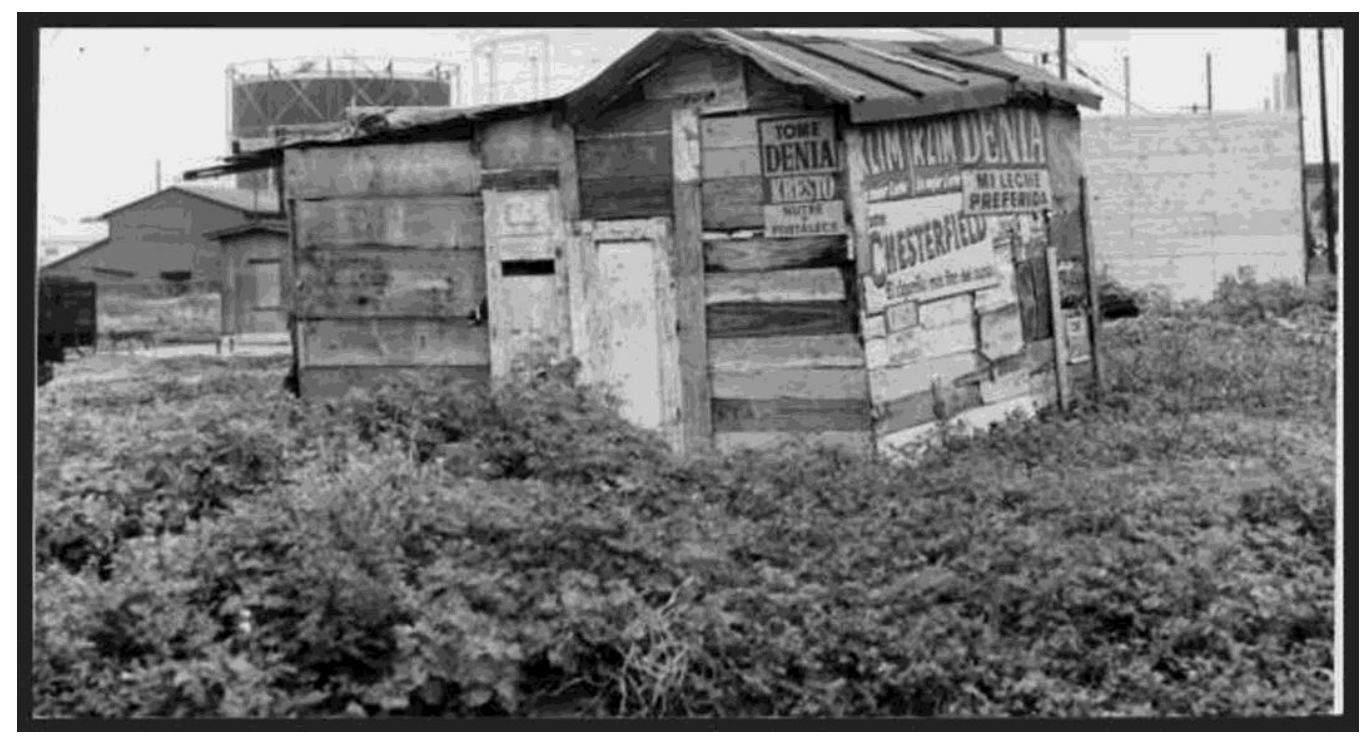

Ilustración 5.4. Rancho en madera en un arrabal de Santurce. 1953. Foto de Luis de Casenave. Proyecto de Digitalización de la Colección de Fotos del Periódico El Mundo, Universidad de Puerto Rico, Recinto de Río Piedras.

Como las personas establecieron sus viviendas en terrenos públicos, el gobierno llevó a cabo varios desahucios para desalojar las áreas ocupadas a partir de la década de 1930. Una de las razones por las que se justificaban los desalojos era que los(as) residentes de los arrabales vivían en condiciones insalubres, por estar cerca o 
en el caño y no tener infraestructura, como alcantarillado sanitario (véase la Ilustración 5.5). Al respecto Stevens (1985) señala que, entre 1937 y 1939, el Departamento de Salud multó a 807 personas por construcciones ilegales en terrenos públicos y destruyó 1.597 construcciones clandestinas. Los desalojos de los arrabales continuaron en las décadas subsiguientes, hasta nuestros días.

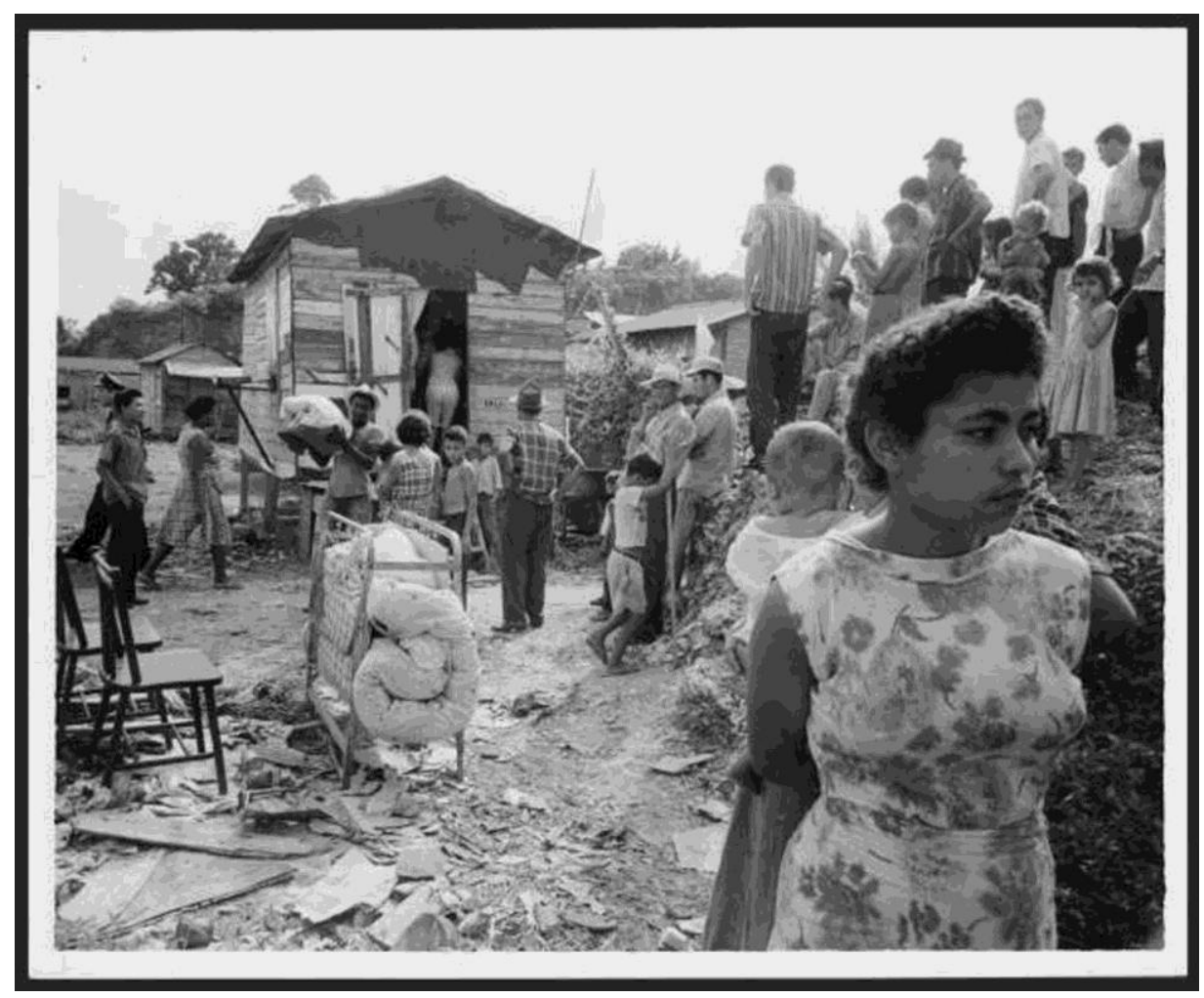

Ilustración 5.5. Familias desalojadas de un arrabal observando la demolición de sus casuchas. 1960. Foto de Teodoro Torres. Proyecto de Digitalización de la Colección de Fotos del Periódico El Mundo, Universidad de Puerto Rico, Recinto de Río Piedras.

Muchas familias fueron relocalizadas en residenciales públicos, proyectos estatales de vivienda para personas de escasos recursos, que en Puerto Rico comúnmente son llamados "caseríos" (véase la Ilustración 5.6). Según Ramírez (1977: 162), este último término “implica viviendas para los pobres y tiene connotaciones negativas". Por otro lado, Safa (1989) encontró en 1969 que, aunque "la mayoría de los residentes de caseríos vive en proyectos de vivienda pública por necesidad, más que por elección, ellos no niegan las claras mejoras físicas en la 
vivienda, en comparación con el arrabal (p. 115)". Sobre los proyectos de vivienda pública, Stevens (1985: 174-175) indica que “fue después de 1950 que el programa de caseríos empezó a hacer su gran aportación como vivienda para los pobres. Entre 1950 y 1970 se construyeron 10.000 unidades de apartamentos en los caseríos con fondos federales y del Estado Libre Asociado". En otras ocasiones, el gobierno les ofrecía a los(as) residentes de los arrabales alguna cantidad monetaria, pero éstos no serían realojados a algún lugar predeterminado. Debido a que el número de familias desahuciadas ha sido mayor que el número de unidades disponibles en los caseríos, algunas de las familias necesitadas escogían otras alternativas, como comprar una casa en una urbanización privada, la reubicación en otro arrabal o en algún otro programa de vivienda (Stevens, 1985: 182).

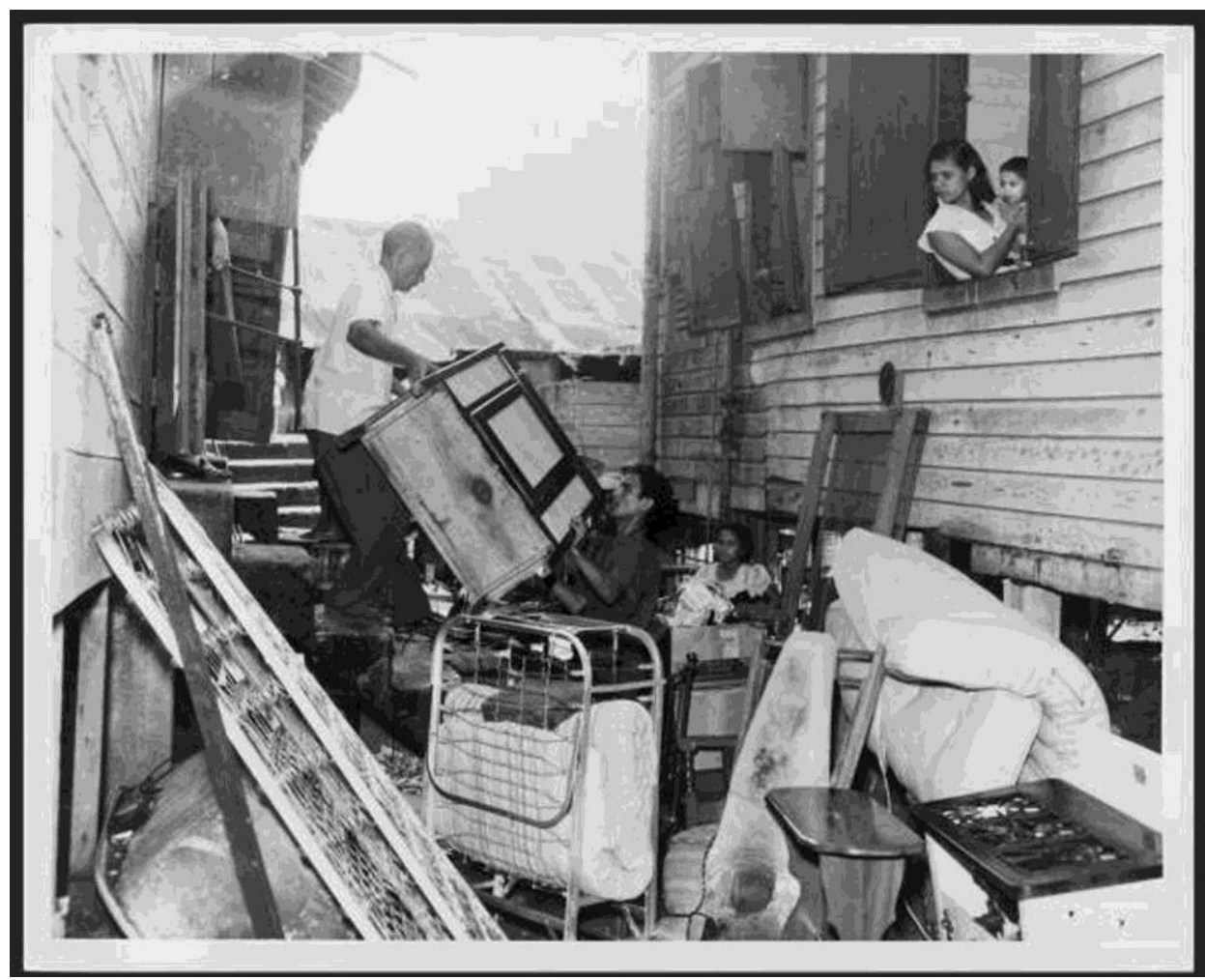

Ilustración 5.6. Inquilinos desocupando ranchones para mudarse hacia el caserío Llorens Torres. 1954. Proyecto de Digitalización de la Colección de Fotos del Periódico El Mundo, Universidad de Puerto Rico, Recinto de Río Piedras. 
Según Sepúlveda y Carbonell (1987), en las décadas de 1960 y 1970, bajo los programas gubernamentales de renovación urbana, las estructuras de gran parte del sector de Santurce, ubicadas en áreas rescatadas al mangle de la orilla del caño durante las décadas de 1930 y 1940, fueron completamente eliminadas. En la actualidad, esas áreas están ocupadas por parques, complejos residenciales, instalaciones de organizaciones privadas y vías de circulación vehicular. El gobierno estatal ha desalojado o realojado familias por estar viviendo en condiciones difíciles para redesarrollar. Estas situaciones han provocado manifestaciones, reuniones con representantes del gobierno y encontronazos con la policía; y han creado en las comunidades desplazadas desconfianza y coraje hacia el gobierno, entre otras emociones, que al día de hoy permanecen (véase la Ilustración 5.7).

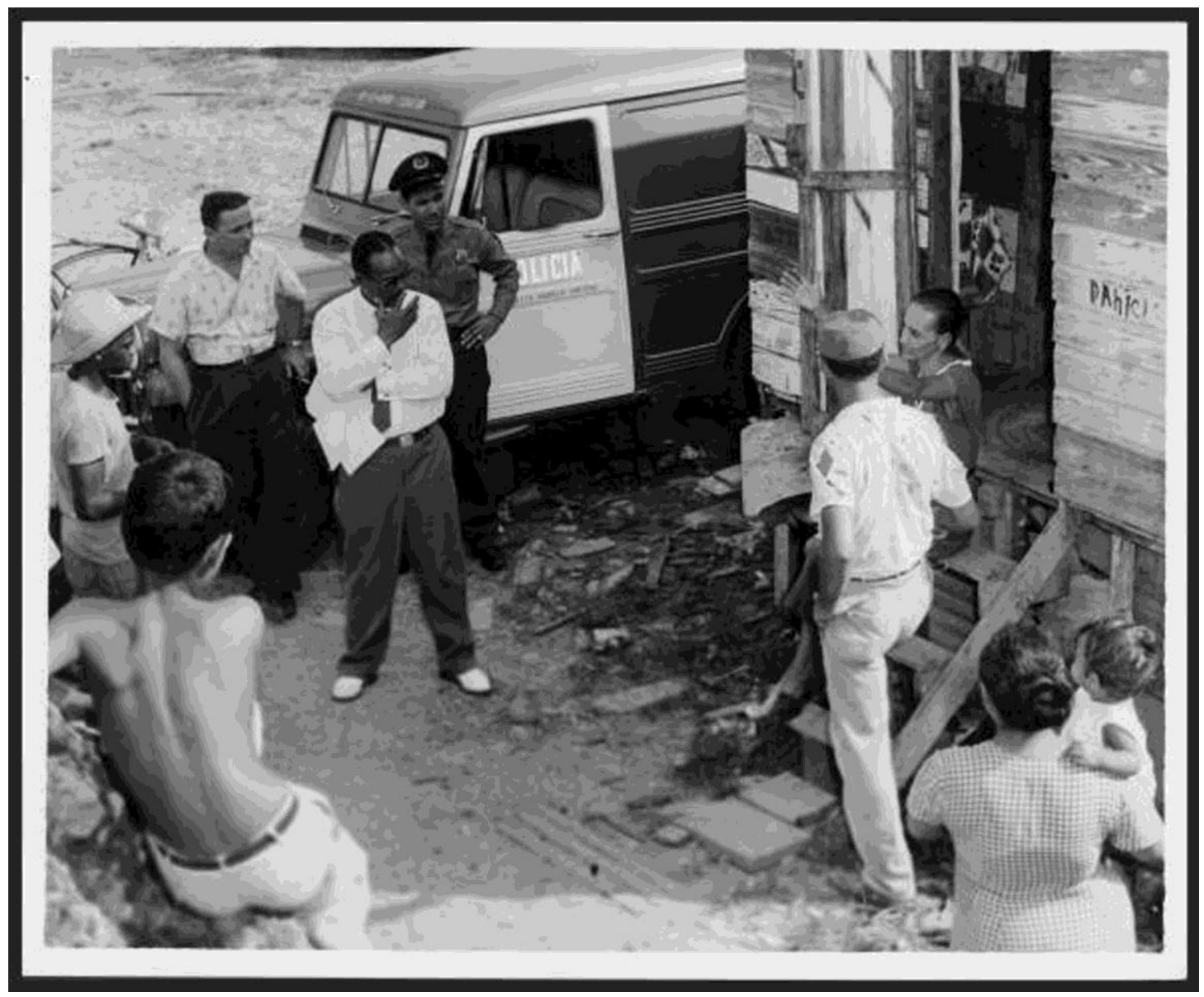

Ilustración 5.7. Alguaciles prestos a efectuar desahucio en terrenos de la sucesión Rexach. 1960. Foto por Teodoro Torres. Proyecto de Digitalización de la Colección de Fotos del Periódico El Mundo, Universidad de Puerto Rico, Recinto de Río Piedras. 
Stevens (1985: 186) señala que, a partir de la segunda mitad del siglo XX, "se evidencia[n] cambios dramáticos en la cualidad física de los arrabales, debidos no tan sólo a las mejoras en el sector público, sino también a la reconstrucción y mejoras de las residencias individuales". Añade que "una vez instalados los servicios públicos a principios del cincuenta, el modelo dominante de casucha de uno o dos cuartos cambió convirtiéndose en vivienda con varios cuartos de madera u hormigón” (p. 186). Para la década de 1970 , muchos residentes habían reconstruido sus viviendas convirtiéndolas en casas más sólidas y bastante elaboradas. La reconstrucción de las viviendas por sus dueños continuaba para la década de 1980, aun cuando los títulos de propiedad no eran seguros. Como señala Stevens (1985: 189), "la calidad del arrabal, en términos generales, la villa miseria [énfasis del autor] de los 1930 y 1940 es ahora, un vecindario de clase baja trabajadora grandemente mejorado y en vías de continuar mejorando".

\subsection{Presente}

En la actualidad, la mayoría de las viviendas existentes en los arrabales son de hormigón y muchas de ellas son terreras, contrario al modo de construir en el pasado, cuando los(as) residentes construían sus viviendas en madera y en zancos del mismo material para evitar que se inundaran con las subidas de la marea, por ejemplo, por la lluvia. Todavía quedan algunas residencias construidas de esta manera (véase la Ilustración 5.8). Otras viviendas fueron reconstruidas en hormigón, pero continúan en zancos, posiblemente para evitar daños a la propiedad en caso de inundaciones. En la comunidad, existen viviendas de hormigón, cuyos primeros niveles están por debajo del nivel del suelo y otras muestran signos de humedad en sus paredes. Posiblemente, esto se deba a su localización en zona inundable, la cual fue antes un manglar. Una 
residente narró que, en el pasado, el piso de su vivienda se hundía, rellenaba y volvía a tirar un piso de madera. También los zancos se hundían.

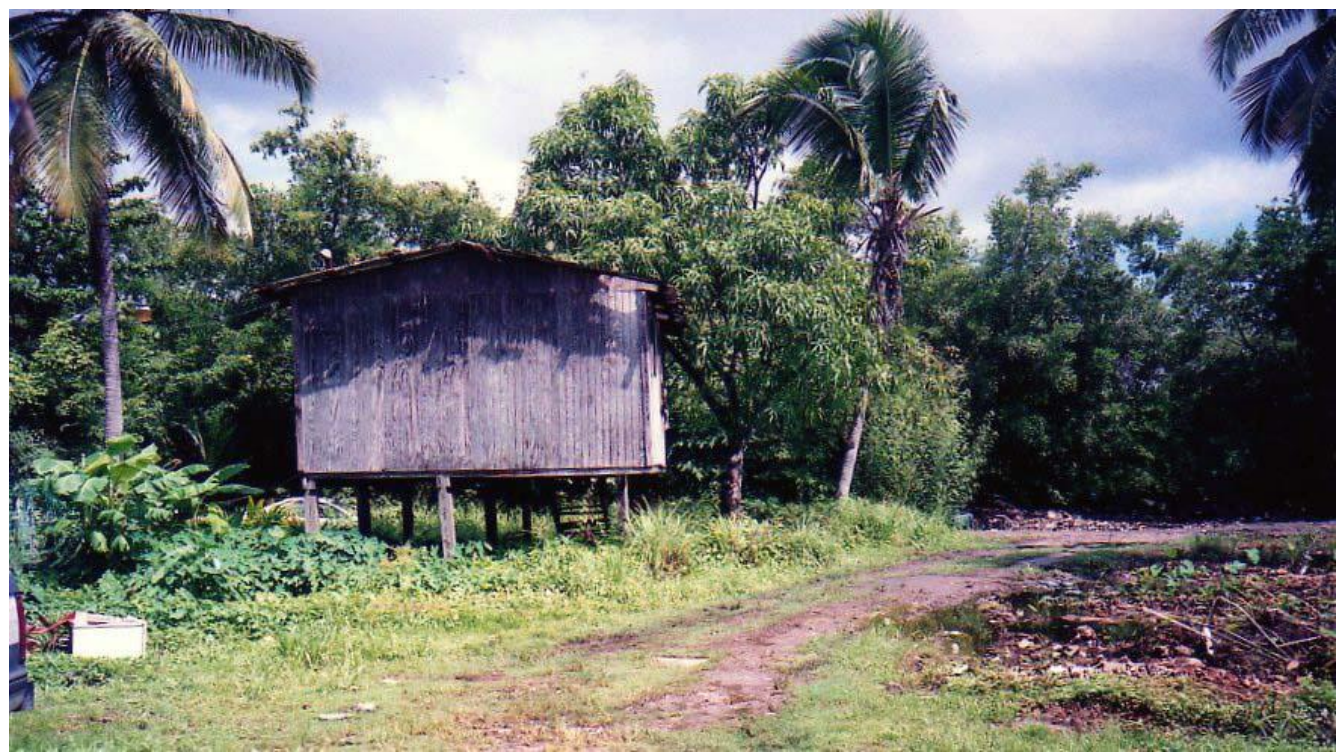

Ilustración 5.8. Vivienda de madera ubicada en zona inundable del caño. Foto de la autora.

Debido a que la comunidad está ubicada en una zona inundable, por haber sido formada en su mayoría a las orillas del caño y parte en el mismo caño, muchas viviendas están por debajo del nivel de mar, por lo que son propensas a inundaciones (véase la ilustración 5.9). Esta situación se empeora cuando el sistema de alcantarillado pluvial no funciona efectivamente y el agua de lluvia se acumula en las carreteras y aceras.

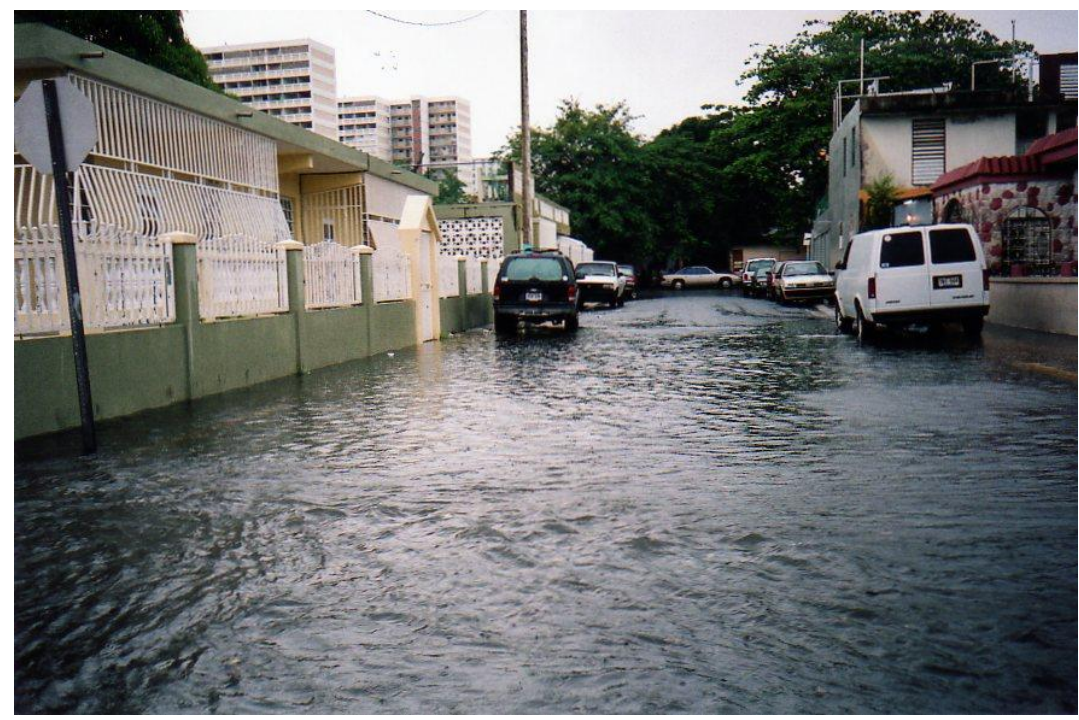

Ilustración 5.9. Calle inundada en el sector bajo estudio. Foto de la autora. 
Muchas de las viviendas están ubicadas en calles estrechas, en las cuales sólo un vehículo puede pasar a la vez y en algunas de éstas no puede pasar un camión. Por otro lado, algunas viviendas están ubicadas en callejones, por las cuales el tránsito vehicular es imposible y por donde sólo pueden pasar personas, en algunas sólo una a la vez (véase la Ilustración 5.10). El ancho de las calles es una de las preocupaciones de los(as) residentes en esta comunidad por la dificultad que tendría alguna agencia en prestar algún servicio urgente, como ambulancia, rescate y bomberos.

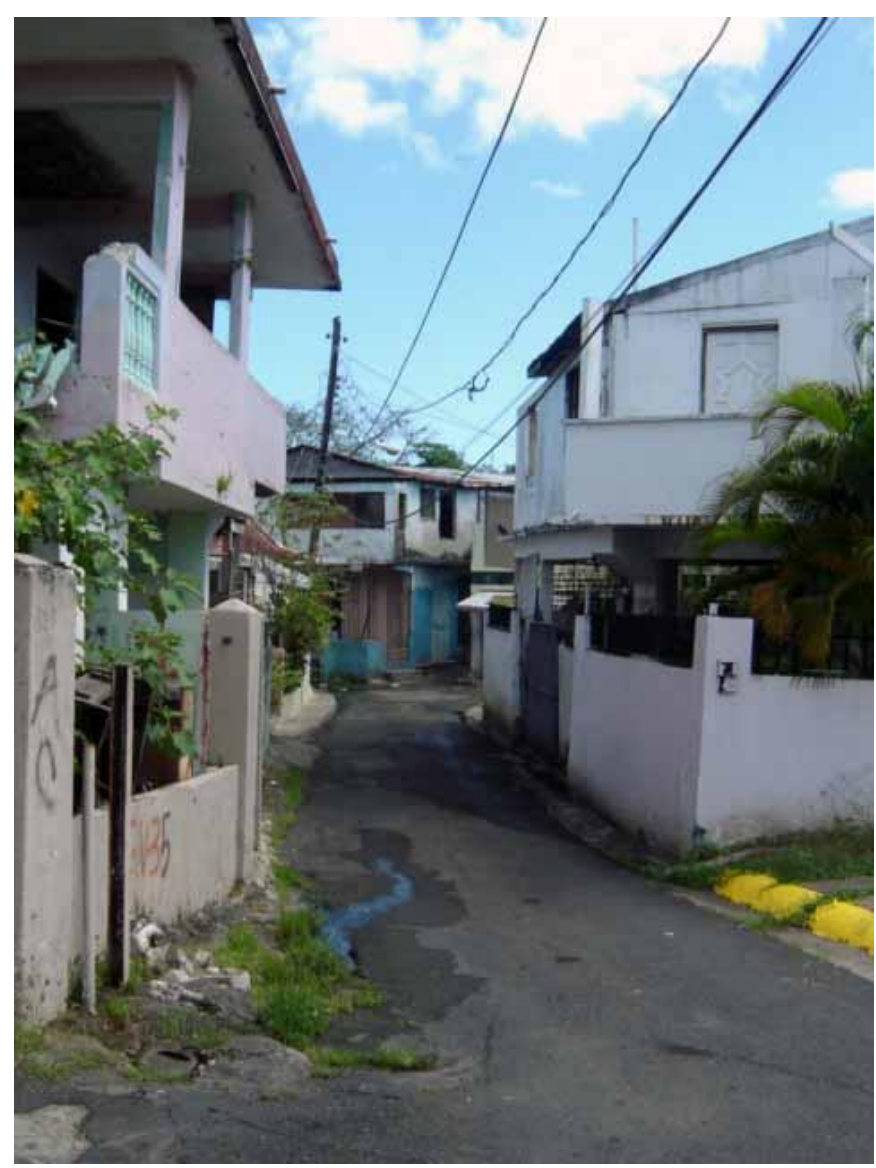

Ilustración 5.10. Calle estrecha y sin aceras en la comunidad. Foto de la autora.

Además, muchas calles de la comunidad no tienen aceras, lo que dificulta el caminar y aumenta el riesgo de un accidente peatonal. Esta situación probablemente es el resultado, como señala Stevens (1985: 184-185), de la modificación en 1951 de las normas establecidas por el gobierno estatal a los arrabales, autorizando, a partir de 
ese año antes mencionado, "mejoras provisionales —agua y calles pavimentadas pero sin el encintado o aceras".

Otro de los problemas que enfrentan los(as) residentes es la acumulación de basura frente y alrededor de sus viviendas. También la basura se acumula en algunas partes del caño, el cual ya está contaminado, provocando que no fluya el agua en todo este canal que conecta con una laguna y la Bahía de San Juan. La ausencia de agua, en algunas partes, hace posible el caminar, ya sea por tierra o por encima de la basura, cruzando de una orilla a la otra (véase la Ilustración 5.11). Según un residente, hasta la década de 1970, todavía había peces y el agua era cristalina.

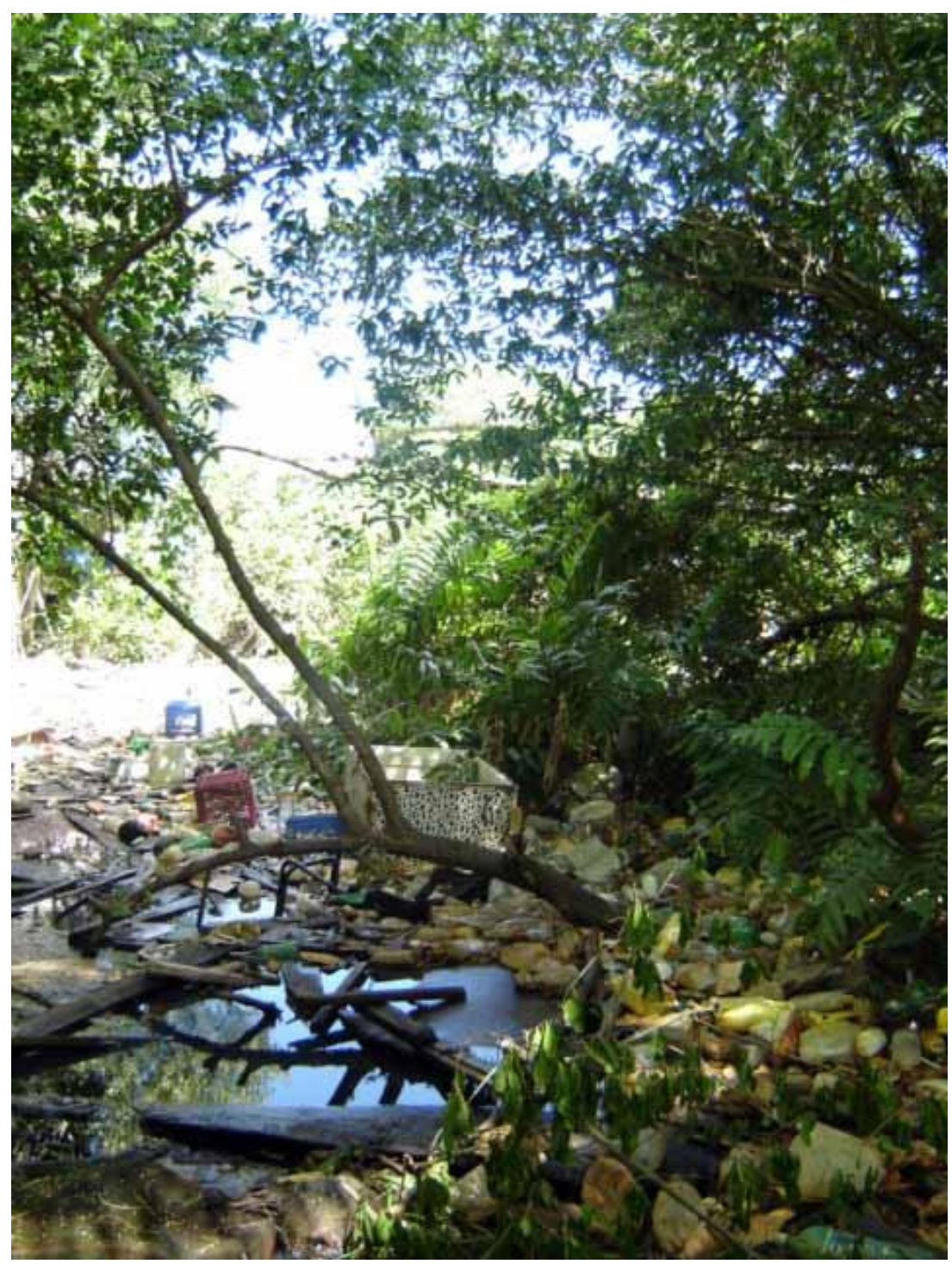

Ilustración 5.11. Parte del caño contaminado con basura. Foto de la autora. 
En el caño hay otras fuentes de contaminación, como los salideros de aguas servidas que terminan en el agua (véase la Ilustración 5.12). En la actualidad, en algunos sectores de la comunidad, las viviendas están conectadas a una tubería común, cuyas aguas servidas van al caño. Según cuentan algunos(as) residentes, en el pasado, los desperdicios humanos llegaban directamente al caño por medio de tuberías desde la vivienda al agua. Actualmente, como parte del plan de desarrollo social para la comunidad por parte del gobierno estatal, se está llevando a cabo un proyecto de instalación del sistema de alcantarillado sanitario para que los desperdicios vayan a una bomba y luego a una planta de tratamiento de aguas.

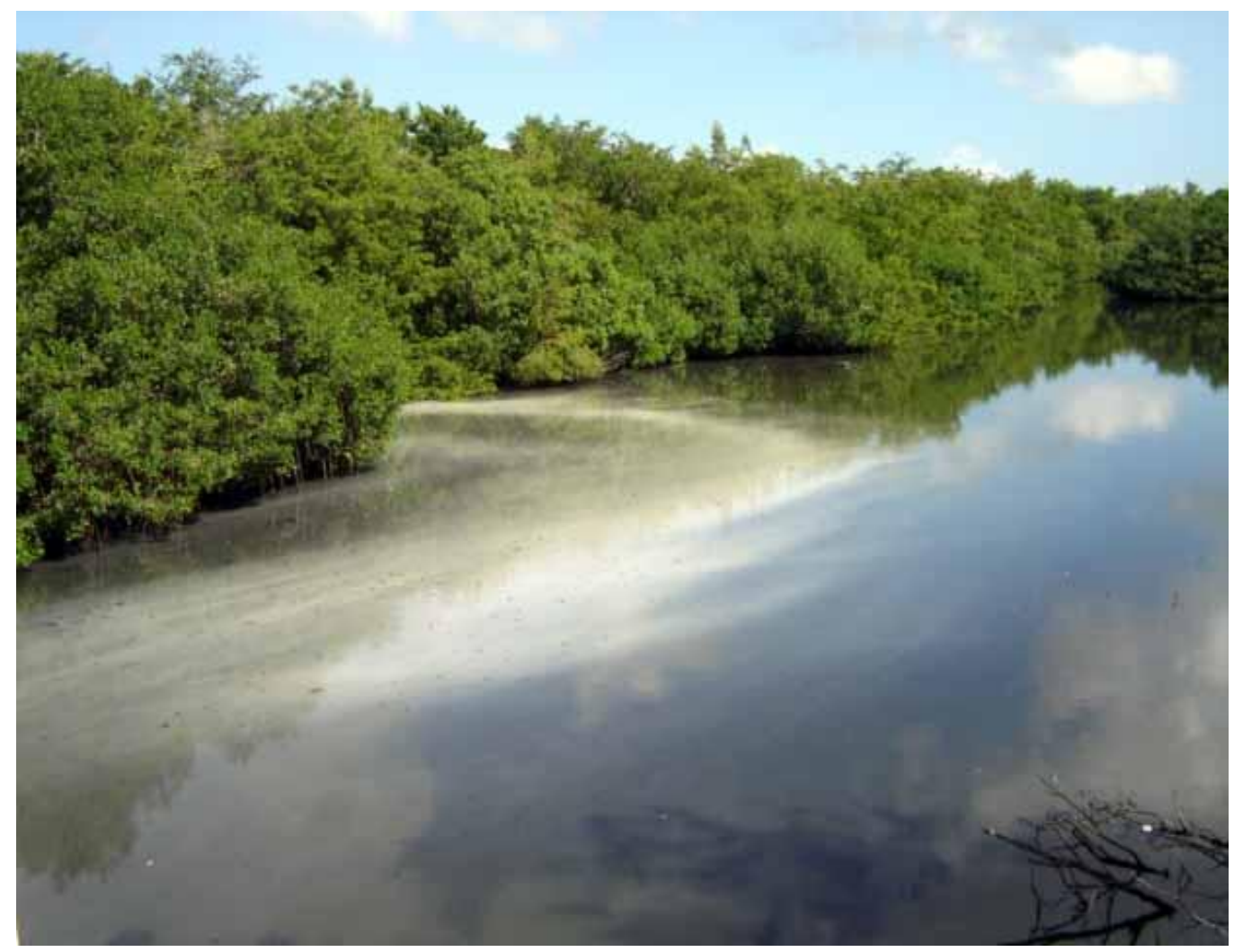

Ilustración 5.12. Vista del caño y de salidero de aguas servidas. Foto de la autora. 
También hay dificultades para que los intereses de los(as) pobres se vean adecuadamente representados en el proceso de decisión, como Morales (1993: 352) define a la pobreza: "Una indigencia total de poder político que impide que los intereses de los grupos indigentes se vean adecuadamente representados en el proceso de decisión y que, por lo tanto, imposibilita el que esos grupos satisfagan las metas y objetivos que se trazan para sí mismos, tanto individual como colectivamente". Cinco años después de aprobarse la Ley Núm. 489 que crea la corporación pública y el fideicomiso de la tierra, un representante de la Cámara de Representantes de Puerto Rico sometió un proyecto de ley para enmendar el Artículo 16 de dicha ley, "para aclarar que no son transferibles los terrenos de dominio público" (Ley Núm. 32 del 23 de junio de 2009). Dicho proyecto de ley fue aprobado por la Cámara de Representantes y el Senado y firmado por el Gobernador Luis Fortuño Burset.

La Ley 489 establecía que las agencias públicas que administren, custodien, dominen, arrienden o posean terrenos o en el Distrito (área que comprende la comunidad estudiada) debían transferir, a partir de 160 días de la vigencia de la misma, el respectivo título a la corporación pública. En el caso de los terrenos de dominio o patrimonio público, la titularidad de los mismos quedaba por esta ley investida en la corporación, con las excepciones del canal a construirse en el caño, así como las servidumbres de vigilancia, de salvamento y la franja de conservación, las cuales se mantendrían como bienes del dominio público, bajo la custodia y administración del Secretario(a) de Recursos Naturales y Ambientales (Ley Núm. 489). Entonces, el fideicomiso de la tierra comprendería todos los terrenos que se traspasasen a la corporación.

Por su parte, la Ley 32 revierte la transferencia de los terrenos públicos, haciendo retroactivo sus efectos al día 24 de septiembre de 2004 y haciendo difícil 
que el fideicomiso cumpla sus objetivos, que redundan en beneficios para sus residentes, particularmente los(as) que no tienen título sobre el terreno porque son invasiones. Esos objetivos son 1) contribuir a resolver el problema de titularidad de muchos residentes, mediante la tenencia colectiva del terreno; 2) atender con equidad el desplazamiento físico o económico de los(as) residentes de bajos ingresos que resulta de los proyectos de reconstrucción urbana, evitando la desintegración y el desplazamiento de la comunidad; 3) garantizar viviendas asequibles; 4) adquirir y poseer tierras en beneficio de la comunidad, incrementando el control local sobre la tierra y evitando la toma de decisiones por dueños(as) ausentes; 5) facilitar la participación de los(as) residentes y la inversión estratégica del sector privado, y redistribuir con equidad el aumento en el valor de la tierra mediante el mecanismo de bonos de participación, diversificando las fuentes de ingresos de las familias y reinvirtiendo en el Distrito; 6) facilitar la reconstrucción y valorización de los espacios urbanos, de acuerdo a la política pública establecida por esta ley, y los planes de desarrollo y uso de suelo que adopte la Junta de Planificación para el Distrito; y 7) recuperar la inversión del Estado en la reconstrucción urbana del Distrito con el propósito de crear un fondo rotativo que permita reinvertir en el Distrito o en otros lugares con propósitos similares (Ley Núm. 489). Otro efecto devastador de la Ley 32 es que ha imposibilitado el realojo de $\operatorname{los}(\mathrm{as})$ residentes porque los terrenos designados para la construcción de los proyectos de vivienda han vuelto a ser dominio público. Por lo tanto, hasta inicios del 2011, no había dónde realojar a todos(as) los(as) residentes, retrasando los demás proyectos, como el dragado del caño. Esto significaba que no se podía dragar el caño contaminado porque no había lugar para acomodar a los(as) residentes que viven en este cuerpo de agua y en sus cercanías, por lo que las personas permanecerían en sus hogares, donde sufren las consecuencias de 
las inclemencias del tiempo, como inundaciones por lluvia, tormentas y huracanes que provocan la acumulación de aguas usadas por varios días. Consecuentemente, las personas seguirán teniendo miedo por su vivienda y preguntando cuándo les realojarán.

Más aún, la Ley 32 no considera los conocimientos y opiniones de los(as) líderes comunitarios(as), incluyendo aquellos(as) que dijeron en televisión haber votado por el gobernador electo. Además, a pesar de las apariciones en los medios de comunicación y las manifestaciones públicas planificadas por la comunidad, el gobierno estatal aprobó dicha ley. También su intento por no hacer valer dicha ley fue frustrado, cuando la junta del fideicomiso de la tierra y su representación legal fueron al Tribunal Federal de los Estados Unidos en Puerto Rico, para solicitar urgentemente una vista con el propósito de dejar sin efecto la Ley Núm. 32, declarándola inconstitucional. Sin embargo, el juez asignado al caso denegó la solicitud de interdicto provisional para detener la implantación de la ley y luego desestimó el caso por abstención (comunicados enviados electrónicamente por la corporación pública). Entonces, como el juez negó dicha solicitud y más tarde desestimó el caso, el fideicomiso ha acudido en más de una ocasión al Tribunal de Apelaciones del Primer Circuito de Boston (EE.UU.), para solicitar un interdicto, obteniendo dicho recurso. De esta manera, se paralizó nuevamente la Ley 32 y se prohibió acciones de los gobiernos municipal y estatal sobre los terrenos, hasta la realización de la vista judicial sobre la apelación de la decisión del juez del Tribunal Federal.

A finales de agosto del 2009, según un comunicado de prensa de la corporación pública, el legislador que presentó el proyecto de Ley 32 ante la legislatura para su aprobación, citó a una vista pública para discutir un nuevo proyecto (Proyecto de la Cámara 1886), sin darle participación a la organización comunitaria 
que agrupa a las 12 organizaciones de las nueve comunidades, a la corporación pública ni al fideicomiso de la tierra. Añade el comunicado que el P. de la C. 1886 pretende enmendar la Ley 32, para que se puedan vender a $\$ 1,00$ los títulos de propiedad sobre el terreno a las familias, las cuales tienen sus residencias en terrenos públicos. Al respecto, un representante de la organización comunitaria que agrupa a las organizaciones locales dijo que les "preocupa que se esté evaluando un proyecto de ley sin contar con la comunidad organizada directamente afectada y ajeno [a] nuestro proceso de participación y autogestión. [...] Por un lado, en nuestro país se destaca la necesidad de la participación ciudadana y por otro, se nos está excluyendo de procesos públicos”. El Tribunal Superior de Estados Unidos examinó el argumento de que la ley es alegadamente inconstitucional en la Constitución de Puerto Rico, Constitución de Estados Unidos y la Ley Federal de Derechos Civiles (Suárez Torres, 2009), contrario a las tres ramas que componen el sistema político puertorriqueño (ejecutiva, legislativa y judicial), que no tomaron seriamente en consideración las opiniones, recomendaciones y acciones de los(as) residentes, sus líderes comunitarios(as) y abogados(as) del fideicomiso de la tierra.

El poder ejecutivo aprobó la Ley 32, a pesar de la realización de conferencias de prensa, las apariciones en televisión y periódicos y las marchas de protesta en la comunidad. Dicha ley fue firmada por el Gobernador Fortuño, contrario al pasado Gobernador Aníbal Acevedo Vilá (2004-2008), quien vetó a mitad del 2008 el Sustitutivo al P. de la C. 2177 (proyecto de la Cámara de Representantes), el cual también pretendía eliminar el Artículo 16 de la Ley 489, luego de haberse reunido con el liderato comunitario, como éste le solicitó, según un comunicado enviado electrónicamente por la corporación pública. O sea, el fideicomiso de la tierra, como 
mecanismo de defensa contra el desplazamiento urbano, ha estado en amenaza anteriormente. Sin embargo, en esta ocasión, la ley fue firmada.

Respecto al poder legislativo, según un comunicado enviado electrónicamente por la corporación pública, el Senado de Puerto Rico aprobó el P. del S. 365 (proyecto del Senado, previo a convertirse en Ley 32), utilizando el mecanismo de descargue ( $\sin$ vistas publicas y sin solicitar opinión de la comunidad). Añade que, aunque estaba presente un numeroso grupo de líderes comunitarios(as), ya la votación había recién terminado, además de que no hubo debate. Por ende, el liderato comunitario no pudo presentar sus ponencias ante el Senado.

Sobre el poder judicial, fue negada la solicitud de interdicto en el Tribunal Federal en Puerto Rico, la cual luego se obtuvo en los Estados Unidos. Entonces, los intereses de esta comunidad pobre no se consideraron ni fueron incluidos en todo el proceso de decisión que ha afectado directamente a la comunidad y todos sus proyectos para el desarrollo socioeconómico de sus residentes.

A pesar de los problemas que enfrenta la comunidad por su localización a las orillas de un caño contaminado, ésta tiene la gran ventaja de estar excelentemente bien ubicada en San Juan. No sólo está cerca de las vías principales capitalinas, también está cercana al aeropuerto internacional y disfruta de una gran vista a la laguna (véase la Ilustración 5.13). Además, está próxima al centro bancario y empresarial del país. Estas ventajas se vuelven motivos de preocupación para muchos(as) residentes porque temen ser realojados(as) para que las grandes empresas y el gobierno estatal desarrollen proyectos de viviendas y hoteles para la clase alta. Según cuenta una residente, a ella le dijeron en 1974: "Mire, señora. Usted no vive en un arrabal. Vive en una zona turística". De la misma manera, otra persona dijo: "Me preocupa que lo hagan interesante para el turismo". 


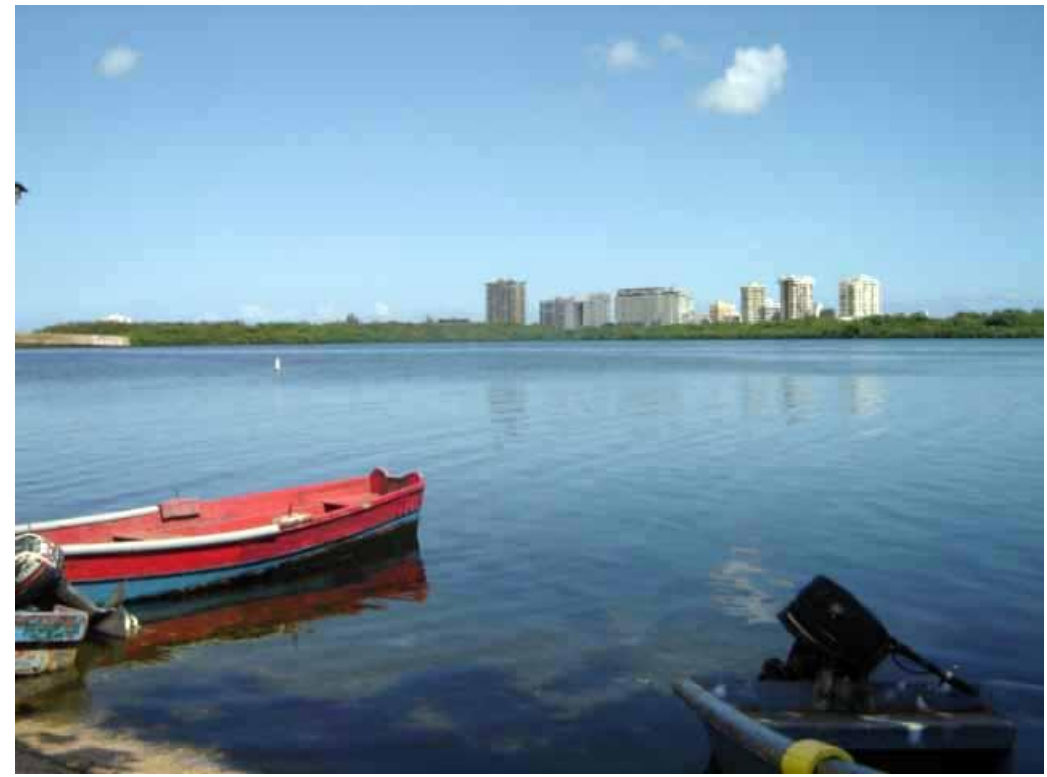

Ilustración 5.13. Vista desde la comunidad a la laguna. Foto de la autora.

Mucho potencial tiene la comunidad para su desarrollo, no sólo está muy bien localizada en San Juan, también sus residentes muestran apego, interés y preocupación por el futuro de su comunidad. Para muchos(as) de ellos(as), el problema es cómo mejorar sus condiciones de vivienda en un lugar privilegiado sin tener que realojarse en un caserío u otro barrio menos céntrico de la ciudad.

Después de más de 80 años de haberse creado esta comunidad, muchos(as) de sus residentes aún esperan ser realojados(as) por los proyectos de desarrollo socioeconómico y ambiental, planificados por el gobierno estatal, y siguen en la incertidumbre sobre el porvenir de sus familias. Posiblemente, esa misma inseguridad sobre sus futuros prevaleció en muchos(as) residentes en las pasadas décadas. También en el presente, hay otros sentimientos que posiblemente hayan tenido pasados(as) residentes, como la desesperación y frustración, al pensar que no se puede detener el proceso de realojo; el desconocimiento sobre los planes para su comunidad y la cólera y el resentimiento hacia el gobierno por querer "sacarlos" de ahí. Además, hay nostalgia por el apego a su comunidad, sobre todo en las personas de edad 
avanzada, quienes fundaron la misma, rellenando sus terrenos y construyendo sus modestas casas. Numerosas familias de tres generaciones han vivido y continúan viviendo en la comunidad, muchas en las mismas viviendas que construyeron sus abuelos y abuelas, pero ahora están hechas en hormigón. Por otro lado, está el temor de ir a vivir a los residenciales públicos, por las experiencias vividas por otros(as) residentes, lo cual podría llevar al rechazo del plan de relocalizarse en nuevos proyectos de viviendas, aunque no sean caseríos. Las actitudes de las personas que residen actualmente en la comunidad hacia el realojo de sus viviendas merecen estudiarse más a fondo.

\subsection{Comunidades especiales}

En el presente, esta comunidad tiene graves problemas sociales, económicos y ambientales, como otras casi 700 que hay en Puerto Rico. Éstas son denominadas como "comunidades especiales" por recibir beneficios de los programas de la Oficina del Coordinador General para el Financiamiento Socio-Económico y la Autogestión, adscrita a la Oficina del Gobernador. Dicha oficina fue creada por la Ley Núm. 1 del 1 de marzo de 2001, como política pública del Estado Libre Asociado de Puerto Rico con la misión de "promover la creación de condiciones que permitan resolver el grave problema de marginalidad existente en las Comunidades Especiales, estimulando la participación activa de sus residentes para el mejoramiento de su calidad de vida" (Oficina de Comunidades Especiales, 2004). Esta oficina define comunidad especial como "un sector de escasos recursos, delimitado geográficamente por el acceso desigual a los beneficios del desarrollo económico y social al que disfrutan otros grupos poblacionales del país" (Oficina de Comunidades Especiales, 2004). Al 2004, había 686 comunidades especiales en Puerto Rico (véase Ilustración 5.14). Según la Oficina de Comunidades Especiales (2004), algunas de las características de estas 
comunidades son altos niveles de deserción escolar y analfabetismo, altos niveles de desempleo y pocas destrezas laborales, problemas sociales (alcoholismo, adicción a drogas y violencia), marginalidad geográfica, problemas ambientales, inadecuados servicios básicos de infraestructura y carencia de sistemas de agua potable y alcantarillado pluvial y sanitario), baja calidad de vida, problemas de seguridad y alto porcentaje de familias y personas viviendo bajo condiciones de pobreza. Todos los 78 municipios de Puerto Rico tienen comunidades catalogadas como "comunidades especiales", pero es de particular interés en esta investigación observar las que están en la región metropolitana, específicamente en San Juan, donde está localizada la comunidad estudiada (véase Ilustraciones 5.15 y 5.16). Sin embargo, esta ley podría ser derogada, afectando a cerca de 2 millones de habitantes en este país. Si eliminaran esta ley, no habría mecanismos, que fomentaran la autogestión ni el apoderamiento de los(as) pobres, creados por la Oficina de Comunidades Especiales, según dijo la ex gobernadora Sila María Calderón (Rivera Marrero, 2010). 


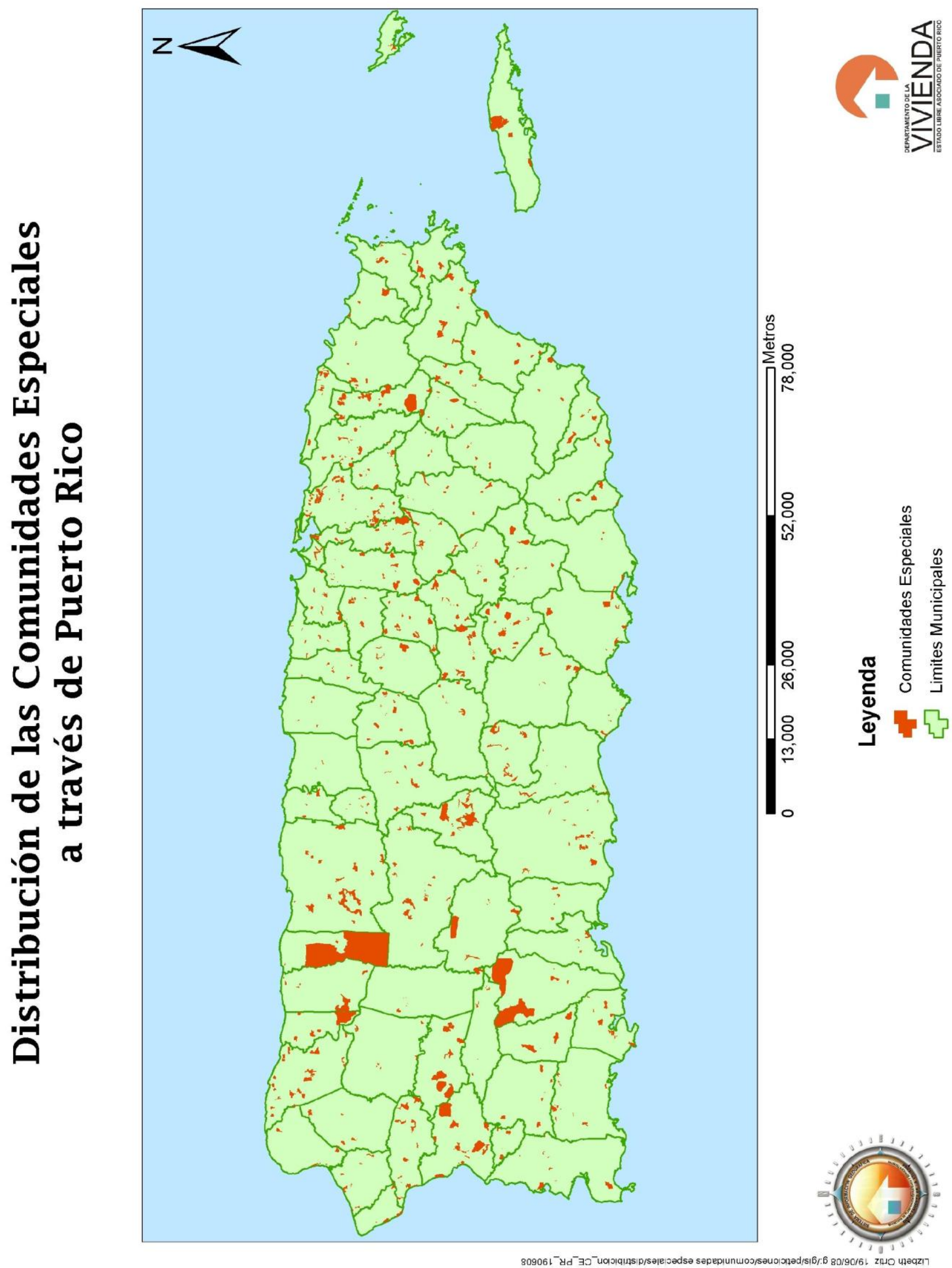

Ilustración 5.14. Distribución de las comunidades especiales a través de Puerto Rico, 2008. Mapa preparado por el Departamento de Vivienda de Puerto Rico. 


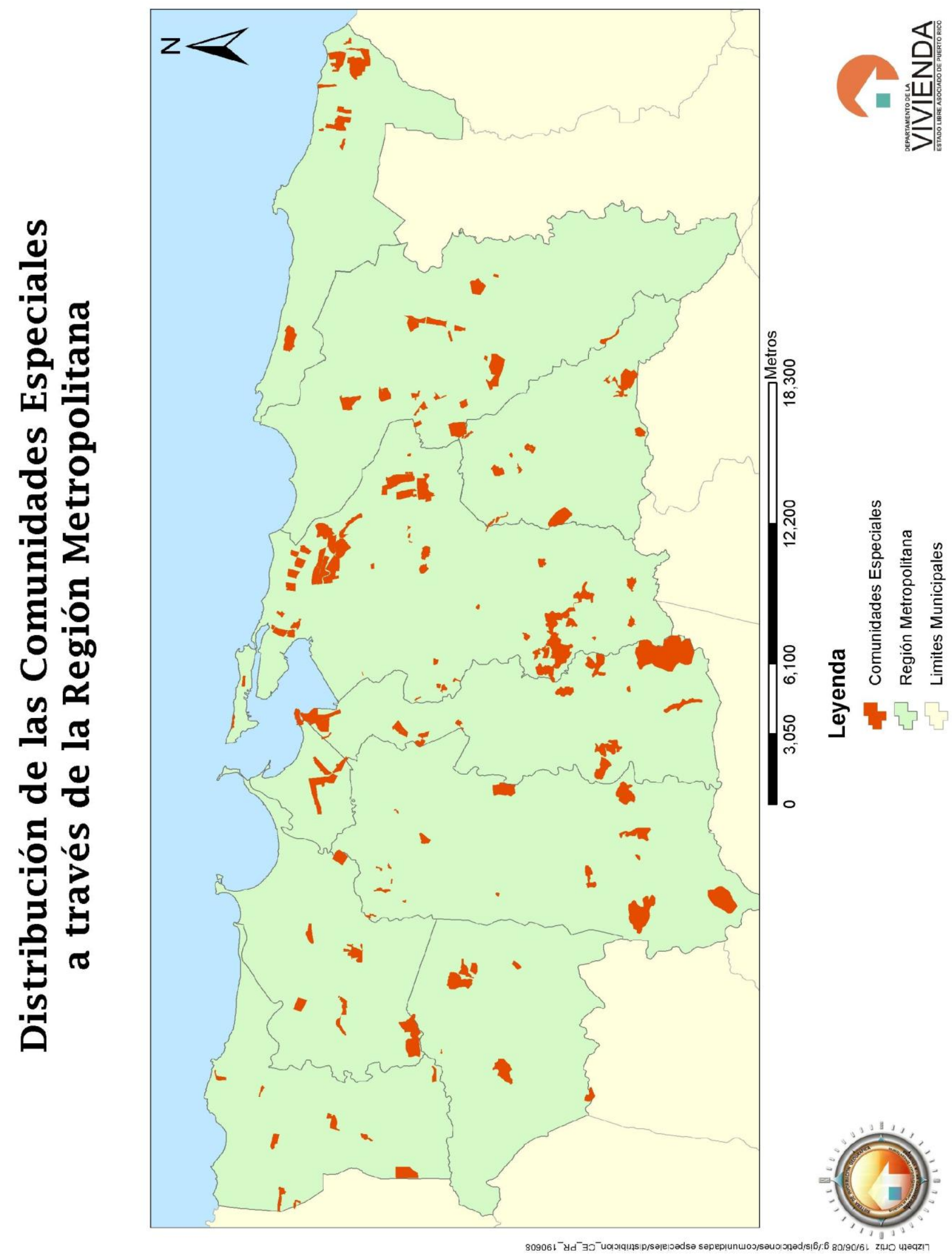

Ilustración 5.15. Distribución de las comunidades especiales a través de la región metropolitana de Puerto Rico, 2008. Mapa preparado por el Departamento de Vivienda de Puerto Rico 


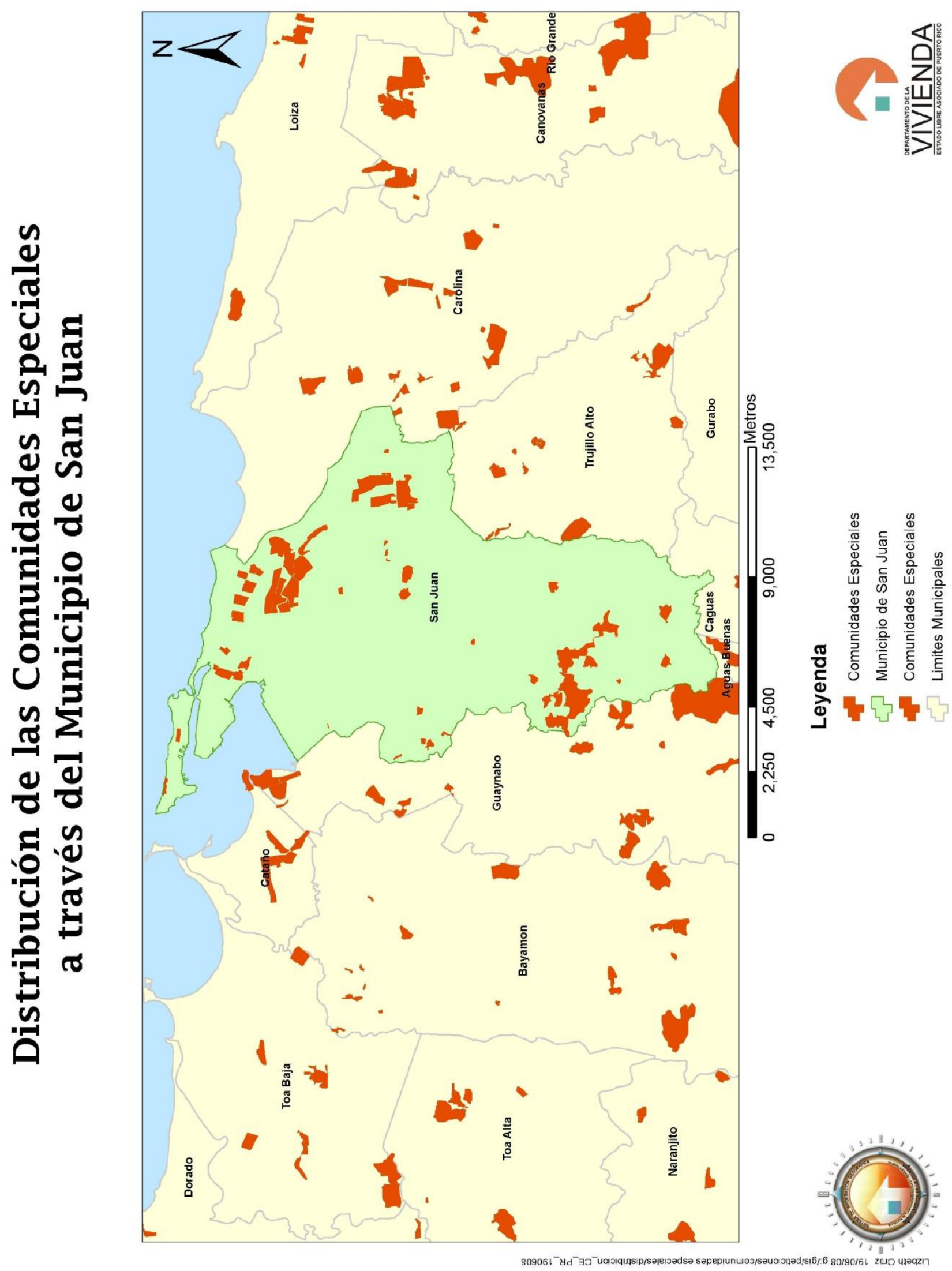

Ilustración 5.16. Distribución de las comunidades especiales a través del municipio de San Juan, Puerto Rico, 2008. Mapa preparado por el Departamento de Vivienda de Puerto Rico. 


\section{Hallazgos sobre actitudes hacia el realojo}

6.1 Actitudes de los(as) residentes a ser realojados(as) y los(as) residentes que ya han sido realojados(as)

Debido a que la mayor diferencia entre las personas a ser realojadas y las ya realojadas es que las primeras no han vivido la experiencia de ser realojadas como las segundas, sospeché que este hecho es un factor principal en las actitudes que tengan sobre dicho proceso. Como las personas realojadas ya vivieron la experiencia del realojo de sus viviendas hace pocos años, tienen conocimientos y vivencias muy particulares que les permiten analizar desde otra perspectiva el proceso de realojo y poder comparar su comunidad de origen y la actual comunidad de reasentamiento. Por lo tanto, pretendí conocer las actitudes de $\operatorname{los}(\mathrm{as})$ residentes, explorando sus impresiones sobre asuntos específicos del proceso de realojo, como la reacción personal y de la comunidad ante la noticia, miedos y comparación con otras comunidades de donde han realojado o realojarán.

6.1.1 Reacción de la comunidad. Los hallazgos documentan una variedad de respuestas de los(as) residentes a ser realojados(as). Para algunos(as) residentes, la comunidad reaccionó tranquilamente, el proceso fue normal y no sorpresivo. Como dijo una mujer de 29 años: "Nadie se sorprendió porque era algo que todo el mundo sabía, que tarde o temprano iba a llegar. Nadie mostró que se haya sorprendido”. Otros(as) residentes señalaron que la reacción fue la resignación y estar a la espera de que llegara el momento o de que les dieran dinero por expropiarle la casa, como dijo una mujer de 68 años: "En la espera de lo que venga. Nadie va a pelear con el gobierno". Otras reacciones comentadas fueron el coraje, el no querer irse porque no estaban de acuerdo, el alarmarse que llevó a llorar y gritar, protesta porque unas personas querían unas casas y otras personas querían otras casas y el no gustarle la 
noticia. Al respecto, una mujer de 56 años dijo: "Sentimentalmente, se afecta porque uno se aferra al lugar donde vive, como ya tú quieres al lugar, llevas muchos años y tú quieres al sitio. Sales libremente, aunque sea malo, que digan que es malo, todo el mundo te conoce y aquí no te va a pasar nada. Tú sales por ahí, no te pasa nada. La gente te conoce. No es como cuando vas nuevo a un sitio, que no te conocen y ahí te puede pasar cualquier cosa. Se unen, hablan, conversan y todo, pero uno tiene las manos, como quien dice, atadas. Porque aunque yo diga: 'yo no me voy', me van a sacar". Además, algunos(as) residentes indicaron que la reacción fue mixta dentro de la comunidad, al explicar que unas personas querían irse ("están locas" o "contentas" por ello), otras no lo han tomado en serio todavía y hay personas que no querían irse. En cuanto a si la comunidad se unió luego de la noticia, muchos(as) residentes dijeron que seguía igual y muy pocos(as) entendían que se había unido.

Por otro lado, los(as) residentes realojados(as) indicaron, en su gran mayoría, que la comunidad reaccionó de manera contenta, muy bien y que deseaban el realojo. Un residente dijo que unos(as) no estaban de acuerdo porque no estaban bien orientados(as) y otros(as) sí lo estaban. También un hombre de 61 años dijo que “después se calmaron porque sabían que iban a un sitio mejor que donde estaban”. Referente a si la comunidad se unió después del realojo, las respuestas fueron mixtas; una mujer dijo que siguió igual y un hombre dijo que había más unidad entre la gente porque se apoyaban.

Entonces, la reacción de la comunidad ante la noticia del realojo, según los(as) residentes a ser realojados(as) y los(as) residentes realojados(as), fue muy variada. Pues, hay residentes a ser realojados(as) que han reaccionado con tranquilidad, otros(as) con resignación y otros(as) con coraje y protesta. También está dividida la opinión sobre si la comunidad se unió luego de la noticia del realojo, ya que unos(as) 
residentes dijeron que eso sucedió y otros(as) residentes indicaron que la comunidad seguía igual.

\subsubsection{Comparación con otras comunidades donde han realojado o} realojarán. Para los(as) residentes a ser realojados(as), el proceso de realojo que vivirán podría ser igual o diferente al de otras comunidades. Entre las razones señaladas por las personas que creían que será igual, destacan que es doloroso porque "nadie quiere que lo saquen de su sitio", como dijo un hombre de 67 años; que siempre son los pobres a quienes sacan de sus casas por razones similares, como construcciones y proyectos, como dijo un hombre; y que no se tomó en cuenta la opinión de la comunidad como le hacen creer porque se hace lo que le convenga al Estado, como dijo una mujer. Otras personas creían que es diferente porque se lleva a cabo por una organización comunitaria, así que "el sistema es diferente", las leyes son diferentes, por lo que darían más dinero que antes. Al respecto, un hombre de 60 años señaló: "Yo vivía en la Parada 26 y hace 42 años a personas, como mi papá, le dieron \$1.000,00 ó \$1.500,00 y los enviaron en caseríos, a Quintana y Las Casas. Creo que va a ser diferente por las leyes. A mí no me van a pagar como en la 26”. Asimismo, un hombre de 66 años opinó: "Yo tumbé casas en Tokío y sé lo que es eso. Antes iba a investigar las casas para sacarlas. [...] Cuando las tumbamos, ya no estaban, ya habían firmado. Mucha gente se quedó en la calle porque lo que le dieron no era suficiente. Es diferente en que están dando un poco más de lo que daban allá. Las casas están carísimas”. Otras personas creían que este proceso de realojo es más lento que los demás porque desde hace mucho tiempo escuchan que los(as) van a realojar. Además, dos personas a ser realojadas dijeron que, al comparar con los realojos de

\footnotetext{
${ }^{4}$ Arrabal de San Juan desaparecido porque sus residentes fueron desalojados(as). En el pasado, esta comunidad estuvo localizada a las orillas del caño, pero ubicada al noroeste de la comunidad estudiada en esta investigación. En la actualidad, esa zona fue desarrollada y hay proyectos de vivienda privada y edificios de oficinas, entre otras estructuras.
} 
comunidades en el pasado, sería peor, como dijo un hombre de 46 años: "Sería mal porque, si es como Tokío, como la 23 Abajo, que informaron que iban a hacer casas, hicieron proyectos millonarios. ¿Beneficios para quién? ¿Para el gobierno? ¿Para la empresa privada? ¿Para los grandes intereses? No vale la pena”. Por otro lado, pocas personas indicaron no saber cómo comparar esos procesos de realojo porque todavía no los habían vivido.

Acerca de los(as) residentes realojados(as), algunos(as) indicaron que no sabían cómo comparar el proceso de realojo que vivieron con otros ocurridos en Puerto Rico y otras personas indicaron que éste es mejor o mucho mejor porque ahora viven mejor que antes o que en otras áreas. Al respecto, un hombre añadió, al comparar con los demás realojos, que en éste no hubo violencia con la policía.

Algunas opiniones de los(as) residentes a ser realojados(as) y de los(as) residentes realojados(as) coincidieron, al comparar el proceso de realojo con otros ocurridos en el pasado en Puerto Rico. Además de las personas que no sabían cómo compararlas, hubo residentes realojados(as) y a ser realojados(as) que entendían que es diferente. Entonces, al comparar las explicaciones de por qué es diferente, las de las personas realojadas se referían a que es mejor por el cambio de la vivienda o el área y las de las personas a ser realojadas se referían a que darán más dinero que antes.

6.1.3 Miedo por la vivienda. La mitad de las personas entrevistadas dijo que no tenía miedo con respecto a su vivienda, ya sea porque se vive con tranquilidad o nunca había tenido problemas con la misma. Sin embargo, dos personas, que dijeron no tener miedo en cuanto a su vivienda, señalaron que tendrían miedo si dragaran el caño viviendo allí todavía. Como dijo un hombre de 66 años: "No tengo miedo porque mientras no hagan el dragado porque se mantiene. Pero, si hacen el dragado, 
me da miedo por la casa. Esto era agua. Lo hemos secado esto aquí" (véase la Ilustración 6.1).

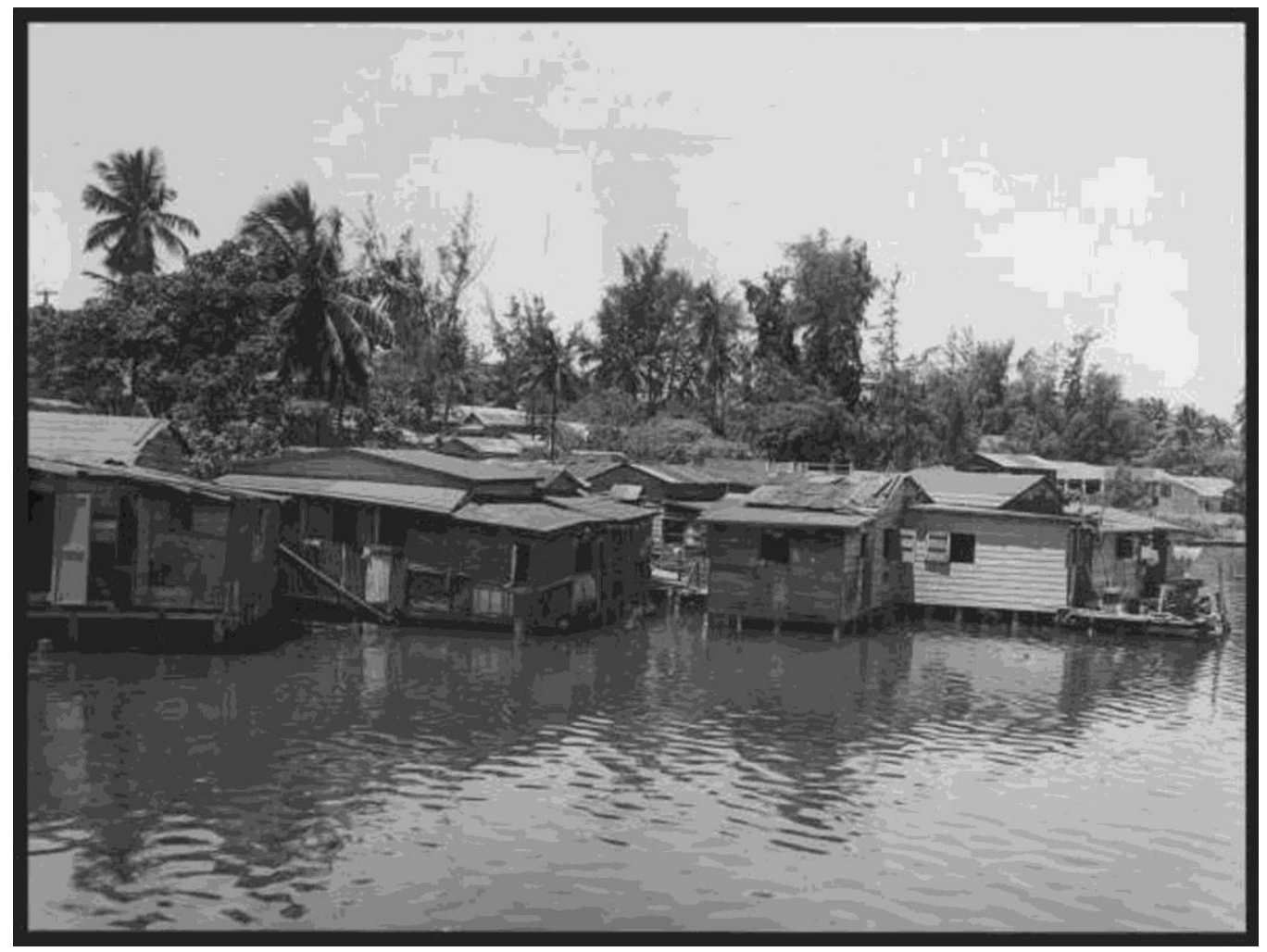

Ilustración 6.1. Vista de la comunidad La Playita en la Laguna Condado en Santurce. 1955. Foto de Mandín Rodríguez. Proyecto de Digitalización de la Colección de Fotos del Periódico El Mundo, Universidad de Puerto Rico, Recinto de Río Piedras.

Asimismo, otro hombre de 60 años dijo: "No tengo miedos, aunque sería que, al destapar el caño contaminado, que suba el nivel del agua. [...] El caño no corre ahora. Desde que están construyendo el puente, el agua se ha podrido. Ahora tiene metano. Muchas personas en $\quad$ tienen cáncer por el caño. Hay días en que no se puede respirar. Mi esposa falleció de cáncer" (véase la Ilustración 6.2). 


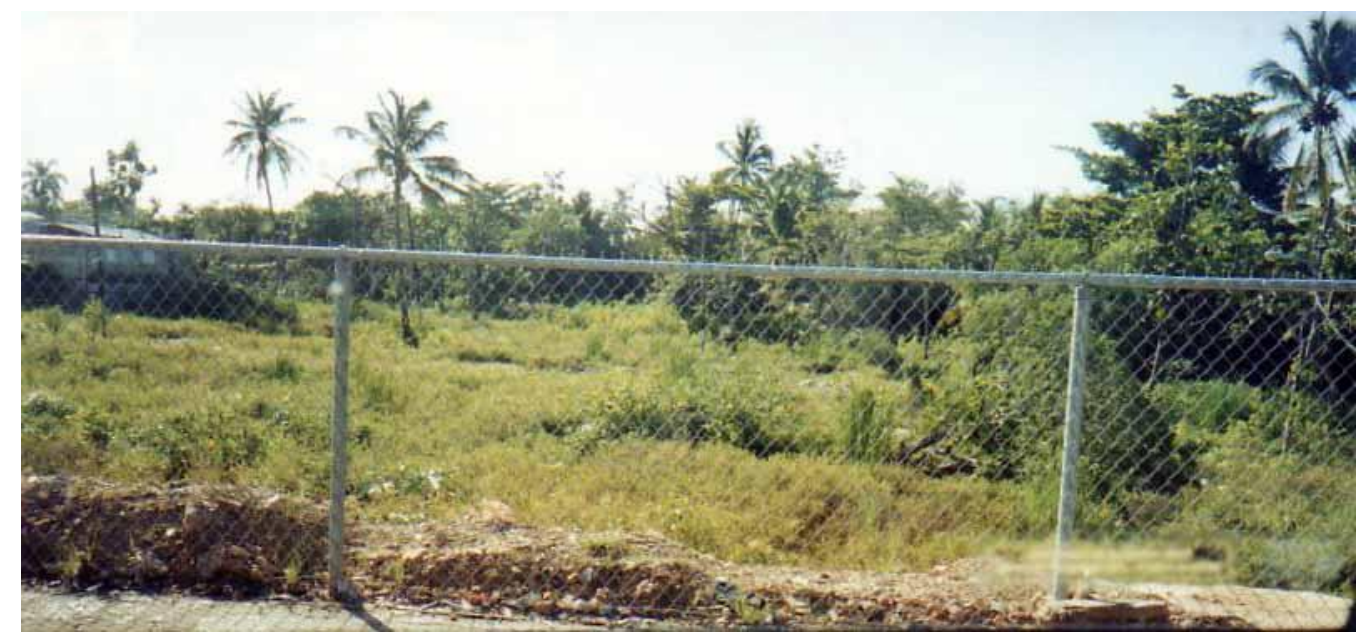

Ilustración 6.2. Área del caño donde antes había viviendas. Foto de la autora.

Por otro lado, la mitad de las personas a ser realojadas dijo que tenía miedo, en cuanto a su vivienda. Sobre los miedos mencionados, algunas personas señalaron que, cuando hay tormentas, huracanes o lluvias, se teme por la vivienda; por las inundaciones que hacen subir la laguna y por la vivienda, si está construida en zinc y madera, que la hace vulnerable al viento, característico de esos eventos atmosféricos. Sobre la subida de la laguna, una residente de mayor edad le preguntó a uno(a) de los(as) empleados(as) de la corporación pública por qué se metía el agua de la laguna y él(ella) le contestó que por varias razones, a saber, sube la marea, el caño está tapado con jacintos y basura y las casas están por debajo del nivel del mar. Por otro lado, otras personas indicaron tener temor, relacionado con el proceso de realojo, como perder su vivienda, el no saber adónde las van a llevar y cuánto les van a pagar por su vivienda y el que les digan sorpresivamente que se tienen que ir, cuando no han salido a buscar vivienda.

Referente a las personas realojadas, la gran mayoría señaló tener miedo, en cuanto a su vivienda pasada, y añadió que era por las tormentas, cuya lluvia podía dañar los enseres y muebles y cuyo viento podía causar daños permanentes al hogar 
("que se fuera, que se la llevara"). También el miedo podía ser por la criminalidad en la antigua comunidad. Por otro lado, la gran mayoría indicó que en la vivienda actual no tenía miedos porque es tranquilo y se siente bien allí, entre otras explicaciones.

Por lo tanto, los(as) residentes a ser realojados(as) y los(as) residentes realojados(as) coincidieron en el temor por la vivienda cuando hay lluvia, tormentas y huracanes. Sin embargo, algunos(as) residentes a ser realojados(as) señalaron un temor que ya no tienen $\operatorname{los}($ as) realojados(as), el relacionado al proceso de realojo, como lo que posiblemente sucederá si dragan el caño y permanecen viviendo allí y adónde irán a vivir.

6.1.4 Miedo por el proceso del realojo. Para casi una tercera parte de las personas a ser realojadas, existe el temor en torno al realojo, específicamente al lugar y la vivienda adónde irán a vivir y si el dinero que les den será suficiente para comprar otra casa. Al respecto, dijo una mujer de 77 años: "Sí. Que no me den una porquería de casa. Que no me vengan a dar suficiente dinero para comprar una casa. No quiero vivir en un caserío, demasiado alboroto". Por otro lado, aproximadamente dos terceras partes de las personas a ser realojadas señalaron no tener miedo al realojo y algunas explicaciones eran que había que enfrentarse a eso, les gustaría que las realojaran a otro sitio mejor y eso no les preocupa. Sin embargo, algunas personas añadieron que eso dependerá de si les dan lo que solicitaron y las especificaciones eran "una casa igual que la que tengo", "si me pagan bien", "que fuera casa por casa", "que me den donde meterme", "casa porque no quiero vivir en caserío y no quiero dinero", "después de que nos consigan casa a mi gusto donde yo quiero, el área que me guste, no donde ellos quieran" y "después que nos pongan a vivir en un sitio que quiero, no hay problema". 
6.1.5 Sentir luego de la noticia del realojo. Varias personas a ser realojadas reportaron reacciones positivas; sus comentarios fueron "magnífico", "no me sentía mal" y "estoy loco por irme de aquí". Estas tres personas que señalaron sentirse de esa manera explicaron que hay que progresar, que al estar cerca del caño uno(a) se puede contagiar con el dengue —enfermedad del trópico, transmitida por un tipo de mosquito, el cual se procrea en agua estancada (véase la Ilustración 6.3) — y que, al hacer un puente sobre el caño, ahora se inunda más.

Sobre las personas que reaccionaron negativamente, sus comentarios fueron "bien mal", "a uno le da miedo, uno se asusta", "mal", "triste", "incómoda" y “preocupación”. Estas personas que indicaron sentirse de esa manera explicaron que ya se está adaptado(a) a un lugar, se lleva muchos años viviendo en la comunidad y está la incertidumbre de qué va a pasar y qué va a hacer.

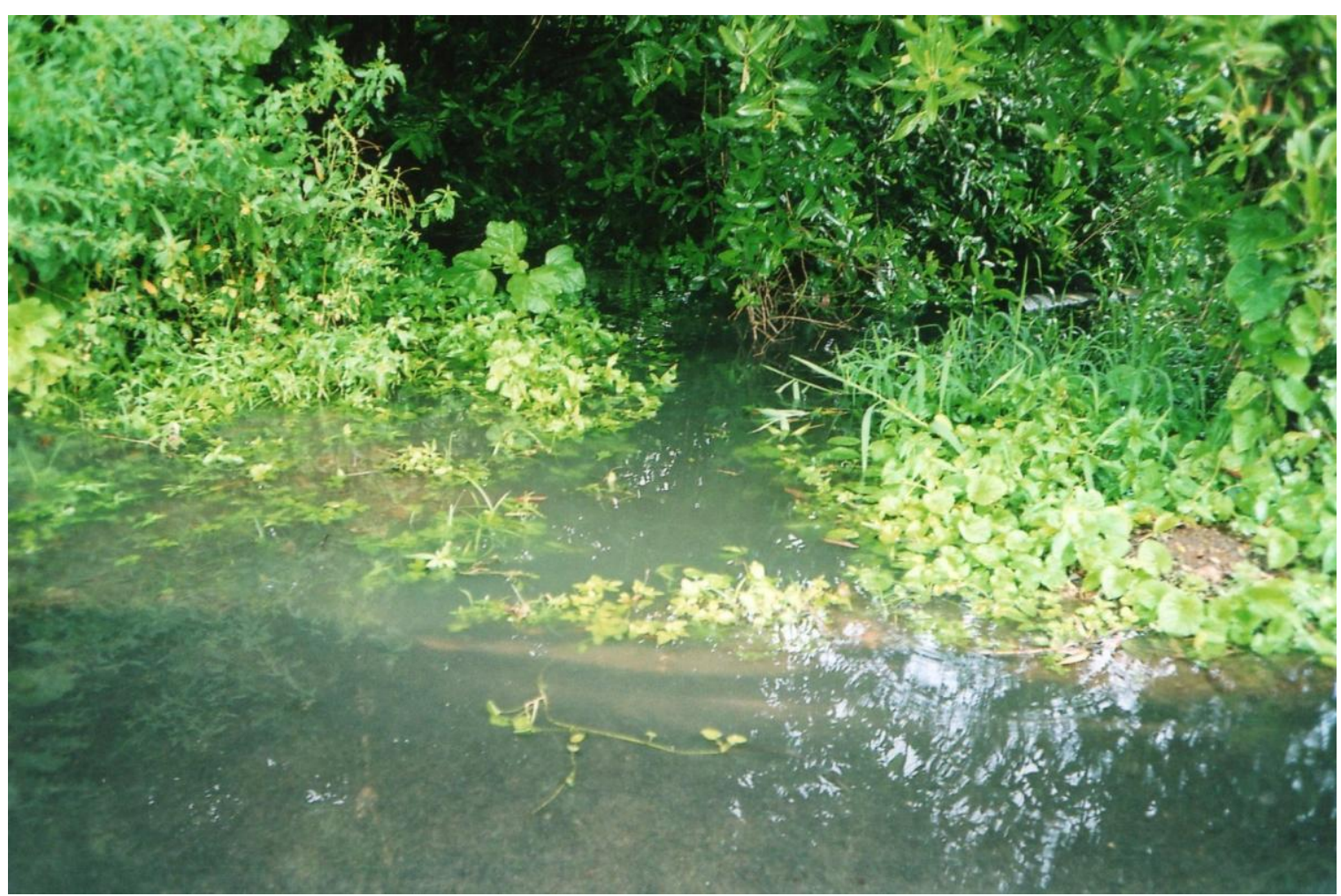

Ilustración 6.3. Agua estancada y desbordada del caño. Foto de la autora. 
En cuanto a las personas que reaccionaron neutralmente, sus comentarios fueron "me da una cosa [igual] que la otra", "lo cogí conforme", "resignada", "no me sentí muy bien ni muy mal", "no me importó" y "raro". Estas personas señalaron sentirse de esa manera porque pueden vivir dondequiera, ya estaban enteradas y conscientes de eso, querían el dinero para irse de allí y las sacarán porque el gobierno quiere el terreno para algo. En resumen, de las 16 personas, 4 indicaron tener una reacción positiva, 6 una reacción negativa y 6 una reacción neutral.

Por otro lado, la gran mayoría de las personas realojadas reportaron sentirse "bien", "contenta", "bien contenta" o "muy feliz", cuando les dijeron que serían realojadas. Estas personas explicaron que se sintieron de esa manera porque tendrían una casa de cemento, tranquilidad y seguridad, ya sabían de la vivienda adonde irían a vivir luego del realojo y, si no lo hicieran, hubieran seguido "allá metido en el agua, allí en la laguna", como dijo un hombre de 61 años. Sólo una persona señaló entristecerse por tantos años viviendo allí, pero por complacer a un familiar, se realojó.

Por lo tanto, son más las personas realojadas que las personas a ser realojadas que indicaron sentirse bien con la noticia del realojo. Además, entre las personas a ser realojadas, hay mayor diversidad de sentimientos y reacciones ante la noticia del realojo.

6.1.6 Proceso de adaptación luego del realojo. Las respuestas de las personas a ser realojadas fueron variadas, ya que la mitad opinó que sería bueno el proceso de adaptación y la otra mitad creía que "va a ser difícil”, "duro", "un poco incómodo" y "lento". En cuanto a las personas que creen que se adaptarán bien, éstas explicaron que no tenían dificultades en adaptarse dondequiera que van y que se mudarían a otra vivienda dentro de la misma comunidad, donde ya conocen gente que 
vive allí. El adaptarse para algunas personas dependerá de si tienen buenos(as) vecinos(as) y si son como ellas, como dijo una mujer. Referente a las personas que creían que no será bueno el proceso de adaptación, éstas explicaron que el haber vivido tantos años allí, el no saber quién será el(la) vecino(a), no saber si se adaptará fácilmente, alejarse de su familia que reside en la comunidad y el empezar a vivir en otro lugar son factores que dificultarían ese proceso. Al respecto, un hombre de 60 años acotó: "No va a ser fácil. Empezar a conocer gente nueva. Aprender lo que hay alrededor, chequear hospitales, supermercado, escuelas, farmacia, transportación pública. No sé”. Por otro lado, hay personas que creían que el proceso de adaptación no será fácil, pero se logrará, como una mujer 56 años que dijo: "Lento, pero uno se adapta. El ser humano se adapta a dondequiera, gracias a Dios. Con una mentalidad adecuada, de sin buscarse problemas con nadie, sin bochinches ni nada de eso. Humildemente".

Entonces, la gran mayoría de las personas realojadas indicaron que el proceso de adaptación fue bueno o muy bueno y explicaron que no habían tenido problemas, comenzaron a tener nuevas relaciones con los(as) vecinos(as), los(as) vecinos(as) se llevan bien y estaban mejor que en la comunidad pasada. Sólo una persona indicó que “por los primeros días una se encuentra rara porque está conociendo a los vecinos, está conociendo el problema de la comunidad, esto y lo otro. Hasta la fecha, todo salió bien porque la vecina de aquí se lleva conmigo, la de acá se lleva conmigo, a veces nos sentamos y hablamos, nos tomamos la tacita de café, esto y lo otro". Sin embargo, hay personas que señalaron dificultad en el proceso de adaptación al vivir en el proyecto de vivienda, como dijo un realojado: "no se educó a los residentes de cómo sería el proceso en sí mismo y cómo serían las viviendas donde iban a ser realojados. Para muchos se les hizo muy difícil ajustarse porque nunca 
habían vivido en condominios. No entienden muy bien el por qué de las cosas. Por ejemplo, se molestan porque no pueden tender la ropa afuera, no pueden dejar los carros donde sea. Hay normas que tienen que seguir pero no las entienden". De la misma manera, otra persona dijo que "a algunos les costó mucho la transición. Pero que eran los jóvenes los que pusieron más problemas, que no querían pagar servicios de comunidad".

6.1.7 Cambio de vida luego del realojo. Les pregunté a las personas a ser realojadas si creían que su vida cambiaría cuando fueran realojadas y a los(as) residentes realojados(as) si creían que sus vidas habían cambiado desde que fueron realojados(as). En cuanto a los(as) residentes a ser realojados(as), la mitad creía que su vida cambiaría porque viviría mejor al no tener que caminar por agua cuando llueve y al estar tranquilo(a) o más tranquilo(a). Otras explicaciones fueron que sería como volver a empezar al vivir en un sitio nuevo y que "no va a ser lo mismo. Después de tantos años en un lugar, irse a otro", como dijo un hombre de 67 años. Por otro lado, una cuarta parte de las personas a ser realojadas dijo que su vida permanecería igual. Pero una mujer especificó que no cambiará, excepto en transportación pública, porque depende de ella y necesita un sitio que esté bien comunicado. La cuarta parte restante no sabía si su vida cambiaría luego del realojo, pero podría depender de cómo fuera el proceso; como dijo un hombre de 46 años: "Si me voy contento, voy a irme positivo. Si me voy enojado es porque no me pagaron bien la casa. Pues, voy a irme incómodo, en contra de mi voluntad y no sería justo de que no tendría beneficios y que uno se quede como clase media abajo”.

Por otro lado, la gran mayoría de las personas realojadas creían que sus vidas habían cambiado desde que fueron realojadas porque tienen una "mejor vida", están "más cerca", sus vehículos están seguros y antes sus hijos siempre estaban con asma. 
Otra explicación la da un hombre de 50 años: "En general, es tranquilidad, es limpieza de comunidad. En ornato, en socialización, compartimos más, belleza de comunidad, de estructuras y áreas verdes y comunidad, en general, y amistad. Ahora somos más amigos que cuando estábamos allá porque estamos más cerca que antes”.

\subsubsection{Lo que esperan de la comunidad futura.}

6.1.8.1 Sentido de comunidad. Poco más de una cuarta parte de los(as) residentes a ser realojados(as) no sabía si tendría el mismo sentido que su comunidad actual; pero, como dijo una mujer de 56 años: "Espera una que así sea. Pero, si no es así, ni modo. ¿Qué va a hacer uno?” Asimismo, una mujer de 68 años dijo: "Puede ser porque a veces uno piensa que aquí está bien, pero puede ser que haya un sitio que sea igual o mejor. No sé. Puede ser un sitio mejor o igual". Una cuarta parte de las personas a ser realojadas creía que no tendría el mismo sentido de comunidad que ésta porque son demasiados años viviendo allí, no se sabe si "sería otro tipo de comunidad o peor", como dijo un hombre de 60 años, y no tendrá los(as) mismos(as) vecinos(as) ni estará con su familia. Una cuarta parte de los(as) residentes a ser realojados(as) creía que tendría el mismo sentido o deseaba que así fuera porque esperaba que estuvieran sus vecinos(as) actuales, que las familias seleccionadas para vivir en el proyecto de vivienda tuvieran el mismo estilo de vida pasivo y se quedaría en el mismo sitio, sólo cambiaría de terreno.

En cuanto a las personas realojadas, más de la mitad creía que donde vivía tenía el mismo sentido de comunidad que de donde fueron realojados(as) porque entendían que había unión y cooperación. Al respecto, un hombre de 50 años dijo: "Sí. Pero, ahora se siente más comunidad, más unidad".

Aunque hay diversidad de opinión sobre si la comunidad de reasentamiento tendrá o tiene el mismo sentido que la comunidad de origen, la gran mayoría de 
los(as) residentes realojados(as) creían que tenían el mismo sentido de comunidad, contrario a una cuarta parte de las personas a ser realojadas que creían así sería.

\subsubsection{Lo que le faltaría o le falta a la comunidad. Las respuestas} son variadas porque hay personas que creían que le faltaría algo, otras que no le faltaría nada y algunas que creían que tal vez le faltaría algo a la nueva comunidad. En cuanto a $\operatorname{los}($ as) residentes a ser realojados(as) que creían que a la nueva comunidad le faltaría algo, en comparación con la comunidad donde estaban residiendo actualmente, éstas señalaron que le faltarán los(as) vecinos(as), las amistades, el ambiente y, como dijo una mujer de 56 años, se "pierde el calor humano que hay, el cariño. Todas esas cosas que hay cuando tú vives mucho tiempo en un sitio. Mira que te lo digo yo y se me salen las lágrimas". Los(as) residentes que creían que no les faltaría nada explicaron que harían nuevas amistades y, como dijo un hombre de 54 años, "lo que perderá es lo malo, por reglas implantadas, que está bien para la comunidad". Acerca de los(as) residentes que creían que tal vez le falte algo, una mujer de 29 años piensó que tal vez se pierda la unidad y "el sentido de ayuda mutua y que tú puedes confiar en mí y yo puedo confiar en ti y que, si tú tienes un problema, yo te ayudo, y yo tengo un problema, tú me ayudas". Asimismo, otra mujer de 40 años dijo: "Puede ser. Tú sabes. Son tantos años. La comunidad. Muchas cosas que hemos vivido aquí desde chiquitos. Hasta ahora uno no va a conseguir eso en otro sitio que uno vaya. Por lo menos, yo he hecho una vida aquí, como uno dice". Por otro lado, para algunos(as) realojados(as), a la comunidad donde fueron realojados(as) les falta un parque, una cancha y una biblioteca electrónica; el resto opinó que no le falta nada en comparación con la comunidad donde vivían antes.

Entonces, los(as) residentes a ser realojados(as), que creían que le faltará algo, señalaron a $\operatorname{los}($ as) vecinos(as), amistades, calor humano y cariño; mientras que, 
los(as) residentes realojados(as), que creían que le falta algo, especificaron instalaciones recreativas y educativas, como cancha y biblioteca electrónica. Por lo tanto, los(as) realojados(as) se enfocaron en aspectos estructurales de su proyecto de vivienda (véase la Ilustración 6.4).

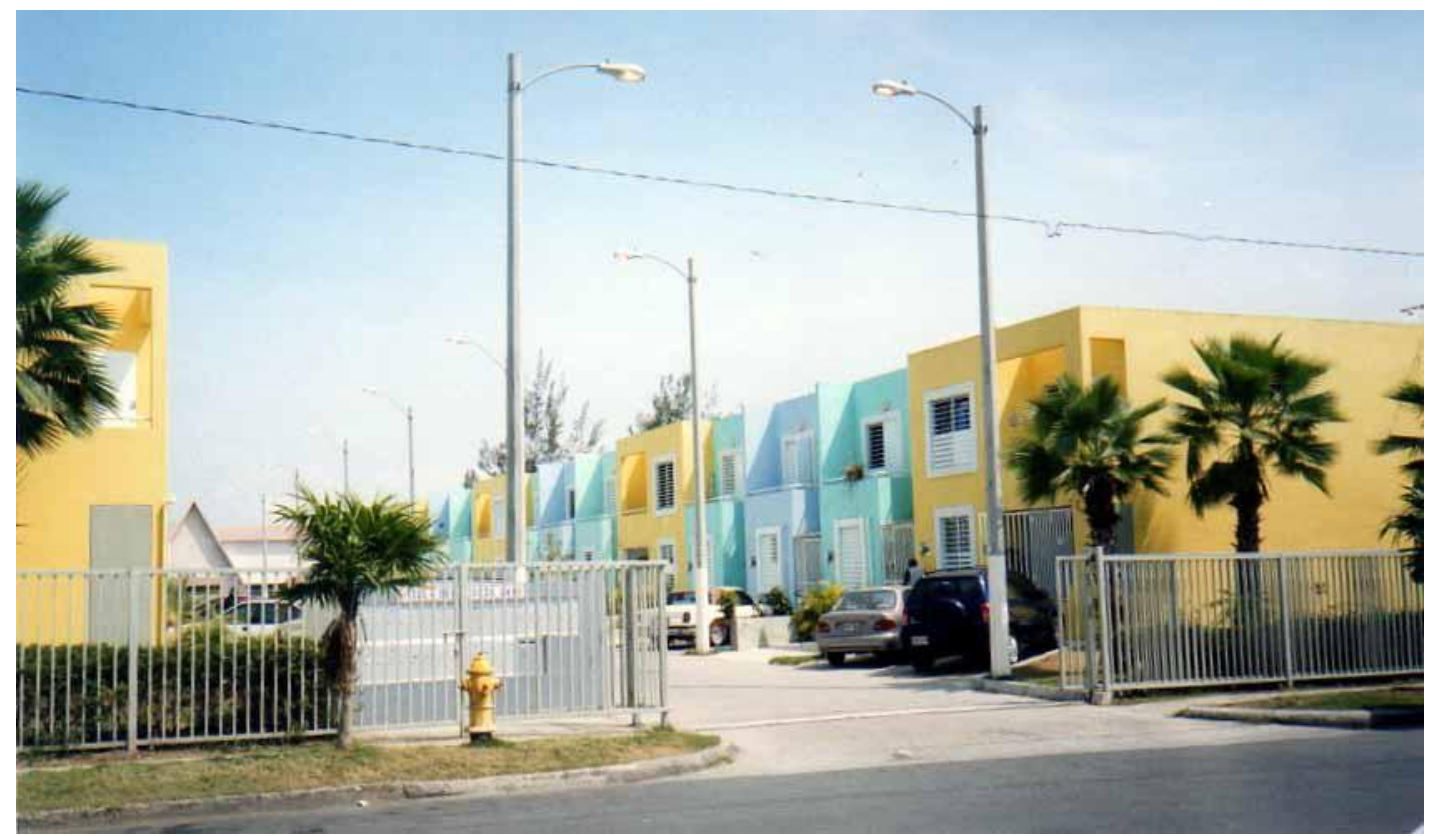

Ilustración 6.4. Uno de los proyectos de vivienda de la comunidad. Foto de la autora.

6.1.8.3 Lo que ganaría o ha ganado la comunidad. Por otro lado, les pregunté a las personas a ser realojadas si creían que la comunidad de reasentamiento ganaría algo en comparación con la de origen. Al respecto, algunas personas creían que ganará algo, otras que no ganarán nada y algunas que no sabían si ganará algo en comparación con la comunidad donde están residiendo.

En cuanto a los(as) residentes a ser realojados(as) que creían que ganará algo la nueva comunidad, éstos indicaron que será más tranquila porque no tendrá tanta drogadicción ni tanta criminalidad, tendrá supermercado y mejores casas, no habrá inundaciones y "la calidad de vida, al vivir organizadamente, en cuanto al espacio. Eso de callejones, zinc", como dijo un hombre de 45 años. Además, una mujer de 29 
años dijo que se ganará en cuanto al modo económico y añadió: “Una vez nos mudemos a un lugar, a un edificio más bonito, pues ya nos estimularemos en comprar cortinas más caras, unos muebles más bonitos porque ya no vivimos en , allí metidos en el caño. Estamos en un lugar más preciso. El carro lo cambiamos para que estemos a tono con los demás y todo este tipo de cosas se mejorarían”. Sobre los(as) residentes a ser realojados(as) que no sabían si la nueva comunidad ganará algo, una mujer de 77 años dijo: "No sé decir. Dicen que el sitio lo hace uno". Un hombre de 46 años comentó: "No sé porque vamos a invadir a otro terreno donde las personas ya están establecidas. No se sabe”. Entre las personas que creían que no ganará algo, una mujer de 47 años opinó que sería "lo mismo porque esta área es tranquila".

Todos(as) los(as) residentes realojados(as) creían que el proyecto de vivienda donde estaban viviendo ganó algo en comparación con el vecindario anterior de donde fueron realojados(as). Mencionaron que se había ganado comodidades, un buzón donde recibir las cartas, seguridad, belleza, más unión y cercanía entre los(as) vecinos(as), quienes comparten y se ayudan mutuamente, un mejor ambiente y mejor calidad de vida. Otra diferencia fue señalada por una mujer de 73 años: "Es mejor que allá porque aquí te tiras y no se te enfangan los pies. Allá cuando llovía tenía que quitarme los zapatos, salir afuera, tirarme un paño para secarme los pies y ponerme los zapatos otra vez". Asimismo, comentó una persona realojada que donde vivía antes tenía que salir en chancletas y con los zapatos en las manos por las inundaciones.

Por lo tanto, los(as) residentes coincidieron en la calidad de vida como la diferencia entre la comunidad de origen y la comunidad de reasentamiento. También coincidieron en el aspecto de las inundaciones que ya no ocurren en la nueva 
comunidad y que las personas a ser realojadas desean que no ocurran donde vayan a vivir.

6.1.9 Características de la comunidad deseada. A los(as) residentes a ser realojados(as) les pregunté cómo deseaban que fuera la comunidad adonde irían a vivir y sus respuestas se enfocaron en las características de los(as) demás residentes y del lugar. En cuanto a los rasgos de las personas, los(as) residentes a ser realojados(as) deseaban que fueran buenos(as) vecinos(as), que aportaran y que se llevaran bien, como una familia, personas amigables, tranquilas y que se ayudaran mutuamente y que la gente fuera parecida como la de su comunidad actual o que sus vecinos(as) actuales siguieran siendo sus vecinos(as) en la otra comunidad. Sobre las características de la comunidad, los(as) residentes deseaban que esa comunidad fuera tranquila, sin problemas, que se viviera en comunidad todos(as) juntos como en familia, cómoda, segura, con instalaciones recreativas (baloncesto y pelota [béisbol], particularmente), que todo estuviera cerca, como la escuela y las paradas de autobús público, y sin inundaciones. Otro deseo es el de un hombre de 54 años: "Que se mantenga en buenas condiciones, que vecinos aporten, que se mantenga balance y organización, que una casa no esté peor que la otra". Entonces, esta persona deseaba que hubiera homogenización socioeconómica en la comunidad.

\subsubsection{Comentarios sobre los proyectos de vivienda por las personas} realojadas. Es posible que las actitudes de los(as) residentes a ser realojados(as) estén influidas por lo que les han contado de los proyectos de vivienda, construidos para las personas que ya han sido realojadas. A poco menos de la mitad, le contaron sobre esos proyectos y de cómo se vive. Entre los comentarios escuchados por los(as) residentes a ser realojados(as), se destacan los relacionados a las cualidades físicas de los proyectos de vivienda y el sentir de las personas ya realojadas a esas viviendas. 
Respecto a las características físicas de los proyectos, los(as) residentes a ser realojados(as) habían escuchado que son bonitos, están bien, se convive allí, son buenos y que los apartamentos son como walkups (bloques cerrados de vivienda). En cuanto a las personas realojadas, habían escuchado que a unos(as) le ha ido bien, algunos(as) tienen que pagar, hay personas que no están contentas, están bien las personas a quienes les dieron casa porque es difícil adaptarse a un edificio, hay personas contentas porque tienen privacidad donde residen en la actualidad y que, aunque son dueños(as) de la casa, no pueden tomar sus propias decisiones. Sobre este último comentario, según una empleada de una organización comunitaria, se pueden hacer cambios a la fachada de la propiedad de tipo horizontal, como color, rejas y ventanas, con la autorización de la junta de residentes reunidos en asamblea. Añadió que, de esta manera, se es uniforme en los cambios a las viviendas, para evitar lo que ha pasado en otros proyectos de viviendas, como las cooperativas. Otros proyectos que en el pasado han dejado de ser uniformes en sus fachadas son los residenciales públicos (caseríos), en los cuales sus residentes ponían rejas con estilo de su preferencia y pintaban el interior del balcón (puerta, paredes y/o rejas) a su gusto, afectando la imagen general del edificio.

A los(as) residentes realojados(as), les pregunté cómo comparaba el proyecto de vivienda con la comunidad de origen y todas las respuestas indicaron mejorías. Las diferencias mencionadas fueron que en la comunidad anterior subía la laguna a las casas, había que cargar los paquetes de la compra por largas distancias, caminar bastante para llevar la basura y había "borrachos, tiros, gente indeseable"; mientras que en el proyecto de vivienda no sube la laguna, no hay que caminar mucho para llevar la basura ni para llegar a la casa con los paquetes de la compra y no se ven 
"borrachos, tiros, gente indeseable". Como dijo un hombre de 50 años: "Es mucho mejor".

6.1.11 Aspectos que agradan y desagradan del proyecto de vivienda. También es importante saber qué les agrada y desagrada de esta nueva comunidad a las personas realojadas porque posiblemente influyen en sus actitudes hacia el realojo, ya que al haber experimentado un cambio de residencia, se tiene los conocimientos para poder evaluar el proceso que vivieron. Los(as) realojados(as) mencionaron que de esta nueva comunidad les agradaba estar cerca de su antigua comunidad, de todo y de paradas de transportación pública y hay "menos garata y pelea". Además, otro aspecto que agradaba es el estilo de vida, como dijo una mujer de 73 años: "El modo de la comunidad vivir, que todo el mundo vive en su casa y, si uno necesita del vecino, es servicial porque nos podemos ayudar unos con los otros". Sobre aspectos que desagradaban de la nueva comunidad, la gran mayoría dijo que no había. Pero les desagradaba a algunas personas realojadas que no hubiera patio ni entretenimiento para jóvenes; pagar mantenimiento, cuando antes no pagaban; y que se tapara la tubería y se desbordaran las aguas servidas.

6.1.12 Regreso a la comunidad. A los(as) residentes a ser realojados(as), les pregunté si regresarían a su comunidad y, a los(as) residentes realojados(as), les pregunté si habían regresado a la antigua comunidad. Más de la mitad de los(as) residentes a ser realojados(as) desearía regresar a la comunidad para vivir, a ver lo que han hecho y cómo ha cambiado y de paseo para visitar a vecinos(as) y familia. Por otro lado, poco menos de la mitad indicó que no regresaría a la comunidad porque no se va a poder ("no voy a tener adónde", "si me sacaron, no puedo volver", "va a estar desolado como un desierto", “esto va a desaparecer”). Sin embargo, dos mujeres especificaron que podrían regresar, si no les dan una vivienda como la que tienen o 
que construyan casas para vender. Todas las personas realojadas dijeron que habían regresado a su antiguo vecindario, ya sea para visitar a la familia o ver a los(as) vecinos(as) y el área donde vivían. Dos mujeres mencionaron que donde vivían no es igual que antes porque está deteriorado, abandonado o han crecido árboles y maleza (véase la Ilustración 6.5). Por lo tanto, los(as) residentes a ser realojados(as) y residentes realojados(as) coincidieron en el deseo de regresar a la comunidad para visitar familias y amistades y ver cómo está el área donde antes vivían.

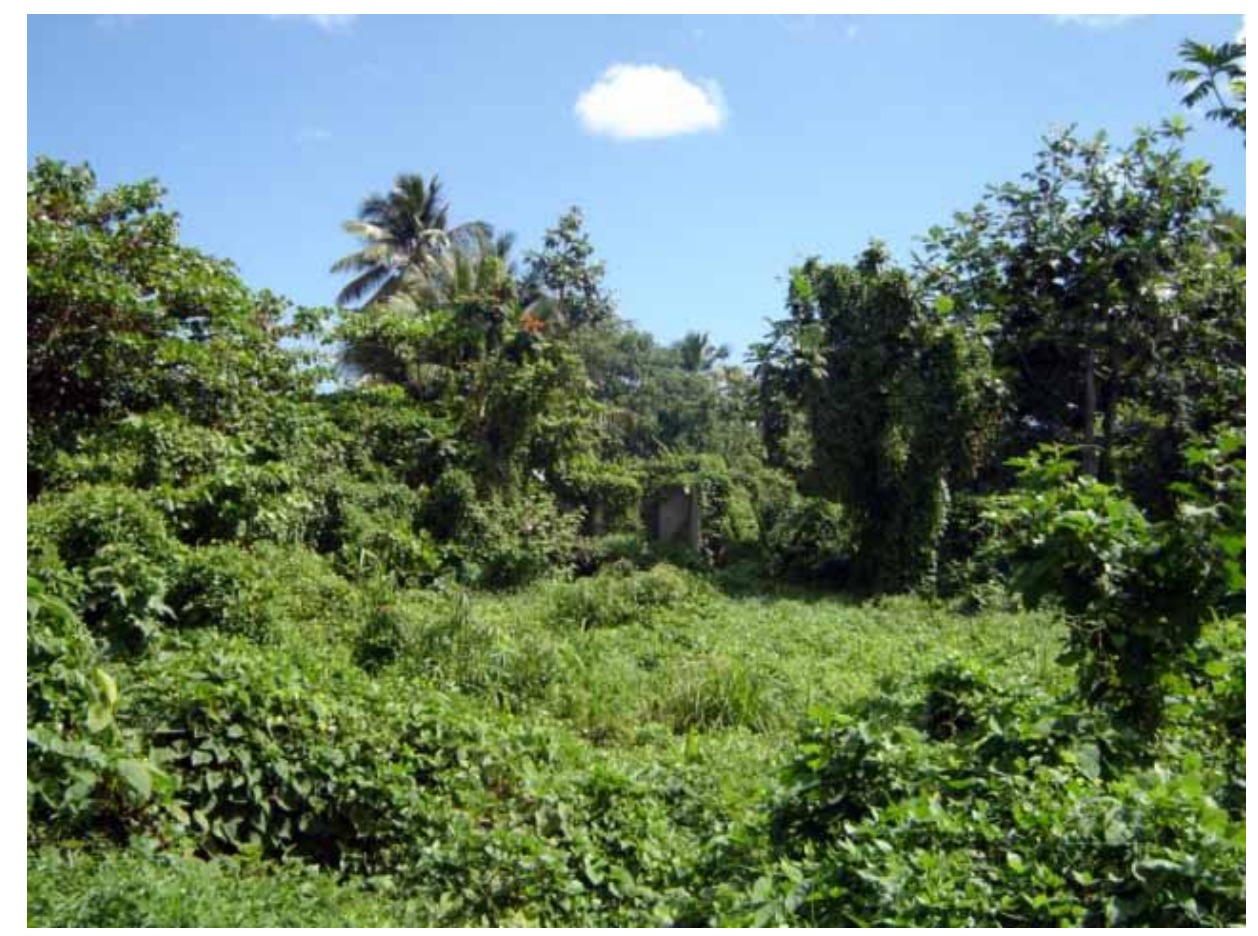

Ilustración 6.5. Árboles y maleza donde antes había viviendas. Al centro se ve una estructura de cemento, que pudo haber sido una vivienda. Foto de la autora.

6.1.13 Extrañar la comunidad. A las personas a ser realojadas les pregunté qué extrañarían de su comunidad luego de que fueran realojadas. La gran mayoría de las personas entrevistadas explicaron que extrañarían a su gente, ya sean algunos(as) o todos(as) sus vecinos(as) y amistades, por su forma de ser, porque son buenos(as) y son como familia, entre otros señalamientos. También indicaron que echarían de 
menos la casa, especialmente su accesibilidad; instalaciones como la escuela, el colmado y el "negocito de billar"; la tranquilidad, la familia y la unión de la comunidad. También algunas personas indicaron que extrañarían los bochinches y las peleas.

Por otro lado, a las personas realojadas les pregunté qué extrañaban de su pasada comunidad y 2 de 5 personas dijeron que nada. Como dijo un hombre de 50 años: "Nada. Dejamos todo lo malo". Las demás personas indicaron que echaban de menos la casa, los cultivos de tubérculos (batata) y vegetales (pana) y "la tiendita de la vecina". En resumen, las personas a ser realojadas y las realojadas coincidieron en mencionar la casa y el colmado, como lugares entrañables de su comunidad.

6.1.14 Comparación de su comunidad con el resto de San Juan. Además, les pregunté cómo compara su comunidad con el resto de San Juan y la gran mayoría de las personas a ser realojadas dijeron que es diferente. Se destaca la opinión de que la comunidad es más tranquila que el resto de San Juan porque en esta ciudad hay mucho bullicio y problema. Un hombre de 60 años añadió: "Diferente porque no hay tanta violencia como afuera: choques, escalamiento". Otras diferencias mencionadas fueron que en San Juan hay mucho turista y que la comunidad es buena y magnífica. Otra diferencia es el diario vivir dentro de la comunidad, como dijo una mujer de 68 años: "No es como el resto de San Juan. ¿Cómo puede comparar con lugares que sean de casas nuevas? No son comparables. Aquí hay que luchar cada día". Otra diferencia es la que mencionó un hombre de 54 años, quien dijo: “Está en progreso. Es muy progresista, en comparación con el resto de San Juan. El proyecto se ha preocupado por echar esto para adelante. Hay más comunidades como esta, pero no creo que estén trabajando como esta. Si consiguieran gente como la de aquí, podrían salir adelante". 
Entre las personas que opinaban que la comunidad es igual que el resto de San Juan, destacan dos explicaciones. Una de ellas vinculó el residir en un lugar con estatus social, como dijo una mujer de 29 años: "Igual. Como vivimos en estatus social, que para muchos es el bajo, pero para mí es el medio, pero vivimos en un estatus social donde la gente piensa: ‘¡Ay! ¡Estás en el caño! ¡Pobres niños! ¡Pobre juventud!' Pues, pensaría que estamos mal, pero realmente yo no siento que tengamos nada que envidiarle a nadie que viva en ningún lado. Así que considero que estamos igual o hasta mejor que mucha gente porque estamos en un tiempo donde el vecino no se recuerda que tú vives ahí”. La otra explicación compara la comunidad con otras que en el pasado se han eliminado. Como señaló una mujer de 56 años: "Yo creo que casi siempre todas las comunidades son casi todas iguales para mí. Sí. Montones se han eliminado, pero ha habido muchas comunidades. Tokío, una barriada grande, y la eliminaron".

Asimismo, la opinión de las personas realojadas está dividida sobre cómo compara su comunidad con el resto de San Juan. Los(as) realojados(as) que creían que es igual dijeron que se está cerca de todos los sitios (“a un paso, para todo"), hay criminalidad y "hay partes que uno pasa y están feas". Por otro lado, las personas que indicaron que es diferente dijeron que en la comunidad hay privacidad porque el proyecto de vivienda no es abierto y el vivir ahí es muy bueno.

Las actitudes de los(as) residentes hacia el realojo de sus viviendas son diferentes entre las personas a ser realojadas y las personas realojadas porque las primeras no han tenido todavía la experiencia de ser realojadas como las segundas. Entonces, la manera de pensar de los(as) residentes a ser realojados(as) difiere de los(as) realojados(as) en cuanto al miedo por su vivienda, qué le falta o le faltaría a la comunidad de reasentamiento y cómo se compara el proceso de realojo de otras 
comunidades donde han realojado o realojarán. Por otro lado, sus actitudes son similares cuando tratan los asuntos del deseo de regresar a la comunidad de origen, extrañar a la comunidad y lo que ha ganado o ganaría la comunidad de reasentamiento.

\subsubsection{Comparación de las actitudes hacia el realojo por género y edad.}

6.1.15.1 Actitudes hacia el realojo por género. Al comparar las actitudes hacia el realojo de los(as) residentes afectados(as) por éste entre las personas del género masculino y femenino, encontré similitudes y diferencias. Ambos géneros son similares en cuanto a las dudas sobre el proceso de realojo (si darán dinero o casa), el deseo de estar cerca de sus familiares luego del cambio de residencia, el tener buenas relaciones con sus vecinos(as) y su actitud sobre el realojo. Al respecto, ambos géneros creían que el gobierno $\operatorname{los}($ as) sacará porque éste hace lo que le conviene y esta situación les afecta porque quieren el lugar y allí se sienten tranquilos(as) y seguros(as).

Sin embargo, ambos géneros no coincidieron en cuanto al proceso de adaptación luego del realojo, las características de la comunidad deseada y las cualidades de las personas pobres. Para el género femenino, la adaptación es posible con humildad y actitud pacífica y adecuada, mientras que el género masculino se enfoca en que la adaptación depende de la experiencia durante el proceso de realojo y en que no será fácil porque hay que conocer gente nueva y las instalaciones alrededor. Sobre la comunidad deseada, el género femenino anhelaba un lugar bien comunicado, con buen sistema de transportación pública, mientras que el género masculino deseaba una comunidad, donde los(as) vecinos(as) aporten y haya un balance y organización. En cuanto a las cualidades de las personas pobres, para el género femenino, son aquéllas que tienen dificultades para conseguir vehículo y casa y proveerles educación 
a sus hijos(as), mientras que los del género masculino pensaban que los(as) pobres son aquéllos(as) que no tienen sentimientos; no tienen hogar y no viven en urbanización y trabajan, por lo que no pueden recibir beneficios del gobierno.

\subsubsection{Actitudes hacia el realojo por edad. Al explorar las} similitudes y diferencias entre las personas menores de 60 años y las de 60 años y más, hallé que sus actitudes son similares en algunos aspectos. Sobre la adaptación en la comunidad de reasentamiento, ambos grupos creían que no iba a ser fácil porque significaba comenzar a vivir en un lugar nuevo. Respecto a las dudas, desconocen el tiempo que falta para el realojo. En cuanto a lo que agradaba de la comunidad de reasentamiento para las personas realojadas, ambos grupos de edad coincidieron en que la relación con sus vecinos(as) es mucho mejor porque están más cerca y siguen siendo serviciales. También ambos grupos señalaron su miedo y renuencia a vivir en un residencial público. Sobre lo que pensaban del realojo planificado, las personas menores de 60 y las de 60 años y más dijeron que, aunque no quieran, el gobierno las va a sacar a la buena o la mala porque contra éste nadie va a pelear, además de que el gobierno saca a los(as) pobres, para hacer proyectos que le beneficien.

Sin embargo, ambos grupos tienen definiciones distintas sobre las características de los(as) pobres. Al respecto, el grupo de personas no viejas tenían opiniones diversas señalando que, entre la gente pobre, hay personas sin sentimientos, buenas y humildes y a quienes se les hace difícil conseguir las cosas. Mientras tanto, las personas viejas se enfocaron en definir a la persona pobre como la que no es de clase media y vive en una comunidad pobre, contrario a una urbanización.

Entonces, hay mayores diferencias en actitudes por género que por edad, ya que el género masculino y el femenino opinaron de forma distinta sobre el proceso de adaptación posterior al realojo, cualidades de la comunidad a donde desean ser 
realojados(as) y las características de los(as) pobres. Sin embargo, de manera general, independientemente del género y la edad, las personas afectadas por el realojo tenían miedos y dudas sobre el proceso porque no saben cuándo será, si les darán dinero o casa, si el dinero será suficiente para comprar otra casa, si tasarán bien su vivienda y si serán mudados(as) a un residencial público, adonde no quieren ir. También se sentían impotentes ante el gobierno y sus planes de sacarlos(as) porque son pobres, para aprovechar sus tierras con el propósito de construir proyectos millonarios, de los cuales sólo el gobierno y las empresas privadas se beneficiarán. Además, sus vecinos(as) son muy importantes para los(as) residentes porque son considerados(as) como familia y su presencia hace que se extrañe la unidad, ayuda mutua, cariño y cordialidad de la comunidad de la comunidad de origen y deseaban que la comunidad de reasentamiento tenga personas así.

\subsection{Proceso de realojo desde la perspectiva de los(as) residentes afectados(as)}

Como el proceso de realojo es el evento de estudio en esta investigación, había que explorar cómo es el mismo, desde la perspectiva de los(as) residentes afectados(as). Sospeché que aspectos muy específicos de este proceso, como las preocupaciones, dudas, preferencias de lugar a vivir, sugerencias y experiencias pasadas de realojo o desalojo son elementos importantes, para entender las actitudes de las personas. También pretendí conocer en detalle los aspectos técnicos del realojo para saber por lo que han pasado los(as) residentes realojados(as), ya que estas experiencias, sean positivas o negativas, modifican sus actitudes sobre el realojo y lo que le comentarían a las personas aún sin realojar que, a su vez, podrían afectar sus ideas y sentimientos en cuanto al cambio de residencia.

6.2.1 Manera en que informaron sobre el realojo. Sobre la manera en que fueron informados(as) los(as) residentes a ser realojados(as), una tercera parte señaló 
que les avisaron personalmente. Además, cerca del 26\% indicó que se informó en reuniones de comunidad y el $20 \%$ se informó por medio de una carta entregada personalmente. Por otro lado, la mayoría de los(as) realojados(as) fueron informados(as) cuando le dijeron personalmente y el 14,3\% fue informada por una carta entregada personalmente. Entonces, para ambas muestras, la manera de informar con mayor porcentaje fue una visita a su vivienda por parte de un(a) representante de la corporación pública, la organización comunitaria o de una agencia gubernamental.

6.2.2 Año en que informaron sobre el realojo. Debido a que muchos(as) de los(as) residentes han comentado que desde hace tiempo se escucha que serán realojados(as) por el gobierno, pregunté el año en que fueron informados(as) para tener más información al respecto. Poco más de la mitad de las personas a ser realojadas fue notificada entre el 2004 y el 2007. También observé que el porcentaje de personas informadas aumenta, a medida que aumenta el año. Además, la mediana de año en que fueron informados(as) es 2004. Según información provista por la corporación pública encargada del realojo, los(as) residentes a ser realojados(as) fueron informados(as) en el 2003. Por lo tanto, la mediana de 2004 se aproxima a la fecha oficial presentada por la corporación pública.

Respecto a las personas realojadas, la mitad indicó haber sido informada entre el 2000 y el 2003. Además, su mediana es el 2000.

6.2.3 Agencia u organización que informó sobre el realojo. En referencia a la agencia u organización que informó a las personas a ser realojadas, cerca de una tercera parte fue notificada por la corporación pública que coordina distintos proyectos en la comunidad, como el dragado del caño. En orden relativo, los(as) residentes a ser realojados(as) mencionaron una organización comunitaria (26,7\%), no sabe $(15,6 \%)$ y un individuo o particular $(11,1 \%)$. Es importante recalcar estas últimas 
dos respuestas porque podrían implicar una posible confusión o desconocimiento en algunos(as) de sus residentes sobre el proceso de realojo. Sobre todo, hay que prestar atención cuando las personas son informadas por particulares, como vecinos(as), familiares o propietarios(as) de las viviendas que están alquilando porque existe la posibilidad de que se esté proveyendo información incompleta o errónea. Entonces, si la persona está confundida, desconoce o tiene información incorrecta sobre el proceso de realojo, esto podría influir sobre las actitudes que tenga sobre el mismo.

Respecto a las personas realojadas, la inmensa mayoría fue informada por una organización comunitaria. Hay que resaltar que en el proceso de información se ha trabajado en equipo, cuando representantes de las agencias estatales, la corporación pública y las organizaciones comunitarias han ido a las viviendas de los(as) residentes a informar sobre el realojo.

6.2.4 Motivo del realojo. La gran mayoría de los(as) residentes a ser realojados(as) indicaron que el motivo del futuro realojo de sus viviendas es el dragado del caño (véase la Tabla 6.1). Además, el 6,7\% de las personas a ser realojadas mencionó que el motivo es otro, como construir proyectos caros, sacarlos(as) para hacer hoteles y beneficiar a acaparadores(as) e inundaciones. Debido a que la comunidad está localizada al lado de dos de las avenidas más transitadas en San Juan y está cerca del aeropuerto internacional, la zona turística y la zona bancaria en la ciudad capital, hay residentes que comentaron haber escuchado y/o creer que serán realojados(as), para desarrollar el área con propósitos lucrativos para el gobierno y/o empresas privadas. Por otro lado, para casi la mitad de las personas realojadas, el motivo es el dragado del caño y para cerca del $24 \%$ es otro, como inundaciones y construcción de bomba de alcantarillado sanitario. 


\section{Tabla 6.1}

Motivo del realojo, según los(as) residentes a ser realojados(as) y los(as) residentes realojados(as)

\begin{tabular}{lcc} 
Motivo & $\begin{array}{l}\text { Residentes a ser } \\
\text { realojados(as) }\end{array}$ & $\begin{array}{c}\text { Residentes } \\
\text { realojados(as) }\end{array}$ \\
\hline Dragado del caño & 78,9 & 47,6 \\
Construcción del puente & 2,2 & 4,8 \\
Arreglos de infraestructura & 5,6 & 9,5 \\
Proyecto comunitario & 2,2 & 4,8 \\
Otro & $6,7 *$ & $23,8 * *$ \\
No sabe & 4,4 & 4,8 \\
Ninguno & 0,0 & 4,8 \\
Total & 100,0 & 100,0 \\
& $(90)$ & $(21)$ \\
** Incluye inundaciones y construcción de bomba de alcantarillado sanitario. & \\
nunca dirán la verdadera razón y sacarnos de aquí y hacer hoteles. & \\
\hline
\end{tabular}

También hay personas en la comunidad que creían que el realojo se debía a que el gobierno y la empresa privada estaban interesados en el terreno que secaron y lo hicieron habitable luego de rellenarlo. Como dijo un hombre de 57 años: "Ahora que está seco, todo el mundo los quiere. Nos tienen marginados. Esto está desde el 1940 y algo”. Asimismo una persona preguntó: “¿Necesitan todo este espacio? Cuando mi papá y mamá vinieron, todo esto era agua. La misma gente rellenó y secó 
y ahora el gobierno lo quiere, quiere el terrenito que hizo la gente". Igualmente, un residente dijo:

El motivo del realojo es otro. Que no se esté tomando en consideración a los residentes, sino otro intereses. Con el dinero que les darán, no va a dar para comprar casas. El y todo el área del caño es un lugar bien ubicado. Hay avenidas, luz, agua, teléfonos, cable TV, acceso a distintas formas de transportación pública. Es un lugar conveniente. Están haciendo arreglos al sistema de alcantarillado que será por succión, han arreglado la cablería del teléfono. Han estado haciendo mejoras que suben el valor del área sin que la gente se de cuenta. Lo que está detrás de esto es poder comprar los terrenos por precios baratos para construir viviendas caras (walkups caros) que se beneficiarán de las mejorías al barrio y de la localización. Que no se menosprecie los esfuerzos de los fundadores obreros que vinieron de los campos y fueron rellenando para secar la laguna.

6.2.5 Preocupaciones. Entre las preocupaciones que tenían los(as) residentes a ser realojados(as), las de mayor porcentaje eran la fecha en que ocurriría $(24,4 \%)$, el valor de la tasación de la vivienda $(20,0 \%)$ y otra, como adónde irían, las opciones de vivienda, los pagos de agua y electricidad en las viviendas adonde serían realojados(as) y el no querer irse $(16,7 \%)$ (véase la Tabla 6.2). Por otro lado, entre las preocupaciones que tenían las personas realojadas, las de mayor porcentaje eran el pago por la nueva vivienda $(28,6 \%)$ y otras de índole diversa, como las inundaciones, la situación de vivienda en aquel momento, la falta de educación sobre el proceso de realojo y el entender que no había razón para mudarse (23,8\%). Además, el 23,8\% de las personas realojadas no tenía preocupación alguna, contrario a 12,2\% de las personas a ser realojadas. 


\section{Tabla 6.2}

Mayor preocupación sobre el proceso del realojo de los(as) residentes a ser realojados(as) y los(as) residentes realojados(as)

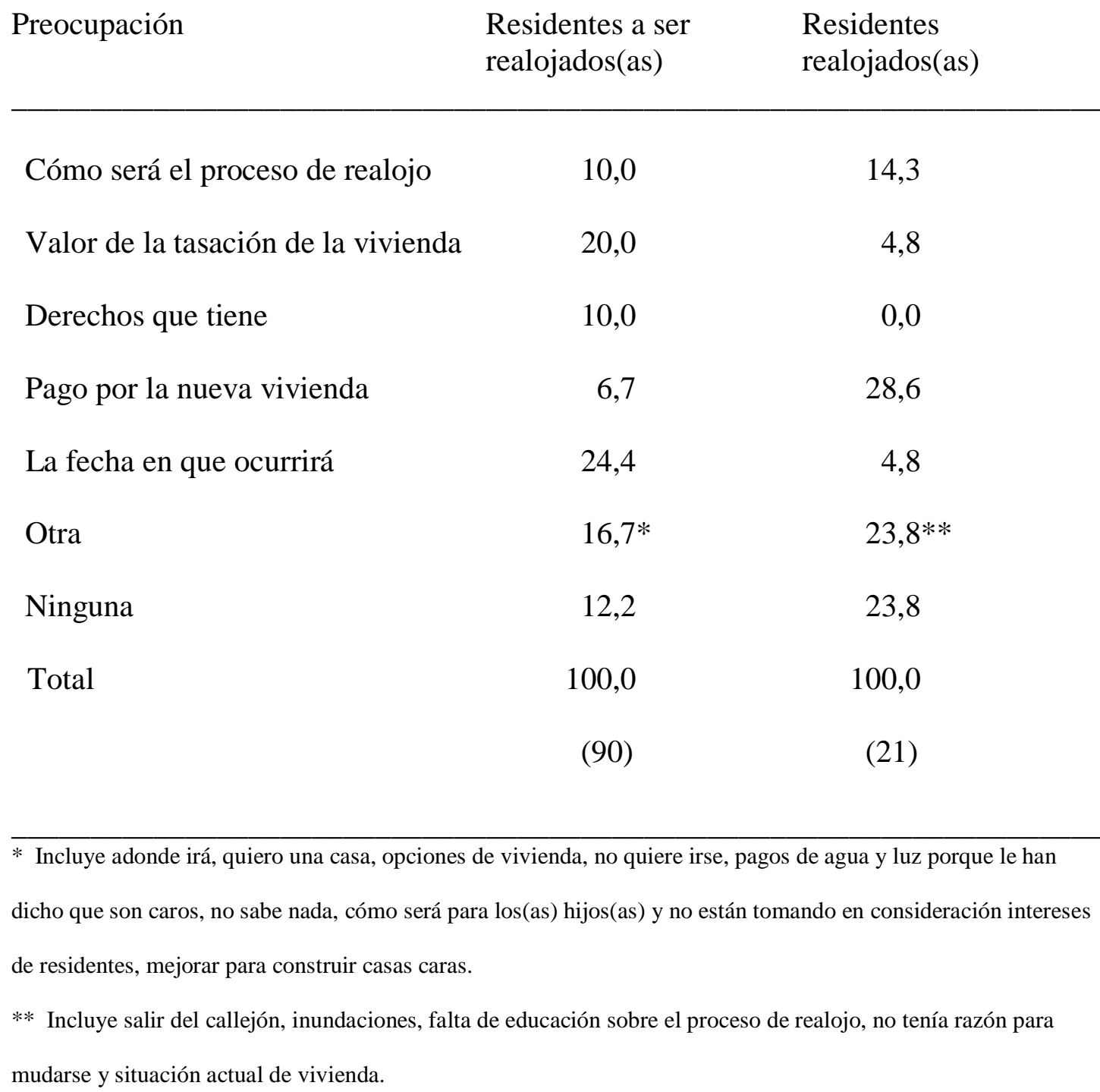

En referencia a las personas realojadas y sus preocupaciones sobre el proceso de realojo, más de la mitad señaló que esa preocupación desapareció después de mudarse. Sin embargo, el 37,5\% de los(as) realojados(as) indicó que su preocupación no desapareció, ya que hay que pagar los servicios y la cuota de mantenimiento en la nueva vivienda, la laguna sigue tapada, todavía está en proceso de adaptación y se iría si le dieran otro lugar a donde ir. 
6.2.5.1 Preocupación por el realojo y percepción de la comunicación con la organización. Para las personas a las que les preocupaba cómo sería el proceso de realojo, la mitad calificó la comunicación con la organización como regular o mala (véase la Figura 6.1). En cuanto a las personas preocupadas por los derechos que tenía, cerca de 7 de cada 10 percibieron la comunicación como regular o mala. Sobre los(as) residentes con la preocupación de cuándo ocurriría el realojo, cerca de 4 de cada 10 calificaron la comunicación con la organización como regular. Entre las personas que no tenían preocupación sobre el realojo, poco más de la mitad la calificó como excelente o buena.

\section{Figura 6.1. Percepción de la comunicación con la organización por mayor preocupación} sobre el realojo de los(as) residentes afectados(as)

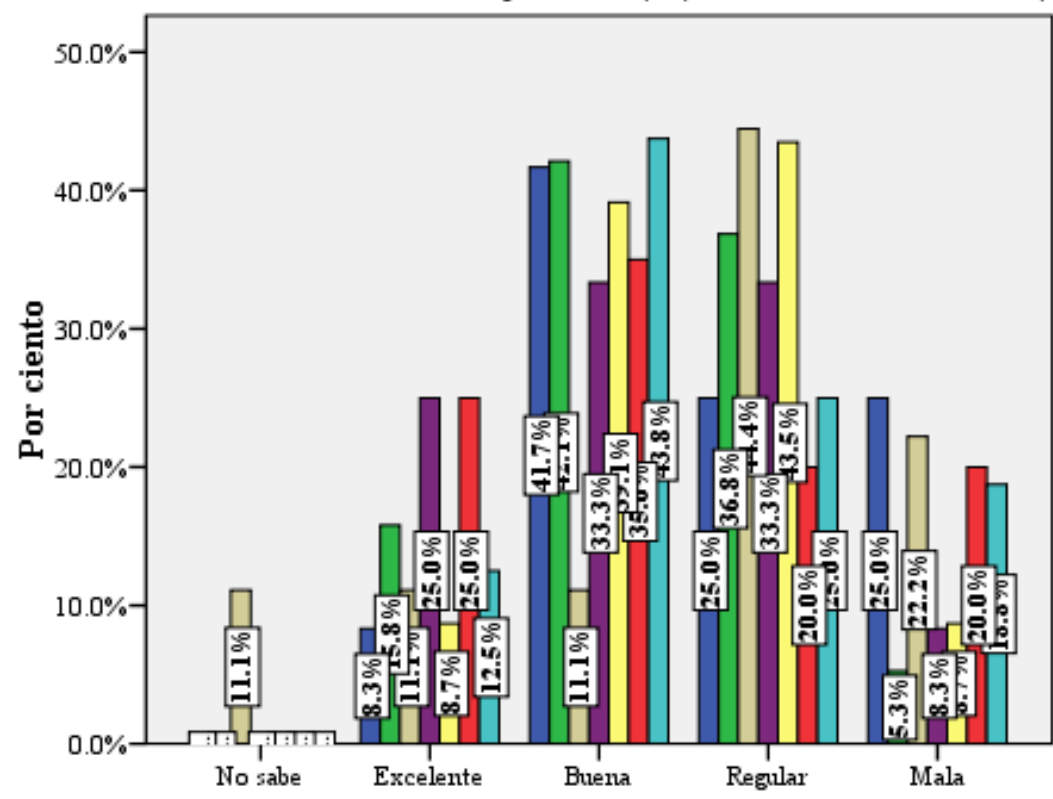

Percepción de la comunicación con la organización

Otra mayor preocupación incluye adonde irá; quiero una casa; opciones de vivienda; no quiere irse; pagos de agua y luz porque le han dicho que son caros; no sabe nada; cómo será para los(as) hijos(as); no están tomando en consideración intereses de residentes; mejorar para construir casas caras; salir del callejón; inundaciones; falta de educación sobre el proceso de realojo; tenía razón para mudarse; y situación actual de vivienda.

6.2.5.2 Preocupación por el realojo y años de estudio. Tres de cada 4 personas preocupadas por cómo sería el proceso de realojo tenían un grado de escuela secundaria o universidad (véase la Figura 6.2). Entre las personas preocupadas por el 
valor de tasación de su hogar, la mitad tenía un grado de escuela elemental y de escuela secundaria. Entre los(as) residentes preocupados(as) por los derechos que tiene, cerca de 7 de cada 10 tenían escuela secundaria o un grado universitario. En cuanto a las personas preocupadas por el pago de la nueva vivienda, cerca de 7 de cada 10 tenían un grado de escuela intermedia o menor. Entre las personas preocupadas por la fecha en que ocurrirá, cerca del $70 \%$ tenía un grado de escuela intermedia o secundaria. Y entre las personas que no tenían preocupación alguna sobre el realojo, más del 30\% tenía un grado universitario y más de un 30\% tenía un grado de escuela elemental.

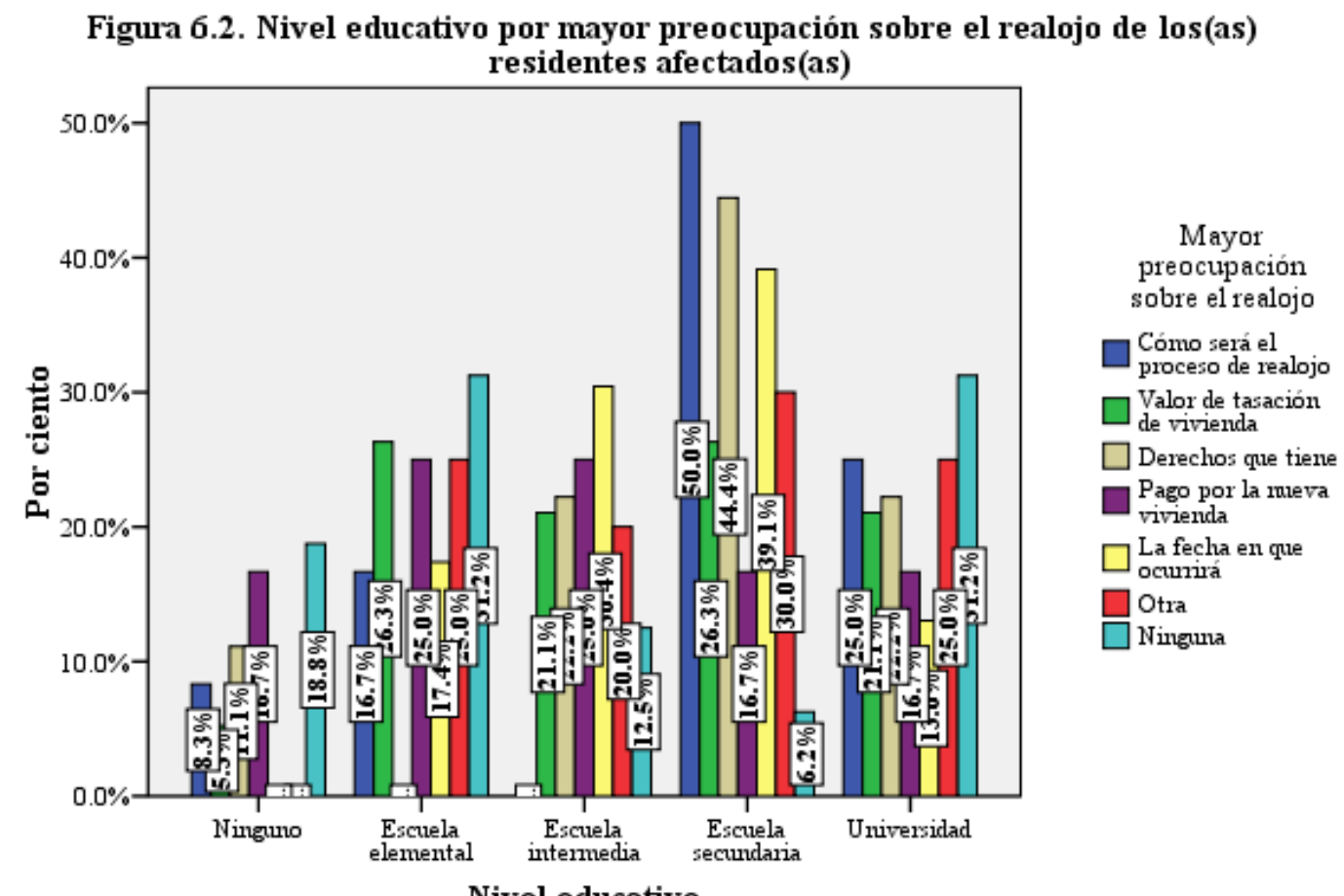

Otra mayor preocupación incluye adonde irá; quiero una casa; opciones de vivienda; no quiere irse; pagos de agua y luz porque le han dicho que son caros; no sabe nada; cómo será para los(as) hijos(as); no están tomando en consideración intereses de residentes; mejorar para construir casas caras; salir del callejón; inundaciones; falta de educación sobre el proceso de realojo; tenía razón para mudarse; y situación actual de vivienda.

6.2.6 Preferencias de lugares a vivir. Sobre el tipo de vivienda, entre las personas a ser realojadas, la mayoría prefería una casa, ya sea propia, terrera, de concreto o madera, en el campo o urbanización y/o con patio o sola (véase la Tabla 
6.3). Además, el $18,9 \%$ mencionó que tenía otra preferencia, como parcela ${ }^{5}$, comunidad de personas de edad avanzada, que no fuera en edificio, en sitio tranquilo y en el área metropolitana. También el 6,7\% quería quedarse en sus viviendas actuales.

Por otro lado, entre las personas realojadas, aproximadamente el $43 \%$ prefería una casa, idealmente con patio e independiente (individual), aunque algunas personas describieron otras casas, como en una parcela en el campo, de un nivel (terrera), en cemento y/o que fuera segura antes los huracanes (véase la Tabla 6.3). Además, el 23,8\% de las personas realojadas señaló que prefería una vivienda horizontal, como donde están viviendo en la actualidad, y el 19,0\% no tenía preferencia alguna.

\section{Tabla 6.3}

Preferencia en cuanto al nuevo lugar donde vivir de los(as) residentes a ser realojados(as) y los(as) residentes realojados(as)

$\begin{array}{lll}\text { Preferencia } & \begin{array}{l}\text { Residentes a ser } \\ \text { realojados(as) }\end{array} & \begin{array}{l}\text { Residentes } \\ \text { realojados(as) }\end{array}\end{array}$

Tipo de vivienda

No tiene

Casa

Vivienda horizontal

Apartamento
65,6

0,0
19,0

14,3

(tabla continúa)

\footnotetext{
${ }^{5}$ Según el Departamento de la Vivienda (2008), una parcela es un predio de terreno de un área no menor de un cuadro ni mayor de tres cuerdas que se le otorga por medio de sorteo a las familias interesadas que habitan en los residenciales públicos o que participen del Programa de Subsidio de Renta bajo la Sección 8, que reúnan los requisitos de elegibilidad para acogerse al Programa de Distribución y Administración de Parcelas o Solares para Vivienda bajo el Título V de la Ley de Tierras de Puerto Rico.
} 


$\begin{array}{lll}\text { Preferencia } & \begin{array}{l}\text { Residentes a ser } \\ \text { realojados(as) }\end{array} & \begin{array}{l}\text { Residentes } \\ \text { realojados(as) }\end{array}\end{array}$

Indiferente

Quedarse donde está

Otra

Total

Ubicación

Dentro de comunidad

Fuera de comunidad

Sin especificar

No tenía preferencia

Total

* Incluye lo que diga su madre, cómoda, no edificio, parcela, sitio tranquilo, igual o mejor a la que tiene, en el área metropolitana y sitio donde pueda vivir bien, comunidad de viejos(as).

Un comentario que refleja la impresión que se tiene de los proyectos de vivienda que lleva a la preferencia de una casa es el de este(a) residente:

será como caserío cualquiera". O sea, aunque cerca de 2 de cada 5 preferían mudarse a una casa, tomaron la decisión de realojarse en un proyecto de vivienda.

En cuanto a la ubicación, fue difícil determinar si el tipo de vivienda que preferían estaba dentro o fuera de la comunidad, debido a que no había alternativas a escoger por ser una pregunta abierta. Sin embargo, al comparar los porcentajes de las 
categorías dentro y fuera de la comunidad, la categoría con mayor porcentaje es la correspondiente a dentro de la comunidad.

Respecto a los(as) residentes realojados(as) y sus preferencias de lugares a vivir, poco más de la mitad sintió que pudo satisfacer esa preferencia. Sin embargo, el $41,2 \%$ de las personas realojadas no se sintió satisfecho y las explicaciones fueron que no tenían patio $(28,6 \%)$, querían casa $(28,6 \%)$ y otras $(42,9 \%)$, como que esa vivienda era la única alternativa a escoger, por 5 años no pueden hacer alteraciones a la vivienda y que no podían hacer algo porque, habiendo seleccionado otro proyecto, les dieron esa vivienda. Esta última razón presentada es preocupante porque podría indicar confusión en el(la) residente sobre los documentos que llena o información provista por él(ella) y/o representante(s) de la organización encargada del realojo. Debido a que en el 2002, se llevó a cabo un censo en el que se preguntó su preferencia por un tipo de vivienda, existe la posibilidad de que hayan personas que crean que su respuesta a esa pregunta en esa entrevista quedó registrada con otro propósito que no fuera el estadístico para conocer las características de la población y vivienda, como fue originalmente.

6.2.6.1 Preferencia de lugar a vivir y edad. Más de la mitad de los(as) residentes prefería una casa, especialmente los(as) viejos(as) (véase la Figura 6.3). En comparación con los(as) menores de 60 años de edad, los(as) viejos(as) solamente preferían una casa y otra opción que no fuera apartamento. 
Figura 6.3. Grupos de edad por preferencia de lugar a vivir de los(as) residentes afectados(as)

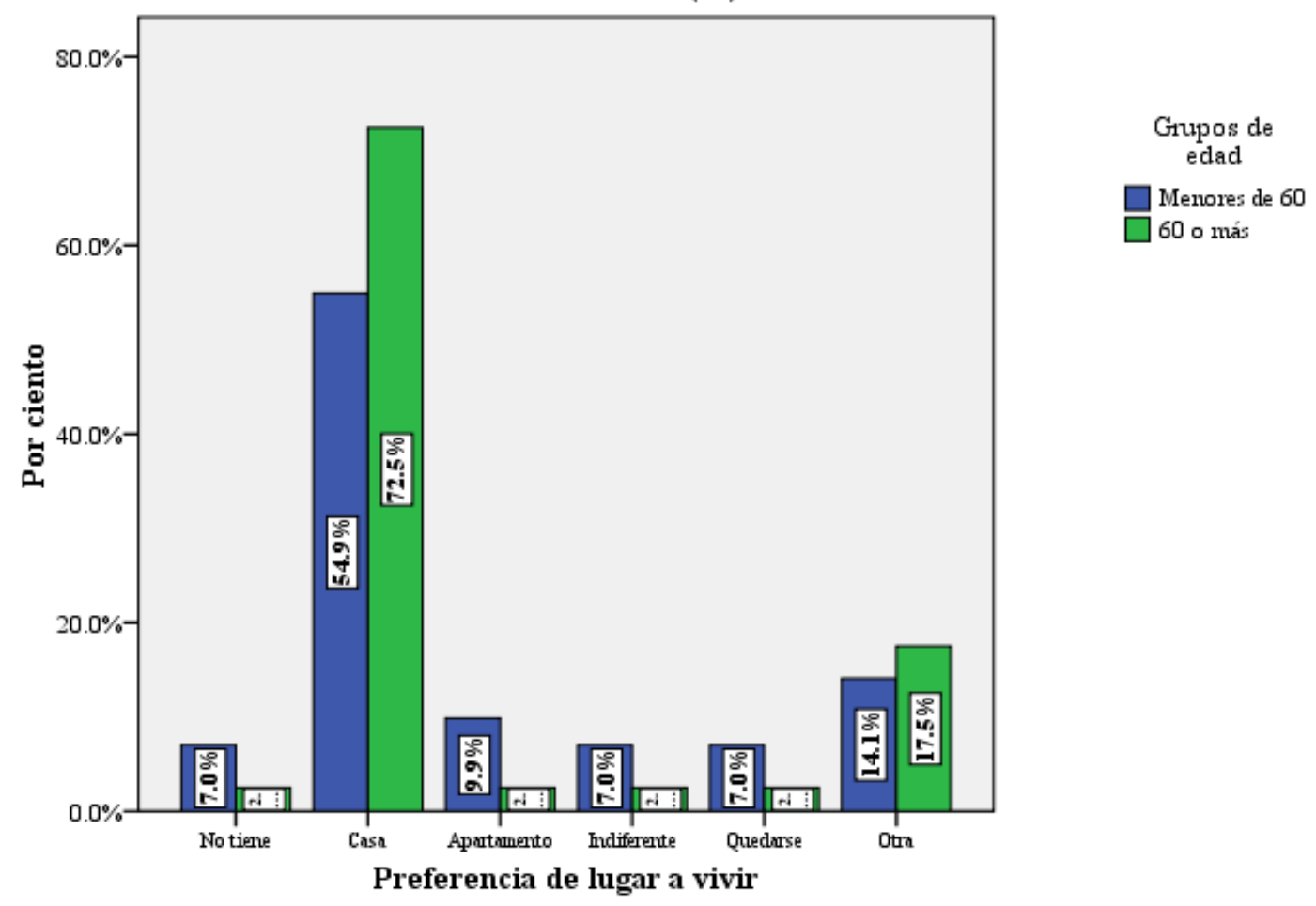

Otra preferencia incluye lo que diga su madre, comoda, no edificio, parcela, sitio tranquilo, igual o mejor a la que tiene, en el área metropolitana, sitio donde pueda vivir bien y comunidad de viejos(as).

\subsubsection{Preferencia de lugar a vivir y año de inicio de residencia en}

comunidad. De las personas que querían quedarse, la mediana del año de inicios de residencia en la comunidad es 1960, siendo la más antigua, al comparar el mismo indicador para los demás lugares preferidos (véase la Figura 6.4). Las personas que preferían mudarse a un apartamento o no tenían preferencia alguna, llegaron en promedio más tarde a residir en la comunidad, por tener las medianas más recientes (1985 y 1988, respectivamente). 
Figura 6.4. Mediana del año de inicio de residencia en comunidad por preferencia de lugar a vivir de los(as) residentes afectados(as)

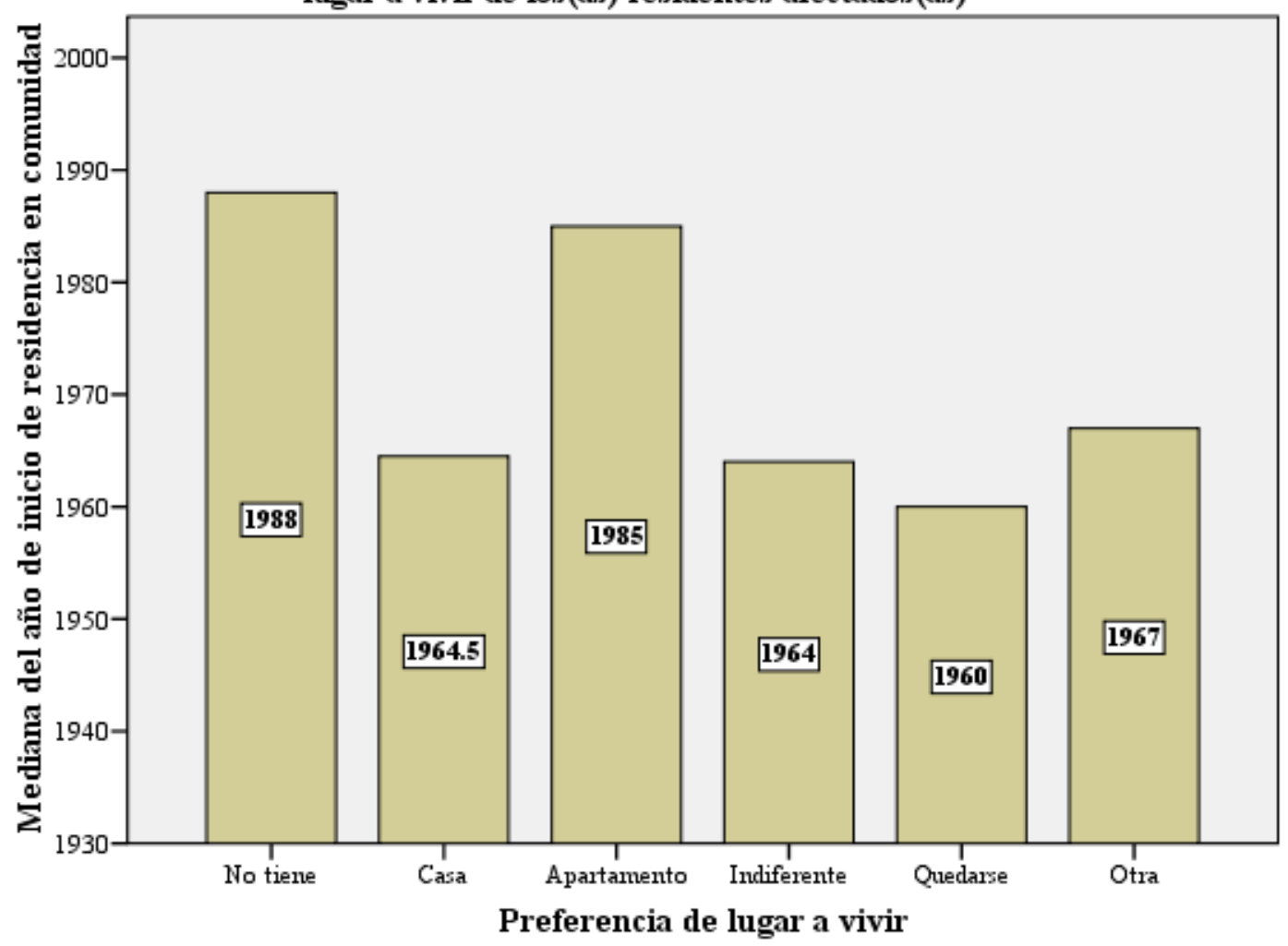

Otra preferencia incluye lo que diga su madre, cómoda, no edificio, parcela, sitio tranquilo, igual o mejor a la que tiene, en el área metropolitana, sitio donde pueda vivir bien y comunidad de viejos(as).

6.2.6.3 Preferencia de lugar a vivir y percepción de los cambios ocurridos en la comunidad. De las personas que preferían una casa o un apartamento, la gran mayoría percibía los cambios como regulares o malos (véase la Figura 6.5). De las personas indiferentes, la gran mayoría percibía los cambios como buenos. De las personas que preferían quedarse, casi todos(as) los percibieron como buenos o regulares.

6.2.7 Experiencias pasadas de realojo y desalojo. Entre los(as) residentes a ser realojados(as), algunas personas habían vivido anteriormente una experiencia similar a la que les esperaba en el futuro y, entre los(as) residentes realojados(as), algunas personas habían vivido esa experiencia en más de una ocasión. Este es el caso del 7,8\% de los(as) residentes a ser realojados(as). Poco más de la mitad de éstos informó que el realojo o desalojo fue en la década de 1960, el 71,4\% fue realojado o 
desalojado a la misma comunidad de estudio, poco más de la mitad fue realojado o desalojado de otra comunidad de San Juan, a poco más de la mitad le dieron dinero (por lo que fue un desalojo), todos(as) fueron realojados(as) o desalojados(as) por el gobierno estatal y poco más de la mitad indicó que la razón del realojo o desalojo fue la construcción de proyectos, como aeropuerto internacional, carretera, escuela, proyecto privado de viviendas y residencial público, y el dragado del caño. Como dijo un(a) residente al respecto: "Hace como 25 años desalojaron y les dieron $\$ 3.000,00$. Tuve que sacar préstamo para comprar casa. Otros tuvieron que irse a caserío por lo poco [dinero que les dieron]". En referencia a los(as) residentes realojados(as), el 4,8\% fue desalojado anteriormente, ocurrió en la década del 1960, fue desalojado en la misma comunidad de estudio, se alojó en la misma comunidad, le dieron dinero, la organización responsable es el gobierno estatal y la razón fue la construcción de un residencial público. Entonces, muchas personas realojadas o desalojadas en el pasado decidieron permanecer en la comunidad.

También en la comunidad algunas personas han sido realojadas en más de una ocasión y no participaron en este estudio por no afectarse por el dragado del caño ni demás proyectos, como una señora de 93 años de edad, quien fue expropiada en cuatro ocasiones, de las comunidades sanjuaneras de Puerta de Tierra, El Fanguito, Villa Kennedy y Barrio Obrero. Ella le dijo a un(a) empleado(a) de la corporación pública que el gobierno nunca la ha dejado vivir tranquila y que ella, junto a las demás, hicieron calles en Puerta de Tierra. 
Figura 6.5. Percepción de los cambios ocuridos en la comunidad por preferencia de lugar a vivir de los(as) residentes afectados(as)

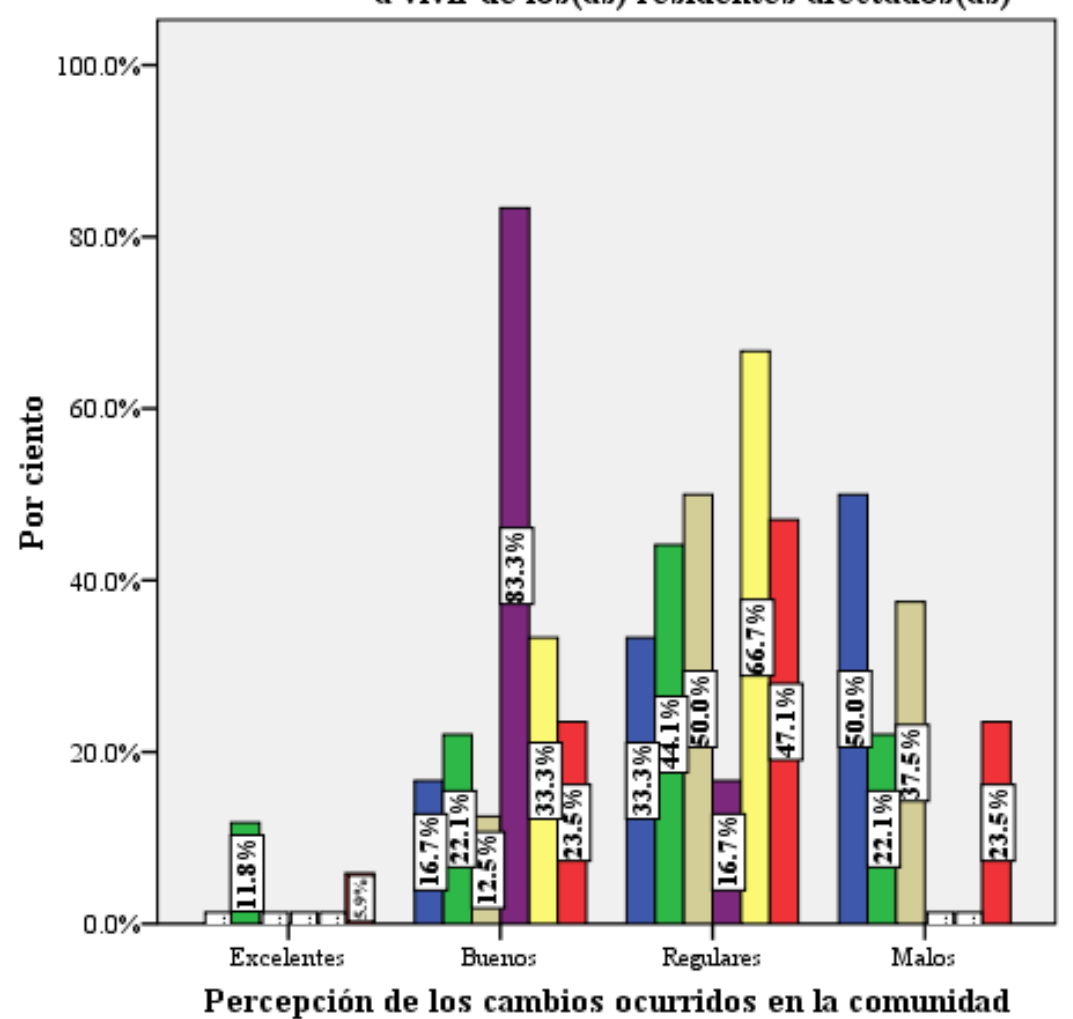

Otra preferencia incluye lo que diga su madre, cómoda, no edificio, parcela, sitio tranquilo, igual o mejor a la que tiene, en el área metropolitana, sitio donde pueda vivir bien y comunidad de viejos(as)

6.2.8 Sugerencias sobre el proceso de realojo. De los(as) residentes a ser realojados(as), la mitad tenía sugerencias y el 76,3\% de los(as) residentes realojados(as) también tenía sugerencias (véase la Tabla 6.4). Las sugerencias más comentadas por los(as) residentes a ser realojados(as) son una mejor comunicación y orientación $(26,5 \%)$, simplificar y aligerar el proceso de realojo $(22,4 \%)$ y realizar cambios, como detener el proceso de realojo y construir viviendas asequibles $(12,2 \%)$.

Por otro lado, las sugerencias más comentadas por los(as) residentes realojados(as) son un mejor diseño y construcción de proyectos de vivienda $(43,8 \%)$ y otras, como atender con ligereza las querellas de las viviendas y crear orden público para reducir el ruido de las motoras $(18,8 \%)$ (véase la Tabla 6.4). 


\section{Tabla 6.4}

Sugerencias para mejorar el proceso de realojo de los(as) residentes a ser realojados(as) y los(as) residentes realojados(as)

Característica

Residentes a ser

Residentes realojados(as) realojados(as)

Tiene sugerencias

Sí

No

Total

Sugerencias

Simplificar y aligerar el proceso

Mejor comunicación y orientación

Mejor diseño y construcción de

proyectos de viviendas

Libertad en hacer alteraciones a viviendas

en proyectos

Hacer o arreglar casas en el mismo lugar

Realojar a mejor sitio, accesible y céntrico

Realizar cambios

Pagar bien las casas

Considerar al realojado(a) para que se sienta
54,4

76,2

45,6

23,8

100,0

100,0

(90)

22,4

12,5

26,5

12,5

10,2

43,8

0,0

12,5

2,0

0,0

6,1

0,0

12,2

0,0

4,1

0,0

a gusto y no se afecte mucho
0,0

(tabla continúa) 
Característica
Residentes a ser

realojados(as)
Residentes

realojados(as)

Otras

$12,2^{*}$

$18,8^{* *}$

Total

100,0

100,0

\footnotetext{
* Incluye que le den dinero o que le den casa donde quieran; mejorar el caño rápidamente; no apartamento; que no realojen a todos(as), que sea voluntario, no saquen a mayores; que ella escoja su casa; y dar terreno y casa.

** Incluye que atiendan ligero querellas de vivienda; orden público para reducir ruido de motoras; que terminen todos los proyectos, que terminen de mudar a personas.
}

Entonces, los(as) entrevistados(as) coincidieron en sugerir: simplificar y aligerar el proceso; mejor comunicación y orientación; y mejor diseño y construcción de proyectos de viviendas.

6.2.9 Percepción de la comunicación con la organización. Poco menos de la mitad de los(as) residentes a ser realojados(as) calificó como excelente o buena la comunicación con la organización encargada de la relocalización. Por otro lado, la gran mayoría de los(as) realojados(as) calificaron como excelente o buena la comunicación con la organización. Un mayor porcentaje de los(as) residentes realojados(as), al comparar con los(as) residentes a ser realojados(as), calificaron la comunicación con la organización como excelente y buena.

6.2.10 Proceso de realojo. Respecto al proceso de realojo, para muchos(as) residentes a ser realojados(as), éste no ha comenzado todavía, añadiendo que no se ha visto algo, que eso no se va ahora, que no han sacado todavía, que todo está parado y/o están esperando todavía. Aunque muchos(as) residentes dijeron que no han realizado los preparativos, señalaron que estaban informados(as) y/o habían ido a 
reuniones. Al respecto, una mujer de 40 años dijo: "Sabemos que en un momento dado vendrán a decir tú sabes, pero no estamos aquí bien preparados. Tenemos en la mente que ya todo esto lo van a quitar. Siempre tenemos en la mente eso. ¿Qué iremos a hacer? Siempre está... Por lo menos, los que vivimos aquí siempre lo tenemos en la mente. ¡Diache! ¡Esto lo van a quitar! Todo esto lo van a destruir. Tenemos que desalojar todo esto. ¿Qué será lo que va a pasar ahora? ¿Qué irá a pasar con nosotros?" Sin embargo, algunos(as) residentes no tenían detalles sobre el proceso de realojo, en particular la fecha. Al respecto, una mujer de 56 años señaló: “Te quedas en duda de vendrán el año que viene o faltan dos años, faltan tres años... No se sabe cuándo es, pero tampoco dicen 'van a estar ahí hasta cierto tiempo’ ¿No que se va pronto? ¿Pronto? ¿Cuándo? Porque pronto puede ser para cinco años o tres, como puede ser el año que viene. Ellos no dicen el tiempo que te queda en el lugar". Un hombre de 66 años explicó: “Avisarán para conseguir casa y no nos mandan a mudar. Se ponen de acuerdo, hay que conseguir la casa, le darán dinero al dueño de la casa que cogerá".

Por otro lado, algunos(as) de los(as) residentes realojados(as) comentaron sobre el proceso previo al realojo y otros(as) residentes opinaron sobre el proceso de mudanza. Antes del realojo, según un hombre, fueron a visitarle de la organización comunitaria y del gobierno, incluyendo un abogado. De manera similar, una mujer de 73 años dijo que una muchacha fue a su casa y ella dijo que pensó: “¿Yo mudarme? A lo mejor". Luego, tenían que "ir a talleres para explicar cómo era", como dijo una mujer de 61 años, quien añadió que "en los talleres, nos hablan de cómo iba a ser el realojo, si nosotros teníamos que buscar quien nos mudara porque ellos no hacían la mudanza. Teníamos que ser nosotros”. El próximo paso podría ser el que dijo una mujer de 45 años, quien empezó "a comprar cosas nuevas para el apartamento". Otra 
mujer de 61 años añadió: "Después, nos trajeron para que los laváramos, quitarles el polvo, para después entregarlos. [...] [V]inimos aquí, lavamos la casa, después recogimos, nos mudamos aquí poco a poco". Sobre la mudanza, algunos(as) residentes recibieron la ayuda de conocidos(as). Un hombre de 50 años dijo que tuvo que regalar cosas, como la estufa de gas porque no es permitida en el nuevo proyecto. Otro hombre de 61 años comentó que le "dijeron que iban a dar dinero para la mudanza, pero no dieron nada".

Las explicaciones sobre el proceso de realojo son distintas porque hay distintos motivos para el realojo de viviendas y cada organización comunitaria tiene diferentes proyectos de viviendas. Por lo tanto, en la comunidad se distingue el realojo por el gobierno (por ejemplo, una agencia gubernamental realojó para la construcción de un puente sobre el caño) y el realojo por comunidad (por ejemplo, dos organizaciones comunitarias han construido tres proyectos de vivienda: dos horizontales y una vertical).

Según fue informado en el 2006 a los(as) residentes de la comunidad que se reunieron en un taller sobre el fideicomiso para la tenencia colectiva de la tierra, el realojo implica la compra de la vivienda por una entidad gubernamental, el cumplimiento de requisitos mínimos de vivienda decente y la obligación de darle vivienda en la comunidad. Además, no es una venta voluntaria de la vivienda.

También, según un(a) empleado(a) de la corporación pública, el proceso de realojo por parte de una agencia gubernamental es más rápido, que podría durar de 3 a 6 meses. Sin embargo, una persona realojada dijo que iba a esperar a ser realojada por el gobierno, pero cedió y se mudó por la organización comunitaria porque esta agencia gubernamental cogía mucho tiempo, aunque "pagaba bueno”. Entonces, el(la) empleado(a) de la corporación explicó que el(la) técnico(a) de realojo visita al(a) 
residente para explicarle, la vivienda es tasada y se le presentan opciones de vivienda, las cuales serán de acuerdo a los ingresos. Añadió que a veces el proceso es tan rápido que no se les avisa a los(as) residentes. Luego de haber realojado a la familia, la vivienda es demolida por la agencia gubernamental. Si el realojo es por la organización comunitaria, el municipio de "San Juan es el propietario de las residencias y las debe tumbar", como dijo la residente a ser realojada. Por otro lado, según una líder comunitaria, a los(as) residentes a ser realojados(as) les dan dinero o casa, que busca la agencia gubernamental o la misma persona, quien puede sugerir alguna que le guste. Añadió que podrían dar hasta \$90.000,00 por vivienda (lo más alto escuchado por ella) (otras cantidades mencionadas por los[as] residentes realojados[as] son $\$ 20.590,00, \$ 25.000,00$ y $\$ 40.000,00)$ o $\$ 5.000,00$ para inquilinos(as) para que con ese dinero paguen los primeros meses de alquiler en otro lugar, además de dinero para la mudanza. Comentó que hay personas que cogen el dinero y se van a otra casa dentro de la comunidad para coger más dinero, como esta persona que recibió dinero por ser inquilino de una de las casas de la propiedad de su madre y se mudó a otra de ella, de donde será realojado(a) nuevamente para recibir más dinero.

Sin embargo, surgen problemas cuando algunas personas vuelven a construir en la vivienda demolida para habitarla nuevamente, tirar basura en ese espacio baldío o para estacionar, en ocasiones, bloqueando la entrada y salida de viviendas aledañas. También surgen problemas cuando las viviendas no son demolidas y son habitadas nuevamente o son refugio para las personas adictas a drogas ilegales, quienes lo utilizan como un espacio para consumir la droga.

6.2.11 Asistencia a reuniones. Para los(as) residentes a ser realojados(as), involucrarse en el proceso de realojo se ha limitado mayormente a asistir a las 
reuniones en su comunidad. Sin embargo, entre las personas que asisten a las mismas, están las que van a todas y las que han ido a sólo algunas. También hay residentes a ser realojados(as) que no han asistido a las reuniones. Como señaló un hombre de 46 años: "Han hecho reuniones, pero no estoy al tanto qué ellos pensarán hacer, si van a sacar a uno, quién se va a beneficiar. Porque como quiera van a sacar a uno a la buena o a la mala". Asimismo, una mujer de 29 años dijo: "Porque se sabe que aquí no se puede quedar. Además, porque tiene algo malo. Lo más malo de aquí que cuando llueve mucho, pues esta partecita se inunda un poco y entonces, tienes que cruzar mojándose los pies. Bueno, a cada rato porque no siempre. Como quiera nosotros sabemos que tenemos que salir de aquí”. Las razones presentadas para no asistir a las reuniones en la comunidad son el estar enfermo(a), el creer que es lo mismo y el creer saber cómo será el realojo. Sobre la primera razón, una mujer de 67 años declaró: "Estoy enferma, pero me cuentan y me dicen que no se va, que hasta dentro de 10 años”. Referente a la segunda razón, una mujer de 68 años afirmó: “Desde el 1958, desde que yo vivo aquí es lo mismo". Y, en cuanto a la tercera razón, un hombre de 46 años opinó: “Anteriormente, he visto cómo es el funcionamiento y sé más o menos. Porque también yo creo que una parte cuando sacan a uno le dan casa por casa. Pero hay que saber qué puerta tocar para que se abra esa puerta porque yo he ido a otros pueblos donde el gobierno saca y les dan casa por casa". Entonces, el no ir a las reuniones y el ir a éstas, pero no entender podría llevar a confusión y definitivamente a desinformación que, a su vez, puede tener consecuencias sobre las actitudes hacia el realojo.

Por otro lado, para los(as) residentes realojados(as) involucrarse en el proceso de realojo era asistir a las reuniones y, en su minoría, ser miembro de la junta de una 
organización comunitaria. Sobre las reuniones, todos(as) $\operatorname{los}($ as $)$ residentes realojados(as) indicaron que asistieron a las mismas.

6.2.12 Sentirse preparados(as) para el proceso de realojo. De 16 personas a ser realojadas, 7 dijeron que se sentían preparados(as), 6 no se sentían preparados(as) y 3 no sabían si lo estaban. Entre las explicaciones dadas por los(as) que se sentían preparados(as), están que el realojo va de cualquier manera, el saber cómo es el realojo y el contar con el apoyo de la familia. Sobre esta última explicación, un hombre de 54 años dijo: "Mi familia está de acuerdo. Vivo bien aquí, pero allí viviré mejor porque tendré menos miedo y el realojo es en la misma área. No te saca de la gente que tú conoces”. Por otro lado, entre las explicaciones dadas por las personas que no se sentían preparadas, están la situación económica que implica el vivir alquilado(a), el proceso va a tardar, el ir a vivir con otras personas y adaptarse en otro sitio y el tener que irse luego que la saquen con resignación. Por último, hay personas que no sabían si estaban preparadas. Como apuntó un hombre de 46 años: "Hasta que no den un paso adelante, no sé decir qué voy a hacer. Hay que ver la perspectiva de qué es lo que sucede, lo que está pasando, para decir lo que uno va a tomar”.

6.2.13 Dudas sobre el realojo. Entre los(as) residentes a ser realojados(as), poco más de la mitad indicó que tenía dudas. Las dudas más comentadas giran en torno a si darán dinero o vivienda. Como comentó un hombre de 60 años: “¿Cómo van a hacer? ¿Cuáles son los mecanismos a tomar? En reuniones, dicen cosas diferentes, contradictorias. Que te darán casa igual, que te darán dinero. Que a la larga dicen una cosa y luego dicen otra. Mira a Tokío. Sacaron y viste lo que hicieron. Eso que no se podía hacer algo". Entonces, si creían que darán dinero, la duda es si deben aceptar esa cantidad, como señaló una mujer de 56 años: "Uno no sabe si están por conveniencia de ellos, qué es lo que le conviene a uno, qué es lo que no le conviene. 
Si uno debe o no debe aceptar la cantidad de dinero que quieren ellos dar por la casa, por su casa, aunque no valga un montón de chavos [dinero], pero vale. ¿Ves? Que si te dan dinero después que consigues una casa por el dinero que te dieron porque todas están caras fuera y si ese dinero no te da para conseguir una casa, ¿adónde vas a ir a vivir?"

Por otro lado, si creían que darán una vivienda, las dudas son adónde irán a vivir, si irán a vivir a un residencial público, si tienen que buscar la vivienda y si hay opciones a escoger sobre el lugar a vivir. Como afirmó una mujer de 40 años: "No quiero ir a un residencial. Ese es el temor mío. Que te digan: 'No. A ti te toca éste. Te compramos la casa, el solar. Te toca en un residencial'. Ese es el temor de nosotros. Porque tantos años en tu casa... Ese es el miedo. Yo creo que ese es el miedo de muchos aquí". Otra duda es "cuánto tiempo faltaría para eso", como dijo un hombre de 66 años. En algunas dudas comentadas por algunos(as) residentes a ser realojados(as), se refleja un sentimiento de pasividad o impotencia al preguntarse “adónde nos van a enviar", "para dónde me van a llevar", "adónde nos van a meter" y “adónde iremos a parar". También estas preguntas denotan incertidumbre. Además, hay residentes que tenían múltiples dudas, como una mujer de 69 años que dijo: "La duda que tengo es que no estoy segura para dónde me van a llevar. Eso es lo que me preocupa. Para qué sitio, que a veces no te dicen. No es para donde tú quieres. Ellos te mandan a buscar casa. Pues, yo me voy a dedicar a buscar donde me guste. Eso es lo que voy a hacer. Adonde me guste”.

Otras dudas que tenían los(as) residentes a ser realojados(as), las cuales fueron presentadas en reuniones comunitarias, están relacionadas con la titularidad del terreno. Debido a que la comunidad se formó parcialmente por rescates de terrenos públicos, una cantidad significativa de residentes no tuvo títulos de propiedad sobre el 
terreno donde están ubicadas sus viviendas, hasta el 2004, cuando se aprobó la Ley Núm. 489, la cual creó un fideicomiso para la tenencia colectiva de la tierra. Sin embargo, al 2006, cuando ya estaban ocupando legalmente esos terrenos, por tener un título colectivo de la tierra, en una reunión comunitaria, dos residentes señalaron que el Alcalde de San Juan pretendía dar títulos de propiedad y una de las personas dijo que la gente gastó dinero solicitando los documentos necesarios (declaración jurada, retratos, etc.) para poder tramitar ese título. Luego de la aprobación de la Ley 32 del 23 de junio del 2009, continuaron las dudas sobre la titularidad del terreno. Esta ley regresó al estado previo al fideicomiso de la tierra — creada por la Ley 489—, en el que algunos(as) residentes tenían títulos de propiedad y otros(as) no, pero añadiendo los(as) que viven sin títulos en los terrenos del Municipio de San Juan (propiedad del gobierno municipal) y están tramitando los documentos para obtener la escritura cedida por éste.

Por otro lado, poco menos de la mitad de los(as) residentes a ser realojados(as) dijo que no tenía dudas sobre el proceso de realojo. De estas personas, una mujer de 67 años declaró: "No. No tengo. Ellos saben que no me pueden quitar esto sin darme los chavos [dinero]". De la misma manera, un hombre de 46 años dijo: "No porque sé más o menos de qué trata. Te dan el dinero y vete y ya y a ver uno a qué se va a aventurar”. Entre las personas a ser realojadas que no tenían dudas, algunas señalaron entender el procedimiento del realojo y creían que les darían dinero.

Entre las personas realojadas, todas señalaron que tenían dudas sobre el proceso de realojo. Sus dudas eran el no saber "cómo iba a ser" y si cualificaban por los ingresos y el número de personas en la familia. Otras dudas fueron articuladas por una mujer de 45 años: "Qué iba a pasar con nuestra vivienda allá abajo, cómo me 
darían el subsidio federal, qué cantidad aportaría el gobierno, ya que las casas no estaban valoradas como el apartamento actual. Estaba por debajo".

Las dudas de los(as) residentes a ser realojados(as) y los(as) residentes realojados(as) coincidieron en la duda de cómo sería el proceso. Además, de manera general, las dudas de las personas a ser realojadas son en torno a lo que recibirán, que podría ser dinero (a base del valor de tasación de su vivienda actual) o una vivienda. Sin embargo, las dudas que tuvieron los(as) residentes realojados(as) son más técnicas, como cumplir con las cualificaciones para poder vivir en el proyecto de vivienda y la aportación del gobierno federal para la adquisición de la vivienda.

Sobre el proceso de realojo, desde la perspectiva de los(as) residentes afectados(as), destacan sus preferencias por lugares para vivir, sugerencias y dudas, coincidiendo en las mismas ideas, las personas a ser realojadas y las realojadas. Es sobre el proceso mismo de realojo, una de las dudas, una de las sugerencias y una de las preocupaciones presentadas por los(as) participantes de este estudio.

\subsection{Diferencias entre el realojo voluntario y el forzado}

Como en el pasado en Puerto Rico, algunas comunidades desaparecieron por el realojo y/o desalojo de sus residentes, por parte del gobierno, los(as) residentes de la comunidad estudiada recuerdan lo sucedido hace décadas, específicamente las personas de edad avanzada, que pudieran influir en sus actitudes hacia el realojo de sus viviendas.

Al preguntarles a los(as) entrevistados(as) si describirían el realojo como voluntario o forzado, las respuestas estuvieron divididas. Entre las personas a ser realojadas, la mitad respondió que es forzado y la otra mitad indicó que es voluntario. Las que señalaron que el realojo es forzado explicaron que debe haber otras opciones y que hay residentes que no quieren irse. Algunos(as) de los(as) residentes explicaron 
que es forzado por los planes del gobierno. Al respecto, un residente a ser realojado de 60 años señaló que allí harán un embarcadero, un malecón, ampliarán la calle y harán apartamentos para la venta y todo en beneficio para el gobierno. De la misma manera, otro hombre de 46 años dijo: "Va a ser forzado porque como quiera me van a sacar porque es el gobierno y lo que diga el gobierno y eso es lo que uno va a coger y yo voy a ir hasta lo último hasta que me den casa por casa y me la tasen bien y yo pueda tener casa en otro lado donde no tenga que pagarle al banco, hipoteca ni yo irme rentado ni nada".

Otras personas señalaron que el realojo no es obligado ni forzado. Además, algunas personas respondieron que es voluntario porque tiene que haber una casa adonde mudarse o dinero para darles. Por otro lado, al ver que en la comunidad otras personas han permanecido luego de haberles ofrecido una vivienda, da la impresión en los(as) demás residentes de que el realojo es voluntario, como señaló una mujer de 29 años: "Voluntario porque aquí hay muchísima gente que le ofrecieron y no se fueron y dijeron: 'cualquier cosa me voy en el segundo, en lo que lo pienso y veo cómo funcionan las cosas'. No es obligatorio". "En el segundo" se refiere al segundo proyecto de vivienda vertical que estaba por construir una organización comunitaria desarrolladora de viviendas. Mudarse a estos dos proyectos de vivienda es opcional y voluntario para los(as) residentes que viven en hogares en la comunidad estudiada, específicamente en zonas identificadas para ser desalojadas por el dragado del caño o proyectos de infraestructura. Las personas que deciden mudarse a estos proyectos de vivienda usualmente no desean esperar a ser desalojadas por el gobierno estatal, ya que es necesario su desalojo para comenzar algún proyecto.

Las personas realojadas mayormente respondieron que es voluntario, explicando que no había obligación para hacerlo. Añadieron que las personas que 
desearan quedarse en sus viviendas lo podían hacer. Una mujer tomó la decisión de mudarse para estar en un sitio más seguro y mejor; mientras, un hombre dijo que estaba deseoso por salir, pero que siempre visualizaba tener una casa aparte y no un apartamento.

Para la corporación pública y las organizaciones comunitarias, la diferencia entre el realojo voluntario y el forzado es que el primero está relacionado con el realojo realizado por una organización de la comunidad. El realojo voluntario implica que los(as) residentes a ser realojados(as) por los proyectos de dragado del caño y de infraestructura tienen la opción de mudarse a los proyectos de vivienda, construidos por estas organizaciones, antes de que sean realojados(as) en el futuro por la agencia gubernamental encargada del proyecto. Entonces, el realojo forzado es el último recurso, cuando no se aceptan las opciones de vivienda presentadas.

Debido a que dos organizaciones comunitarias están autorizadas para desarrollar viviendas para los(as) residentes afectados(as) por proyectos específicos (dragado del caño y de infraestructura) y demás residentes, se les presentó la opción de realojarse a proyectos de viviendas, diseñados por las organizaciones, antes del eventual realojo por la corporación pública para poder llevar a cabo dichos proyectos. Por lo tanto, las personas a ser realojadas y las realojadas coincidieron en catalogar este proceso de realojo como voluntario porque saben de personas que decidieron permanecer en sus viviendas en la comunidad.

6.4 Cambios ocurridos en la comunidad antes del proceso de realojo, desde la perspectiva de los(as) residentes que vivían en ésta

Debido a que la comunidad lleva casi un siglo desde su fundación y a que han pasado varios años desde la creación de la ley que creó la corporación pública que planifica, coordina y desarrolla proyectos para y con la comunidad, han ocurrido 
cambios en la misma. Por ende, quise conocer esos cambios, desde la perspectiva de los(as) residentes y si hay diferencia en la percepción sobre los cambios entre las personas a ser realojadas y las realojadas.

6.4.1 Cambios estructurales. Respecto a los cambios estructurales en la comunidad, se mencionaron las mejoras en instalaciones recreativas, como el parque y la cancha. Por otro lado, el puente, que en el momento de la entrevista estaba en construcción, fue señalado por una mujer de 39 años como un cambio visible en la comunidad (véase la Ilustración 6.6). Además, mencionó que quitaron el salón de belleza y el colmado.

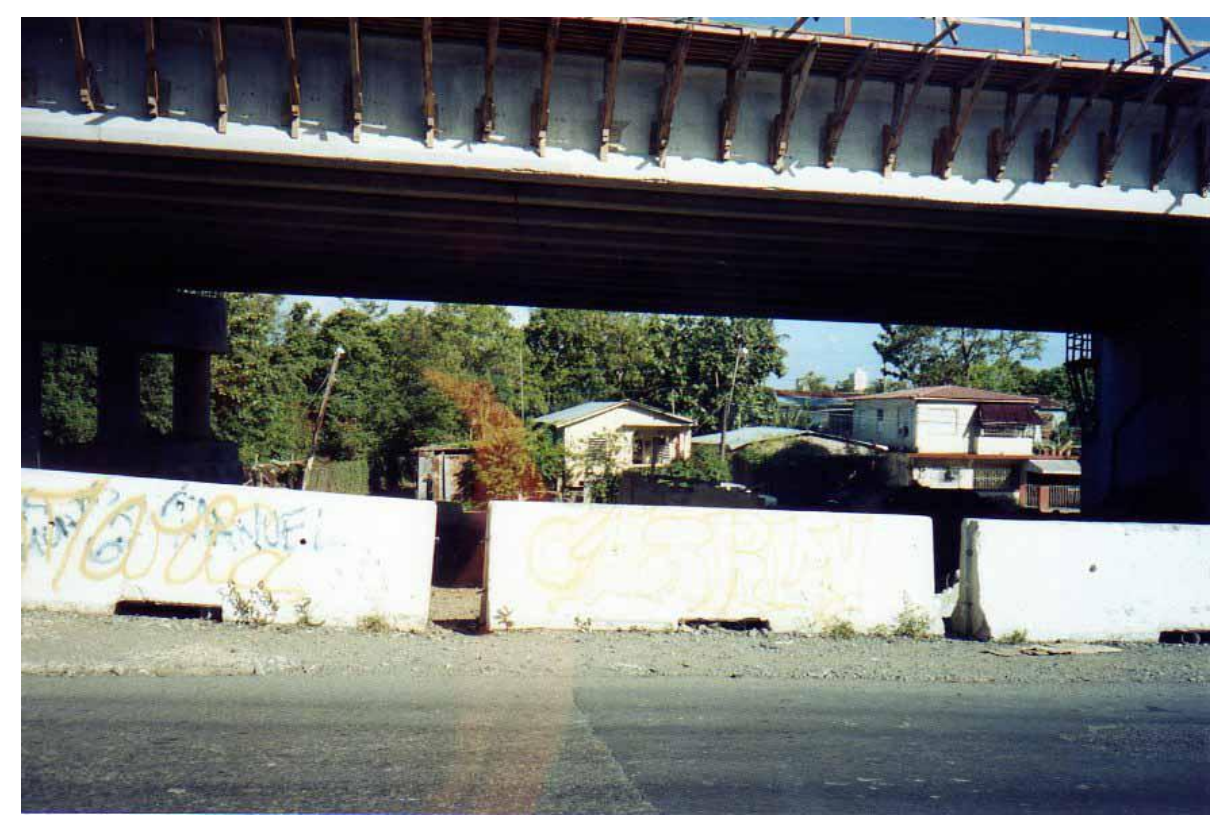

Ilustración 6.6. Puente en construcción sobre el caño. Foto de la autora.

6.4.2 Cambios sociales. Entre los problemas sociales mencionados como cambios por los(as) residentes a ser realojados(as), resaltan la adicción a drogas ilegales, la criminalidad y la presencia de personas sin hogar (deambulantes). Al respecto, un hombre de 54 años dijo: “no están llegando aquí, pero en están llegando. Son drogadictos y deambulantes. El realojo por carretera por $\square$ les pagó bien y ahora ha venido gente a hacer casuchas". O sea, estas personas están 
ocupando las viviendas, de donde fueron realojadas personas en el pasado. Otra de las consecuencias negativas de la adicción a drogas es la cercanía del lugar de ventas con lugares recreativos, como un parque infantil, el cual fue construido recientemente y hasta el mismo supuesto encargado del punto de drogas dijo que no debió haberse construido ahí. Además, según una líder comunitaria, algunos(as) niños(as) se han involucrado indirectamente en ese negocio ilegal al decir "aguas" cuando pasa alguien que parece ser sospechoso(a).

En cuanto a la llegada de personas de la República Dominicana, algunos(as) residentes comentaron que son gente buena y que se llevan bien con ellas. Otros(as) compararon a los(as) dominicanos(as) con los(as) puertorriqueños(as), al decir que hay personas buenas y malas y que, así como los(as) de Puerto Rico van a otros sitios, ellos(as) vienen aquí. Sin embargo, tal parece que hay residentes a ser realojados(as) que no tenían vínculos con los(as) dominicanos(as). Como señaló un hombre de 46 años: "No tengo problemas porque ellos viven su vida y yo vivo la mía". Asimismo, una mujer de 69 años dijo: “Cada uno tiene derecho a vivir donde le plazca. Después que no se metan conmigo, que vivan dondequiera".

Por otro lado, desde la perspectiva de una de los(as) líderes comunitarios(as), algunos(as) dominicanos(as) cogen el caño de escondite y construyen casas para coger beneficios (para ser realojados[as]). También ella mencionó a una persona dominicana que hizo un taller de hojalatería a las orillas del caño, lo cual está prohibido por las leyes ambientales. Añadió que, además de venir indocumentados(as), los(as) inmigrantes construyen para beneficiarse y ponen "pillos" de agua y luz (conexiones ilegales a tuberías de agua potable y toma de electricidad para no pagar por el consumo de agua y luz). En cuanto a la ubicación de sus viviendas, durante el trabajo de campo, observé que, mientras más una se acerca 
al caño, mayor es la probabilidad de encontrarse con algún(a) dominicano(a) residiendo allí, por lo que hay menor probabilidad de encontrarse con un(a) dominicano(a) que viva más cerca de la avenida (al otro lado del caño). Es precisamente esa zona (entre el caño y casi llegando a la avenida), la que será desalojada porque es terreno que antes era caño y, con el dragado, se espera que el caño vuelva a su estado natural anterior.

Para otros(as) residentes realojados(as), no ha habido cambios sustanciales en la comunidad y siguen siendo los(as) mismos(as) residentes. Para algunos(as) residentes realojados(as), los cambios ocurridos son que algunas partes de la comunidad ahora están baldías (posiblemente donde antes había viviendas y/o negocios) y la llegada de dominicanos(as). Un residente realojado de 50 años dijo que “estaban llegando dominicanos buscando nuevo bienestar económico. Igual que puertorriqueños a Estados Unidos”. También algunos(as) residentes opinaron que unos(as) son inmigrantes buenos(as) y otros(as) son malos(as). Un realojado de 61 años dijo: "Vienen a hacer daños a los sitios a veces. Algunos no porque son buenos, pero otros..." Por lo tanto, los(as) residentes a ser realojados(as) y residentes realojados(as) coincidieron en señalar que uno de los cambios ocurridos en la comunidad es la llegada de dominicanos(as), quienes para los(as) residentes pueden ser personas buenas o malas, como los(as) puertorriqueños(as), y han llegado a Puerto Rico, como los(as) puertorriqueños(as) han ido a otros países, como los Estados Unidos.

Además, la presencia de dominicanos(as) ha creado la duda entre algunos(as) residentes porque algunos(as) de los(as) primeros(as) han construido sus hogares en viviendas de donde desalojaron a sus pasados(as) habitantes. La duda que tenían era si recibirían los beneficios del programa de realojo por estar viviendo en una zona (a 
orillas del caño) de impacto por el dragado del caño. Por lo tanto, ellos(as) se preguntaban si se afectará el presupuesto que se estimó a base de una cantidad de residentes a ser realojados(as), según fotografías aéreas tomadas en el 2002. Según una líder comunitaria, si se benefician las personas que residen en las viviendas que no fueron demolidas, el presupuesto seguiría aumentando porque la cantidad de familias nunca bajaría, ya que una familia reemplazaría la otra, y habría que conseguir más dinero. Otra duda era si las personas que estaban residiendo ilegalmente (sin ciudadanía americana ni permiso de residencia) en la zona de impacto recibirán los beneficios del programa de realojo. Según la Ley Pública 105-117 de los Estados Unidos, los(as) residentes ilegales no recibirán pagos por el realojo ni otro tipo de asistencia. Entonces, como se realojarán a las familias que residen en lo que antes era caño, para poder llevar a cabo el dragado de ese cuerpo de agua (proyecto que se realizará con fondos federales, provenientes de los Estados Unidos), la corporación pública se ha de regir por las leyes de ese país, por lo que muy posiblemente no realojarán a los(as) residentes ilegales (mayormente dominicanos[as]).

6.4.3 Percepción de cambios ocurridos en la comunidad. Respecto a la percepción de los(as) residentes a ser realojados(as) sobre los cambios ocurridos en la comunidad, aproximadamente la mitad $(48,9 \%)$ señaló regular, el 31,1\% indicó excelente y bueno y el 20,0\% contestó malo. Por otro lado, el 42,9\% de las personas realojadas percibió como excelentes o buenos los cambios ocurridos en la comunidad, el 33,3\% como malos y el $23,8 \%$ como regulares.

Al comparar la percepción de los(as) residentes a ser realojados(as) y la de los(as) residentes realojados(as), es mayor el porcentaje de residentes a ser realojados(as) que percibió como regulares los cambios y es mayor el porcentaje de 
realojados(as) que percibió como excelentes o buenos los cambios ocurridos en la comunidad.

Desde la perspectiva de los(as) residentes, antes del proceso de realojo, la comunidad había experimentado cambios, como mejora de instalaciones, eliminación de lugares y construcción de estructuras. Además, la llegada de dominicanos(as) a residir en su comunidad se mencionó como uno de los cambios ocurridos por los(as) residentes a ser realojados(as) y los(as) realojados(as).

\subsection{Impacto socioeconómico del realojo en la comunidad}

Debido a que el realojo implica un cambio de residencia, aunque sea dentro de la misma comunidad, lleva a que el(la) residente se aleje, se acerque o que no hayan cambios en la distancia entre la vivienda y las de sus familiares y/o amistades y de negocios, oficinas médicas y centro médico-hospitalarios. Cambios como éstos podrían influir sobre la manera de pensar de los(as) residentes sobre el realojo. De la misma manera, el cambio de residencia podría afectar la decisión de continuar un negocio propio en la comunidad de reasentamiento.

6.5.1 Seguir yendo a los mismos lugares. En cuanto a desear seguir yendo a los mismos lugares, tres cuartas partes de los(as) residentes a ser realojados(as) dijeron que desean hacerlo, una vez sean realojados(as). Estas personas señalaron que desean seguir visitando al(la) mismo(a) médico(a), hospital, supermercado y/o farmacia porque el servicio es bueno, está cerca o ya se conoce (al[la] médico[a]). Además, una cuarta parte de los(as) residentes dijo que el seguir yendo a esos lugares dependerá de la distancia y si se tiene transportación.

Por otro lado, la gran mayoría de las personas realojadas dijeron que siguen yendo a los mismos lugares de antes, como la farmacia, el dispensario (centro médico de urgencias) y el colmado. Sobre las razones, apuntó un hombre de 50 años: "Sigo 
yendo al mismo colmado y farmacia, por distancia, economía y amabilidad y cortesía en el servicio".

6.5.2 Estar cerca de familiares y amistades. Tres cuartas partes de los(as) residentes a ser realojados(as) esperaban estar cerca de ellos(as), una vez fueron realojados(as) porque "la familia no puede estar lejos", como dijo una mujer de 29 años, y "ya conoce", como dijo un hombre de 46 años. Además, una cuarta parte de las personas a ser realojadas no tenía preferencia alguna, ya sea porque no tiene familia en la comunidad, se adapta donde sea, las visita o se visitan mutuamente.

Por otro lado, la gran mayoría de las personas realojadas señalaron estar ahora cerca o más cerca de familiares y amistades. Por lo tanto, las personas a ser realojadas y realojadas señalaron el deseo de mantener sus lazos familiares y sociales.

6.5.3 Relación con los(as) vecinos(as). Respecto a la relación con los(as) vecinos(as) actuales, a los(as) residentes a ser realojados(as), les pregunté cómo era la misma y cómo esperaban que fuera su relación con los(as) vecinos(as) en la nueva comunidad. Todos respondieron que era buena, muy buena, excelente, formidable o buenísima la relación con los(as) vecinos(as). Entre las explicaciones, destacan que "son buenos los vecinos", "se llevan bien conmigo y yo con ellos", "en esta zona somos familias" y "nos llevamos bien, como familia". Respecto a cómo esperaban que sea la relación con los(as) vecinos(as) de la nueva comunidad, 6 de 16 residentes a ser realojados(as) esperaban que fuera excelente, muy bien o buena, como dijo una mujer de 47 años: "Muy bien porque yo no tengo problemas con nadie. Al contrario, busco amistades". Por otro lado, 6 de los(as) 16 residentes esperaban que fuera igual que la actual relación que tienen con sus vecinos(as), como comentó una mujer de 29 años: "Muchas cosas van a cambiar, como ya te conté. Pero espero que dentro de esas cosas que cambien, pues, nos podamos ver todos los días en la cara, cuando vaya para 
el trabajo y ellos también vayan para sus trabajos, que sea como aquí: 'Buenos días, vecina. ¿Cómo está todo? ¿El niño (si tiene niños), cómo está? ¿Por qué no lo he visto? ¿Qué sucedió? ¿Está enfermito?’ Cositas así, que se ven sencillas, pero valen mucho". También hay residentes que no esperan algo particular, como dijo una mujer de 68 años: "Así que lo mismo que me da una cosa que otra". Referente a los(as) residentes realojados(as) y su relación con $\operatorname{los}($ as) vecinos(as) actuales, algunos(as) respondieron que es buena o muy buena, como dijo un hombre de 50 años: "Muy buena porque nos llevamos bien y no ha habido peleas, garatas y nos conocimos por muchos años".

También cuando les pregunté si mantenían contacto con sus antiguos(as) vecinos(as), la gran mayoría respondió afirmativamente y añadió que se visitan mutuamente o se encuentran casualmente. Al respecto, una mujer de 73 años afirmó: "Muchas veces me he encontrado con varias personas y me preguntan cómo estoy. A veces me dicen: 'Como tú pasaste a la losa, no visitas a nadie'. Yo me siento bien donde estoy". El comentario de pasar a la losa es bastante popular en Puerto Rico; implica una distinción entre lo urbano y lo rural y pudo haber surgido en el pasado, cuando al cambiar de tipo de vivienda, se cambiaba de tipo de piso de la vivienda. Posiblemente, en el pasado las viviendas rurales tenían suelo de tierra y las urbanas tenían losa. En la actualidad, cuando alguien escucha ese comentario, podría éste entender que la otra persona vive en San Juan. También se podría entender como si la persona que vive en la losa vive mejor que antes o que otras personas. Por lo tanto, este comentario tiene una connotación de clase. Además, una mujer de 45 años comentó que su relación con sus vecinos(as) actuales es "igual que como allá abajo [antigua comunidad]" y añadió que sus "vecinos son familiares más cercanos". 
Por lo tanto, para los(as) residentes a ser realojados(as) y los(as) residentes realojados(as), era buena, como mínimo, la relación con los(as) vecinos(as). Además, así como los(as) residentes a ser realojados(as) esperaban que fuera buena o igual su relación con los(as) futuros(as) vecinos(as), los(as) residentes realojados(as) han mantenido contacto con sus pasados(as) vecinos(as).

6.5.4 Contacto con sus pasados(as) vecinos(as). El realojo tuvo un impacto socioeconómico en la comunidad, desde la perspectiva de los(as) residentes a ser realojados(as) y los(as) residentes realojados(as). Uno de los indicadores para medir el impacto es el grado de contacto con las personas de la comunidad que ya han sido realojadas. A los(as) residentes a ser realojados(as) les pregunté si conocían personas que ya han sido realojadas, si han vuelto a tener contacto con ellas y si les han comentado sobre su experiencia de vivir en otra comunidad. Más de la mitad de los(as) residentes a ser realojados(as) indicó conocer personas que ya han sido realojadas. Del 63,3\% que afirmó conocer personas realojadas en el pasado, más de la mitad $(61,4 \%)$ dijo que ha vuelto a tener contacto con ellas. A la gran mayoría $(94,3 \%)$, le comentaron sobre su experiencia de vivir en otra comunidad. Entre los comentarios sobre dicha experiencia, resaltan la satisfacción de vivir en lugares buenos y tranquilos (27,3\%); están arrepentidos(as) de mudarse por estrés, angustia y distancia (18,2\%); comentarios mixtos de que a unos(as) les gusta y a otros(as) no $(15,2 \%)$; dificultad por adaptarse $(9,1 \%)$ y otros, como problemas con el realojo que llevó a que viviera alquilado(a) porque la casa no estaba lista y que enviaron a supuesta comunidad contaminada $(9,1 \%)$.

Por otro lado, a los(as) residentes realojados(as), les pregunté si tenían contacto y el tipo con las personas que fueron sus vecinos(as) en la antigua comunidad, de donde fueron realojados(as). Al respecto, más de la mitad $(61,9 \%)$ 
tenía contacto con sus antiguos(as) vecinos(as). De los(as) residentes realojados(as) que tenían contacto con las personas de la pasada comunidad, poco menos de la mitad $(46,2 \%)$ saluda cuando coincide ocasionalmente con sus pasados(as) vecinos(as) y menos del 10,0\% se llaman y visitan mutuamente.

6.5.5 Negocios de ventas al detal. Otros de los indicadores para medir el impacto socioeconómico del realojo en la comunidad son el tener un negocio de ventas, la continuación del negocio luego del realojo, la posibilidad de afectarse las ventas por el realojo y la clientela. Entre los(as) residentes a ser realojados(as), solamente el 7,8\% tenía un negocio de ventas, de los cuales la mayoría $(71,4 \%)$ deseaba continuar el negocio una vez fuera realojado(a). De los(as) residentes que deseaban continuar el negocio luego del realojo, la mayoría $(80,0 \%)$ entendía que las ventas se afectarían, de quienes la mitad creía que tendrían clientela nueva. Entre las personas que creían que las ventas se afectarían luego del realojo, más de la mitad pensaba que sus clientes(as) serían otros(as) porque no estarían los(as) mismos(as) vecinos(as).

Entre los(as) residentes realojados(as), solamente dos personas tenían negocio de ventas, de los cuales una tenía ese negocio en la comunidad de donde fue realojada y la otra persona no lo tenía antes. La persona realojada que tenía un negocio de ventas en la comunidad de donde fue realojada entendía que las ventas se afectaron con el cambio de comunidad por el realojo, específicamente mejoraron porque tenía más pedidos, porque en la actualidad sus clientes son los(as) mismos(as) de antes más los(as) nuevos(as). Por otro lado, el porcentaje de realojados(as) con ingresos por negocio propio debería ser más alto que el reportado en la encuesta porque muchas personas venden algún producto desde su residencia. Durante el trabajo de campo, observé residentes que venden bebidas, dulces y artículos del hogar, pero no 
informaban esos ingresos para propósitos de impuestos y posiblemente para no ser llamados(as) la atención por parte de la asociación de residentes u organización comunitaria y no correr el riesgo de cesar operaciones del negocio o ser desalojado(a) por incumplir con el reglamento.

El realojo ha tenido un impacto económico en la comunidad porque sus residentes desean seguir yendo o han seguido yendo a los mismos lugares de antes para satisfacer sus necesidades de alimentación y salud, por la calidad del servicio, trato y confianza. Además, los negocios propios de los(as) residentes se han mantenido y/o han aumentado por el incremento en clientela, pues se suman sus clientes de la comunidad de origen y los(as) nuevos clientes de la comunidad de reasentamiento. Sobre el impacto social, los(as) residentes desean estar o ya están cerca de familiares y/o amistades, tienen una buena, como mínimo, relación con los(as) vecinos(as) y desean mantener o han mantenido contacto con vecinos(as) de la comunidad de origen. 


\section{Hallazgos sobre pobreza urbana}

Debido a que la comunidad estudiada es pobre y urbana, pretendí revaluar el debate teórico sobre la pobreza urbana, analizando las características de los(as) residentes afectados(as) por el realojo. También pretendí explorar si estas características influyen en las actitudes hacia el realojo y si hay diferencia entre las personas a ser realojadas y las realojadas.

\subsection{Características sociales}

7.1.1 Educación. Según el sistema de educación de Puerto Rico ${ }^{6}$, las categorías con mayor porcentaje entre $\operatorname{los}(\mathrm{as})$ residentes a ser realojados(as) son escuela secundaria $(30,0 \%)$ e intermedia $(21,1 \%)$ (véase la Tabla 7.1$)$. Por otro lado, en cuanto a $\operatorname{los}($ as) residentes realojados(as), las categorías más destacadas son universidad $(33,3 \%)$ y escuela secundaria $(28,6 \%)$.

\section{Tabla 7.1}

Años de estudio de los(as) residentes a ser realojados(as) y los(as) residentes realojados(as)

$\begin{array}{lll}\text { Característica } & \begin{array}{l}\text { Residentes a ser } \\ \text { realojados(as) }\end{array} & \begin{array}{l}\text { Residentes } \\ \text { realojados(as) }\end{array}\end{array}$

No fue a la esuela

Escuela elemental

Escuela intermedia

Escuela secundaria
8,9

21,1

21,1

30,0
0,0

23,8

14,3

28,6

(tabla continúa)

\footnotetext{
${ }^{6}$ El sistema de educación de Puerto Rico se divide en cuatro niveles básicos: escuela elemental (primer grado a sexto grado), escuela intermedia (séptimo a noveno), escuela secundaria (décimo a duodécimo) y universidad (grado asociado, bachillerato, maestría, doctorado y postdoctorado).
} 


\begin{tabular}{lcc} 
Característica & $\begin{array}{l}\text { Residentes a ser } \\
\text { realojados(as) }\end{array}$ & $\begin{array}{l}\text { Residentes } \\
\text { realojados(as) }\end{array}$ \\
\hline Universidad & 18,9 & 33,3 \\
Total & 100,0 & 100,0 \\
& $(90)$ & $(21)$ \\
Mediana de años de estudios & 9 & 12 \\
Total & 90 & 21 \\
\hline
\end{tabular}

Otro indicador de educación es la mediana de años de estudio, la cual para los(as) residentes a ser realojados(as) es 9 años (véase la Tabla 7.1). Para los(as) residentes realojados(as) es 12 años. Por lo tanto, la muestra de los(as) realojados(as) tiene una mediana de educación 3 años más alta que la correspondiente de la muestra de los(as) residentes a ser realojados(as). Además, en Puerto Rico, las personas con esa cantidad de años de estudio podrían trabajar, pero usualmente en empleos de poca remuneración, en los que se paga el sueldo mínimo establecido por ley. Por lo tanto, se agrava la situación cuando la mediana de años de estudios de las personas a ser realojadas es 9 porque muchos trabajos exigen el diploma del duodécimo grado o algún grado universitario (12 años o más).

\subsection{Características económicas}

7.2.1 Estado de empleo. Más de la mitad de los(as) residentes a ser realojados(as) y los(as) realojados(as) estaba fuera de la fuerza laboral, ya sea porque era ama de casa, estaba incapacitado(a) o estaba pensionado(a), entre otras (véase la Tabla 7.2). En las demás categorías, los(as) residentes a ser realojados(as) tenían un porcentaje más alto de personas empleadas que sus contrapartes. 
Específicamente, sobre las personas que reportaron estar empleadas, el sector con más porcentaje para ambas muestras es el de servicios (56,3\% para los[as] residentes a ser realojados[as] y 40,0\% para los[as] residentes realojados[as]). Además, la gran mayoría de los(as) residentes a ser realojados(as) y los(as) residentes realojados(as) que estaban empleados(as), lo estaban a tiempo completo y en trabajos permanentes.

\section{Tabla 7.2}

Estado de empleo de los(as) residentes a ser realojados(as) y los(as) residentes realojados(as)

$\begin{array}{lll}\text { Estado de empleo } & \begin{array}{l}\text { Residentes a ser } \\ \text { realojados(as) }\end{array} & \begin{array}{l}\text { Residentes } \\ \text { realojados(as) }\end{array}\end{array}$

Estado de empleo

$\begin{array}{lrr}\text { Empleado(a) } & 35,6 & 23,8 \\ \text { Desempleado(a) } & 8,9 & 14,3 \\ \text { Fuera de la fuerza laboral } & 55,6 & 61,9 \\ \text { Total } & 100,0 & 100,0 \\ & (90) & (21)\end{array}$

En cuanto a los(as) que indicaron estar desempleados(as), la mitad de los(as) residentes a ser realojados(as) indicó que, por cesantía, despido o cierre de su lugar de trabajo, no tenían un empleo en el momento de la entrevista; y la gran mayoría de estas personas llevaban menos de un año en esa situación. Entre los(as) realojados(as) desempleados(as), dos terceras partes señalaron que estaban en esa situación laboral por problemas personales o familiares y todas llevaban un año o más sin empleo. 
Sobre los(as) residentes que reportaron estar fuera de la fuerza laboral, en ambas muestras predominan las categorías de ama de casa y pensionado(a) del seguro social, a las cuales les siguen, en orden relativo, las de incapacitado(a) y pensionado(a) por empleo. Además, la mayoría de los(as) residentes a ser realojados(as) y los(as) realojados(as) llevaban 10 años o más fuera de la fuerza laboral. El estar desempleado(a) o fuera de la fuerza laboral podría llevar a vivir en condiciones de pobreza a las personas afectadas por la reducción en sus ingresos.

7.2.2 Ingresos. Sobre los distintos tipos de ingresos reportados por los(as) residentes a ser realojados(as) y los(as) residentes realojados(as), se destacan los recibidos por pensión $(38,9 \%$ y 47,6\%, respectivamente), ya sea del seguro social o del retiro de algún empleo, y por salario $(26,7 \%$ y $23,8 \%$, respectivamente) (véase la Tabla 7.3). Es interesante mencionar el ingreso por "chiripeo" (“chivitos", como también se le llama en Puerto Rico), el ingreso devengado al realizar trabajos informales y generalmente solicitados por conocidos(as). Respecto a este tipo de ingreso, el 7,8\% de los(as) residentes a ser realojados(as) reportó hacer recibido ingresos por chiripeo, mientras que el porcentaje de los(as) residentes realojados(as) es 3 veces mayor, siendo 23,8\%. Además, el 10,0\% tuvo ingresos devengados por algún negocio propio, mientras que ningún(a) (0,0\%) de los(as) residentes realojados(as) reportó recibir ese tipo de ingresos. La razón podría ser que está prohibido tener negocios en los proyectos de vivienda, adonde fueron realojados(as). Aunque el 9,5\% de los(as) residentes realojados(as) reportó un negocio de ventas, estos(as) residentes no indicaron tener ingreso por negocio propio. Posiblemente, como no están cumpliendo con lo establecido para vivir en ese proyecto de vivienda, algunos(as) participantes no proveyeron detalles. 


\section{Tabla 7.3}

Tipos de ingresos de los(as) residentes a ser realojados(as) y los(as) residentes realojados(as)

Característica

Residentes a ser

Residentes realojados(as) realojados(as)

Ingreso por salario

Sí

No

Total

100,0

(90)

26,7

23,8

73,3

76,2

100,0

Ingreso por negocio propio

Sí

No

Total

100,0

(90)

Ingreso por renta (alquiler)

Sí

No

Total

100,0

(90)

5,6

0,0

94,4

100,0

Ingreso por chiripeo

Sí

7,8

23,8

No
92,2 
Característica

Residentes a ser

realojados(as)
Residentes

realojados(as)

Total

100,0

100,0

(90)

Ingreso por pensión

Sí

No

Total
38,9

61,1

100,0

(90)
47,6

100,0

Ingreso por ayuda de conocidos(as)

Sí

7,8

14,3

No

92,2

85,7

Total

100,0

100,0

(90)

Otro tipo de ingreso

Sí

6,7

9,5

No

93,3

90,5

Total

100,0

100,0

(90)

Además del tipo de ingreso que reciben los(as) residentes a ser realojados(as) y los(as) realojados(as), les pregunté la cantidad aproximada de ingreso familiar al mes. En ambas muestras, aproximadamente dos quintas partes reportaron recibir entre $\$ 250,00$ y $\$ 749,00$ dólares al mes (véase la Tabla 7.4). A esta categoría, en orden 
relativo, le sigue la correspondiente a entre $\$ 750,00$ y $\$ 1.249,00$ dólares, ya que el $20,2 \%$ de $\operatorname{los}$ (as) residentes a ser realojados(as) y el 23,8\% de los(as) residentes realojados(as) reportaron esa cantidad de ingreso. La mayoría de los(as) residentes participantes de este estudio (71,9\% de los[as] residentes a ser realojados[as] y 76,2\% de los[as] realojados[as]) recibieron menos de \$1.250,00 dólares al mes.

Otra característica económica es la mediana del ingreso familiar mensual, la cual es \$700,00 dólares para los(as) residentes a ser realojados(as) (véase la Tabla 7.4). Por otro lado, la mediana del ingreso familiar mensual para los(as) residentes realojados(as) es $\$ 675,00$ dólares.

\section{Tabla 7.4}

Ingreso mensual familiar y mediana de los(as) residentes a ser realojados(as) y los(as) residentes realojados(as)

Característica
Residentes a ser realojados(as)
Residentes realojados(as)

Ingreso mensual familiar

$\begin{array}{lcr}\text { Menos de } \$ 250,00 & 10,1 & 9,5 \\ \$ 250,00 \text { a } \$ 749,00 & 41,6 & 42,9 \\ \$ 750,00 \text { a } \$ 1.249,00 & 20,2 & 23,8 \\ \$ 1.250,00 \text { a } \$ 1.749,00 & 12,4 & 9,5 \\ \$ 1.750,00 \text { o más } & 15,7 & 14,3 \\ \text { Total } & 100,0 & 100,0 \\ & (89)^{*} & (21)\end{array}$

(tabla continúa) 
Característica

Residentes a ser

realojados(as)
Residentes

realojados(as)
Mediana

Total
$\$ 700,00$

$89 *$
$\$ 675,00$

21

* Una persona no reportó su ingreso mensual familiar.

7.2.3 Condición de pobreza. Para calcular el porcentaje de personas que viven bajo el nivel de pobreza, utilicé los umbrales de pobreza del 2007, calculados por el Negociado Federal del Censo y comparé el ingreso anual familiar, multiplicando el ingreso mensual familiar por 12, a su umbral correspondiente, de acuerdo con la edad del jefe o de la jefa del hogar, cantidad de personas y la presencia de niños(as) emparentados(as) menores de 18 años (véase el Anejo L). Más de tres cuartas partes de los(as) residentes a ser realojados(as) y de los(as) realojados(as) recibieron ingresos en el 2007 por debajo del nivel de pobreza (véase la Tabla 7.5). Sin embargo, el porcentaje de residentes realojados(as) bajo el nivel de pobreza es mayor que el correspondiente a los(as) residentes a ser realojados(as), siendo 81,0\% y $77,5 \%$, respectivamente.

\section{Tabla 7.5}

Condición de pobreza de los(as) residentes a ser realojados(as) y los(as) residentes realojados(as)

$\begin{array}{lll}\text { Condición de pobreza } & \begin{array}{l}\text { Residentes a ser } \\ \text { realojados(as) }\end{array} & \begin{array}{l}\text { Residentes } \\ \text { realojados(as) }\end{array}\end{array}$

Bajo el nivel de pobreza

77,5

81,0

(tabla continúa) 
Condición de pobreza

Residentes a ser

realojados(as)
Residentes

realojados(as)
Sobre el nivel de pobreza

Total

100,0

$(89)^{*}$
19,0

100,0

* Una persona no reportó su ingreso mensual familiar.

7.2.4 Ayudas económicas. Otra característica relacionada con la pobreza urbana es el bienestar social (también llamado bienestar público). En Puerto Rico, por su relación con los Estados Unidos, se reciben ayudas económicas para las personas que cualifiquen por tener ingresos bajos y clasificadas como pobres por agencias federales (de EE.UU.). De manera general, dos quintas partes de los(as) residentes a ser realojados(as) y los(as) residentes realojados(as) recibían ayudas económicas del gobierno federal (véase la Tabla 7.6).

Entre las ayudas económicas que recibían los(as) residentes, el Programa de Asistencia Nutricional (P.A.N.) fue la más reportada, con un $89,5 \%$ y 100,0\%, respectivamente. Según el Departamento de la Familia (2007a), el Programa de Asistencia Nutricional (P.A.N.) ofrece ayuda económica a las personas o familias de bajos ingresos para que puedan suplementar sus necesidades alimentarias, comprando alimentos en establecimientos autorizados (supermercados, por ejemplo). Las personas beneficiarias reciben una tarjeta electrónica, como una tarjeta de débito, a la cual la agencia deposita mensualmente una cantidad monetaria y los recipientes puedan ir a comprar sus alimentos. Otras ayudas económicas reportadas son los 
subsidios de agua y electricidad, cuyos(as) beneficiarios(as) reciben un crédito en las facturas, si no exceden una cantidad fija de consumo de agua y de electricidad.

\section{Tabla 7.6}

Ayudas económicas y sus tipos de los(as) residentes a ser realojados(as) y los(as)

residentes realojados(as)

$\begin{array}{lll}\text { Característica } & \begin{array}{l}\text { Residentes a ser } \\ \text { realojados(as) }\end{array} & \begin{array}{l}\text { Residentes } \\ \text { realojados(as) }\end{array}\end{array}$

Recibe ayudas económicas

Sí

No

Total

No

Total

Tipo de ayuda: P.A.N.

Sí

89,5

10,5

100,0

(38)

Tipo de ayuda: Desempleo

Sí

2,6

No

97,4

Total

100,0

(38)
0,0

100,0

47,6

52,4

100,0

100,0

0,0

100,0

100,0

(10)

(tabla continúa) 
Característica

Residentes a ser

Residentes

realojados(as)

realojados(as)

Tipo de ayuda: Plan 8

Sí

No

Total
0,0

100,0

100,0

(38)
0,0

100,0

100,0

(10)

Tipo de ayuda: Subsidio de agua

Sí

2,6

10,0

No

97,4

90,0

Total

100,0

100,0

(38)

Tipo de ayuda: Subsidio de electricidad

Sí

10,5

0,0

No

89,5

100,0

Total

100,0

100,0

(38)

Tipo de ayuda: Otra ayuda

Sí

10,5

0,0

No

89,5

100,0

Total

100,0

100,0

(38) 
7.2.4.1 Condición de pobreza y ayudas económicas. Sólo la mitad de las personas pobres a ser realojadas recibió ayudas económicas del gobierno, así como cerca del $60 \%$ de las personas pobres realojadas (véase la Tabla 7.7). Es preocupante que el resto de las personas a ser realojadas y las personas realojadas que fueron clasificadas como pobres no fueran recipientes del bienestar social porque recibirlo podría ayudarles a vivir en mejores condiciones.

\section{Tabla 7.7}

Condición de pobreza y ayudas económicas de los(as) residentes a ser realojados(as) y $\operatorname{los}($ as) residentes realojados(as)

$\begin{array}{lll}\text { Recibió ayudas } & \begin{array}{l}\text { Bajo el nivel } \\ \text { de pobreza }\end{array} & \begin{array}{l}\text { Sobre el nivel } \\ \text { de pobreza }\end{array}\end{array}$

Residentes a ser realojados(as)

$\begin{array}{lrr}\text { Sí } & 52,2 & 5,0 \\ \text { No } & 47,8 & 95,0 \\ \text { Total } & 100,0 & 100,0 \\ & (69)^{*} & (20)\end{array}$

Residentes realojados(as)

$\begin{array}{lrr}\text { Sí } & 58,8 & 0,0 \\ \text { No } & 41,2 & 100,0 \\ \text { Total } & 100,0 & 100,0\end{array}$

\footnotetext{
* Una persona no reportó su ingreso mensual familiar, por lo que no pude calcular el nivel de pobreza.
} 
También es posible que sean personas clasificadas como pobres, pero no cualificaron para recibir ayudas económicas, por no tener ingresos suficientemente bajos y/o consumir una cantidad mayor de agua y/o electricidad que la especificada para recibir subsidios por esos servicios. $\mathrm{O}$ sea, que puede haber residentes en la comunidad con necesidades sin satisfacer sin las ayudas del gobierno y residentes que, recibiendo ayudas económicas, viven en condiciones de pobreza.

7.2.4.2 Razones por las que reciben ayudas económicas. También a los(as) residentes que señalaron recibir ayudas económicas, les pregunté por qué las recibían. Entre sus razones se destacan que el ingreso era insuficiente o inexistente (23,7\%), que eran elegibles para recibir alguna o algunas de las ayudas $(23,7 \%)$ y para tener comida $(23,7 \%)$ (véase la Tabla 7.8$)$. Posiblemente, la última razón la dieron para explicar la ayuda del Programa de Asistencia Nutricional, el cual es un subsidio estatal que provee mensualmente acceso gratuito a alimentos. Por otro lado, entre las razones que dieron los(as) residentes realojados(as), destacan el tener una situación familiar o personal (50,0\%), como el nacimiento de un(a) hijo(a), falta de empleo, divorcio e incapacidad e ingreso insuficiente o inexistente $(20,0 \%)$.

\section{Tabla 7.8}

Razones por las que recibe ayudas económicas los(as) residentes a ser realojados(as) y los(as) residentes realojados(as)

$\begin{array}{lll}\text { Razón } & \begin{array}{l}\text { Residentes a ser } \\ \text { realojados(as) }\end{array} & \begin{array}{l}\text { Residentes } \\ \text { realojados(as) }\end{array}\end{array}$

Recomendado por agencia o conocido 
Razón

Residentes a ser

Residentes

realojados(as)

realojados(as)

Preguntó si era elegible

23,7

10,0

Por comida

23,7

10,0

Situación personal o familiar

50,0

Otras

0,0

Total

100,0

100,0

* Incluye mucha gente coge ayuda; no contestó; por los(as) hijos(as); siempre he recibido cupones y el Departamento de la Familia le recomendó subsidio de teléfono; y para proveer a mi familia.

7.2.5 Préstamos bancarios. También relacionado a la pobreza urbana, está el tener préstamos bancarios, no sólo porque endeuda a la persona, también denota que los ingresos devengados son insuficientes para sufragar unos gastos.

Una tercera parte de los(as) residentes a ser realojados(as) y de los(as) realojados(as) tenía al menos un préstamo bancario. Específicamente, más de la mitad de $\operatorname{los}($ as) residentes a ser realojados(as) y de los(as) realojados que indicaron tener préstamos, señaló tener un préstamo bancario (65,5\% y 57,1\%, respectivamente). En cuanto a las razones presentadas al preguntarles por qué solicitaron préstamos, entre los(as) residentes a ser realojados(as), la razón con mayor porcentaje $(41,4 \%)$ es comprar, construir y arreglar la casa. La segunda razón es saldar o consolidar deudas con $24,1 \%$. Por otro lado, entre los(as) realojados, las dos razones con mayor porcentaje son saldar o consolidar deudas $(28,6 \%)$ y comprar vehículo un de motor $(28,6 \%)$ 
7.2.6 Clase social. Al presentarles si se clasificaban bajo las categorías de clase baja, media y alta, aproximadamente la mitad de los(as) residentes a ser realojados(as) y los(as) realojados(as) indicó que pertenecía a la clase media (57,8\% y 47,6\%, respectivamente). En la categoría de clase baja, porcentajes similares de cada una de las muestras reportaron pertenecer a esa clase social. Por otro lado, en la clase alta, se puede observar una diferencia porcentual, ya que el 1,1\% de los(as) residentes a ser realojados(as) señaló pertenecer a ella, contrario al 9,5\% de los(as) residentes realojados(as).

7.2.6.1 Clase social e ingreso mensual familiar. Aunque no le pregunté a los(as) participantes por qué seleccionaron esa clase social como a la que pertenecen, encontré que el ingreso mensual familiar es uno de los factores que podrían haber tomado en consideración al momento de autoclasificarse. Al comparar el ingreso mensual familiar con la clase social, hallé que, a medida que aumenta el ingreso reportado, menor es el porcentaje de personas que dijeron pertenecer a la clase baja y mayor el porcentaje de personas que dijeron ser parte de la clase media (véase la Tabla 7.9). También calculé la mediana del ingreso y encontré que, a mayor la clase social, mayor es esta medida descriptiva. Al comparar las medianas del ingreso mensual familiar, hallé que hay una diferencia de $\$ 300,00$ entre la clase baja y la media y de $\$ 1.640,00$ entre la clase baja y alta. Aunque los(as) residentes afectados(as) por el realojo que se autoclasificaron como de clase alta tuvieron una mediana de ingreso de $\$ 2.240,00$, esta cantidad no es representativa de lo que gana la clase alta de Puerto Rico, por ser esta cantidad muy menor. Sin embargo, como la mayoría de las personas que se autoclasificaron como clase alta son realojados(as) y obtuvieron ingresos altos, en comparación con el porcentaje de personas a ser 
realojadas que señalaron ser miembros de esta clase social, posiblemente el ingreso alto es un factor determinante en la toma de decisión de realojarse voluntariamente.

\section{Tabla 7.9}

Clase social e ingreso mensual familiar de los(as) residentes afectados(as) por el realojo

Clase social

Baja Media Alta Total

Ingreso mensual familiar

$\begin{array}{lccrr}\text { Menos de } \$ 250,00 & 72,7 & 27,3 & 0,0 & 100,0 \\ \$ 250,00 \text { a } \$ 749,00 & 47,8 & 50,0 & 2,2 & 100,0 \\ \$ 750,00 \text { a } \$ 1.249,00 & 39,1 & 60,9 & 0,0 & 100,0 \\ \$ 1.250,00 \text { a } \$ 1.749,00 & 30,8 & 69,2 & 0,0 & 100,0 \\ \$ 1.750,00 \text { o más } & 11,8 & 76,5 & 11,8 & 100,0 \\ \text { Total } & 40,9 & 56,4 & 2,7 & 100,0 \\ \text { Mediana } & \$ 600,00 & \$ 900,00 & \$ 2.240,00 & \end{array}$

Nota: 1 persona no reportó su ingreso mensual familiar.

\subsection{Aspiraciones, pasatiempos y pertenencia a organización}

7.3.1 Aspiraciones. Sobre las aspiraciones ${ }^{7}$ de $\operatorname{los}($ as) residentes a ser realojados(as), las más destacadas son mudarse $(31,1 \%)$ y tener, comprar o arreglar la casa $(22,2 \%)$ (véase la Tabla 7.10$)$.

\footnotetext{
${ }^{7}$ Debido a que las personas podían mencionar más de una aspiración y no había alternativas a escoger por ser una pregunta abierta, los porcentajes no suman 100.
} 
Tabla 7.10

Principales aspiraciones de los(as) residentes a ser realojados(as) (en orden descendente)

Aspiraciones*

Por ciento

Mudarse

Tener, comprar o arreglar casa

Otras

$17,8^{* *}$

Prosperar, progresar económicamente

14,4

No tiene

11,1

Iniciar, continuar o terminar estudios

Conseguir empleo

Seguir adelante...

Iniciar o continuar negocio

Dar educación a hijos(as)

Tener salud y tranquilidad

Viajar o pasear

Pensionarse del trabajo

\footnotetext{
* El(la) participante podía mencionar más de 1.

** Incluye comprar el panteón, quedarse en su casa, esperar esposo, regresar a país de origen, hacer una familia en Puerto Rico, ver cómo progresa esto, irse de luna de miel a Nueva York, saber a donde se va a realojar para terminar de criar a hijos(as), vivir pacíficamente, llevar viejos(as) a citas médicas, tener carro, buscar a Dios e hija tenga casa propia.
} 
Por otro lado, sobre las aspiraciones de los(as) residentes realojados(as), $38,1 \%$ de ellos(as) no tenía alguna aspiración y el 23,8\% aspiraba mudarse (véase la Tabla 7.11). Por lo tanto, una parte de los(as) residentes a ser realojados(as) y de los(as) realojados(as) aspiraba a mudarse, aunque ya hayan cambiado de vivienda como los(as) últimos(as).

\section{Tabla 7.11}

Principales aspiraciones de los(as) residentes realojados(as) (en orden descendente)

No tiene

Mudarse

Otras

Tener, comprar o arreglar casa

Iniciar, continuar o terminar estudios

Seguir adelante...

Iniciar o continuar negocio

Prosperar, progresar económicamente
38,1

$14,3^{* *}$

9,5

9,5

9,5

9,5

4,8

* El(la) participante podía mencionar más de 1.

** Incluye viajar, quedarse ahí tranquila y casarse nuevamente.

7.3.2 Pasatiempos. En cuanto a los pasatiempos ${ }^{8}$ de los(as) residentes a ser realojados(as), los más mencionados son ver televisión $(35,5 \%)$ y salir, caminar o pasear $(34,4 \%)$ (véase la Tabla 7.12).

\footnotetext{
${ }^{8}$ Debido a que las personas podían mencionar más de un pasatiempo y no había alternativas a escoger por ser una pregunta abierta, los porcentajes no suman 100.
} 
Tabla 7.12

Principales pasatiempos de los(as) residentes a ser realojados(as) (en orden descendente)

Pasatiempos*

Por ciento

Ver televisión

Salir, caminar, pasear

Compartir con familiares y amistades

21,1

Limpiar, arreglar y recoger la casa

17,8

Escuchar, estudiar y practicar música

Hacer deportes

Otras

$14,4 * *$

Leer

Hacer juegos pasivos

Hacer manualidades

6,7

\footnotetext{
* El(la) participante podía mencionar más de 1.

** Incluye trabajar, descansar, comer, limpiar zapatos, peinar, apostar hipismo, hacer cosas de mecánica, cocinar, arreglar paraguas, maquillar, hacer chivitos como handyman, beber alcohol y dormir.
}

Respecto a los(as) residentes realojados(as), los pasatiempos con mayor porcentajes son salir, caminar o pasear $(47,6 \%)$ y hacer juegos pasivos, como pescar, jugar dominó, jugar billar y hacer crucigramas $(28,6 \%)$ (véase la Tabla 7.13 ). Por lo tanto, un alto porcentaje de los(as) residentes a ser realojados(as) y de los(as) realojados(as) coincide en que su pasatiempo es salir, caminar o pasear. 
Tabla 7.13

Principales pasatiempos de los(as) residentes realojados(as) (en orden descendente)

Pasatiempos*

Por ciento

Salir, caminar, pasear

47,6

Hacer juegos pasivos

28,6

Otras

$28,6^{* *}$

Ver televisión

23,8

Leer

19,0

Compartir con familiares y amistades

19,0

Hacer manualidades

19,0

Hacer deportes

9,5

Escuchar música

9,5

* El(la) participante podía mencionar más de 1.

** Incluye cocinar, comer, dormir, buscar nietos(as) a la escuela y limpiar.

7.3.3 Pertenencia a organización. Un bajo porcentaje de los(as) residentes a ser realojados(as) (7,8\%) y de los(as) residentes realojados(as) (14,3\%) contestó afirmativamente a la pregunta. Es interesante señalar que el porcentaje de realojados(as) que pertenecía a alguna organización es el doble de la correspondiente a la muestra de los(as) residentes a ser realojados(as).

Al relacionar la pertenencia a una organización y la condición de pobreza, encontré que proporcionalmente son más las personas a ser realojadas no clasificadas ${ }^{9}$

\footnotetext{
${ }^{9}$ Clasifiqué a los(as) participantes de este estudio como pobres o no pobres, siguiendo los umbrales de de pobreza del 2007 del Negociado Federal del Censo.
} 
como pobres que indicaron pertenecer a una organización que las clasificadas como pobres $(15,0 \%$ y $5,8 \%$, respectivamente). Por lo tanto, un mayor porcentaje de pobres que no pobres no pertenecía a una organización (94,2\% vs. 85,0\%, respectivamente).

En cuanto a las personas realojadas, proporcionalmente son más las no pobres que las pobres que pertenecían a una organización $(25,0 \%$ vs. $11,8 \%$, respectivamente). Por lo tanto, un mayor porcentaje de pobres informó no pertenecer a una organización que de no pobres $(88,2 \%$ vs. $75,0 \%$, respectivamente).

Al comparar ambas muestras, encontré que es mayor el porcentaje de personas pobres a ser realojadas que no pertenecían a una organización $(94,2 \%)$.

\subsection{Características de la vivienda}

7.4.1 Tenencia del hogar. Más de la mitad de los(as) residentes a ser realojados(as) y de los(as) realojados(as) era dueño(a) de su hogar (véase la Tabla 7.12). Entre los(as) residentes a ser realojados(as) también se destaca el porcentaje de personas que informaron ser parientes del dueño(a). Es importante notar el porcentaje de personas realojadas que informó ser inquilino(a) en uno de los tres proyectos de vivienda porque esta práctica está prohibida. Para explicar que alguien haya contestado que es inquilino(a) de una vivienda en un proyecto construido para las familias que estaban residiendo en lugares de donde serían realojadas de no haberse mudado antes, entiendo que existen dos posibilidades. Una posibilidad es que la persona se considere inquilina, cuando es propietaria verdaderamente, porque al no poder realizar cambios durante 5 años a la estructura, específicamente la fachada de su vivienda, no se considera dueño(a) de la misma. Como dijo una persona realojada: "No eres dueño de tu propia casa. Preferiría que nos pagara. Hay restricciones. Es tu casa o no es tu casa. No puedes hacer cambios en 5 años". Otra posibilidad es que 
el(la) propietario(a) de la vivienda haya alquilado la misma y esté recibiendo ingresos por ello.

7.4.2 Año en que comenzó a residir en esa vivienda. El 7,8\% de los(as) residentes a ser realojados(as) señaló un año de la primera mitad del siglo XX y el 75,6\% residía en su hogar desde algún año de la segunda mitad del siglo pasado (véase la Tabla 7.14). La mediana del año desde que comenzó a residir en esa vivienda es 1981. Por otro lado, los(as) realojados(as) comenzaron a residir en los proyectos de vivienda a partir del 2001; la gran mayoría (80,9\%) comenzó a residir en esa vivienda entre el 2002 y el 2004. La mediana del año desde que comenzó a residir en esa vivienda es 2003.

\section{Tabla 7.14}

Características sobre vivienda de los(as) residentes a ser realojados(as) y los(as) residentes realojados(as)

$\begin{array}{lll}\text { Característica } & \begin{array}{l}\text { Residentes a ser } \\ \text { realojados(as) }\end{array} & \begin{array}{l}\text { Residentes } \\ \text { realojados(as) }\end{array}\end{array}$

Tenencia

Dueño(a)

60,0

76,2

Inquilino(a)

18,9

4,8

Otro(a)

21,1

19,0

Total

100,0

100,0

(90)

Otro tipo de tenencia

Pariente de dueño(a)

78,9

100,0

(tabla continúa) 
Característica

Heredero(a)

Total

a 1959

1960 a 1969

1970 a 1979

1980 a 1989

1990 a 1999

2000 en adelante

Total

Mediana

Total

2001

2002

2003

2004

2006
Residentes a ser realojados(as)
Residentes

realojados(as)
21,1

100,0

100,0

(19)

(4)
1,1

6,7

10,0

17,8

13,3

15,6

18,9

16,7

100,0

(90)

1981

90

14,3

33,3

23,8

23,8

4,8

(tabla continúa) 


$\begin{array}{lll}\text { Característica } & \begin{array}{l}\text { Residentes a ser } \\ \text { realojados(as) }\end{array} & \begin{array}{l}\text { Residentes } \\ \text { realojados(as) }\end{array}\end{array}$

Total

100,0

Mediana

2003

Total

21

Año desde que reside en comunidad

\begin{tabular}{lcc}
1930 a 1939 & 2,2 & 0,0 \\
1940 a 1949 & 14,6 & 9,5 \\
1950 a 1959 & 18,0 & 23,8 \\
1960 a 1969 & 18,0 & 9,5 \\
1970 a 1979 & 15,7 & 14,3 \\
1980 a 1989 & 11,2 & 19,0 \\
1990 a 1999 & 16,9 & 14,3 \\
2000 en adelante & 3,4 & 9,5 \\
Total & 100,0 & 100,0 \\
& $(89)^{*}$ & $(21)$ \\
Mediana & 1967 & 1974 \\
\hline
\end{tabular}

* Una persona no recuerda.

7.4.3 Año en que comenzó a residir en la comunidad. Poco más de una tercera parte de los(as) residentes a ser realojados(as) comenzó a residir entre las décadas de 1950 y 1960 (véase la Tabla 7.12). Además, la gran mayoría (94,4\%) residía en la comunidad desde antes del 1999. Es interesante señalar que un 2,2\% 
residía en la comunidad desde la década del 1930 porque posiblemente son fundadores(as) de la misma. La mediana del año desde que reside en la comunidad es 1967. Por otro lado, poco menos de la mitad de los(as) realojados(as) vivía en la comunidad desde las décadas de 1970 a 1990. La mediana del año desde que reside en la comunidad es 1974. Para las personas a ser realojadas, las décadas con mayor porcentaje son las de 1950 y 1960 y para las personas realojadas es la de 1950, coincidiendo para ambas muestras la década de 1950 con el porcentaje más alto. Además, al comparar las medianas, se observa que la correspondiente a las personas realojadas es más reciente.

7.4.4 Antepasados(as) en la comunidad. El 71,1\% de las personas a ser realojadas tenía antepasados(as) que han vivido en la misma comunidad (véase la Tabla 7.15). De estas personas, cerca del $40 \%$ indicó que sus antepasados(as) llegaron durante la primera mitad del siglo $\mathrm{XX}$.

\section{Tabla 7.15}

Antepasados(as) de los(as) residentes a ser realojados(as) y los(as) residentes realojados(as) en la comunidad

\begin{tabular}{lll} 
Característica & $\begin{array}{l}\text { Residentes a ser } \\
\text { realojados(as) }\end{array}$ & $\begin{array}{l}\text { Residentes } \\
\text { realojados(as) }\end{array}$ \\
\hline
\end{tabular}

Antepasados(as) que han vivido en comunidad

$\begin{array}{lcr}\text { Sí } & 71,1 & 57,1 \\ \text { No } & 28,9 & 42,9 \\ \text { Total } & 100,0 & 100,0\end{array}$


Característica
Residentes a ser

realojados(as)
Residentes

realojados(as)

Fecha en que llegaron antepasados(as)

\begin{tabular}{|c|c|c|}
\hline 1910 a 1919 & 3,1 & 0,0 \\
\hline 1920 a 1929 & 6,3 & 0,0 \\
\hline 1930 a 1939 & 10,9 & 8,3 \\
\hline 1940 a 1949 & 18,8 & 25,0 \\
\hline 1950 a 1959 & 23,4 & 33,3 \\
\hline 1960 a 1969 & 10,9 & 33,3 \\
\hline 1970 a 1979 & 9,4 & 0,0 \\
\hline 1980 a 1989 & 3,1 & 0,0 \\
\hline 1990 a 1999 & 4,7 & 0,0 \\
\hline 2000 en adelante & 1,6 & 0,0 \\
\hline No sabe & 7,8 & 0,0 \\
\hline \multirow[t]{2}{*}{ Total } & 100,0 & 100,0 \\
\hline & (64) & (12) \\
\hline Mediana & 1950 & $1953-4$ \\
\hline Total & $59 *$ & 12 \\
\hline
\end{tabular}

* No están incluidas las personas que no sabían cuándo llegaron sus antepasados(as) y las personas que no tienen antepasados(as) que hayan vivido en la comunidad.

La mediana del año en que llegaron sus antepasados(as) es 1950. Por otro lado, el $57,1 \%$ de las personas realojadas tenía antepasados(as) que han vivido en la misma comunidad. De estas personas, el 33,3\% indicó que sus antepasados(as) 
llegaron durante la primera mitad del siglo XX. La mediana del año en que llegaron sus antepasados(as) es 1954. Para las personas a ser realojadas, las décadas con mayor porcentaje son las décadas de 1940 y 1950 y, para las personas realojadas, son las décadas 1950 y 1960, coincidiendo para ambas muestras la década de 1950 con el porcentaje más alto. Además, al comparar las medianas, se observa que ambas son muy similares.

7.4.5 Aspectos que molestan de la comunidad. Entre los aspectos de la $\operatorname{comunidad}^{10}$ que molestaban a los(as) residentes a ser realojados(as), los más mencionados son las inundaciones $(21,1 \%)$; la venta y el uso de drogas ilegales $(21,1 \%)$; la basura acumulada alrededor $(17,8 \%)$; las plagas de animales, como ratas y mosquitos $(14,4 \%)$; la no disposición apropiada de las aguas servidas $(13,3 \%)$ (véase la Ilustración 7.1); y el abandono, descuido y falta de mantenimiento de la comunidad $(13,3 \%)$ (véase la Tabla 7.16). Cabe señalar que el 18,9\% mencionó que no hay aspectos que le molesten.

\section{Tabla 7.16}

Principales aspectos de la comunidad que le molestan a los(as) residentes a ser realojados(as) (en orden descendente)

$\begin{array}{ll}\text { Aspectos que molestan* } & \begin{array}{l}\text { Residentes a ser } \\ \text { realojados(as) }\end{array}\end{array}$

Inundaciones

Venta y uso de drogas ilegales

Ninguno

(tabla continúa)

\footnotetext{
${ }^{10}$ Debido a que las personas podían mencionar más de un aspecto y no había alternativas a escoger por ser una pregunta abierta, los porcentajes no suman 100 .
} 
Aspectos que molestan*

Residentes a ser

realojados(as)

Basura acumulada alrededor

Plagas de animales (ratones, mosquitos)

No disposición apropiada de aguas servidas

Abandono, descuido y falta de mantenimiento de comunidad

Vecinos(as) problemáticos(as)

Caño contaminado y tapado

Otras

Calles dañadas y maltratadas

Ineficiencia del gobierno

Falta de espacio (estacionamiento y recreación)

Falta de vigilancia, seguridad y protección

Criminalidad

Ruidos en las calles

Personas sin hogar (deambulantes)

\footnotetext{
* El(la) participante podía mencionar más de 1.

** Incluye abuso a ancianos(as), falta de progreso en personas, politiquería por encima de intereses de comunidad, discriminación y selección de personas a realojar, mala administración de bienes, peste y fanguero al llover.
}

En cuanto a los aspectos de la comunidad que molestaban a los(as) residentes realojados(as), los más mencionados son los requisitos para vivir en los proyectos de vivienda $(23,8 \%)$, los vicios de construcción de dichos proyectos $(19,0 \%)$, los(as) vecinos(as) problemáticos(as) $(14,3 \%)$ y el diseño de los proyectos $(14,3 \%)$ (véase la 
Tabla 7.17). El 28,6\% de los(as) realojados(as) indicó que no hay aspectos que le molesten.

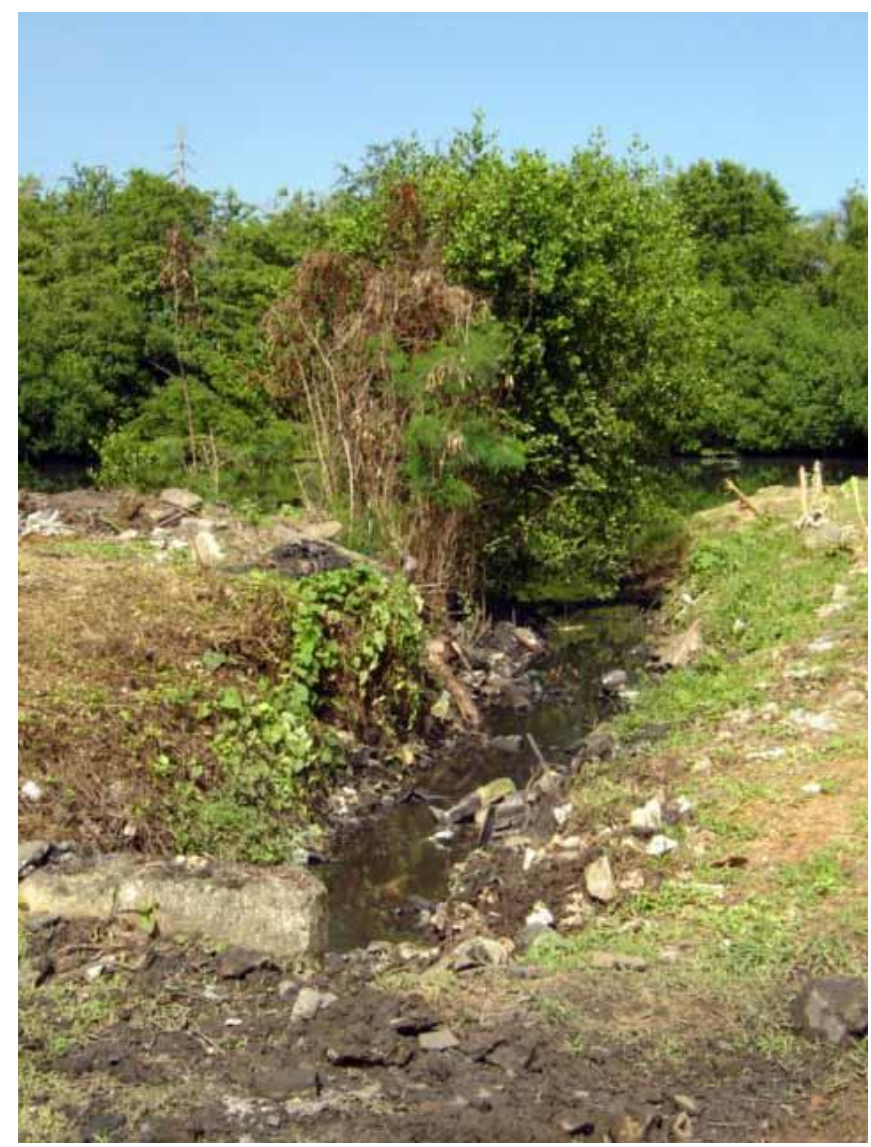

Ilustración 7.1. Desagüe y basura acumulada en el caño. Foto de la autora.

\section{Tabla 7.17}

Principales aspectos de la comunidad que le molestan a los(as) residentes realojados(as) (en orden descendente)

Aspectos que molestan*

Residentes

realojados(as)

Ninguno

28,6

(tabla continúa) 
Aspectos que molestan*

Residentes

realojados(as)

Requisitos para vivir en proyectos

23,8

Vicios de construcción

19,0

Vecinos(as) problemáticos(as)

Diseño de proyectos

Basura alrededor de proyectos

Basura fuera o en recipiente equivocado

Situación actual del caño y laguna

Criminalidad alrededor de proyectos

Otras

* El(la) participante podía mencionar más de 1.

** Incluye abandono por parte del gobierno.

Al comparar los aspectos que molestan a las personas a ser realojadas y las realojadas, resalta que no coincidieron en los mismos y que los aspectos que desagradaban son particulares del área donde residen. En el caso de los(as) residentes a ser realojados(as), los aspectos que les molestaban son de tipo social (drogas ilegales) y ambiental (inundaciones, basura acumulada, plagas de animales, aguas servidas [véase la Ilustración 7.2] y falta de mantenimiento), mientras que los aspectos que molestaban a los(as) residentes realojados(as) son de tipo residencial (requisitos para vivir, vicios de construcción y vecinos[as] problemáticos[as]).

Sobre el problema de la basura, observé que éste es más grave cuando la basura es acumulada ilegalmente en terrenos baldíos, donde las viviendas fueron demolidas. Ejemplos de artículos tirados son ropa, zapatos viejos y una cabecera de 
cama. Según comentó una líder comunitaria, en una ocasión limpiaron y cercaron con candado el área, pero dicen en la comunidad que le dieron la llave a un(a) deambulante (persona sin hogar) y volvió a convertirse en un basurero que mide más de 6 pies de altura.

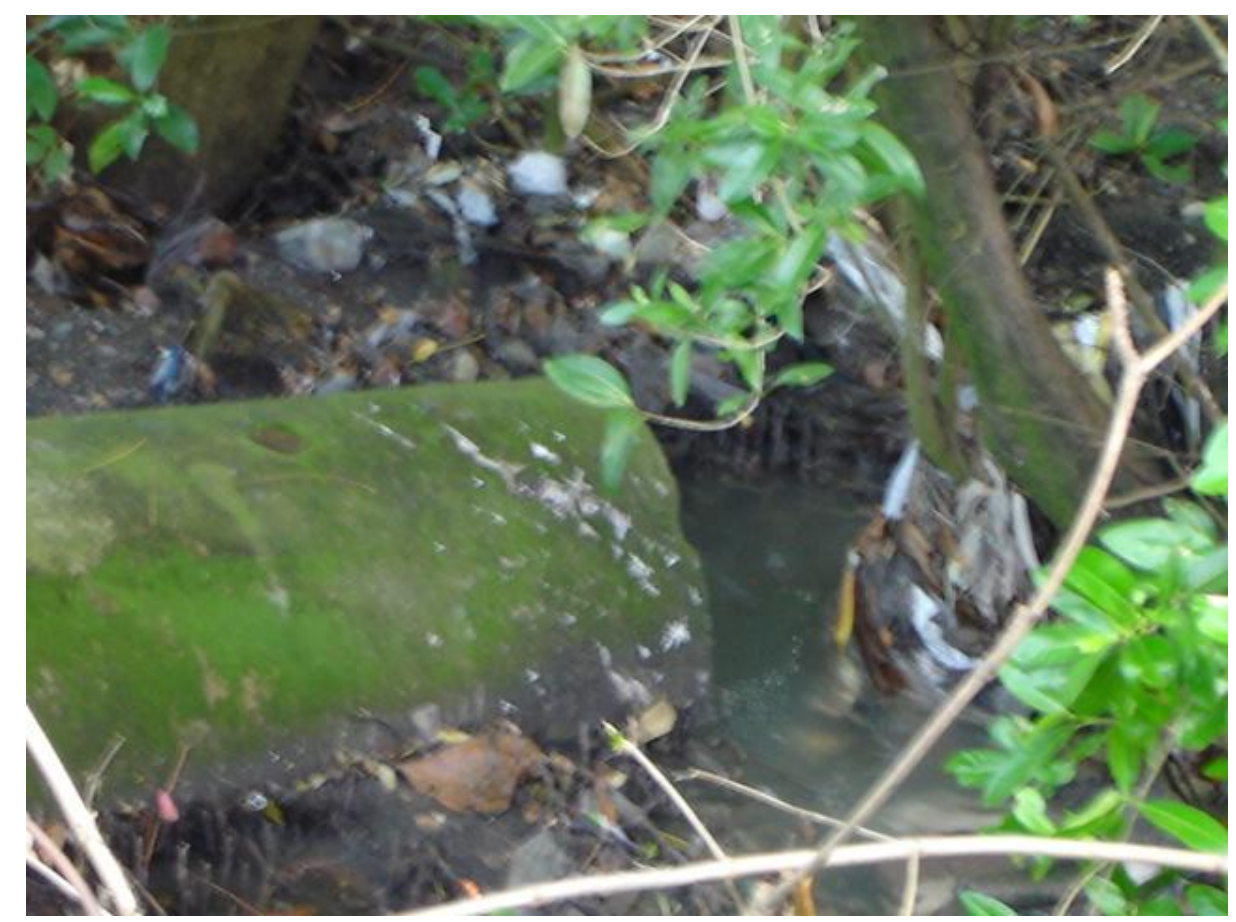

Ilustración 7.2. Desagüe de aguas servidas al caño. Foto de la autora.

En cuanto al problema de las inundaciones y las aguas servidas, un líder comunitario dijo que, cuando llueve, sube la marea y sale el agua a la calle con el babote negro del manglar y añadió que el problema es que el agua que sube está llena de excrementos porque los tubos de aguas servidas salen al caño y el agua del caño no fluye por lo tapado que está. Entonces, esta situación crea otro problema, el de las tuberías tapadas, porque las salidas de las mismas al caño están tapadas, según un residente. Otro problema relacionado es el mencionado por un(a) residente, quien señaló que se llena el alcantarillado, por lo que sube excreta por el inodoro. Sobre la causa de este problema, una persona dijo que "el agua no está deteriorada por los 
residentes que la fundaron, sino por el gobierno que no puso verja para proteger el agua. Está dañado por edificios que han construido y tiran sus aguas sucias". Cuando el problema es de inundaciones por lluvia, una persona realojada dijo que en su casa anterior no podía quedarse porque "el nivel del agua no bajaba por un mes. Aún con sol, estaba lleno de agua”.

7.4.6 Problemas sociales en la comunidad. Además de los aspectos sociales que molestaban de la comunidad, están los problemas sociales ${ }^{11}$ que los(as) residentes identificaron como presentes en la comunidad. La gran mayoría de los(as) residentes a ser realojados(as) creían que había problemas sociales. Los problemas sociales más mencionados por los(as) residentes a ser realojados(as) son la adicción a drogas ilegales (presencia de puntos de drogas y de personas usándolas [inyectándose]) (45,6\%), criminalidad (asesinatos y homicidios) (43,3\%), deserción escolar $(27,8 \%)$ y embarazo en adolescentes (27,8\%) (véase la Tabla 7.18).

\section{Tabla 7.18}

Principales problemas sociales presentes en la comunidad, según los(as) residentes a ser realojados(as) (en orden descendente)

Problemas sociales*
Residentes a ser

realojados(as)
Drogadicción

Criminalidad

Deserción escolar

Embarazo en adolescentes

(tabla continúa)

\footnotetext{
${ }^{11}$ Debido a que las personas podían mencionar más de un problema social y no había alternativas a escoger por ser una pregunta abierta, los porcentajes no suman 100.
} 
Problemas sociales*

Residentes a ser

realojados(as)

Ninguno

Otros

Personas sin hogar (deambulantes)

Alcantarillado tapado

Desempleo

Falta de seguridad

Falta de atención y supervisión a jóvenes
24,4

$7,8 * *$

\section{3,3}

3,3

2,2

2,2

2,2

\footnotetext{
* El(la) participante podía mencionar más de 1.

** Incluye servicios de agua y luz suspendidos, vertedero clandestino, dengue, abuso a personas mayores, desorden y bullicio de gente, hacinamiento y diferencias con dominicanos(as).
}

Otros problemas sociales mencionados son la presencia de deambulantes (véase la Ilustración 7.3) y de "maleantes, personas raras", problemas económicos, como la pobreza y la falta de trabajo, y "muchachos realengos, abandono de niños". También mencionaron otros tipos de problemas, como el ambiental, refiriéndose a "plagas de mosquitos, alacranes, cucarachas, ratas" e inundaciones, y de infraestructura, como la presión baja del agua y apagones y bajones de electricidad. Sobre si conocían personas con esos problemas, sólo un residente respondió afirmativamente y añadió que no son allegados y dos residentes dijeron que no conocen personas afectadas. Además, el $24,4 \%$ de las personas a ser realojadas mencionó que no hay problemas en su comunidad. 


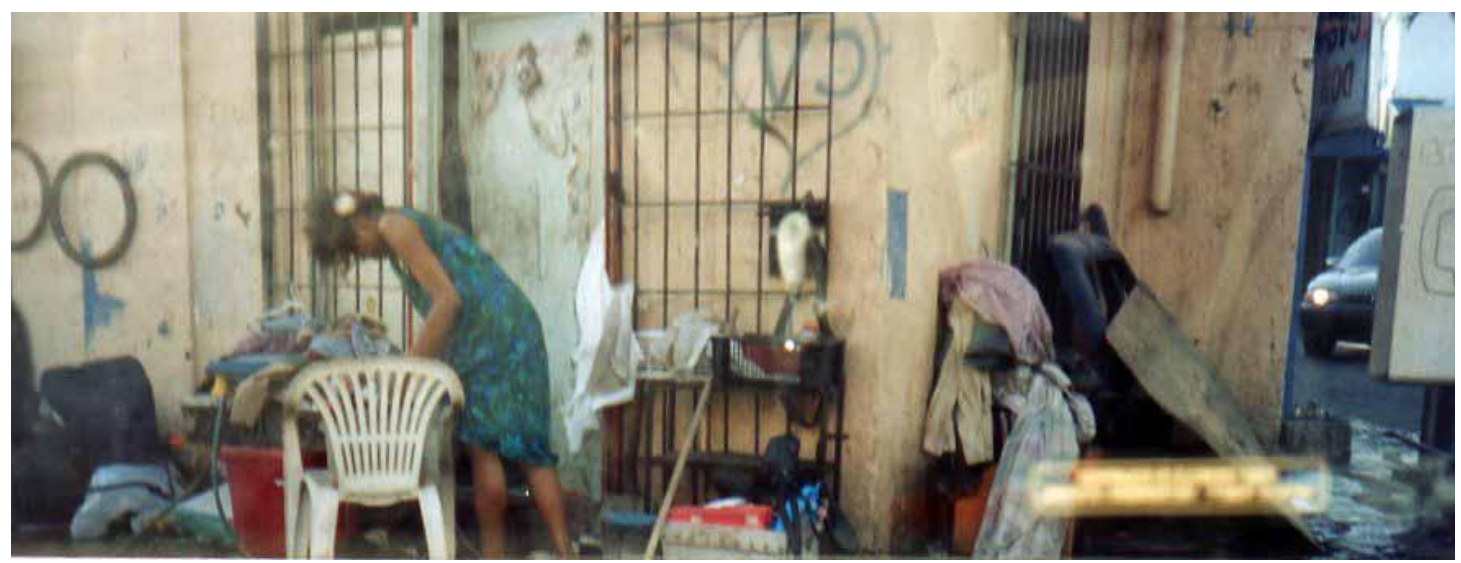

Ilustración 7.3. Mujer sin hogar, con pertenencias frente a vivienda, ubicada en la avenida principal que cruza la comunidad estudiada. Foto de la autora.

Entre los problemas sociales mencionados por los(as) residentes realojados(as), están los(as) vecinos(as) problemáticos(as) (14,3\%), ruido dentro y fuera de los proyectos de vivienda $(9,5 \%)$, adicción a drogas ilegales $(9,5 \%)$ y criminalidad (asesinatos y homicidios) (9,5\%) (véase la Tabla 7.19). Otro problema mencionado es la existencia de casas abandonadas que se han vuelto "hospitalillos" (lugares donde los[as] adictos[as] consumen las drogas ilegales [particularmente, inyectándose drogas intravenosas]).

\section{Tabla 7.19}

Principales problemas sociales presentes en la comunidad, según los(as) residentes realojados(as) (en orden descendente)

Problemas sociales*

Residentes realojados(as)

Ninguno 61,9

Vecinos(as) problemáticos(as) 14,3

Ruido dentro y fuera de proyectos 9,5

(tabla continúa) 
Problemas sociales*

Residentes

realojados(as)

Drogadicción

Criminalidad

Otras

No sabe

Falta de atención y supervisión a jóvenes
9,5

9,5

$4,8 * *$

4,8

4,8

* El(la) participante podía mencionar más de 1.

** Incluye basura.

El residente de 61 años que mencionó ese último problema dijo que "se ha dañado ahora porque han sacado casas y todo eso y se ha vuelto tierra de nadie”. Más de la mitad de los(as) realojados(as) indicó que no había problemas sociales en su comunidad.

Sobre si conocían personas con esos problemas, más de la mitad de los(as) residentes realojados(as) afirmó conocerlas y sólo una persona dijo que no había problemas ni conoce gente con problemas. Los(as) residentes a ser realojados(as) y los(as) residentes realojados(as) coincidieron al mencionar la criminalidad, deserción escolar y embarazos en adolescentes, como los problemas sociales que abundan en su comunidad. Al comparar los problemas sociales mencionados por las personas a ser realojadas y las realojadas, resalta que el porcentaje de personas realojadas que indicó que no había problemas es 2,5 veces el porcentaje de personas a ser realojadas que contestó lo mismo. Aunque son varios los problemas sociales presentes en la 
comunidad, pocos(as) residentes indicaron conocer personas que tenían estos problemas.

\subsection{Haber vivido en otras comunidades de San Juan}

Pocas personas señalaron haber vivido en otras comunidades de la ciudad capital, siendo el $22,2 \%$ de las personas a ser realojadas y el $38,1 \%$ de las personas realojadas. Sobre las comunidades de San Juan donde ha vivido el 22,2\% de los(as) residentes a ser realojados(as), poco más de la mitad son barrios pobres. Asimismo, la mitad de las comunidades donde ha vivido el $38,1 \%$ de $\operatorname{los}($ as) residentes realojados(as) son barrios pobres.

\subsection{Parientes residiendo en la comunidad}

Casi tres cuartas partes de $\operatorname{los}($ as) residentes a ser realojados(as) tenían parientes en la comunidad estudiada. De estos(as) residentes, cerca del $41 \%$ señaló que tenía 5 o más parientes y cerca del $40 \%$ dijo que tenía 1 ó 2 parientes residiendo en la misma comunidad. La mediana de parientes es 3. Además, casi todos(as) $(90,9 \%) \operatorname{los}($ as $)$ residentes a ser realojados(as) que tenían parientes en la misma comunidad señalaron que se ayudan mutuamente.

Por otro lado, más de la mitad $(61,9 \%)$ de los(as) residentes realojados(as) tenía parientes en la comunidad estudiada. De estos(as) residentes, poco más de la mitad $(53,8 \%)$ señaló que tenía 1 ó 2 parientes residiendo en la misma comunidad. La mediana de parientes es 2. Además, casi todos(as) $(84,6 \%)$ los(as) residentes realojados(as) que tenían parientes en la misma comunidad señalaron que se ayudaban mutuamente. Aproximadamente cuatro quintas partes de los(as) residentes a ser realojados(as) y aproximadamente tres quintas partes de los(as) residentes realojados(as) veían a sus parientes todos los días. 


\subsection{Redes de apoyo en la comunidad}

7.7.1 Matrimonio. El 34,4\% de los(as) residentes a ser realojados(as) y el 43,9\% de los(as) residentes realojados(as) indicó haberse casado(a) con alguien de la comunidad. Además, más de la mitad de los(as) residentes a ser realojados(as) y los(as) residentes realojados(as) señaló conocer otras personas que se habían casado con personas de la misma comunidad $(67,8 \%$ y $71,4 \%$, respectivamente). Al comparar ambas muestras, destaca el porcentaje mayor de realojados(as) que se habían casado con residentes de la comunidad y el porcentaje mayor de realojados(as) que conocían personas que se habían casado con miembros de la comunidad.

\subsubsection{Compadrazgo. Una tercera parte de los(as) residentes a ser} realojados(as) habían escogido padrinos y/o madrinas de la misma comunidad, siendo este porcentaje 3,5 veces el correspondiente a las personas realojadas que habían escogido padrinos y/o madrinas a sus hijos(as) de la comunidad $(9,5 \%)$ (véase la Tabla 7.20). Posiblemente, la diferencia se deba a la religión que practique el(la) residente, ya que en esta comunidad hay otras religiones además de la católica, la cual se destaca entre las demás por la selección de padrinos y madrinas en tres de sus sacramentos, a saber, el bautismo, la confirmación y el matrimonio. En la comunidad estudiada, hay varias iglesias cristianas y personas que han señalado practicar las mismas. Las religiones presentes en la comunidad son la adventista, bautista, católica, discípulos de Cristo, metodista, mita y pentecostal. Por lo tanto, con excepción de la católica, hay un mínimo de seis religiones con practicantes en la comunidad, quienes posiblemente no han asignado padrinos y madrinas a sus hijos(as). Entre las razones presentadas por los(as) residentes a ser realojados(as) para la selección de otros(as) residentes como padrinos y madrinas, se destacan el conocerlos(as) desde hace tiempo $(20,0 \%)$, el llevarse bien $(20,0 \%)$ y que son buenos(as) vecinos(as) $(16,7 \%)$. Por otro 
lado, $\operatorname{los}$ (as) realojados(as) que escogieron padrinos y/o madrinas indicaron que lo hicieron porque los(as) vecinos(as) son serios(as). Además, independientemente de que hayan seleccionado padrinos y/o madrinas, más de la mitad de los(as) residentes a ser realojados(as) y de los(as) realojados(as) indicó conocer personas que lo hayan hecho $(64,4 \%$ y $57,1 \%$, respectivamente).

\section{Tabla 7.20}

Compadrazgo en la comunidad de los(as) residentes a ser realojados(as) y los(as) residentes realojados(as) en la comunidad

Característica

Haber asignado padrinos o madrinas de la misma comunidad

Sí

No

Total

$$
33,3
$$

$$
66,7
$$

100,0

\section{9,5}

90,5

100,0

Razón por la que asignaron padrinos y madrinas de la comunidad

Vecino(a) quería serlo

Vecinos(as) buenos(as)

Los(as) conoce desde hace tiempo

Son como familia

Vecinos(as) serios(as)

Son cercanos(as)

Nos llevamos bien

\section{6,7}

16,7

20,0

10,0

10,0

6,7

20,0
0,0

0,0

0,0

0,0

100,0

0,0

0,0 


$\begin{array}{lll}\text { Característica } & \begin{array}{l}\text { Residentes a ser } \\ \text { realojados(as) }\end{array} & \begin{array}{l}\text { Residentes } \\ \text { realojados(as) }\end{array}\end{array}$

$\begin{array}{lrr}\text { Hay confianza } & 10,0 & 0,0 \\ \text { Total } & 100,0 & 100,0\end{array}$

Conocer personas que hayan asignado padrinos o madrinas de la comunidad

$\begin{array}{lrr}\text { Sí } & 64,4 & 57,1 \\ \text { No } & 35,6 & 42,9 \\ \text { Total } & 100,0 & 100,0\end{array}$

7.7.3 Relaciones entre vecinos(as). Cerca del $68 \%$ de las personas a ser realojadas dijo conocer personas que habían nacido en el mismo lugar, ya sea barrio y/o municipio, siendo 1,7 veces el porcentaje de los(as) realojados(as) que indicaron lo mismo. La gran mayoría de los(as) residentes a ser realojados(as) y de los(as) realojados(as) indicaron que había ayuda y/o cooperación entre vecinos(as) (87,8\% y $85,7 \%$, respectivamente).

De las personas a ser realojadas que indicaron que los(as) vecinos(as) se ayudaban, los tipos de ayuda ${ }^{12}$ más mencionados son hacer favores (tareas del hogar, como planchar y cocinar, hacer mudanza y cargar la compra) $(24,1 \%)$, estar pendiente y/o velar (al enfermo[a], al viejo[a] y a vecinos[as] con familiares fallecidos[as]) $(16,5 \%)$, dar comida $(12,7 \%)$, ayudar al enfermo(a) $(11,4 \%)$, ayudar en emergencias

\footnotetext{
12 Debido a que las personas podían mencionar más de un tipo de ayuda y no había alternativas a escoger por ser una pregunta abierta, los porcentajes no suman 100.
} 
(tormentas e inundaciones) $(11,4 \%)$, y ayudar de manera general $(11,4 \%)$ (véase la Tabla 7.21).

\section{Tabla 7.21}

Principales tipos de ayuda entre los(as) vecinos(as), según los(as) residentes a ser realojados(as) (en orden descendente)

Tipos de ayuda*

Residentes a ser

realojados(as)

Hacer favores

24,1

Estar pendiente/velar

16,5

Dar comida

12,7

Ayudar al enfermo(a)

11,4

Ayudar en emergencias (inundaciones, tormentas)

11,4

Ayudar de manera general

11,4

Prestarse cosas

10,1

Reparar casa

10,1

Visitar/hacer compañía

10,1

Limpiar áreas comunes

8,9

Dar ingredientes de cocina

Proveer transportación

6,3

Organizar actividades sociales

5,1

Resolver problemas técnicos

5,1

Dar vigilancia

3,8

Cuidar niños(as)

3,8

(tabla continúa) 
Tipos de ayuda*

Residentes a ser

realojados(as)

Dar agua y electricidad

Regalar frutos del campo

Compartir

Otras

* El(la) participante podía mencionar más de 1.

** Incluye hacer regalos de Navidad y cooperar en reuniones.

De las personas realojadas que indicaron que los(as) vecinos(as) se ayudaban, los tipos de ayuda más mencionados son limpiar áreas comunes $(44,4 \%)$, hacer favores (destapar tuberías, limpiar, cambiar llantas de auto y buscar el correo) (27,8\%), estar pendiente y/o velar (al enfermo[a] y al viejo[a]) (22,2\%), dar ingredientes de cocina $(16,7 \%)$ y visitar y/o hacer compañía (al enfermo[a]) $(11,1 \%)$ (véase la Tabla 7.22).

\section{Tabla 7.22}

Principales tipos de ayuda entre los(as) vecinos(as), según los(as) residentes realojados(as) (en orden descendente)

Tipos de ayuda*

Residentes

realojados(as)

Limpiar áreas comunes

44,4

Hacer favores

27,8

(tabla continúa) 
Tipos de ayuda*

Residentes

realojados(as)

Estar pendiente/velar

22,2

Dar ingredientes de cocina

16,7

Visitar/hacer compañía

Cortar patio

Decorar

11,1

Ayudar en emergencias

Proveer transportación

Ayudar al enfermo(a)

Prestarse cosas

Dar vigilancia

Resolver problemas económicos

Ayudarse de manera general

Otras

Total

* El(la) participante podía mencionar más de 1.

** Incluye ayudarse mutuamente y pintar estacionamiento.

Debido a que esta comunidad se formó hace poco menos de un siglo y a la alta expectativa de vida de los(as) residentes en Puerto Rico, pude explorar si los(as) residentes sabían si viven aún las personas que fundaron la comunidad. De los(as) residentes a ser realojados(as), más de la mitad (60,0\%) dijo que aún vivían en la comunidad algunas personas que la fundaron. De estas personas, cerca del $65 \%$ dijo 
que es su vecino(a) o un(a) amigo(a) y el 25,9\% dijo que es un familiar. Es interesante que el 9,3\% de los(as) residentes a ser realojados(as) indicó ser fundador(a) de la comunidad, por lo que la han visto desarrollarse y posiblemente han de tener sentimientos que han de influir sobre sus actitudes hacia el realojo.

Por otro lado, de los(as) residentes realojados(as), la mitad (52,4\%) dijo que aún vivían en la comunidad algunas personas que la fundaron. De estas personas, cerca del $82 \%$ dijo que es su vecino(a) y el 18,2\% dijo que es un(a) familiar. En esta muestra no hay residentes realojados(as) que se consideren fundadores(as) de la comunidad.

\subsection{Composición del hogar}

Tres de cada 10 residentes a ser realojados(as) vivían en un hogar de 2 miembros (1 persona adicional a la persona entrevistada) y el 28,9\% vivía en un hogar con 2 ó 3 miembros más. Además, el 22,2\% de los(as) residentes a ser realojados(as) vivía solo(a). Por otro lado, poco más de la mitad $(57,1 \%)$ de las personas realojadas vivía con 2 ó 3 personas más y el 23,8\% vive solo(a). Ambas muestras tienen porcentajes similares de residentes(as) viviendo solos(as). Sobre el parentesco de las personas que vivían con los(as) residentes participantes de este estudio, poco menos de la mitad de las personas residiendo en los hogares de los(as) residentes a ser realojados(as) y de los(as) residentes realojados(as) eran $\operatorname{los}($ as) hijos(as) y cerca de una cuarta parte eran los(as) cónyuges.

\subsection{Características de los(as) pobres}

Al preguntarles quiénes son los(as) pobres a los(as) residentes a ser realojados(as), éstos mencionaron características objetivas y subjetivas. Entre las objetivas, destacan las de tipo material, como el no poseer o tener dificultad para conseguir una vivienda, un vehículo, ropa (o ropa nueva) y zapatos. Otras 
características son que no pueda darles educación a sus hijos(as), que no tengan donde dormir y comer y recursos ni dinero para comprar y comer. Entre las características subjetivas, está la sentimental/emocional, como dijo un hombre de 46 años: "Los que no tienen corazón, que no tienen sentimiento. Son gente que es pobre. Porque si tienes un buen corazón, un corazón bonito, eres rico”. De la misma manera, una mujer afirmó que los(as) pobres son gente buena y humilde. Además, dos residentes a ser realojados de 69 y 77 años señalaron a $\operatorname{los}($ as) "deambulantes que andan por las calles" y personas metidas "en el vecindario todos los días pidiendo taza de café o plato de comida" como personas pobres. Por otro lado, sobre si se consideran pobres, 6 residentes de los 16 indicaron que sí. Entre las razones presentadas, destacan la dificultad para conseguir algo y el lugar de residencia. En cuanto a la primera explicación, una mujer de 39 años dijo: "Somos nosotros porque se nos hace difícil conseguir las cosas, como vehículo, casa, educación que no puedo darle a mis hijos”. Respecto al otro tipo de explicación, el vivir en una barriada o comunidad pobre y no en una urbanización les hace ser pobres, como apuntó un hombre de 60 años: "Yo porque no soy de clase media. Vivo en una comunidad pobre. Esto no es una urbanización”. Interesante es una explicación de un hombre de 54 años, quien dijo que es pobre porque trabaja, por lo que no puede recibir beneficios del gobierno y añade que los(as) que viven en residencial público no son pobres porque reciben mucho del gobierno. Por otro lado, dos mujeres contestaron que no son pobres. Una indicó que no le falta nada y la otra señaló que es de clase media porque tiene un techo.

Respecto a los(as) residentes realojados(as) y las características presentadas para describir a las personas pobres, destacan las objetivas. Entre las objetivas, están el querer tener una mejor casa y un carro nuevo, el tener pocos o bajos recursos y el 
no tener familiares ni dinero. Así como mencionaron quiénes son los(as) pobres, algunas personas indicaron quiénes son los(as) ricos(as), como una mujer de 45 años que dijo que "el que tiene a Papá Dios en el alma es rico" y como una mujer de 73 años, quien sentenció que "el rico tiene todas las comodidades que quiere tener un ser humano". Además, un hombre de 50 años, quien cree que hoy día no existen los(as) pobres, identificó a unas personas en condiciones particulares como pobres al decir que "son los que andaban descalzos en casas de paja".

Los(as) residentes a ser realojados(as) y los(as) residentes realojados(as) coincidieron en que los(as) pobres no tienen los recursos suficientes, no tienen vivienda o no pueden tener una mejor vivienda y no tienen vehículo o no pueden tener un vehículo nuevo. Los(as) residentes afectados(as) por el realojo coincidieron en las razones presentadas para explicar por qué se consideran pobres, las cuales son la dificultad de conseguir cosas y su lugar de residencia actual, ya que desean vivir en otros sitios.

\subsection{Considerarse pobres}

Por otro lado, sobre si se consideran pobres, más de la mitad de los(as) residentes dijo que lo son y las razones presentadas son que siempre lo han sido por razones económicas y cuestiones de trabajo, no tienen dinero para lo que necesitan y no pueden vivir en una mejor vivienda que la que tienen. Esta última razón la dio una mujer de 73 años: "Si pudiera irme de aquí para otro sitio. Hay mucha gente que cogió esto aquí porque era lo que había, pero hay mucha gente que se quiere ir porque no se sienten bien".

Los(as) residentes afectados(as) por el realojo de sus viviendas tienen algunas características mencionadas por las teorías de la pobreza urbana, como bajo nivel de escolaridad, porcentaje considerable de recipientes de ayudas económicas (bienestar 
social), baja participación en organizaciones, alto porcentaje de personas fuera de la fuerza laboral y desempleadas, residencia de personas que no tienen aspiraciones y presencia de problemas sociales, como criminalidad y drogadicción.

Entonces, las actitudes de los(as) residentes afectados(as) por el realojo de sus viviendas son influidas por sus impresiones, de acuerdo a experiencias vividas. El realojo de sus viviendas ha causado en los(as) residentes dudas y preocupaciones y ha llevado a que ellos(as) propongan sugerencias para mejorarlo, influyendo, a su vez, en las actitudes. También las ideas que tengan sobre si el realojo es forzado o voluntario, su percepción de los cambios ocurridos en su comunidad y el impacto socioeconómico sobre su lugar de residencia afectan las actitudes sobre el realojo de sus viviendas. Asimismo, algunas características socioeconómicas de los(as) residentes y de su comunidad, que son incluidas en el análisis de la pobreza urbana, podrían estar relacionadas con su manera de pensar acerca del realojo. 


\section{Discusión}

\subsection{Actitudes sobre el realojo en la comunidad}

A principios de la década de 1960, la eliminación y realojo de arrabales eran vistos por los(as) residentes afectados(as) como una exposición a los peligros de una nueva manera de vivir (Back, 1962). En la actualidad, para la comunidad estudiada, particularmente las personas a ser realojadas, el futuro realojo planificado de sus viviendas les provocaba desconocimiento, miedo e incertidumbre sobre el porvenir porque no saben adónde vivirán. También sospechaban que el realojo tenía un motivo ulterior y oculto, basándose en lo observado y/o vivido en comunidades desaparecidas, como Tokío y El Fanguito, donde desalojaron porque sus antiguos(as) residentes (invasores[as]) estaban viviendo en terrenos no aptos para construir. Sin embargo, más tarde éstos se desarrollaron, incluyendo edificios comerciales, instalaciones gubernamentales y deportivas, escuelas y complejos de apartamentos.

En esta investigación, hallé que los(as) residentes a ser realojados(as) querían continuar viviendo en sus hogares porque éstos son muy parecidos a las preferencias señaladas de las viviendas adonde les gustaría mudarse. También Back (1962) determinó que los(as) residentes de los arrabales querían permanecer allí porque eran propietarios(as) de sus viviendas o sentían que eran sus hogares. Al respecto, casi todos(as) los(as) residentes a ser realojados(as) vivían en una casa independiente, unifamiliar, propia, terrera e individual. Por lo tanto, querían tener una vivienda igual o mejor que la que tenían. Además, había añoranza por su comunidad porque allí nacieron y/o se criaron, sus antepasados(as) la fundaron, vivían algunos(as) de sus fundadores(as) y es zona accesible, céntrica y transitable. 


\subsection{Preferencia por el lugar a vivir}

Aunque la muestra de este estudio y la del censo de población y vivienda que se realizó por y para la comunidad en el 2002 son distintas, las compararé para examinar si las características han cambiado en los cinco años de diferencia. Según el censo del 2002, el 94,1\% de los(as) residentes señaló que le gustaría tener una casa unifamiliar, si tuviera que mudarse. Sin embargo, ha habido un descenso en el porcentaje de residentes a quienes les gustaría ser realojados(as) en una casa, ya que en el 2007, apenas el 65,2\% de las personas a ser realojadas y el 42,9\% de las realojadas preferían una casa.

La preferencia de los(as) residentes afectados(as) por el realojo por una vivienda con características muy particulares es muy similar a la casa ideal de las personas que participaron en el estudio de Back (1962). Aunque en la encuesta de dicho estudio había preguntas específicas, para conocer en detalles los atributos de la casa ideal, y, en esta investigación, las respuestas sobre este particular corresponden a una pregunta abierta, hay similitudes en la descripción de la vivienda de sus sueños. Esta vivienda es una casa individual y construida en concreto. En más de 40 años, no había cambiado el modelo de la casa ideal en Puerto Rico. Es precisamente este sueño un inconveniente en el proceso de presentarles a las personas a ser realojadas las opciones de vivienda y los planes de desarrollo socioeconómico y vivienda. Esto se debe a que la construcción de este tipo de vivienda es costosa y requiere mucho más terreno que las demás opciones: apartamento en complejo y vivienda horizontal (donde no hay patio lateral entre las casas). Entonces, solamente les cumplirían el deseo de proveerles una vivienda en concreto, aunque esto más bien se debe al cumplimiento de proveerles una vivienda segura (contra las inclemencias del tiempo, por ejemplo) y mejor que la que tenían, en lo posible. 
Además de preferir una casa, el que sea propia es muy importante para los(as) residentes. Así como son propietarios(as) de sus viviendas, los(as) residentes a ser realojados(as) deseaban seguir siendo los(as) dueños(as) de las propiedades adonde se muden. Además de evitar el gasto adicional de una hipoteca o alquiler, que posiblemente no puedan sufragar por los bajos ingresos, sospecho que deseaban mantener ese sentido de seguridad que se obtiene cuando se tiene una propiedad inmueble. Este hallazgo coincide con el de Safa (1980: 122), quien encontró que “dada la existencia marginal que la mayoría de los pobres se ve obligada a vivir, un hogar propio representa seguridad, independencia y posición social”.

Sobre la comunidad de reasentamiento, hay también interés en el lugar adonde irán a vivir y un deseo de que éste esté próximo a vecinos(as), familiares y comerciantes, como los(as) antiguos residentes de arrabales y residenciales públicos que participaron del estudio de Back (1962). Además, las cualidades más importantes sobre la localización de la vivienda para los(as) participantes del estudio de Back fueron mencionadas por los(as) participantes de esta investigación. Después de más de 40 años, se seguía deseando un lugar tranquilo, con buenos(as) vecinos(as), cómodo y salubre.

Respecto a mudarse a los proyectos de vivienda (vivienda horizontal y apartamentos) construidos en la comunidad para los(as) residentes, las objeciones a vivir en éstos, presentadas por los(as) participantes de esta investigación, coincidieron con las señaladas por los(as) encuestados(as) en el estudio de Back (1962), sobre ir a vivir a residenciales públicos. El tener que pagar un alquiler, seguir un reglamento y vivir en un apartamento son disuasivos. Sobre esta última objeción, hay una preferencia por vivir en una casa con patio, para sembrar vegetales y tubérculos, por ejemplo. Sin embargo, para las personas interesadas en mudarse a un proyecto de 
vivienda, el cambio de residencia implica un cambio en la manera de vivir, como encontró Back. Según comentarios de residentes realojados(as), ellos(as) habían obtenido calidad de vida y tranquilidad y reducido sus preocupaciones, desde que viven en los nuevos proyectos de vivienda.

Como ha señalado la corporación pública, a las personas a ser realojadas, les darán la opción de escoger su casa, por lo que existe el riesgo de que decidan mudarse fuera de la comunidad, como han hecho otras personas, quienes se han mudado a comunidades cercanas o a otros municipios de Puerto Rico. Asimismo, durante el trabajo de campo, varias personas señalaron su interés de mudarse a otra comunidad. Aunque sin explicar su deseo, esto rompe los vínculos con la comunidad y ejemplifica lo que Safa (1980) y Ramírez (1976) encontraron hace tres décadas: las aspiraciones para el futuro son individuales y/o familiares. Safa encontró que la eliminación de arrabales por parte del gobierno y la consecuente dispersión de sus residentes en caseríos, urbanizaciones y arrabales han roto los antiguos vínculos y debilitado la solidaridad local de las familias y el potencial para la acción política independiente. En el caso aquí estudiado, la decisión de los(as) mismos(as) residentes que decidan mudarse fuera de la comunidad sería un factor adicional de dicha dispersión.

Un efecto positivo del realojo voluntario es que, para las personas realojadas en proyectos de vivienda, el vivir en una estructura de concreto les da seguridad y tranquilidad porque ya no temen como antes a los huracanes, cuando vivían en casas cerca o en el caño y/o construidas en madera y zinc. Este hallazgo coincidió con el de Safa (1980), cuando ella señala que los fuegos y huracanes ya no son tan peligrosos porque los edificios del caserío están construidos en hormigón.

Sin embargo, los(as) realojados(as) también tenían quejas sobre los proyectos de vivienda. Éstas son similares a las de hace 30 años, cuando Safa (1980) señaló que 
los hombres que vivían en el caserío no tenían un lugar donde reunirse informalmente entre amigos para hablar. En la actualidad, los proyectos de vivienda en la comunidad no tienen parque ni cancha, cuando sus residentes lo deseaban. Tampoco, en algunos proyectos, hay un espacio común destinado para el encuentro informal de personas, como la plaza del centro del pueblo.

8.2.1 Renuencia a relocalización en residencial público. No es sorprendente que nadie mencionara su deseo de ser realojado(a) a un residencial público. Aunque no explicaron su renuencia a mudarse allí (sólo una persona dijo que no quería porque hay mucho alboroto), posiblemente se deba a que estos proyectos tienen, por lo general, la imagen de ser lugares donde se concentran graves problemas sociales, como la venta y uso de drogas ilícitas, prostitución, abuso infantil y venta de artículos robados. Otras posibles razones son que, por ser vivienda pública, no se puede ser dueño(a) de la misma, además de que son apartamentos (vivienda vertical), cuando se prefiere vivir en una casa. De la misma manera, Cotto Morales (2006) señala que la resistencia de los(as) residentes de algunas barriadas populares a mudarse a residenciales públicos se debe a que perderían el derecho de poseer una vivienda y se volverían inquilinos(as) del gobierno. Entonces, esta renuencia contrasta con la situación encontrada por Back (1962), quien acotó que dos terceras partes de los(as) residentes de arrabales querían mudarse y dos terceras partes de los(as) residentes de vivienda pública querían permanecer allí. Entonces, posiblemente, el deterioro de estos proyectos de vivienda haya causado la reducción abrupta de la proporción de personas interesadas a mudarse a estos lugares.

En este estudio, los(as) participantes no deseaban mudarse a estos proyectos de vivienda pública, pero no añadieron si se mudarían, si no hubiera más alternativas. De la misma manera, Ramírez (1976) encontró que a la inmensa mayoría de los(as) 
residentes de los arrabales no les agrada los caseríos, pero se mudan a éstos, cuando no tienen otras opciones.

\subsection{Cambios estructurales en comunidad de origen}

Esta comunidad ha progresado, en donde hay residencias similares a las de clase media; como Ramírez (1976) y Safa (1980) señalaron, con el tiempo los arrabales y sus casas muestran mejoras. También, en este estudio, encontré que, como Ramírez halló, había un deseo entre los(as) residentes de permanecer en su casa y que el gobierno realice arreglos sin forzarlos(as) a mudarse.

Las mejoras en esta comunidad hacen diferenciarla del arrabal estudiado por Safa (1980: 26) en 1959 y 1960, cuando ella encontró que los(as) residentes del arrabal "estaban privados de muchos servicios esenciales, tales como el recogido de basura, un sistema de alcantarillado, alumbrado en las calles y calles pavimentadas". En la actualidad, la comunidad que estudié tiene todos estos servicios.

Un efecto de los mejoramientos constantes realizados en la comunidad por los(as) mismos(as) residentes y el gobierno estatal y municipal, movilizados por las peticiones de los(as) residentes, es la contribución en el aumento del valor de la tierra (Ramírez, 1976) y las viviendas. El valor de las propiedades se puede medir por los valores de tasación de las viviendas que ocuparon las personas realojadas. Estos valores fluctúan entre $\$ 20.590,00$ y $\$ 90.000,00$, según reportaron el valor de sus viviendas de donde fueron realojados(as) algunos(as) participantes de este estudio y una líder comunitaria. No obstante, Ramírez (1976) y Safa (1980) encontraron que los(as) residentes de los arrabales que estudiaron dejaron de invertir en sus viviendas

y/o hacerles mejoras por la inseguridad de que el gobierno les(as) compensaran o porque no rendía beneficios hacer mejoras, si les(as) sacarían de allí de todas maneras. Sin embargo, en la comunidad que estudié, son los(as) líderes y el personal 
de la corporación pública quienes les dicen que no hagan arreglos que puedan aumentar el valor de la casa, si ésta ya está tasada, pero pueden hacer otras, como darle mantenimiento.

Por otro lado, el progreso en la comunidad, como la instalación de un sistema de alcantarillado sanitario, ha creado sospechas en algunos(as) residentes sobre si será para el disfrute de ellos(as) o de personas adineradas que podrían vivir allí, luego de que desalojen a los(as) habitantes actuales y construyan propiedades caras. Al respecto, un residente dijo que, como ya está instalada la electricidad, televisión por cable, teléfono, agua y alcantarillado, el terreno está listo para que las personas ricas lo disfruten luego del dragado del caño y la realización de demás proyectos.

Por otro lado, el realojo de los(as) residentes ha llevado a que queden vacías e inhabitables las viviendas que ocuparon en la comunidad, creando el problema de la ocupación ilegal por parte de personas extranjeras sin permiso para residir en Puerto Rico y de personas sin hogar, mayormente adictas a drogas ilegales. Otro problema resultante es la falta de mantenimiento de los espacios vacíos donde antes había casas, los cuales se han convertido en basureros clandestinos, creando mal olor y guarida de animales, como ratas y ratones. También los(as) vecinos(as) quedaron aislados(as) y los caminos se volvieron difíciles de recorrer por la grama alta, los escombros al destruir las casas (pedazos de losetas) y basura, como harapos, frutas podridas y viejos objetos del hogar. En los arrabales de Cataño, Ramírez (1976) observó la atmósfera de decadencia como resultado de la destrucción de casas y otras estructuras y que llevó a que residentes se vieran obligados(as) a irse por el deterioro de la comunidad. Sin embargo, en esta comunidad, los(as) residentes no se han ido esperando a ser realojados(as) por el dragado del caño u otro proyecto. 


\subsection{Pobreza urbana}

Según la literatura sobre la pobreza, un método para medir este problema social es la línea de pobreza. En la comunidad estudiada, el 77,5\% de las personas a ser realojadas y el $81,0 \%$ de las personas realojadas fueron clasificadas como pobres. Estas tasas de pobreza son más altas que las de Puerto Rico y Estados Unidos para el 2007, siendo 45,5\% y 13,0\%, respectivamente (U.S. Census Bureau, 2008a).

También en los estudios sobre la pobreza en Puerto Rico, se han encontrado varios causantes de este problema, presentes en la comunidad estudiada. Un porcentaje significativo de desempleo, bajo porcentaje de empleados(as), alto porcentaje de personas sin empleo (desempleadas y fuera de la fuerza laboral) y alto porcentaje de personas económicamente inactivas (fuera de la fuerza laboral) son factores económicos relacionados con la pobreza. Además, aunque la persona esté fuera de la fuerza laboral por estar pensionada, la pensión suele ser baja y lo mismo podría suceder entre las personas empleadas que devengan sueldos bajos.

Un factor social que incide sobre la pobreza es la escolaridad, cuyo nivel es bajo para las personas afectadas por el realojo. Entonces, una alta tasa de pobreza lleva a un alto porcentaje de residentes que reciben ayudas económicas del gobierno, para satisfacer sus necesidades de alimentación y vivienda. Al respecto, poco menos de la mitad de los(as) residentes afectados(as) por el realojo recibió, para el 2007, ayudas del gobierno. La inmensa mayoría fue beneficiaria del Programa de Asistencia Nutricional. También un sector considerable de las personas afectadas por el realojo que tenían ingresos por debajo de nivel de pobreza no recibió ayudas económicas (47,8\% de las personas pobres a ser realojadas y $41,2 \%$ de las personas pobres realojadas). Además de los aspectos objetivos de la pobreza, están los aspectos subjetivos, como la percepción que se tiene sobre éste. Las personas a ser realojadas 
mencionaron el no poseer o tener dificultad para conseguir una vivienda, un vehículo, ropa y zapatos, no poder dar educación a hijos(as) y no tener para comer; así como García Toro (2002) encontró que un alto porcentaje de participantes de su estudio percibió la pobreza como la falta de recursos económicos. También las personas realojadas mencionaron el querer tener una mejor vivienda y un vehículo nuevo, el tener pocos recursos y no tener familiares ni dinero. O sea, se percibe la pobreza como la falta o escasez de recursos económicos suficientes para obtener o mejorar algo, como vivienda, vestimenta y alimentación. García Toro encontró que el impacto de la pobreza fue percibido como devastador al considerar a las familias participantes de su estudio como excluidas social, económica y mayormente del campo político. De la misma manera, los(as) residentes de la comunidad estudiada mencionaron, en entrevistas y durante el trabajo de campo, que el propósito del realojo es sacarlos(as) para dar paso a que el gobierno realice proyectos para beneficio de otras personas, particularmente las ricas. Por lo tanto, los(as) residentes creían que no son prioridad para el gobierno, que éste no quiere beneficiarlos(as) con sus proyectos y que, por ser pobres, hay que sacarlos(as) de áreas que el gobierno entiende son mejor utilizadas por otras personas.

\subsubsection{Enfoques teóricos}

8.4.1.1 Marginalidad. Referente a la marginalidad como explicación al problema de pobreza urbana de esta comunidad, hay cualidades presentes entre los(as) residentes por sus características y comentarios realizados. Sin embargo, como dice Monreal (1996), ninguna de las características presentadas en la literatura sobre los(as) marginados(as) son exclusivas de ellos(as) y muchos(as) de los(as) marginados(as) no poseen tales rasgos. Entre las expresiones de marginalidad presentes en la comunidad estudiada, están las relacionadas a su origen histórico y sus 
características socioeconómicas. Esta comunidad se formó como un asentamiento ilegal, carente de equipamientos urbanos, por migrantes rurales que llegaron a la urbe capitalina en busca de trabajo, quienes vivieron en un principio en viviendas precarias, coincidiendo con la definición de marginalidad de Gravano (2005) y la de marginalidad urbana de Perlman (1976). En referencia a las características de marginalidad en los(as) residentes afectados(as) por el realojo, un alto porcentajes de residentes son empleados(as) de servicios, desempleados(as), subempleados(as), con ingresos bajos y sin recibir ayudas económicas, trabajadores(as) informales, coincidiendo con lo señalado por Colón Reyes (2006), Gravano, Monreal y Perlman.

También los(as) residentes de la comunidad estudiada tienen cualidades positivas, como señalan Monreal y Perlman. Entonces, hay residentes empleados(as) con trabajos estables (Monreal), estrechos lazos de amistad y parentesco, confianza y ayuda mutua, adaptación al medio urbano, poco deseo de regresar al lugar de origen, amplio contacto y conocimiento de las noticias locales y nacionales y deseo de trabajar (Perlman). Respecto a las cualidades de la comunidad en general, éste es el lugar desde el que expresan sus quejas y privaciones y donde se concentran sus luchas por las deficiencias de servicios básicos o la ilegalidad de los asentamientos (Monreal, 1996).

Por otro lado, algunas cualidades típicas de la marginalidad no están presentes en la comunidad ni en sus residentes, como que son inmigrantes que se aislaron en enclaves con características rurales como mecanismo de autodefensa, sin aprovecharse lo que les ofrecía la sociedad urbana (Monreal, 1996); que hay desorganización interna de las comunidades y el aislamiento externo; y que la población desconoce y no participa en procesos políticos por apatía y como el radicalismo que lleva a motines esporádicos y violentos. 
Siguiendo la definición de marginalidad de Ramírez (1976), la comunidad estudiada tiene una participación restringida en las instituciones sociales, sin poder influir en la toma de decisiones ni en los beneficios del desarrollo económico. No obstante, los(as) residentes se han movilizado para defender sus intereses colectivos, especialmente frente a los proyectos de desalojo impulsados por el gobierno insular. Además, la comunidad no está separada ni está fuera del sistema político, sino que es parte de un sistema más amplio, aunque no logre una representación efectiva de sus aspiraciones. Por ejemplo, hay acceso a las instituciones públicas, pero principalmente como recipientes de subsidios estatales, como es el caso de casi la mitad de los(as) residentes afectados(as) por el realojo.

También hay colaboración entre la corporación pública y las organizaciones comunitarias con las agencias del gobierno estatal y municipal, en la planificación y ejecución de proyectos y actividades, como recogido de escombros, construcción de instalaciones recreativas y realización de actividades sociales, como ferias de salud. Sin embargo, la comunidad ha vivido la decepción, el engaño y el incumplimiento de la palabra, cuando los(as) políticos(as) visitan la comunidad antes de las elecciones generales y, luego de ser electos(as), no cumplen lo prometido a los(as) residentes. Por lo tanto, participan activamente como votantes, pero tal parece que sus opiniones e ideas no se consideraron en la toma de decisiones ni en la creación de leyes que les afecta directa e indirectamente.

En la comunidad estudiada, los(as) residentes afectados(as) por el realojo se relacionan con el gobierno municipal, el gobierno estatal y la corporación pública, como Ramírez (1976) halló que los(as) participantes de su estudio no estaban enajenados(as) de los asuntos políticos, aunque éstos no conformaban su preocupación principal. Particularmente, los(as) participantes de este estudio 
comentaban sobre los planes y proyectos propuestos para su comunidad, las visitas de los(as) políticos(as) y los compromisos establecidos y los proyectos creados por pasados(as) políticos(as), como la primera alcaldesa de San Juan, Felisa Rincón de Gautier, y el ex gobernador, Pedro Rosselló González.

8.4.1.2 Cultura de la pobreza. Comparé los resultados de este estudio con las características que Lewis le atribuye a la cultura de la pobreza, así como Safa y Ramírez compararon sus hallazgos con la teoría de Lewis. Los(as) residentes afectados(as) por el realojo de sus viviendas tenían algunas de las características de la cultura de la pobreza, como un nivel educativo bajo, además de que un 10\% de los(as) residentes a ser realojados(as) no fue a la escuela y la gran mayoría apenas llegó hasta la escuela secundaria. Por otro lado, como apuntó Lewis (1983), no se ha dado en Puerto Rico un movimiento pacifista, revolucionario o religioso que organice y dé esperanzas a los(as) pobres y que fomente con efectividad la solidaridad y el sentido de identificación con los(as) más pobres, para destruir la base psicológica y social de la cultura de la pobreza. Más bien, las organizaciones luchan principalmente por el bienestar de su comunidad inmediata, aunque sostengan relaciones con otras organizaciones de otras comunidades en San Juan y demás municipios, organizaciones no gubernamentales y universidades.

Sin embargo, hay cualidades de la cultura de la pobreza que son poco comunes en la comunidad estudiada aquí, como una alta incidencia de uniones libres y matrimonios consensuales. Referente a su estado marital, cerca de 14 de cada 100 personas señalaron convivir con su pareja sin haberse casado por lo civil o por la iglesia, siendo una de las categorías de estado marital menos mencionadas. Al comparar los porcentajes de personas afectadas por el realojo que estaban casadas 
$(37,8 \%)$ con las que convivían $(14,4 \%)$, encontré que el primero es 2,6 veces el segundo.

Aunque es bajo el porcentaje de residentes afectados(as) por el realojo que pertenecen a una organización, hay 13 organizaciones y 1 de esas organizaciones agrupa a los(as) delegados(as) de 12 organizaciones comunitarias locales, convirtiéndose en la representante de estas organizaciones. Por ende, no se puede afirmar que haya un mínimo de organización fuera de la familia, que haya bajo nivel de organización o que sean agrupaciones informales o asociaciones voluntarias ocasionales y transitorias, ya que una organización podría llevar casi 20 años trabajando desde y para la comunidad. En cuanto a la participación social de los(as) residentes, más de la mitad de ambos grupos tenía préstamos bancarios, menos de la mitad de ambos grupos recibía ayudas económicas de mínimo cinco agencias del gobierno y entre 2 y 4 de cada 10 residentes tenían empleo. Contrario a lo establecido por Lewis, había participación e integración efectiva en las instituciones principales del país, incluyendo las de bienestar social. Además, los(as) residentes hacían uso de bancos (para obtener préstamos, como mínimo), hospitales y tiendas; son ésos los lugares que precisamente echarían o echaban de menos y desearían o deseaban seguir patrocinando, luego del realojo.

Sobre las actitudes de los(as) pobres identificadas por Lewis, algunas están presentes entre los(as) residentes de la comunidad estudiada. Las expresiones de los(as) participantes denotan actitudes asociadas con la cultura de la pobreza, a saber, el sentimiento de ser discriminado(a); temor, suspicacia, desconfianza hacia el gobierno y los(as) acaparadores(as) (usualmente empresas privadas) y resignación. Sobre la discriminación, entre los(as) residentes afectados(as) por el realojo, escuché repetidas veces la queja de que los(as) sacarían de sus residencias porque eran pobres. 
En cuanto al temor, lo hay por las condiciones de su actual vivienda; su futuro luego del realojo; su estado de salud, si permanecen residiendo allí, cuando draguen el caño; por su capacidad adquisitiva, si el dinero dado por su actual vivienda no es suficiente para conseguir otra (para las personas que creen que las desalojarán, en vez de realojo, como establece la corporación pública que hará); y por la supuesta posibilidad de ser realojado(a) a un caserío. Referente a la suspicacia, actitud crítica y desconfianza frente gobierno, han comentado que el realojo es forzado por los planes que tiene el gobierno de beneficiarse a sí mismo y a los(as) acaparadores(as). Concerniente a la resignación, algunas personas reaccionaron ante la noticia del realojo con esta actitud.

También había sentido de comunidad y espíritu de cuerpo, como lo describió Lewis, porque los(as) vecinos(as) se ayudaban, desde las tareas del hogar, hasta en momentos de gran necesidad; precisamente extrañarán a los(as) vecinos(as), las amistades, el ambiente, el calor humano y el cariño. Muchos(as) residentes expresaron el deseo de que sus vecinos(as) de la comunidad de origen estén en la comunidad de reasentamiento; y que hay unión en la comunidad de origen y en la comunidad de reasentamiento. Sin embargo, el sentido de comunidad se limitaba al vecindario y usualmente no se expandía a las demás ocho comunidades. Además, aún dentro del vecindario, donde hay un proyecto de vivienda y viviendas en las calles (fuera de los proyectos de vivienda), las personas que vivían en el proyecto de vivienda generalmente la consideraban como su comunidad. Es decir, ésta se vuelve una comunidad dentro de la comunidad.

Por otro lado, la comunidad, en general, no presenta algunas características de índole psicológica entre las personas afectadas por el realojo, como fatalismo, orientación temporal dirigida primordialmente hacia el presente y bajo nivel de aspiración. Sobre este, es relativamente bajo el porcentaje de residentes que dijeron no 
tener aspiraciones ( 1 de cada 10 personas a ser realojadas y cerca de 4 de cada 10 realojadas). Por otro lado, en cuanto a poseer escaso sentido histórico, los(as) residentes afectados(as) por el realojo recordaban comunidades pobres en San Juan que fueron eliminadas, luego de sacar a sus residentes, como Tokío, 23 Abajo y El Fanguito, y donde han construido proyectos residenciales y comerciales. Referente a ser provincianos(as), vivir en función de su ambiente inmediato y que sólo saben de sus propios problemas, situación local, vecindario y estilo de vida, los(as) residentes, además de recordar otras comunidades similares a la suya, aunque desaparecidas, entendían que algunos problemas presentes en su comunidad también estaban en otras partes del país y podían comparar su comunidad con el resto de San Juan. Por lo tanto, sabían lo que pasaba más allá de su comunidad.

8.4.1.3 Subclase. Por ser urbana y pobre, la comunidad estudiada posee algunas características indicativas de una subclase. Por ejemplo, la gran mayoría de las personas a ser realojadas residen en áreas degradadas de la ciudad (Myrdal, 1962) de San Juan, por estar residiendo dentro de los 50 metros a orillas del caño, en terrenos que originalmente eran pantanosos y en la actualidad están pavimentados. En cuanto a la identificación con los problemas sociales, mayormente los(as) residentes afectados(as) por el realojo no se identificaron con los mismos, aunque dejaron saber que la criminalidad, las personas sin hogar, las drogas ilegales y los embarazos en adolescentes están presentes en la comunidad. Otro problema característico de la pobreza urbana es el desempleo, ya que aproximadamente 1 de cada 10 personas a ser realojadas y personas realojadas estaba en esa situación laboral. No sólo estaban sin empleo, sino que todas las personas realojadas y algunas a ser realojadas desempleadas llevaban un año o más en esa situación. También más de la mitad de las personas afectadas por el realojo estaba fuera de la fuerza laboral. 
Por ende, es muy alto el porcentaje de personas sin empleo, ya sea porque eran amas de casa, pensionados(as), incapacitados(as) o estaban buscando trabajo.

A esta situación, se añade que más de la mitad de los(as) residentes a ser realojados(as) empleados(as) y menos de la mitad de los(as) realojados(as) empleados(as) estaban en el área de servicios, la cual se caracteriza por bajos salarios y ningún o pocos beneficios marginales. Sobre los ingresos, menos de 3 de cada 10 de ambos grupos estudiados tenían ingresos por salario, lo cual es cónsono con el bajo porcentaje de residentes de residentes empleados(as). Otro ingreso mencionado es el de chiripeo, recibido por cerca de 1 de cada 10 personas a ser realojadas y cerca de 2 de cada 10 personas realojadas. Contrario a la estabilidad de un ingreso por pensión, el ingreso por salario es menos estable porque dependerá de tener un empleo y/o de poder mantenerlo porque la mitad de los(as) desempleados(as) a ser realojados(as) lo perdió por despido, cesantía o cierre del lugar de realojo. Otras características socioeconómicas son la alta tasa de pobreza y que poco menos de la mitad de ambos grupos estudiados recibía ayudas económicas del gobierno.

Según Myrdal (1962), el under-class tiene una escasa participación social. Sin embargo, este indicador no está presente porque los(as) residentes afectados(as) por el realojo participaban en las instituciones como empleados(as), recipientes de ayudas económicas y recipientes de préstamos bancarios. Otras cualidades de la subclase ausentes en la comunidad estudiada son las centrales en la teoría, las cuales son que la subclase está compuesta por segmentos más desaventajados de la comunidad urbana negra y el éxodo de segmentos de clase trabajadora y clase media de las zonas urbanas (Wilson, 1987). En la comunidad aquí estudiada, es muy bajo el porcentaje de residentes que se autoidentificaron como negros(as), siendo $8,1 \%$, y no se ha 
reportado en la literatura que, en el pasado, residentes de esta comunidad y pertenecientes a la clase media se hayan ido.

Por lo tanto, las cualidades de una subclase presentes en la comunidad estudiada son estar localizada parcialmente en una zona degradada; problemas sociales como criminalidad, drogas ilegales, desempleo, embarazos en adolescentes, personas sin hogar y pobreza; residentes que no son miembros de la fuerza laboral; y residentes que son recipientes de bienestar público. Sin embargo, los(as) residentes no tenían las cualidades de escasa participación social, que son segmentos más desaventajados de una comunidad urbana negra y que hubo un éxodo de segmentos de la clase media.

8.4.2. Comunidades pobres. Sobre los términos arrabal, slum, shantytown, barrio y gueto, los cuales se utilizan para identificar a las comunidades urbanas y pobres, y las definiciones presentadas por los(as) estudiosos(as) en las ciencias sociales, sólo algunos conceptos y algunas de sus definiciones pueden aplicarse a la comunidad estudiada en la actualidad o a lo que fue en el pasado. Al revisar dichos términos, sólo arrabal y barrio pueden describir la comunidad estudiada en sus inicios y en la actualidad.

Las definiciones de arrabal por parte de Stevens (1985) y Ramírez (1976) se asemejan a las características de la comunidad estudiada, ya que ésta es un vecindario permanente de clase baja, "decente" y urbanizada (Stevens), así como lugar de residencia permanente para muchos(as) de sus habitantes, quienes tratan de mejorar sus viviendas, para fijar su residencia (Ramírez). Por otro lado, las definiciones de barrio pobre por parte de Colón Reyes (2002), Quiles (2003) y Ramírez (1976) describen mayormente a la comunidad estudiada. Debido a que en la comunidad hay terrenos que no fueron rescatados por sus habitantes, no se ajustan totalmente las 
definiciones que indican que es una comunidad de invasores o que se estableció ilegalmente en terrenos privados. No obstante, la comunidad podría ser clasificada como barrio pobre porque, en su mayoría, se estableció en terrenos pertenecientes al gobierno, parcialmente en terrenos marginales, que la gente ocupó y dividió y donde fabricó sus hogares, de acuerdo a sus recursos, y donde en el pasado se construyeron viviendas subestándares que, con el tiempo, se mejoran constantemente, de acuerdo a sus recursos y aspiraciones (Cólón Reyes y Ramírez). También la comunidad podría ser catalogada como barrio, por haber sido convertida por sus habitantes en terreno adecuado, incorporado al área urbana de San Juan (Quiles).

Sin embargo, algunas definiciones del barrio no se ajustan totalmente a la comunidad, por la carencia de características como comportamientos de grupos conflictivos y problemas étnicos, y el predominio de minorías raciales (Gravano, 2003). Aunque hay extranjeros(as) residiendo en la comunidad, proporcionalmente son muy pocos(as), en comparación con los(as) nativos(as), y su presencia no se mencionó como un problema social de la comunidad. En menor grado, la descripción de barrio pobre de Hunter (1964) incluye características de la comunidad, como condiciones de vivienda subestándares, problemas de higiene e inadecuados servicios públicos, porque algunos residentes vivían en extrema pobreza y la falta de alcantarillado sanitario en algunos sectores provocaba problemas de insalubridad.

Entonces, siguiendo las definiciones prevalecientes, para clasificar a una comunidad urbana y pobre, considero que la comunidad estudiada puede ser catalogada como barrio pobre porque la mayoría de sus terrenos son marginales, pertenecientes al gobierno estatal y fueron ocupados por los(as) residentes. Originalmente, las viviendas fueron construidas, de acuerdo a los recursos de sus dueños(as), estando en condiciones subestándares hasta que fueron mejorando con el 
tiempo; al convertirlos en terrenos adecuados, sus residentes los incorporaron al San Juan urbano. Actualmente, existen problemas sociales, como venta y uso de drogas ilegales, criminalidad, desempleo, nivel educativo bajo, pobreza, bajos ingresos y deterioro del medio ambiente.

8.4.3 Aspectos socioeconómicos. Según el censo de la comunidad del 2002, el 28,3\% de los(as) residentes tenía un grado de escuela secundaria y el 25,0\% tenía un grado de escuela elemental. Por lo tanto, coincide el hallazgo de que cerca de 3 de cada 10 tenía un grado de escuela secundaria.

Además, las medianas de años de estudio de la comunidad son bajas (9 para las personas a ser realojadas y 12 para las personas realojadas), pero no tan bajas, como las presentadas por Ramírez (1976), quien encontró un promedio de 5,4 años de estudio para los adultos de 20 años o más. Estas bajas medianas de escolaridad de la comunidad estudiada están relacionadas con empleos de baja remuneración e inestables y, como consecuencia, ingresos bajos y alto riesgo de vivir en la pobreza.

Referente al estado de empleo, 4 de cada 10 realojados(as) empleados(as) y cerca de 6 de cada 10 residentes a ser realojados(as) empleados(as) tenía en el 2007 un empleo en el sector de los servicios. Ha aumentado el porcentaje de residentes con empleos de servicios, ya que, en el censo del 2002, se encontró que el 29,1\% de los(as) residentes de 16 años o más tenía un empleo en esta área. Es alto el porcentaje de los(as) residentes de esta comunidad empleados(as) en el sector de servicios, como encontró Ramírez (1976) en Cataño. Sin embargo, en comparación el arrabal estudiado por Safa (1980), el porcentaje hallado en la comunidad aquí estudiada lo duplica $(56,3 \%$ de las personas empleadas a ser realojadas y el 40,0\% de las personas empleadas realojadas estaban en el sector de los servicios versus $23,3 \%$ de los hombres adultos del arrabal). Posiblemente, el aumento se deba a cambios en la 
economía insular, como el descenso de la industria manufacturera y el ascenso de la industria de servicios. No obstante, como usualmente son empleos de baja remuneración vulnerables a las fluctuaciones en la economía, tales empleos están sujetos a periodos flojos y despidos, como señaló Safa.

De la misma manera, según el censo de la comunidad del 2002, entre los(as) residentes que estaban fuera de la fuerza laboral, predominaban los(as) pensionados(as) por empleo, las amas de casa y los cuidadores del hogar y las personas con algún impedimento o enfermedad. Por otro lado, también ha aumentado el porcentaje de residentes desempleados(as) y fuera de la fuerza laboral, ya que en esta comunidad el $64,5 \%$ de las personas a ser realojadas y el 76,2\% de las personas realojadas estaba en esa situación laboral, contrario al 13,6\% de los hombres adultos en el arrabal estudiado por Safa (1980). Posiblemente, el aumento se debe a la inclusión de las personas que estaban fuera de la fuerza laboral porque estaban pensionadas, ya que esta muestra tiene una estructura de edad avanzada. No obstante, al comparar el porcentaje de personas desempleadas, es mayor el indicador de las comunidades estudiadas por Ramírez (1976) (20,6\%) que el correspondiente a la comunidad estudiada $(8,9 \%$ de los[as] residentes a ser realojados[as] y $14,3 \%$ de $\operatorname{los}[\mathrm{as}]$ residentes realojados[as]).

El censo del 2002 también encontró que las dos fuentes de ingresos más reportadas son salarios/sueldos/honorarios y pensión del seguro social. El chiripeo en Puerto Rico se practica desde hace décadas porque Ramírez (1976) lo mencionó como una fuente de ingreso importante. También en la comunidad estudiada, algunos residentes reportaron devengar ingreso al realizar tareas sueltas, como las llama Ramírez, siendo el 7,8\% de los(as) residentes a ser realojados(as) y el $23,8 \%$ de los(as) residentes realojados(as). 
Según el censo del 2002, el 85,6\% de los(as) residentes tuvo como ingreso mensual del hogar $\$ 1.249,00$ o menos. Para el 2007, el porcentaje de residentes que reportó esta cantidad fue menor para ambas muestras, siendo 71,9\% para los(as) residentes a ser realojados(as) y 76,2\% para los(as) realojados(as). O sea, en los cinco años, ha aumentado el porcentaje de residentes que reportaron recibir un ingreso mensual familiar de \$1.250,00 dólares o más.

En cuanto a los negocios de ventas al detal de los(as) pocos(as) residentes participantes que indicaron tener alguno, son más los(as) residentes a ser realojados(as) que los(as) residentes realojados(as) que vendían productos. De la misma manera, un porcentaje muy bajo de residentes con negocio propio se encontró en el censo del 2002 en la comunidad de estudio, siendo el 2,5\%, sin distinguir si la persona es realojada o será realojada. Construcción, colmado y mecánica fueron los tipos de negocio propio con mayores porcentajes. En la comunidad estudiada, está prohibido tener negocios en los proyectos de vivienda, pero algunos(as) residentes no cumplían con el reglamento, vendiendo pasteles (plato típico navideño en Puerto Rico), dulces, bebidas alcohólicas y no alcohólicas y artículos para el hogar, sin anunciarse públicamente para que no hayan sospechas. Al respecto, Ramírez (1976: 64) indicó que "el arrabal proporciona varios modos de obtener dinero, modos no permitidos en los caseríos porque el reglamento de la autoridad de vivienda prohíbe ciertos tipos de actividades". No obstante, estas ventas al detal no son suficientes para tener un ingreso considerable del cual se pueda depender.

Otra característica similar entre estas comunidades es la ausencia de tierra cultivable como medio básico de subsistencia. Así, Safa comparó desfavorablemente al arrabal con una aldea de campesinos(as), la cual podría sostenerse cultivando sus propios alimentos. En la comunidad, las casas están muy cercanas entre sí y, de 
manera general, no tienen o tienen muy poco patio trasero, frontal y/o lateral. Además, el terreno aledaño al caño y el que antes ocupaba el caño están contaminados por las aguas usadas y basura acumulada, por lo que no son aptos para sembrar. Sin embargo, contrario al hallazgo de Safa de que sólo unos(as) pocos(as) residentes dueño(as) de cafetines o colmados se ganan la vida en el interior del arrabal, en la comunidad estudiada, hay una diversidad de negocios: colmados, bares, talleres de mecánica, talleres de hojalatería y pintura, tiendas de tatuaje, salones de belleza y cooperativa de pescadores(as), entre otros, aunque ninguno(a) de estos(as) dueños(as) participó en este estudio ni tengo datos que indiquen si residen o no en la comunidad. También hay una cantidad significativa de residentes que reciben pensión y/o ayudas económicas del gobierno, por lo que hay una dependencia económica respecto al mundo exterior, como Safa señaló en su estudio. La corporación pública ha desarrollado un programa de adiestramiento para la formación de microempresarios(as), lo cual contribuiría a la reducción en la dependencia económica a las instituciones sociales de bienestar público.

Respecto al bienestar público, poco menos de la mitad de los(as) residentes a ser realojados(as) y realojados(as) recibía ayudas económicas del gobierno, siendo una proporción similar a la observada por Safa (1980), quien señaló que casi la mitad de las familias encabezadas por una mujer recibía alguna asistencia pública.

8.4.4 Residencia en la comunidad. En esta comunidad, 3 de cada 5 residentes a ser realojados(as) y cerca de 3 de cada 4 residentes realojados(as) eran dueños(as) de sus hogares. Estas proporciones son menores que las a encontradas por Safa (1980) y Ramírez (1976) de que la inmensa mayoría de los(as) residentes de los arrabales que estudiaron eran propietarios(as) de sus viviendas (83,3\% halló Safa y Ramírez indicó que es lo típico). Al mismo tiempo, estos porcentajes son más altos que los 
encontrados en el censo del 2002, donde se halló que el 54,6\% de los(as) residentes era propietario(a) y el 31,6\% era el(la) inquilino(a) de la vivienda.

El tiempo de residencia en la comunidad es tan variado como el correspondiente al arrabal que estudió Safa. En la comunidad estudiada, encontré que los(as) primeros(as) fundadores(as) llegaron hace un siglo $\mathrm{y}$, hasta la primera década del 2000, siguieron llegando personas para residir. Como muchos(as) de los(as) fundadores(as) ya fallecieron o son personas de edad avanzada en la actualidad, no forman parte del liderato comunitario. Sin embargo, sus descendientes (de segunda y tercera generaciones), expresaron renuencia a irse de la comunidad. También estas personas a ser realojadas recordaban cómo sus antepasados(as) rellenaron y secaron el terreno y construyeron sus viviendas, las cuales han sido heredadas por varias generaciones y hasta mejoradas (de madera y zinc a concreto).

Cabe destacar la diferencia entre las medianas de los años en que comenzaron a residir en la comunidad los(as) residentes a ser realojados(as) y los(as) realojados(as), siendo 7 años. En promedio, las personas que fueron realojadas llevaban menos tiempo residiendo en la comunidad, en comparación con las personas a ser realojadas.

Sólo cerca de 1 de cada 5 residentes a ser realojados(as) y cerca de 2 de cada 5 realojados(as) habían vivido en otras comunidades de San Juan y la mitad o más de éstas eran comunidades pobres. Al respecto, Safa (1980) señaló que muy pocas personas del arrabal que estudió han vivido en otro tipo de vecindad desde que llegaron a San Juan, contrario al patrón de asentamientos descrito en otras ciudades latinoamericanas.

8.4.5 Composición del hogar. En cuanto al estado marital de convivencia, el porcentaje de personas en la comunidad que indicaron este estado $(14,4 \%)$ es similar 
al encontrado por Ramírez (1976) (13,3\% de las personas de 14 años o más) y menor que el de Safa (1980) (menos del 25\%, sin especificar su edad). Como apunta Safa, “es mucho menos de lo que informara Mintz sobre el área de haciendas en Puerto Rico. [...] u Oscar Lewis sobre el arrabal que estudió" (p. 62). Al igual que en el censo del 2002, las personas a ser realojadas y las realojadas que no vivían solas tendían a vivir con su cónyuge y/o su hijo(a).

8.4.6 Lazos de parentesco, amistad, compadrazgo y ayuda mutua. La comunidad aquí estudiada es muy similar al arrabal estudiado por Safa (1980), en cuanto a relaciones entre vecinos(as). En ambas comunidades, había unión por lazos de parentesco, compadrazgo y amistad y por patrones de cooperación y ayuda mutua, desarrollados desde hace años, como señala Safa. Tales lazos permiten que la comunidad se integre socialmente, aún entre los(as) residentes no emparentados(as) entre sí (Safa, 1980).

En cuanto al parentesco, más de la mitad de los(as) residentes de la comunidad tenían parientes residiendo en el lugar y se veían a diario, como encontró Safa en el arrabal. Como señaló Ramírez, "los parientes fuera del grupo doméstico son también una fuente de ayuda y compañerismo" (p. 80), ya que, en la comunidad bajo estudio, la gran mayoría de los(as) residentes con parientes viviendo allí también se ayudaban mutuamente. Respecto al matrimonio entre vecinos(as), cerca de 1 de cada 3 residentes a ser realojados(as) y cerca de 2 de cada 5 residentes realojados(as) se habían casado con alguien de la comunidad. Sin embargo, esto no es tan frecuente como Safa había señalado en su estudio y explicándolo como el resultado natural del contacto restringido con el mundo exterior.

Sobre los lazos de amistad, el arrabal investigado por Safa y la comunidad estudiada son similares porque ambos son amigables, casi todos(as) allí se conocen y reconocen 
inmediatamente al extraño(a). Aún las pocas personas involucradas en los negocios ilícitos (robo de piezas de auto y venta de drogas ilegales) fueron amables conmigo y me saludaban cuando coincidíamos. En cuanto a la cooperación y ayuda mutua, es más evidente en tiempos de crisis, como señaló Safa. En casos de tormentas y huracanes, inundaciones, enfermedad y fuego, es notable la ayuda de los(as) vecinos(as). Además, en el diario vivir, cerca de 1 de cada 10 personas a ser realojadas y cerca de 1 de cada 20 personas realojadas se prestaban las cosas. De la misma manera, Safa (1980) halló que los(as) vecinos(as) se prestaban artículos pequeños. También los(as) vecinos(as) se ayudaban de otras maneras, como hacer favores, estar pendiente o velar, compartir comida y limpiar áreas comunes. Señaló Safa que el compartir liga a los(as) residentes entre sí en un sistema de ayuda mutua y la interdependencia de sus residentes refuerza la comunidad.

También les une, a los(as) residentes, los lazos de compadrazgo. En el pasado, era frecuente escoger a los(as) vecinos(as) como compadres y/o comadres para las dos formas de bautismo (el ritual católico y el popular [de aguas, como se le dice]), según Safa (1980). Sin embargo, en esta comunidad ya no es frecuente asignar a vecinos(as) como padrinos y/o madrinas para sus hijos(as) (1 de cada 3 personas a ser realojadas y cerca de 1 de cada 10 personas realojadas le asignaron a sus vecinos[as] estos roles). Posiblemente, esto se deba a la presencia de otras religiones cristianas, en las que no se practica este rito o al menos de esta manera.

Tampoco es frecuente asignar al padrino y/o madrina de aguas, quien es la persona encargada de bautizar, siguiendo un libro que explica el ritual, al bebé en la casa con agua bendita (puede obtenerse en la misa de Pascua — sábado de Gloria, durante la Semana Santa-) o cualquier agua que fuera bendecida a la manera del padrino o madrina porque hay una emergencia o riesgo de que el(la) menor fallezca. 
Posiblemente, era una costumbre común cuando la mortalidad infantil era un grave problema de salud pública en Puerto Rico. Entonces, si no muere el(la) bebé, se le lleva a la iglesia para que le bauticen (ritual católico). Aunque no es común, todavía se practica. Dos años antes de mi estudio, una residente de 83 años de edad bautizó a un bebé de dos meses que no estaba enfermo, pero, como su padre había abandonado el hogar, la madre quiso que le echaran las aguas al infante, en espera de que su esposo regresara para retomar el plan de llevarlo a la iglesia para que lo bauticen. También está el padrino de carga, quien era la persona que llevaba el(la) bebé de la casa a la iglesia, aunque es mucho menos común, en la actualidad. O sea, una persona podía tener hasta tres padrinos y/o madrinas.

Aunque los(as) residentes son solidarios(as) con sus vecinos(as), generalmente esta actitud es restringida a las personas que vivían cerca. Como subraya Safa (1980) "la fuerte solidaridad de la comunidad del arrabal no se extiende más allá de los límites estrechos del vecindario. No existen mecanismos para fomentar un sentido de solidaridad de clase entre las familias del arrabal en conjunto" (pp. 110-111). Respecto a esto último, las personas que entrevisté rara vez mencionaron alguna otra comunidad de las nueve estudiadas, aún estando ligadas por la corporación pública e incluidas en una zona de impacto denominada el distrito y teniendo en común el problema del caño contaminado.

8.4.7 Pasatiempos. Ramírez (1976) encontró que ver la televisión era el pasatiempo favorito de los(as) residentes de los arrabales y caseríos. Sigue siendo el entretenimiento más mencionado por los(as) participantes de este estudio, especialmente de los(as) residentes a ser realojados(as).

Según el censo del 2002, las actividades recreativas, deportivas o culturales con mayor porcentaje mencionadas por los(as) residentes son los deportes $(68,5 \%)$, 
los juegos $(8,3 \%)$, las actividades comunitarias $(7,3 \%)$, otras $(6,8 \%)$ y la televisión $(6,1 \%)$. Aunque los deportes, los juegos y la televisión fueron mencionados por los(as) participantes de este estudio, los porcentajes son distintos, especialmente el correspondiente practicar deportes y ver televisión. Sin embargo, el pasatiempo que más llama la atención es salir, caminar y/o pasear porque entre 3 y 5 personas de cada 10 participantes de este estudio disfruta su tiempo libre fuera de su vivienda y posiblemente dentro de la comunidad. Como un grupo de residentes disfruta de esa manera, es muy importante que, en la planificación del uso del espacio en los proyectos de construcción, se considere que a algunas personas les gusta salir, caminar y/o pasear, para que se identifique un espacio de uso público, placentero y seguro. Además, si hay residentes cuyos pasatiempos son salir, caminar y/o pasear y compartir con familiares y amistades que residan en la misma comunidad, se les debería proveer de vías seguras y espacio accesible, como crear aceras, o mantener en buenas condiciones las existentes, para que puedan seguir con sus pasatiempos y otras personas se animen a tenerlas.

8.4.8 Aspiraciones. Los(as) residentes afectados(as) por el realojo tenían varias ambiciones para ellos(as) y sus hijos(as), como prosperar, estudiar y tener casa y/o negocio. También Safa (1980) encontró que hasta las familias más pobres aspiraban a un futuro mejor. Apenas 1 de cada 10 residentes a ser realojados(as) y 2 de cada 5 realojados(as) no tenían aspiraciones. Por lo tanto, encuentro poca evidencia de que los(as) residentes de esta comunidad se orienten predominantemente hacia el presente, lo que no les permite planificar a largo plazo, como Lewis (1983) y Ramírez (1976) alegaron que los(as) pobres tienen. Empero, las aspiraciones de los(as) participantes en este estudio se limitan a logros individuales y/o familiares, que implican un mejoramiento personal con repercusiones socioeconómicas para ellos(as) 
mismos(as), como adquirir propiedades, cambiar de residencia, educarse y tener negocio. Como señala Safa (1980: 44-45), "las aspiraciones para el futuro siempre se expresan desde el punto de vista de la movilidad ascendente individual o familiar, y no desde el punto de vista de la solidaridad de clase. Les importan más las diferencias de nivel socioeconómico entre ellos mismos y mejorar su posición en la comunidad del arrabal, que reducir las brechas entre su propio nivel social y el de otros grupos de clase en la metrópoli”.

8.4.9 Problemas sociales y aspectos que desagradan. Según el censo del 2002, los aspectos desagradables más mencionados por los(as) residentes son drogadicción, inundaciones, alboroto (motoras, aviones, música), criminalidad (robos, tiros de bala) y mal olor. Cinco años después de haberse realizado el censo del 2002, las inundaciones y la drogadicción todavía molestaban, en particular a las personas a ser realojadas. Además, la criminalidad fue mencionada frecuentemente por las personas a ser realojadas y las realojadas, al igual que los(as) participantes del censo, pero en menor proporción.

El uso y venta de drogas ilegales es un problema reportado desde hace décadas en las comunidades pobres. En el estudio de Safa (1980), todas las familias, particularmente las que residían en vivienda pública, mencionaron a las drogas como un problema. Las drogas fueron señaladas como un aspecto que molestaba de la comunidad por 1 de cada 5 residentes a ser realojados(as) y cerca de 1 de cada 2 como un problema social presente. Posiblemente, los porcentajes tan bajos de residentes realojados(as) que señalaron las drogas como un problema o aspecto que moleste se deben a que se refieren solamente, como comunidad, al proyecto de vivienda. Esto también significa que residir en el proyecto de vivienda provee calidad de vida, tranquilidad y seguridad, al no haber venta ni uso de drogas ilegales en esos predios. 
En el área bajo estudio, compuesta por nueve comunidades, hay un mínimo de cinco puntos de distribución de drogas. Según un residente, uno de estos puntos es más grande que el presente en la comunidad que estudió Lewis, para probar la teoría de la cultura de la pobreza, y que desde hace años tiene fama en Puerto Rico por ser un gran centro de de ventas de estupefacientes. Por otro lado, no solamente este problema ha afectado a las familias con miembros usuarios(as) y vendedores(as) de drogas; también ha restringido el uso de las instalaciones recreativas y deportivas para el disfrute de sus residentes porque están cerca de los puntos de drogas o son usadas para el uso de las drogas, particularmente la inyección de sustancias controladas. Además, la presencia de estos puntos ha limitado las áreas por donde uno(a) puede o no puede pasar y las horas del día y la noche en las que es seguro o no lo es caminar.

Por otro lado, este problema está muy relacionado con la violencia y pone en riesgo a los(as) residentes, especialmente a las personas ajenas a esto, como cuando hay un tiroteo (intercambio de disparos) por disputa entre puntos y/o control de los puntos o entre los(as) narcotraficantes(as) y la Policía de Puerto Rico. Otro efecto de este problema es la exposición de los(as) niños(as) a las drogas y las armas de fuego, corriendo el riesgo de que consideren como normal este ambiente. También este problema expone a los(as) residentes a la presencia de extraños(as) que entran a la comunidad para comprar drogas ilegales, quienes podrían ser personas peligrosas o deambulantes. Además, se vuelve un ambiente deprimente y de terror, cuando en una de las avenidas principales que cruza la comunidad, ocasionalmente se ven adictos(as) con los efectos secundarios inmediatos de las drogas. Mayormente, se pueden ver a estas personas en un estado de debilitamiento de la parte superior del cuerpo, que hace que se doble hacia el frente y hacia abajo y se mueva de un lado a otro, sin caerse, y en un estado alucinante, poco alerta y de reacción lenta a estímulos. Como 
consecuencia, la presencia de puntos de drogas ilegales hace de la comunidad un lugar poco seguro e intranquilo para sus habitantes, afectando negativamente el bienestar de sus habitantes.

8.4.10 Liderato y organizaciones comunitarias. La comunidad estudiada está organizada y tiene un liderato, contrario a lo encontrado por Ramírez (1976) y Safa (1980) en otros arrabales y caseríos estudiados. En la comunidad, hay como mínimo 13 organizaciones comunitarias y, según un líder, la más vieja fue fundada en 1992. Por lo tanto, el liderazgo comunitario es completamente lo opuesto a lo encontrado por Safa y Ramírez: en los vecindarios estudiados por ellos el liderazgo era fluido, disperso, de corta duración, informalmente organizado e inestable. En el área que estudié, las organizaciones comunitarias también se apoyaban mutuamente y recibían la cooperación de otras asociaciones de comunidades pobres y colaboradores(as) externos(as), como profesores(as) y estudiantes universitarios(as) y artistas.

8.4.11 Política y relaciones con el gobierno. De manera general, los(as) residentes de esta comunidad estudiada son muy similares a los(as) residentes del arrabal que estudió Safa (1980: 110), en la actitud de "esperar a que el gobierno resuelva sus problemas. [...] Esta tradición de dependencia inhibe en gran medida el desarrollo de la conciencia de clase entre los pobres de la zona urbana. Los fuerza a buscar soluciones en los partidos políticos establecidos, en los que no tienen poder real, en vez de desarrollar poder político en sus propias filas”. Esta actitud se puede observar en los comentarios de los(as) residentes y los(as) líderes, cuando señalaban que la cooperación del gobierno es necesaria para llevar a cabo la actividad y es deber del gobierno realizar esa tarea específica. Estos señalamientos usualmente llevan a la discusión sobre si es imprescindible la ayuda o presencia del gobierno y si es posible realizar la actividad sin éste. Este tema es controversial en Puerto Rico por varias 
razones: como contribuyentes, se espera que el gobierno provea servicios al pueblo, sufragados con los impuestos; la visión del partido gobernante de privatizar los servicios y reducir el tamaño del gobierno; y el gobierno quiere estar al tanto e involucrarse en las actividades de la comunidad, para establecer su presencia y, de alguna manera, recordarle a los(as) residentes que el gobierno está tomando acción y se preocupa por su bienestar, como medio de publicidad, para asegurarse votos en las próximas elecciones.

Me parece que el gobierno y la comunidad tienen una relación codependiente. Según líderes comunitarios(as), el gobierno ha tomado represalias en contra de los(as) residentes disidentes que han participado en actividades no aprobadas por el gobierno. A la vez, se invita al gobierno y se acepta la participación de éste, sin haber sido invitado, a las actividades. Aunque algunos(as) residentes son renuentes a disentir del gobierno por temor a represalias, otros(as) le creen al gobierno y le aceptan los títulos de propiedad individual sobre el terreno, donde están sus viviendas, creando una división en la comunidad, entre las personas que apoyan el fideicomiso (bien común) y las que quieren su título sobre la tierra (bien individual). Además, varias acciones legislativas que involucran directamente a los(as) residentes son incongruentes entre sí. Por ejemplo, por un lado, un proyecto de ley dejó sin tierra al fideicomiso de la tierra, creando especulación sobre el terreno, estimulando un posible desplazamiento y desmembramiento de la comunidad. Por otro lado, legisladores(as) han hecho proclamas.

La comunidad estudiada y las comunidades que estudió Ramírez son similares en que "la mayor parte de la gente no lucha contra el gobierno" y que, de manera general, lo "que la gente obtiene como individuos nunca como grupo, consiste en una mayor compensación por la casa" (Ramírez 1976: 83), aunque en las primeras hubo 
expropiación y en la de este estudio habrá realojo de viviendas. La enmienda a la Ley 489 que dejó sin títulos a los(as) residentes con viviendas en terrenos públicos creó indignación y furia en un sector de los(as) residentes, aunque no está planificada la expropiación masiva de los(as) residentes. Sin embargo, estos sentimientos no se expresaron en un movimiento masivo que tuviera éxito en la desaprobación o veto del proyecto de ley o la derogación de la misma. Para expresar el repudio hacia ese proyecto de ley, hubo una sola marcha liderada por artistas y líderes comunitarios(as), pero no tuvo el efecto deseado en la legislatura, la oficina del gobernador ni el tribunal.

\subsection{Impacto socioeconómico del realojo en la comunidad de origen y de} reasentamiento

La presencia de empleados(as) del gobierno, la corporación pública y la agencia contratada para realizar el realojo en la comunidad han generado diversas reacciones en los(as) residentes. Para algunas personas, la presencia de extraños(as) tomando medidas y viendo documentos en la calle les crea suspicacia y creen que se aproxima el realojo. Pero otras personas no se alarman porque ya han visto esa escena antes y varias veces han ido a tasar su casa. Esta reacción es diferente a la observada por Ramírez (1976: 82), quien señaló que “el impacto de la eliminación del arrabal se hizo evidente cuando los empleados de la agencia comenzaron a trazar mapas del área, calcular el costo de la casa y marcar cada una de ella con un número negro”.

\subsubsection{Lugares importantes para los(as) residentes afectados(as) por el} realojo. Al presente, la comunidad estudiada, como la investigada por Safa (1980), tiene colmados o pequeñas tiendas donde venden productos enlatados y otros artículos imperecederos. Son precisamente estos lugares a los que se desea regresar y extrañarían las personas realojadas. Estas tienditas son importantes porque, además de 
resolver a la persona la necesidad de adquirir un artículo (comprado o fiado — se pagaría luego-), evitando que salga de la comunidad a comprar a un supermercado, son lugares de encuentro entre vecinos(as). También estas tienditas les dan la oportunidad de empleo a los(as) mismos(as) residentes.

Por ejemplo, mi abuelo materno tenía un colmado en el área, llamado Monge’s Grocery, y sus dos hermanos tenían otro llamado El Canario, localizado un poco más al frente. Entonces, cada tienda tenía su mensajero para que llevara la compra. Fue durante el trabajo de campo, cuando me enteré de que el mensajero de la tienda de mi abuelo era el padre de un(a) empleado(a) de la corporación pública. Aunque los colmados estaban muy cerca entre sí, tenían clientes. Aunque desconozco las razones que tenían para escoger la tienda, me pareció curiosa la anécdota de un matrimonio de edad avanzada, en el que el esposo iba al colmado de mis tíos abuelos y la esposa iba al de mi abuelo. Una de las razones por las que hace décadas también el colmado era importante es la relación entre el(la) comerciante y el(la) cliente(a). Según cuenta mi familia, mi abuelo y sus hermanos les daban un aguinaldo de Navidad a sus clientes, una bolsa de papel con turrón, nueces o avellanas; y manzanas, uvas o una lata grande de coctel de frutas, melocotones o peras en almíbar. Además, cuando fallecía un(a) cliente(a), mi abuelo y sus hermanos donaban los ingredientes para la bebida de chocolate caliente (leche y/o chocolate en barra) y el queso (merienda típica en funerales en Puerto Rico).

\subsubsection{Relaciones personales entre la comunidad de origen $y$ de} reasentamiento. En este estudio, encontré residentes realojados(as) que visitaban el área donde vivieron para saludar a sus antiguos(as) vecinos(as) y familiares. Además, varias personas a ser realojadas indicaron el deseo de regresar a la comunidad para visitar a sus parientes y antiguos(as) vecinos(as). Sin embargo, Safa (1980) encontró 
que luego del realojo de los(as) residentes del arrabal al caserío, los vínculos entre parientes y vecinos(as) se rompieron y los patrones de cooperación y confianza se debilitaron.

8.5.3 Sentido de comunidad. Aunque no exploré la formación de una conciencia de clase, como lo hizo Safa (1980), quien encontró que ésta fue impedida por la relocalización de $\operatorname{los}($ as) residentes del arrabal por medio de la renovación urbana, encontré que el sentido de comunidad se afectó. El realojo voluntario de los(as) residentes que decidieron mudarse a los nuevos proyectos de vivienda limitó el sentido de comunidad al proyecto donde viven y no al territorio más amplio donde está localizado. Entonces, para una cantidad considerable de residentes realojados(as), comunidad es el proyecto de vivienda horizontal o complejo de apartamentos, con acceso controlado y propia junta de residentes. Este hallazgo salió a relucir cuando, durante la entrevista, había alguna pregunta que hacía referencia a la comunidad y muchas personas hablaban del proyecto de vivienda y pocas indicaban que estaban confundidas y me preguntaban a cuál me refería.

8.5.4 Adaptación a la comunidad de reasentamiento. Como en los proyectos de vivienda se mudaron personas de la misma área, han vuelto a ser vecinos(as) nuevamente. Por lo tanto, la adaptación no ha sido difícil en este aspecto, sino en la obligación de cumplir con las reglas de los proyectos de vivienda, contrario a lo indicado por Safa (1980), quien encontró que la adaptación en la comunidad de reasentamiento es difícil para algunas personas porque extrañan a sus amistades del arrabal, donde se conocían. 


\section{Conclusiones}

Los modelos teóricos reseñados para esta tesis no son completamente adecuados para analizar el problema de la pobreza urbana en la comunidad estudiada, porque ésta no tiene todas las cualidades que cada teoría le atribuye a los(as) pobres de la zona urbana. Sin embargo, al comparar las teorías de la marginalidad, la cultura de la pobreza y la subclase, encuentro que la primera podría explicar mejor este problema social en la comunidad estudiada, particularmente su participación política restringida, como Ramírez (1976) definió este concepto.

Según la literatura sobre la pobreza urbana, los(as) pobres tienen una escasa participación en las instituciones principales de la sociedad. En este estudio, encontré que los(as) residentes afectados(as) por el realojo participaban en menor grado como empleados(as), pero en mayor grado como recipientes de ayudas económicas del gobierno, prestatarios(as) bancarios(as) y personas económicamente inactivas (desempleados[as] y fuera de la fuerza laboral). Con ingresos bajos, se limitaba aún más su participación como consumidores(as) de los comercios, especialmente los que están en la comunidad y que son importantes para ellos(as). Su restringida participación como consumidores también tiene consecuencias sobre los(as) negocios en la comunidad (colmados, salones de belleza y farmacia) porque tendrían que mantener bajos los precios, para seguir atrayendo a la clientela local.

Por otro lado, los hallazgos indican una dependencia económica del exterior, por no ser una comunidad sostenible. Un alto porcentaje de residentes afectados(as) por el realojo estaban empleados(as) en el sector de los servicios; un número considerable de personas se beneficiaban de los programas de bienestar público, particularmente el de alimentación; existe una grave escasez de tierra cultivable y un 
bajo porcentaje de personas con negocio propio. Estas tendencias se asocian con condiciones de vida precarias y vulnerables a las fluctuaciones en la economía nacional y global, aumentando las probabilidades de continuar viviendo con dificultades económicas y/o bajo el nivel de pobreza.

En cuanto al realojo, las actitudes de los(as) residentes dependen de experiencias previas con el gobierno estatal (si la persona fue desalojada o realojada anteriormente); si la persona que le informó u orientó sobre el proceso es confiable o no, si le dijo la verdad o no; y la asistencia a reuniones donde disminuye la probabilidad de que personas no autorizadas les den información incorrecta, creando confusión. Asimismo, pueden incidir en los modos de pensar de las personas sobre el realojo de sus viviendas lo observado, vivido y/o escuchado sobre otras comunidades desaparecidas, como Tokío y El Fanguito, donde el gobierno estatal desalojó y construyó luego, sin poder los(as) residentes regresar a vivir en éstas; y los comentarios de las personas realojadas sobre la experiencia y su satisfacción con el cambio de hogar. El realojo voluntario tuvo aspectos positivos y negativos, según informaron los(as) residentes que participaron en esta investigación. Las personas que decidieron mudarse de vivienda antes de que estuvieran obligadas a hacerlo, se sentían seguras y sin miedo por vivir en una residencia de concreto, contrario a la vulnerabilidad de una casa de madera y zinc, al lado del o en el caño tapado y contaminado. Además, algunos(as) residentes han vuelto a convivir con sus vecinos(as), quienes se mudaron también, por lo que no se han roto los lazos de amistad y de ayuda mutua y éstos han aumentado al tener nuevos(as) vecinos(as). Por otro lado, los aspectos negativos se refieren a la vivienda misma porque ésta no se asemeja a la casa ideal, excepto en el material de construcción, concreto, siendo precisamente un factor que causa el sentido de seguridad en las personas que viven en 
ellas. Igualmente, el seguir un reglamento y asistir a una junta de residentes, para acordar los cambios en las fachadas, incomodan a los(as) residentes, además de tener que pagar cuotas de mantenimiento. También en estos proyectos de vivienda faltan instalaciones deportivas y recreativas que desean sus residentes, para poder compartir más con sus vecinos(as) y en familia.

Muchas de las personas a ser realojadas comparten la idea de que el gobierno quiere sacarlas porque son pobres y para poder construir para las personas ricas, provocando miedo por un supuesto desalojo, cuando las organizaciones comunitarias y la corporación pública han establecido en innumerables ocasiones que realojarán, proveyéndoles una vivienda segura y salubre, igual o mejor que la que tienen. Entonces, la corporación pública, siendo parte del gobierno estatal, tiene la difícil tarea de mantener informados(as) a los(as) residentes; reorientarlos(as), eliminando toda información errónea dada posiblemente con mala intención, para crear confusión en la comunidad; y luchar por dejar saber que, aunque trabajan desde el gobierno, se dedican a crear e implantar proyectos para el desarrollo socioeconómico de la comunidad. También es muy posible el que la gran mayoría de sus empleados(as) no residan en la comunidad no aporta en la formación de la confianza necesaria para que los(as) residentes piensen que están velando y luchando por sus intereses.

Muchos(as) residentes comparten el temor de que el gobierno les saque y se desintegre la comunidad, un temor intensificado con la Ley 32, que llevaría a que cada residente obtenga su título individual sobre el terreno donde está su vivienda, a una subsiguiente especulación sobre el terreno y al aumento de la adquisición de terrenos por parte de extraños(as) (comprando las propiedades de un grupo de residentes, a precios irresistibles), para la construcción de propiedades caras, con vista a la laguna y los caños. Esta situación también llevaría a que los(as) propietarios(as) 
de las viviendas en alquiler aumenten la renta y los(as) residentes se tengan que ir porque no puedan pagarla. Aunque los(as) residentes no quieren que desaparezca la comunidad, como pasó en los barrios Tokío y El Fanguito, esto podría suceder, al gobierno haber modificado la ley que creó el fideicomiso de la tierra y permitiendo que empresarios(as), desarrolladores(as) e inversionistas tengan acceso al terreno, por medio de la compra directa de las propiedades a sus dueños(as). Así, el temor de que el gobierno saque a los(as) residentes de la comunidad está más fundado que antes que se enmendara la ley que le otorgaba a cada residente su título de tenencia colectiva de la tierra.

Por otro lado, los cambios a las leyes crean una inestabilidad psicológica/emocional, como la desconfianza del gobierno; aumentan la suspicacia y la confusión; y provocan una división entre los(as) residentes que apoyan al gobierno en sus decisiones y los(as) que apoyan a la corporación pública, especialmente en el asunto de la titularidad de los terrenos. Además, la creación y/o modificación a las leyes que les afecta directamente causa que los(as) residentes estén a la expectativa sobre lo nuevo que les pueda pasar y que les tome por sorpresa, afectando a su vez los proyectos programados.

Los(as) residentes a ser realojados(as) mostraron suspicacia, miedo, impotencia e incertidumbre hacia el realojo. Estas actitudes provienen de la falta de poder político, la codependencia con el gobierno y la marginalidad en que viven. La sospecha de que el gobierno los(as) quiere sacar de allí, para construir proyectos caros para gente rica, denota que dependen del gobierno y que no tienen el capital político para evitarlo ni el poder adquisitivo para comprar una vivienda, si los(as) desalojan. Al respecto, el vivir en pobreza, el tener bajos ingresos, el estar sin empleo o subempleado(a), el recibir bienestar social, los precios altos de las casas en venta y los 
valores bajos de tasación de sus viviendas en esta comunidad pobre contribuyen al desarrollo del miedo, impotencia e incertidumbre sobre su futuro. También sus actitudes de miedo e incertidumbre sobre adónde irán a vivir están vinculadas con el temor a perder la posición social como propietarios(as) de su hogar.

Tales actitudes provienen de las aspiraciones individuales de los(as) residentes a progresar y ascender en la escala social. Más bien, entre los(as) residentes prevalece una actitud individualista porque sólo se preocupan por su casa, su valor de tasación, cuánto dinero le darán por su casa, si le darán casa o dinero, si el dinero que le den será suficiente para comprar otra y adónde lo(a) mandarán a vivir. Por lo tanto, les interesa principalmente la movilidad ascendente individual y no se unen a las demás comunidades pobres en amenaza o no de desaparecer, para demostrar al gobierno y a la sociedad su capacidad para progresar de manera colectiva, invertir en el desarrollo del capital humano, reducir la pobreza y aumentar la calidad de vida. Finalmente, el desconocimiento e inseguridad sobre adónde irán a vivir y si coincidirán con sus vecinos(as) actuales crean angustia y ansiedad en los(as) residentes porque los lazos fuertes de amistad y de ayuda mutua y cooperación proveen comodidad y sentido de pertenencia a la comunidad. Entonces, existe el temor a que el cambio de residencia rompa esos lazos sociales, retrasando el proceso de adaptación a la comunidad de reasentamiento, afectando el sentido de comunidad y espíritu de cuerpo, como lo describió Lewis.

Históricamente, los(as) residentes de esta comunidad urbana y pobre de San Juan siempre han tenido dificultades para mejorar sus condiciones de vida. Hace más de medio siglo, los(as) fundadores(as) se desplazaron del campo por las limitadas oportunidades económicas y se establecieron en terrenos no aptos para construir, sobre babote y agua del caño, donde en la actualidad todavía residen personas, pero en 
calles pavimentadas, aunque altamente propensas a inundaciones. Nuevamente, los(as) residentes tienen la amenaza de ser desplazados(as) porque esos terrenos se habilitaron, por las constantes mejoras solicitadas al gobierno y porque los avances en el diseño y la construcción de edificios en los campos de ingeniería y arquitectura permiten desarrollar estructuras en terrenos no convencionales.

A lo largo de este estudio, he documentado que las actitudes dominantes de los(as) residentes hacia el realojo de sus viviendas, particularmente las de las personas a ser realojadas, son la resignación e impotencia, ante el gobierno y su supuesto plan de sacarlos(as) porque son pobres; la desconfianza y suspicacia hacia el gobierno y el posible propósito ulterior de sacarlos(as) de la comunidad, para construir proyectos millonarios para los(as) ricos(as); y la incertidumbre y el miedo, por su futuro, vulnerabilidad de la vivienda actual en las riberas del caño contaminado y realojo a caseríos. Su condición de marginalidad moldea las actitudes hacia el realojo de sus viviendas. La participación política restringida y la dependencia del gobierno y el exterior llevan a la impotencia, incertidumbre y desconfianza, en cuanto a la toma de decisiones que afectan directa e indirectamente a la comunidad. Asimismo, sus ingresos bajos, falta de empleo y recibimiento de bienestar público contribuyen al miedo y la resignación, por la escasez de recursos y limitado poder adquisitivo, que redunda en mayor dificultad de comprar o alquilar una vivienda, si el(la) residente es desalojado(a) o es realojado(a) a un lugar que no le satisface. De la misma manera, el tener aspiraciones individuales y procurar su movilidad ascendente individual llevan al miedo y la incertidumbre, sobre el paradero de la comunidad y todo lo que conlleva: lazos de parentesco, amistad y compadrazgo y redes de ayuda mutua y cooperación. 


\section{Recomendaciones}

Las personas a ser realojadas y las realojadas difieren en sus características socioeconómicas, como educación, ingresos y estado de empleo, y algunos aspectos sobre la residencia en la comunidad, como tiempo viviendo en la misma, presencia de fundadores(as) y descendencia de los(as) mismos(as), entre otras, que merecen ser exploradas en el futuro, para determinar si éstas influyen en su actitud hacia el realojo de su vivienda. En promedio, las personas realojadas tenían mayor nivel educativo que las personas a ser realojadas, el cual tal vez implique mayor conocimiento y/o entendimiento del proceso de realojo. Proporcionalmente, son más las personas realojadas desempleadas y fuera de la fuerza laboral, con ingresos bajos, que hacían chivitos y estaban bajo el nivel de pobreza, en comparación con las personas a ser realojadas. Por lo tanto recomiendo investigar si las dificultades económicas fueron un factor determinante en la decisión de realojarse a un proyecto de vivienda.

Otro factor que pudo haber influido en la decisión de cambiar de residencia es la pertenencia a una organización. Como es doble el porcentaje de residentes realojados(as) que indicó ser miembro de una organización, en comparación con los(as) residentes a ser realojados(as), sería interesante conocer, si esta organización es comunitaria y si el ser líder y/o estar al tanto de lo que ocurre en la comunidad, les permite ampliar sus conocimientos e intercambiar ideas que lleven a decidir a realojarse. Además, si una persona es miembro de una organización comunitaria, tendría mayor información de lo que ocurre en la comunidad y los planes para la misma.

En cuanto a los(as) líderes comunitarios(as), durante el trabajo de campo, encontré que algunos(as) de ellos(as) serán realojados(as) por algún proyecto, por lo 
que estas organizaciones comunitarias estaban compuestas por personas que vivirán la experiencia de cambiar de residencia, como los(as) aproximadamente 1.600 residentes a ser realojados(as). De antemano, podrían saber lo que sentirán en el futuro cercano los(as) residentes a ser realojados(as) y podrían llevar a cabo estrategias para facilitar la adaptación al lugar donde serán realojados(as). Asimismo, por residir en la comunidad, saben lo que será beneficioso, productivo y saludable para sus residentes.

Respecto a la residencia en la comunidad, como las personas realojadas en mayor proporción que las personas a ser realojadas no son descendientes de los(as) fundadores(as) de la comunidad y comenzaron a residir en ésta relativamente reciente, habría que estudiar si estas cualidades inciden en el apego a la comunidad que, a su vez, podría influir en su decisión de mudarse. Además, como entre los(as) realojados(as) participantes no había fundadores(as) de la comunidad, esto pudo haber contribuido en la toma de decisión de cambiar de residencia. También los(as) realojados(as) percibieron mejor la comunicación con la organización, por lo que posiblemente se sintieron mejor orientados(as), lo cual pudo haber ayudado en su opinión de realojarse voluntariamente. De la misma manera, en comparación con las personas a ser realojadas, un mayor porcentaje de personas realojadas asistió a las reuniones, por lo que posiblemente estaban mejor informadas sobre el proceso de realojo, pudiendo haber llevado a tener menos ansiedad y sentirse mejor preparados(as) para tomar la decisión de realojarse. Otro factor que pudo haber empujado a los(as) residentes a que se mudaran es su percepción de los cambios ocurridos en la comunidad, sobre el cual un mayor porcentaje señaló que eran negativos. Por lo tanto, la percepción negativa de la comunidad pudo haberles empujado a realojarse antes de tiempo. También recomiendo realizar un estudio para determinar los factores que inciden en la decisión de las personas a realojarse 
voluntariamente, porque números considerables de personas realojadas, que preferían una casa y tenían dudas sobre el realojo, aceptaron mudarse a un apartamento o vivienda horizontal.

Aunque no fue una variable incluida en esta investigación, sugiero que se explore si el haber vivido más afuera o más adentro en el caño influye en la disposición de realojarse porque las experiencias de vivir en la zona más degradada y contaminada suelen ser más difíciles que las de personas que viven más alejadas del caño (en tierra seca y donde hay menos hacinamiento). También propongo que se estudie si el haber tenido vicisitudes, como inundaciones que hayan causado daños a la propiedad, muebles y/o enseres y fuegos que se hayan propagado rápida y fácilmente por el hacinamiento de las viviendas, fue fundamental en la decisión de mudarse. Además, recomiendo realizar un estudio para analizar el cambio de vida luego del realojo, dándole seguimiento a los(as) residentes que estaban esperando a ser realojados(as) y conocer los cambios ocurridos en el área de donde serían realojados(as).

Para saber más del asunto del fideicomiso de la tierra, sería importante conocer las actitudes de los(as) residentes que aceptaron los títulos de propiedad individual sobre el terreno o que desean recibirlo, para explorar si quieren permanecer en la comunidad; si han recibido ofertas para comprar su propiedad; si desean venderla para irse a vivir a otra área y por qué; y si todavía sospechan que el gobierno les quiere sacar, para construir residencias caras. También sería interesante explorar si las personas de edad avanzada prefieren obtener el título de propiedad individual, como el cumplimiento de un sueño desde hace décadas, o el título de propiedad colectiva (fideicomiso). Con la variable de edad, podría estar relacionada el tiempo de residencia en esa vivienda o comunidad, sospechando que las personas de edad 
avanzada que llevan varias décadas viviendo en la comunidad y en esa residencia particularmente preferirían el título de propiedad individual, como observé en la comunidad estudiada. Igualmente, considero relevante realizar un estudio de satisfacción, para conocer si las personas realojadas están a gusto en su nueva residencia y si sienten que sus deseos por una mejor vivienda fueron satisfechos.

Por otro lado, según mis observaciones, para que los(as) residentes tengan una experiencia positiva antes, durante y después del realojo, no sólo hay que planificar la estructura de la vivienda, sino que también se debe organizar el espacio alrededor de ésta, para poder satisfacer los deseos de estar cerca del colmado, farmacia, escuela, instalaciones médico-hospitalarias y paradas de transportación pública. Otra sugerencia es que, en la construcción de los proyectos de vivienda, se continúe tomando en consideración las cualidades ideales de la vivienda y se satisfagan los deseos de las personas, como procurar que antiguos(as) vecinos(as) vuelvan a estar cerca, construir un parque, cancha y/o plaza e incluir patio y/o un espacio para hacer un huerto comunal.

Como son nueve comunidades las incluidas en los proyectos del dragado del caño y desarrollo socioeconómico, conformando un gran distrito y una amplia zona de impacto, recomiendo que se realicen actividades para integrarlas aún más. De esta manera, los lazos de amistad, cooperación y ayuda mutua se expandirían, sobrepasando los límites locales entre las nueve comunidades, aumentando así la unión entre éstas y fortaleciendo el sentido amplio de comunidad. Quizás así se tendría mayor conocimiento de lo que pasa más allá del vecindario inmediato y se desarrollaría una conciencia colectiva, teniendo presente que lo que afecta a una de las comunidades afecta a las otras ocho. 
Debido a que las actitudes de las personas a ser realojadas podrían depender de lo que les digan las personas realojadas sobre sus experiencias, es bien importante que lo vivido antes, durante y después del realojo sea positivo, cumpla con las reglas establecidas y satisfaga las expectativas de los(as) residentes. De este modo, las personas próximas a realojarse estarán informadas desde la perspectiva del residente que vivió esa experiencia y posiblemente estén motivadas a tener una experiencia igual o mejor que la que el(la) realojado(a) le contó.

Como algunos(as) residentes a ser realojados(as) señalaron dudas sobre el proceso de realojo, propongo la evaluación externa de las actividades, especialmente las reuniones, adiestramientos y de tipo educativas, que realicen la corporación pública y las organizaciones comunitarias, para determinar si se cumplieron los objetivos establecidos y si el mensaje llegó a los(as) asistentes, como la realización de una postprueba. Además, se podrían identificar personas claves, no líderes, que hayan entendido muy bien, para que puedan corregir al escuchar alguna información incorrecta sobre el realojo, dragado del caño y otro asunto importante. Así la voz se regaría correctamente y se estaría reforzando lo dicho en las actividades y reuniones.

Igualmente, recomiendo que para reducir la ansiedad y el miedo, hay que insistir en los(as) residentes a ser realojados(as) que el gobierno federal decretó que no construirá más residenciales públicos. Así también habría menos confusión y se eliminaría esta duda que causa miedo y angustia.

Entonces, el cambio de residencia a los proyectos de vivienda no sólo lleva a tranquilidad y seguridad ante el paso de tormentas y huracanes, que por tener una vivienda en concreto minimiza los efectos de estos eventos atmosféricos; también aumenta la calidad de vida de sus residentes porque, en mayor porcentaje que las personas a ser realojadas, ellas indicaron que pertenecían a la clase alta y que no había 
problemas sociales en donde viven. Aunque no pregunté por qué se autoclasificaron en esa clase social y debido a que su ingreso mensual familiar es más bajo que el de los(as) residentes a ser realojados(as), sería interesante conocer si el cambio de residencia a un nuevo apartamento o vivienda horizontal es un factor determinante que hace que las personas entiendan que pertenecen a la clase alta.

Sobre la pobreza urbana, propongo que los nuevos enfoques teóricos incluyan los siguientes factores que en esta investigación son importantes: la relación de la comunidad con el gobierno; la formulación de leyes que les afecte directa e indirectamente; la presencia e interés de las agencias gubernamentales en los asuntos de la comunidad; y el desplazamiento urbano y la planificación, desarrollo y ejecución de los mecanismos para evitarlo. Por otro lado, la ironía de que el gobierno programa y desarrolla proyectos desde y para la comunidad, para el mejoramiento de la calidad de vida, pero también enmienda y crea leyes que dificultan hacer lo programado, redunda grave y negativamente en la posesión más importante: la vivienda. Por lo tanto, el papel del gobierno es crucial en la investigación del problema de la pobreza urbana por ser el organismo que legisla, establece orden y prioridades y asigna fondos para la creación de programas y servicios, para la población general y grupos particulares.

Finalmente, sobre la política pública para el desarrollo socioeconómico de la comunidad y su fideicomiso de la tierra particularmente, recomiendo que la consulta, con sus residentes y líderes comunitarios(as), sea obligatoria, en lo concerniente a la creación de leyes y enmiendas a éstas que redundan en los proyectos ya programados y futuros. Así como el personal de la corporación pública lleva a la comunidad sus asuntos para conocer las opiniones y actitudes de los(as) residentes, los(as) demás funcionarios(as) públicos(as) deberían conocer y tomar seriamente en consideración 
lo que tienen que decir sus habitantes. También sugiero que las posibles enmiendas a las leyes principales, que atañen a la comunidad, sean congruentes entre sí para evitar la paralización o aplazamiento de los proyectos porque éstos podrían no estar conformes a la ley o en lo que se dilucidan polémicas legales en los foros judiciales. De esta manera, se podría tener un progreso acelerado en el desarrollo socioeconómico y se podrían alcanzar los objetivos establecidos, redundando en aumento en la calidad de vida de un sector de residentes capitalinos(as) que viven en pobreza en medio de la opulencia de las zonas bancaria y turística. 
Bibliografía

Abrams, C. (1971). The language of cities: A glossary of terms. Nueva York: The Viking Press.

Administración de Vivienda Pública. (2008). Listado de residenciales. Recuperado el 7 de enero de 2009 de http://www.avp.gobierno.pr

Aguirre Baztán, A. (Ed.). (1995). Etnografía: Metodología cualitativa en la investigación sociocultural. Barcelona: Editorial Boixareu Universitaria.

Aliena Miralles, R. (2002). Más allá de la subclase y la pobreza. Modernidad, identidad y exclusión social en la obra de Anthony Giddens. Revista Anthropos: Huellas del Conocimiento, 194, 165-177.

Alós, F. (2002). Aportaciones al debate sobre vivienda. Acciones e Investigaciones Sociales, 16, 81-87. Recuperado el 12 de febrero de 2008 de http://www.unizar.es/centros/eues/html/archivos/temporales/16_AIS/AIS_16( 08).pdf

Andrade-Vera, M. (2001). Cómo transferir el poder de las ONGs a la comunidad para superar la mentalidad de la pobreza: Metodología C-VAP. La Paz, Bolivia: Project Concern International.

André Mance, E. (2002). La pobreza y la colaboración solidaria. Revista Anthropos: Huellas del Conocimiento, 194, 100-108.

Andreatta, V. (2005). Favela-Bairro, un nuevo paradigma de urbanización para asentamientos informales. Cuadernos Internacionales de Tecnología para el Desarrollo Humano, 3, 1-8.

Angotti,T. (2009). The right to the city versus bridging the urban divide. The Urban Reinventors, 3, 1-5. Recuperado el 31 de diciembre de 2009 de http://urbanreinventors.net/3/angotti/angotti-urbanreinventors.pdf

Angrosino, M. (2004). Projects in ethnographic research. Long Grove, Illinois, EE.UU.: Waveland Press.

Aponte Torres, G. (1985a). Desarrollo urbano de los terrenos de la finca Seboruco de Santurce. Tesis de maestría, Centro de Estudios Avanzados de Puerto Rico y el Caribe, San Juan, Puerto Rico.

Aponte Torres, G. (1985b). San Mateo de Cangrejos (Comunidad cimarrona en Puerto Rico): Notas para su historia. San Juan, Puerto Rico: Oficina Estatal de Preservación Histórica de La Fortaleza. 
Autoridad de Acueductos y Alcantarillados. (2008). Alcantarillado sanitario. Recuperado el 20 de marzo de 2008 de http://www.acueductospr.com/4_comunicaciones/alcantarillado_sanitario_acu eductospr.htm

Autoridad de Carreteras. (1989). Manual de orientación y realojo en proyectos con participación federal. San Juan, Puerto Rico: Autor.

Aylwin Azúcar, P. (2005). Experiencia chilena en la lucha contra la pobreza con participación de la sociedad civil. Ética y Gobernabilidad, 6. Recuperado el 12 de febrero de 2008 de http://www.iigov.org/eg/attachment.drt?art=14505

Back, K.W. (1974). Slums, projects, and people: Social psychological problems of relocation in Puerto Rico. Westport, Connecticut, EE.UU.: Greenwood Press.

Barnard, A. (2000). History and theory in anthropology. Cambridge: Cambridge University Press.

Bennholdt-Thomsen, V. \& Garrido, A. (1981). Marginalidad en América Latina. Una crítica de la teoría. Revista Mexicana de Sociología, 43 (4), 1505-1546.

Bernard, H.R. (2006). Research methods in anthropology: Qualitative and quantitative approaches. (4a. ed.). Lanham, Maryland, EE.UU.: Altamira Press.

Borsdorf, A. \& Hidalgo, R. (2009). The fragmented city: Changing patterns in Latin American cities. The Urban Reinventors, 3, 1-18. Recuperado el 31 de diciembre de 2009 de http://urbanreinventors.net/3/borsdorfhidalgo/borsdorfhidalgourbanreinventors.pdf

Botey Vallès, J. (2002). La pobreza no existe, existen los pobres. Testimonio de un compromiso. Revista Anthropos: Huellas del Conocimiento, 194, 206-215.

Bourgois, P. (2002). Office work and the crack alternative among Puerto Rican drug dealers in East Harlem. En G. Gmelch \& W.P. Zenner (Eds.), Urban life: Readings in the anthropology of the city (4a. ed.) (pp. 306-320). Prospect Heights, Illinois, EE.UU.: Waveland Press.

Boyd, M. (2005). The downside of racial uplift: The meaning of gentrification in an African American neighborhood. City \& Society, 17 (2), 265-288.

Brewer, J.D., Lockhart, B., \& Rodgers, P. (1998). Informal social control and crime management in Belfast. The British Journal of Sociology, 49 (4), 570-585.

Brown, A. \& Kristiansen, A. (2009). Urban policies and the right to the city: Rights, responsibilities, and citizenship. Recuperado el 31 de diciembre de http://urbanreinventors.net/3/UN-urban.pdf 
Bryce-Laporte, R.S. (1973). Relocalización urbana y adaptación familiar en Puerto Rico. Revista de Ciencias Sociales, XVII (1), 53-72.

Buchanan, P.G. (2000). That the lumpen should rule: vulgar capitalism in the postindustrial age. Journal of American \& Comparative Cultures, 23 (4), 1-14.

Busà, A. (2009). The right to the city: The entitled and the excluded. The Urban Reinventors, 3, 1-13. Recuperado el 31 de diciembre de 2009 de http://urbanreinventors.net/3/busa/busa-urbanreinventors.pdf

Cahill, C. (2007). Negotiating grit and glamour: Young women of color and the gentrification of the Lower East Side. City \& Society, 19 (2), 202-231.

Cantero, P.A., Rodríguez, J. \& Alverio, M.H. (1978). Estudio sobre factores que determinan la pobreza en Puerto Rico. San Juan, Puerto Rico: Universidad de Puerto Rico.

Castells, M. (1981). Capital multinacional, estados nacionales, comunidades locales. México, D.F.: Siglo Veintiuno Editores.

Castells, M. (1986). La ciudad y las masas: Sociología de los movimientos sociales urbanos. Madrid: Alianza Editorial.

Castells, M. (2004a). La cuestión urbana. (16a. ed.). México, D.F.: Siglo Veintiuno Editores.

Castells, M. (2004b). Movimientos sociales urbanos. (16a. ed.). México, D.F.: Siglo Veintiuno Editores.

Caulfield, J. (1992). Gentrification and familism in Toronto: A critique of conventional wisdom. City \& Society, 6 (1), 76-89.

Cebrián Abellán, A. (2000). Los indicadores de la pobreza en la República de Guatemala. Papeles de geografía, 31, 23-38. Recuperado el 12 de febrero de 2008 de http://www.um.es/dpgeografia/papeles/n31/02\%20Los\%20indicadores\%2023-38.pdf

Center for Urban Studies, University College. (Ed.). (1964). London: Aspects of change. Londres: MacGibbon \& Kee.

Coalición para el Habitat. (1997). Política y gestión urbana en la región del Caribe. Santo Domingo, República Dominicana: Autora.

Colón Reyes, L. (2002). Neoliberalismo, globalización y pobreza en Puerto Rico. En F.E. Martínez \& F.A. Catalá (Eds.), Ensayos sobre la pobreza en Puerto Rico (pp. 19-61). San Juan, Puerto Rico: Publicaciones Puertorriqueñas. 
Colón Reyes, L. (2006). Pobreza en Puerto Rico: Radiografía del proyecto americano. (5a. ed.). San Juan, Puerto Rico: Editorial Luna Nueva.

Colten, C.E. (2006). Vulnerability and place: Flat land and uneven risk in New Orleans. American Anthropologist, 108 (4), 731-734.

Consejo de Desarrollo Estratégico de Puerto Rico (1993). El problema de la pobreza en Puerto Rico. Revista de Administración Pública, 26 (Edición Especial), 201-233.

Corretjer Hernández, A.L. (2001). Las invasiones de terreno: Una violación de ley o una necesidad social. Revista de Derecho Puertorriqueño, 40 (1), 111-136.

Cotto, L. (1981). The urban crisis. Homines, 5 (1-2), 173-196.

Cotto, L. (2006). Desalambrar. San Juan, Puerto Rico: Editorial Tal Cual.

Cresswell, R. \& Godelier, M. (1981). Útiles de encuesta y de análisis antropológicos. Madrid: Editorial Fundamentos.

Dalaker, J. (2001). Poverty in the United States: 2000. Current Population Reports: Consumer Income. Washington, D.C., EE.UU.: U.S. Census Bureau.

De Sebastián, L. (2002). Globalización, exclusión y pobreza. Revista Anthropos: Huellas del Conocimiento, 194, 55-64.

Deckha, N. (1999). Historic preservation and the cultural politics of the American downtown. City \& Society, 11 (1-2), 193-200.

Del Pilar, J.A. \& Udasco, J.O. (2004). Marginality theory: The lack of construct validity. Hispanic Journal of Behavioral Sciences, 26 (1), 3-15.

Departamento de la Familia. (2007a). Programa de asistencia nutricional (PAN). Recuperado el 13 de octubre de 2008, de http://www.familia.gobierno.pr

Departamento de la Familia. (2007b). Servicios. Recuperado el 23 de marzo de 2009, de http://www.familia.gobierno.pr

Departamento de la Vivienda. (2008a). Reglamento para la distribución y administración de parcelas o solares para vivienda bajo el Título V de la Ley de Tierras de Puerto Rico (enmendado). San Juan, Puerto Rico: el autor. Recuperado el 3 de febrero de 2009 de http://www.gobierno.pr/NR/rdonlyres/5312F581-9AD3-40D7-8C04FEB38A85816C/0/REGLAMENTOPAALADISTRIBUCIONY.pdf

Departamento de la Vivienda. (2008b). Servicios. Recuperado el 23 de marzo de 2009 de http://www.vivienda.gobierno.pr

Departamento de Salud. SAPEESI. División de Estadísticas. (2004). Informe anual de estadísticas vitales: 2002. San Juan, Puerto Rico: Autor. 
DeWalt, K.M. \& DeWalt, B.R. (2002). Participant observation: A guide for fieldworkers. Walnut Creek, California, EE.UU.: Altamira Press.

Dickie-Clark, H.F. (1966). The marginal situation: A contribution to marginality theory. Social Forces, 44 (3), 363-370.

Duggal, V.P. (1979). Poverty in Puerto Rico. Horizontes, 23 (45), 53-68.

Dumouchel, J.R. (1975). Dictionary of development terminology. Nueva York: McGraw-Hill Book Company.

Dye, T.R. (1987). Understanding public policy. (6a. ed.). New Jersey, New Jersey, EE.UU.: Prentice-Hall, Inc.

Eller, T.J. (1996). Dynamics of economic well-being, poverty 1992-3: Who stays poor? Who doesn't? Current Population Reports: Household Economic Studies. Washington, D.C., EE.UU.: U.S. Census Bureau.

Espina Barrio, A.B. (1997). Manual de antropología cultural. Salamanca, España: Amarú Ediciones.

Espinola Orrego, G. (2007). Buscando arraigo: Inmigrantes y vivienda, otro modo de exclusión. Universitas: Revista de Filosofía, Derecho y Política, 6, 91-106. Recuperado el 12 de febrero de 2008 de http://universitas.idhbc.es/n06/0606.pdf

Etzioni, A. (1976). Social problems. New Jersey, New Jersey, EE.UU.: Prentice-Hall, Inc.

Fernández Gallego de Lerma, J., Barberá Gómez, A., Casado Florez, M.I., GarcíaOchoa Blanco, M.J., \& Rodríguez Rodríguez, O. (2009). Cañada Real Galiana: intervención sanitaria urgente en las "favelas españolas". Puesta al Día en Urgencias, Emergencias y Catástrofes, 9 (2), 97-102.

Friedlander, D., Greenberg, D.H., \& Robins, P.K. (1997). Evaluating government training programs for the economically disadvantaged. Journal of Economic Literature, 35 (4), 1809-1855.

Fuller Marvel, L. (1989). Sector informal y planificación: Un modelo para resolver problemas de vivienda en Puerto Rico. Plerus, 21, 176-184.

Fundación Fomento de Estudios Sociales y de Sociología Aplicada. (1994). Las condiciones de vida de la población sobre la provincia de Salamanca. Madrid: Autora.

Gafar, J. (2002). Poverty measures, dimensions, and some strategies for its reduction in the Caribbean. Caribbean Studies, 30 (1), 205-243. 
García, V. (2002). Familia y pobreza: Propuestas alternas de transformación. En F.E. Martínez \& F.A. Catalá (Eds.), Ensayos sobre la pobreza en Puerto Rico (pp. 164-208). San Juan, Puerto Rico: Publicaciones Puertorriqueñas.

García, C. \& Álvarez, A. (2003) ...y sin embargo se vive. De la infravivienda a la vivienda urbana en Mérida Yucatán México. Revista Electrónica de Geografía y Ciencias Sociales, 7 (146). Recuperado el 12 de febrero de 2008 de http://www.ub.es/geocrit/sn/sn-146(143).htm

García Fajardo, J.C. (2002). ¿Quién dijo que todo está perdido? Revista Anthropos: Huellas del Conocimiento, 194, 197-205.

García Herrera, L.M. (2001). Elitización: Propuesta en español para el término gentrificación. Revista Bibliográfica de Geografía y Ciencias Sociales, 6 (332). Recuperado el 4 de octubre de 2007 de http://www.ub.es/geocrit/b3w332.htm

García Herrera, L.M. (2003). ¿De cabañas a palacios? Vivienda y proceso de elitización en el Cabo-Los Llanos (Santa Cruz de Tenerife, Canarias). Revista Electrónica de Geografía y Ciencias Sociales, 7 (146). Recuperado el 12 de febrero de $2008 \mathrm{de} \mathrm{http://www.ub.es/geocrit/sn/sn-146(075).htm}$

Gattino, S. \& Aquín, N. (1999). Las familias de la nueva pobreza: Una lectura posible desde el Trabajo Social. Buenos Aires: Espacio Editorial.

Geertz, C. (1996). Los usos de la diversidad. (1a .ed.). Barcelona: Ediciones Paidós.

Ghannam, F. (2002). Remaking the modern: Space, relocation, and the politics of identity in a global Cairo. Berkeley, California, EE.UU.: University of California Press.

Giddens, A. (2004). Sociología. (4a. ed.). Madrid: Alianza Editorial

Giuliani, F. \& Wiesenfeld, E. (2003). Promoting sustainable communities: Theory, research, and action. Community, Work \& Family, 6 (2), 159-182.

Giusti Cordero, J.A. (1996). Para leer a Mintz... en puertorriqueño: Una aproximación bibliográfica y crítica. Fundamentos, 3-4, 101-108.

Glazer, N. (1967). Housing policy and the family. Journal of Marriage and the Family, 29 (1), 140-163.

Glick, J.E. (1999). Economic support from and to extended kin: A comparison of mexican americans and mexican inmigrants. International Migration Review, 33 (3), 745-765.

Godreau, I.P. (2002). Changing space, making race: Distance, nostalgia, and the folklorization of blackness in Puerto Rico. Identities: Global Studies in Cultural and Power, 9, 281-304. 
Goldín, L., Rosenbaum, B., \& Eggleston, S. (2006). Women's participation in Nongovernment organizations: Implications for poverty reduction in precarious settlements of Guatemala City. City \& Society, 18 (2), 260-287.

Goldschmidt, W. (1977). Anthropology and the coming crisis: An autoethnographic appraisal. American Anthropologist, 79 (2), 293-308.

González, J.E. (1963). Antropología de la pobreza. Revista de Ciencias Sociales, 7 (3), 253-278.

González, J.L. (1974). En el fondo del caño hay un negrito. En Lecturas Puertorriqueñas. (pp. 263-266). Madrid: Ediciones Plaza Mayor.

González Martínez, A. (2003). El desarrollo y la desigualdad económica: La contribución de la Revista de Ciencias Sociales. Revista de Ciencias Sociales, 12, 12-66.

Goode, J. (2002). How urban ethnography counters myths about the poor. En G. Gmelch \& W.P. Zenner (Eds.), Urban life: Readings in the anthropology of the city (4a. ed.) (pp. 279-295). Prospect Heights, Illinois, EE.UU.: Waveland Press.

Government Development Bank for Puerto Rico. (2003). New aggressive program to promote quality of life in poor communities. Puerto Rico Business Review, 27 (4), 6 .

Gravano, A. (2003). Antropología de lo barrial: Estudios sobre producción simbólica de la vida urbana. Buenos Aires: Espacio Editorial.

Gravano, A. (2005). El barrio en la teoría social. Buenos Aires: Espacio Editorial.

Gravlee, C.G. (2005). Ethnic classification in Southeastern Puerto Rico: The cultural model of "color". Social Forces, 83 (3), 949-970.

Greenbaum, S.D. (1985). [Reseña del libro Cuban americans: Masters of survival]. American Anthropologist, 87 (2), 461.

Greenbaum, S.D. (1990). Marketing Ybor City: Race, ethnicity, and historic preservation in the sunbelt. City \& Society, 4 (1), 58-76.

Greenbaum, S. (2002). Social capital and deconcentration: Theoretical and policy paradoxes of the HOPE VI program. North American Dialogue 5 (1), 9-13.

Greenbaum, S.D. (2004). [Reseña del libro Wizards and scientists: Exploration in afro-cuban modernity and tradition]. American Anthropologist, 106 (3), 630.

Greenbaum, S.D. \& Greenbaum, P.E. (1984). Integrating ethnographic and quantitative research: A reply to Kleinfeld with implications for american indian self-determination. Anthropology and Education Quarterly, 15 (2), $171-173$ 
Guerra, P.A. (2002). Pobreza: Seis consideraciones sociológicas y un corolario para América Latina. Revista Anthropos: Huellas del Conocimiento, 194, 72-82.

Hammersley, M. \& Atkinson, P. (1995). Ethnography: Principles in practice. (2a. ed.). Londres: Routledge.

Hannerz, U. (1980). Exploring the city: Inquiries toward an urban anthropology. Nueva York: Columbia University Press.

Haviland, W.A. (1997). Anthropology. (8a. ed.). Montreal, Canadá: Harcourt Brace College Publishers.

Henry, K (2009). Tales of a little ghetto girl. The Urban Reinventors, 3. Recuperado el 31 de diciembre de 2009 de http://urbanreinventors.net/3/henry.pdf

Hermida, A.G. (1979). Un aspecto del procedimiento de desahucio: El desalojo voluntario. Boletín Judicial, 1 (1), 28.

Hollman, R. (1978). Poverty: Explanations of social deprivation. Nueva York: St. Martin's Press.

Hugo, G., Champion, A., \& Lattes, A. (2003). Toward a new conceptualization of settlements for demography. Population and Development Review, 29 (2), 277-297.

Hunter, D.R. (1964). The slums: Challenge and response. Nueva York: The Free Press of Glencoe.

Hyland, S.B. \& Brimhall, R.B. (2005). Evaluation anthropology in community development/community building. NAPA Bulletin 24, 125-137.

Isaac, J. (1950). Problems of cultural assimilation arising from population transfers in Western Germany. Population Studies, 3, 23-37.

Jacobson, D. (1987). The cultural context of social support and support networks. Medical Anthropology Quarterly, 1 (1), 42-67.

Jagun, A., Brown, D.R., Milburn, N.G., \& Gary, L.E. (1990). Residential satisfaction and socioeconomic and housing characteristics of urban black adults. Journal of Black Studies, 21 (1), 40-51.

Jones, D. (1987). The "community" and organizations in the community. En L. Mullings (Ed.). Cities of the United States. Studies in urban anthropology. (pp. 99-121). Nueva York: Columbia University Press.

Junta de Planificación. (1971). La problemática de la pobreza en Puerto Rico. San Juan, Puerto Rico: Autor.

Junta de Planificación. (1978). Situación de la vivienda en Puerto Rico 1977-80. San Juan, Puerto Rico: Autor. 
Kellet, P. (2003). El espacio doméstico y la generación de ingresos: La casa como sitio de producción en asentamientos informales. Revista Electrónica de Geografía y Ciencias Sociales, 7 (146). Recuperado el 12 de febrero de 2008 de http://www.ub.es/geocrit/sn/sn-146(110).htm

Knox, P.L. (1991). The restless urban landscape: Economic and sociocultural change and the transformation of metropolitan Washington, D.C. Annals of the Association of American Geographers, 81 (2), 181-209.

Krueger, P.M., Rogers, R.G., Ridao-Cano, C., \& Hummer, R.A. (2004). To help or to harm? Food stamp receipt and mortality risk prior to the 1996 Welfare Reform Act. Social Forces, 82 (4), 1573-1599.

Kushner, G. (1969). The anthropology of complex societies. Biennial Review of Anthropology, 6, 80-131.

Labarca Bonnet, R.L. \& López Domínguez, J.M. (1973). Desarrollo, dependencia y marginalidad en Puerto Rico. Horizontes, 17 (33-34), 73-92.

Labica, G. (2002). ¿Sobran hombres? Revista Anthropos: Huellas del Conocimiento, 194, 134-144.

Langon, M. (2002). Pobreza humana y educación. Revista Anthropos: Huellas del Conocimiento, 194, 145-150.

Leacock, L. (1987). Theory and ethics in applied urban anthropology. En L. Mullings (Ed.). Cities of the United States. Studies in urban anthropology. (pp. 317336). Nueva York: Columbia University Press.

Lewis, O. (1972). La cultura de la pobreza. Barcelona: Editorial Anagrama.

Lewis, O. (1983). La vida. Miguel Hidalgo, México: Grijalbo.

Lewis, O. (1985). Antropología de la pobreza: Cinco familias. México, D.F., México: Fondo de Cultura Económica.

Lewis, O. (2002). The culture of poverty. En G. Gmelch \& W.P. Zenner (Eds.), Urban life: Readings in the anthropology of the city (4a. ed.) (pp. 269-278). Prospect Heights, Illinois, EE.UU.: Waveland Press.

Ley Núm. 350 del 2 de septiembre de 2000 para enmendar el Art. 177 del Código Penal de 1974 del Estado Libre Asociado de Puerto Rico

Ley Núm. 201 del 26 de agosto de 2002 para enmendar, añadir y renumerar el art. 4 de la Ley Núm. 97 de 1972 del Estado Libre Asociado de Puerto Rico

Ley Núm. 429 del 22 de septiembre de 2004 para enmendar la Ley Núm. 97 de 1972 del Estado Libre Asociado de Puerto Rico 
Ley Núm. 489 del 24 de septiembre de 2004 del Estado Libre Asociado de Puerto Rico

Ley Núm. 83 del 5 de mayo de 2006 para enmendar el Artículo 1 de la Ley Núm. 49 de 4 de enero de 2003 del Estado Libre Asociado de Puerto Rico

Ley Núm. 32 del 23 de junio de 2009 para enmendar el Artículo 16 de la Ley Núm. 489 de 24 de septiembre de 2004 del Estado Libre Asociado de Puerto Rico

Ley Pública 105-117 para enmendar el Acta de 1970 de Asistencia de Realojo Uniforme y Políticas de Adquisición de Inmuebles para prohibir a un(a) extranjero(a) que no está presente legalmente en los Estados Unidos de recibir asistencia bajo esa Acta del Congreso de los Estados Unidos.

Lichter, D.T. \& Crowley, M.L. (2002). Poverty in America: Beyond welfare reform. Population Bulletin, 57 (2), 3-35.

Logie, G. (1978). Glossary of population and housing. Amsterdam: Elsevier Scientific Publishing Company.

Logie, G. (1986). Glossary of planning and development. Amsterdam: Elsevier Science Publishers.

Logiudice, E. (2002). Miseria global. Revista Anthropos: Huellas del Conocimiento, $194,65-71$.

Lok-Dessallien, R. (2000). Review of poverty concepts and indicators. Recuperado el 24 de septiembre de 2002, de http://www.undp.org/poverty/publications/pov_red

Lomnitz, L.A. (1985). Cómo sobreviven los marginados. (8a. ed.). México: Siglo Veintiuno Editores.

Low, S.M. (1996a). Spatializing culture: The social production and social construction of public space in Costa Rica. American Ethnologist, 23 (4), 861879 .

Low, S.M. (1996b). The anthropology of cities: Imaging and theorizing the city. Annual Review of Anthropology, 25, 383-409.

Low, S.M. (Ed.). (1999). Theorizing the city: The new urban anthropology reader. New Brunswick, New Jersey, EE.UU.: Rutgers University Press.

McNicoll, G. (1997). Population and poverty: A review and restatement. Nueva York: Population Council. (No. de publicación 105). 
Margarit, D. (2003). El sentido del bienestar en una política social de vivienda: El caso de la fase piloto del Chile Barrio. Revista Electrónica de Geografía y Ciencias Sociales, 7 (146). Recuperado el 12 de febrero de 2008 de http://www.ub.es/geocrit/sn/sn-146(089).htm

Mas Hernández, R. (2001). [Reseña del libro Globalización: Transformaciones urbanas, precarización social y discriminación de género]. Revista Bibliográfica de Geografía y Ciencias Sociales, 6 (336). Recuperado el 4 de octubre de 2007 de http://www.ub.es/geocrit/b3w-336.htm

Massey, D.S. \& Denton, N.A. (1994). American apartheid: Segregation and the making of the underclass. Cambridge, Massachusetts, EE.UU.: Harvard University Press.

Meertens, D. (2002). Desplazamiento e identidad social. Revista de Estudios Sociales, $11,1-3$.

Merry, S.E. (2002). Urban danger: Life in a neighborhood of strangers. En G. Gmelch \& W.P. Zenner (Eds.), Urban life: Readings in the anthropology of the city (4a. ed.) (pp. 115-126). Prospect Heights, Illinois, EE.UU.: Waveland Press.

Miller, H. (1964). Poverty in Puerto Rico. San Juan, Puerto Rico: Puerto Rico Planning Board.

Miranda Regina, J.E. (2002). Obreros rurales: "El campamento sin tierra en Mato Grosso do Sul: La lucha y la resistencia contra la pobreza y la miseria en Brasil". Revista Anthropos: Huellas del Conocimiento, 194, 155-160.

Monreal, P. (1996). Antropología y pobreza urbana. Madrid: Los Libros de la Catarata.

Morales, J. (1993). Desarrollo político y pobreza. Revista de Administración Pública, 26 (Edición Especial), 351-363.

Morales, R. (2000). Métodos para medir la pobreza. La Paz, Bolivia: Universidad Andina Simón Bolívar.

Morell Blanch, A. (2002). Reflexiones en torno a la idea de pobreza. Revista Anthropos: Huellas del Conocimiento, 194, 10-21.

Moskowitz, H.S. \& Lindbloom, C.G. (1993). The new illustrated book of development definitions. New Jersey, EE.UU.: Center for Urban Policy Research.

Muñiz, V. (1996). Resistencia y afirmación de identidad: Las mujeres puertorriqueñas luchan contra el desplazamiento en un barrio de la ciudad de Nueva York. Revista de Ciencias Sociales, 1 (Nueva época), 156-177.

Myrdal, G. (1962). Challenge to affluence. Nueva York: Phanteon. 
Naife, M. (1998). Dynamics of economic well-being, poverty 1993-4: Trap door? Revolving door? Or both? Current Population Reports: Household Economic Studies. Washington, D.C., EE.UU.: U.S. Census Bureau.

Oficina de Comunidades Especiales. (2004). Comunidades especiales: Informe de transición. San Juan, Puerto Rico: Autor.

Oficina de la Gobernadora, Junta de Planificación y Oficina de la Procuradora de las Mujeres. (2004). Perfil demográfico y socioeconómico de la población desagregado por género, Puerto Rico: 2000. San Juan: Junta de Planificación. Recuperado el 13 de enero de 2009 de http://www.censo.gobierno.pr

Ortega Blake, J.A. (1982). Diccionario de planeación y planificación (Un ensayo conceptual). México, D.F.: Editorial Edicol.

Otero, C.R., Cantó Sánchez, O., \& Gradín Lago, C.M. (2004). Inequality, poverty, and mobility: Choosing income or consumption as welfare indicators. Papeles de Trabajo del Instituto de Estudios Fiscales (Serie economía), 18, 1-52. Recuperado el 12 de febrero de 2008 de http://www.ief.es/Publicaciones/PapelesDeTrabajo/pt2004_18.pdf

Paláu, A. (1980). Técnicas de investigación para el estudio de la pobreza en Puerto Rico: Un nuevo acercamiento. Homines, 4 (2), 25-38.

Paravisini, C. (1989). Factores asociados a la pobreza en Puerto Rico: 1970 y 1980. San Juan, Puerto Rico: Universidad de Puerto Rico, Escuela Graduada de Salud Pública.

Pardo Flores, J.J. (2002a). Bibliografía sobre el tema de la pobreza. Revista Anthropos: Huellas del Conocimiento, 194, 35-54.

Pardo Flores, J.J. (2002b). Medición y cifras de la pobreza. Revista Anthropos: Huellas del Conocimiento, 194, 22-34.

Peattie, L. \& Aldrete-Haas, J.A. (1981). "Marginal" settlements in developing countries: Research, advocacy of policy, and evolution of programs. Annual Review of Sociology, 7, 157-175.

Pérez, R. (2006). The misunderstanding of mexican community life in urban apartment space: A case study in applied anthropology. City \& Society, 18 (2), 232-259.

Pérez de Jesús, M. (1973). El desarrollo económico, la sobrepoblación y la desigualdad en Puerto Rico. Revista de Ciencias Sociales, 17 (2), 167-214.

Perlman, J. (1976). The myth of marginality: Urban poverty and politics in Rio de Janeiro. Berkeley, California, EE.UU.: University of California Press. 
Pettit, B. (2004). Moving and children's social connections: Neighborhood context and the consequences of moving for low-income families. Sociological Forum, 19 (2), 285-311.

Plotnicov, L. (1991). Afterthoughts: Old and New Directions. City \& Society, 5 (2), 169-171.

Plyushteva, A. (2009). The right to the city and the struggles over public citizenship: Exploring the links. The Urban Reinventors, 3, 1-17. Recuperado el 31 de diciembre de 2009 de http://urbanreinventors.net/3/plyushteva/plyushtevaurbanreinventors.pdf

Potuoğlu-Cook, Ö. (2006). Beyond the Glitter: Belly Dance and Neoliberal Gentrification in Istanbul. Cultural Anthropology, 21 (4), 633-660.

ProAmbiente. (2008). Conozcamos al mangle rojo. Recuperado el 20 de marzo de 2008 de http://www.proambientepr.org/semillas/temas_educativos/manglares/tm/rojo.h tml

Proctor, B.D. \& Dalaker, J. (2002). Poverty in the United States: 2001. En Current Population Reports: Consumer Income. Washington, D.C., EE.UU.: U.S. Census Bureau.

Puccia, E, Borman, K.M., Greenbaum, S.D., \& Yelvington, K.A. (2001). Missionary zeal and high tech work on Florida's space coast. Anthropology of Work, 22 (1), 22-27.

Quiles Rodríguez, E.R. (2003). San Juan tras la fachada: Una mirada desde los espacios ocultos. (1508-1900). San Juan, Puerto Rico: Editorial Instituto de Cultura Puertorriqueña.

Quiñones, M.A. (1996). La antropología y la producción etnográfica: Un obscuro objeto del deseo. Fundamentos, 3-4, 3-15.

Ramírez, R.L. (1970). Pobreza en Puerto Rico: Teoría y praxis. Revista de Administración Pública: Seminario sobre el Problema de la Pobreza en Puerto Rico, 1-14.

Ramírez, R.L. (1976). El arrabal y la política. San Juan, Puerto Rico: Editorial de la Universidad de Puerto Rico.

Rapp, R. (1987). Urban kinship in contemporary America: Families, classes, and ideology. En L. Mullings (Ed.), Cities of the United States. Studies in urban anthropology. (pp. 219-242). Nueva York: Columbia University Press.

Real Academia Española. (2001). Diccionario de la lengua española. (22a. ed.). Madrid: Editorial Espasa Calpe. 
Requena, J. (2003). "La peor casa en el peor barrio". Barrios de inmigración y marginalidad en la periferia urbana de Barcelona. El caso de Badalona. Revista Electrónica de Geografía y Ciencias Sociales, 7 (146). Recuperado el 12 de febrero de 2008 de http://www.ub.es/geocrit/sn/sn-146(058).htm.

Reyes Angleró, M. (2007, 28 de octubre). ¡Barrio, mi querido barrio...! La supervivencia de las comunidades ante el empuje de la revitalización urbana. [La Revista]. El Nuevo Día. pp. 14-17.

Reyes Avilés, H. (2006a, 24 de septiembre). Amenazada la seguridad por la miseria. El Nuevo Día. pp. 6-7.

Reyes Avilés, H. (2006b, 24 de septiembre). Peligro entre el lucro y la necesidad. El Nuevo Día. p. 8.

Rivera, G. (2009). Favelas, public housing, and the recofinguration or urban space in brazilian slums. The Urban Reinventors, 3, 1-13. Recuperado el 31 de diciembre de 2009 de http://urbanreinventors.net/3/rivera/riveraurbanreinventors.pdf

Rivera, J.E. (1974). La pobreza en Puerto Rico. San Juan, Puerto Rico: Universidad de Puerto Rico, Escuela Graduada de Salud Pública.

Rivera de Morales, N. (1971). Urbanismo en Puerto Rico. San Juan, Puerto Rico: Universidad de Puerto Rico, Escuela de Salud Pública.

Rivera Marrero, M. (2007a, 1 de julio). Hijos de invasores: Abruma el déficit de vivienda. El Nuevo Día. pp. 6-7.

Rivera Marrero, M. (2007b, 1 de julio). Hijos de invasores: Vivo el recuerdo del rescate. El Nuevo Día. p. 8.

Rivera Marrero, M. (2010, 7 de febrero). 'Atropello' contra los sectores pobres. $E l$ Nuevo Día. p. 8.

Rodríguez Álvarez, A. (1987). Development of marxist thought in anthropology: A historical review. Cupey, 4 (1), 74-79.

Rothstein, F.A. (1999). Declining odds: Kinship, women's employment, and political economy in rural Mexico. American Anthropologist, 101 (3), 579-593.

Rotenberg, R. (2002). The metropolis and everyday life. En G. Gmelch \& W.P. Zenner (Eds.), Urban life: Readings in the anthropology of the city (4a. ed.) (pp. 93-105). Prospect Heights, Illinois, EE.UU.: Waveland Press.

Ruiz, E. (1963). Algunas observaciones e interpretaciones sobre un arrabal puertorriqueño. Revista de Ciencias Sociales, 7 (1-2), 149-168.

Safa, H.I. (1980). Familias del arrabal: Un estudio sobre desarrollo y desigualdad. San Juan, Puerto Rico: Editorial de la Universidad de Puerto Rico. 
Salas, J. \& Colavidas, F. (2004). Los programas de mejora de la ciudad informal, herramientas de lucha contra la pobreza. Informes de la Construcción, 56 (491), 19-32.

Salinas, P.J. (2006). Pobreza y salud: Un problema global, sus causas, consecuencias y soluciones. MedULA: Revista de la Facultad de Medicina, 15 (1), 16-22. Recuperado el 12 de febrero de 2008 de http://www.saber.ula.ve/db/ssaber/Edocs/pubelectronicas/medula/Vol15num1/ articulo3.pdf

Sánchez, E. (1998). "Slum", lugar no apto para turistas. Familia y Escuela, 203, 11.

Sanjek, R. (1977). Cognitive maps of the ethnic domain in urban Ghana: Reflections on variability and change. American Ethnologist, 4 (4), 603-622.

Sanjek, R. (1990). Urban anthropology in the 1980s: A world view. Annual Review of Anthropology, 19, 151-186.

Sargatal Bataller, M.A. (2000). El estudio de la gentrificación. Revista Bibliográfica de Geografía y Ciencias Sociales, 228. Recuperado el 4 de octubre de 2007 de http://www.ub.es/geocrit/b3w-228.htm

Sargatal Bataller, M.A. (2001). Gentrificación e inmigración en los centros históricos: El caso del barrio del Raval en Barcelona. Scripta Nova. Revista Electrónica de Geografía y Ciencias Sociales, 94 (66). Recuperado el 4 de octubre de 2007 de http://www.ub.es/geocrit/sn-94-66.htm

Sawhill, I.V. (1988). Poverty in the U.S.: Why it is so persistent? Journal of Economic Literature, 26, 1073-1119.

Sen, A.K. (1993). Sobre conceptos y medidas de pobreza. Revista de Administración Pública, 26 (Edición Especial), 3-31.

Sepúlveda, A. \& Carbonell, J. (1987). Cangrejos-Santurce: Historia ilustrada de su desarrollo urbano (1519-1950). San Juan, Puerto Rico: Centro de Investigaciones CARIMAR, Oficina Estatal de Preservación Histórica.

Severino, C. (1999). Los procesos de urbanización y metropolización de San Juan: Factores principales del consumo de espacio y de la configuración territorial de la sociedad puertorriqueña. En F.E. Martínez (Ed.), Futuro económico de Puerto Rico: Antología de ensayos del proyecto sobre el futuro económico de Puerto Rico (pp. 319-343) San Juan, Puerto Rico: Editorial de la Universidad de Puerto Rico.

Shafritz, J.M. (Ed.). (1998). International encyclopedia of public policy and administration. Boulder, Colorado, EE.UU.: Westriew Press. 
Sharff, J. (1987). The underground economy of a poor neighborhood. En L. Mullings (Ed.). Cities of the United States. Studies in urban anthropology. (pp. 19-50). Nueva York: Columbia University Press.

Shaw, K. (2009). A curiously qualified legacy of resistance to gentrification. The Urban Reinventors, 3, 1-15. Recuperado el 31 de diciembre de 2009 de http://urbanreinventors.net/3/shaw/shaw-urbanreinventors.pdf

Sieber, R.T. (1987). Urban gentrification: Ideology and practice in middle-class civic activity. City \& Society, 1 (1), 52-63.

Sieber, R.T. (1991). Introduction: New directions in contemporary urban development. City \& Society 5 (2), 99-102.

Silva, L.F. (1993). Aspectos económicos de la pobreza. Revista de Administración Pública, 26 (Edición Especial), 365-383.

Sin, D.D., Svenson, L.W., \& Man, P. (2001). Do area-based markers of poverty accurately measure personal poverty. Canadian Journal of Public Health, 92 (3), 184-187.

Small, M.L. \& Newman, K. (2001). Urban poverty after the truly disadvantaged: The rediscovery of the family, the neighborhood, and culture. Annual Review of Sociology, 27 (1), 23-46.

Smith, J.W. \& Klemanski, J.S. (1990). The urban politics dictionary. California, EE.UU.: Abc-Clio.

Sotomayor, O. (1998). Poverty and income inequality in Puerto Rico: 1970-1990. San Juan, Puerto Rico: Universidad de Puerto Rico.

Sotomayor, O. (2002). La pobreza en Puerto Rico. En F.E. Martínez \& F.A. Catalá (Eds.), Ensayos sobre la pobreza en Puerto Rico (pp. 1-18). San Juan, Puerto Rico: Publicaciones Puertorriqueñas.

Sotomayor, O. \& Kicinski, E. (1997). Pobreza y desigualdad en Puerto Rico: Problemas y alternativas. Boletín de Economía, 2, 18-19.

Sotomayor, O. \& Kicinski, E. (1999). Pobreza y desigualdad en Puerto Rico: Problemas y alternativas. En F.E. Martínez (Ed.), Futuro económico de Puerto Rico: Antología de ensayos del proyecto sobre el futuro de económico de Puerto Rico. (pp. 163-187). San Juan, Puerto Rico: Editorial de la Universidad de Puerto Rico.

Stanley, M. (2002). The urban experience: A psychological analysis. En G. Gmelch \& W.P. Zenner (Eds.), Urban life: Readings in the anthropology of the city (4a. ed.) (pp. 83-92). Prospect Heights, Illinois, EE.UU.: Waveland Press. 
Stevens, R.W. (1985). Los arrabales de San Juan: Una perspectiva histórica. Revista de Ciencias Sociales, 24 (1-2), 153-197.

Stinson Fernández, J. (1996). Hacia una antropología de la emigración planificada: El Negociado de Empleo y Migración y el caso de Filadelfia. Revista de Ciencias Sociales, 1 (Nueva Época), 112-155.

Suárez Torres, L. (2009, 14 de agosto). El circuito de Boston falla a favor del Fideicomiso. El Nuevo Día. p. 24.

Susser, I. \& Kreniske, J. (1987). The welfare trap: A public policy for deprivation. En L. Mullings (Ed.), Cities of the United States. Studies in urban anthropology. (pp. 51-68). Nueva York: Columbia University Press.

Toro, H. (2008). Inequality in Puerto Rico: Facing the Challenges. ReVista: Harvard Review of Latin America, Spring, 37-41.

Torres Rivera, F. (1992). Descomposición social y pobreza en Puerto Rico: Breve cuadro descriptivo a la altura del año 199. Revista de Estudios Generales, 6 (6), 207-215.

Turaine, A. (1977). La marginalidad urbana. Revista Mexicana de Sociología, 39 (4), 1105-1142.

U.S. Census Bureau. (2001). Poverty: How the Census Bureau calculates poverty. Recuperado el 20 de mayo de 2002 de http://www.census.gov/hhes/poverty/povdef.html

U.S. Census Bureau. (2003a). Censo de Población y Vivienda de 2000, compendio de datos 3 del Censo 2000. Washington, D.C., EE.UU.: Autor.

U.S. Census Bureau. (2003b). Public use microdata sample. 2000 Census of Population and Housing. Technical documentation. Washington, D.C., EE.UU.: Autor.

U.S. Census Bureau. (2007). Encuesta de la Comunidad del 2006, muestra de microdatos para uso público: Puerto Rico [Base de datos]. Washington, DC, EE.UU.: Autor.

U.S. Census Bureau. (2008a). 2007 American Community Survey 1-year estimates. Ranking tables. Poverty. Recuperado el 28 de agosto de 2008 de http://factfinder.census.gov/servlet/GRTTable?_bm=y\&_box_head_nbr=R1701\&-ds_name=ACS_2007_1YR_G00_\&-_lang=en\&format $=\mathrm{US}-30 \&-\mathrm{CONTEXT}=\mathrm{grt}$

U.S. Census Bureau. (2008b). Encuesta de la Comunidad del 2007, muestra de microdatos para uso público: Puerto Rico [Base de datos]. Washington, DC, EE.UU.: Autor. 
U.S. Census Bureau. (2008c). Poverty. Poverty thresholds 2007.

Recuperado el 22 de febrero de 2008 de

http://www.census.gov/hhes/www/poverty/threshld/thresh07.html

Van Weesep, J. (1994). Gentrification as a research frontier. Progress in Human Geography, 18 (1), 74-83.

Vasconcelos, C. (2003). Vivienda, territorios de exclusión y nuevas políticas sociales en Portugal. Revista Electrónica de Geografía y Ciencias Sociales, 7 (146).

Recuperado el 12 de febrero de 2008 de http://www.ub.es/geocrit/sn/sn146(124).htm

Vélez, M. (1995a). Características demográficas y socioeconómicas de la población bajo nivel de pobreza: Puerto Rico, 1990. Revista CIDE, 23-31.

Vélez, M. (1995b). La población de Puerto Rico bajo el nivel de pobreza, su estructura de sexo y sus características demográficas y socioeconómicas. San Juan, Puerto Rico: Universidad de Puerto Rico, Escuela Graduada de Salud Pública.

Vilagrasa Ibarz, J. (2000). Los debates sobre pobreza urbana y segregación social en Estados Unidos. Scripta Nova. Revista Electrónica de Geografía y Ciencias Sociales, 76, 55-78. Recuperado el 12 de febrero de 2008 de http://www.ub.es/geocrit/sn-76.htm

Walker, M.A. (1970). Reflexiones sociológicas sobre el problema de la pobreza. Revista de Administración Pública: Seminario sobre el Problema de la Pobreza en Puerto Rico, 1-10.

Walker, M.A. (1977). Dinámica de la pobreza: Una perspectiva psico-social. Ceiba, 5 (9-10), 110-118.

Wardell, H. (2002). Ambiguation, disjuncture, commitment: A social analysis of caribbean cultural creativity. The Journal of the Royal Anthropological Institute, 8 (3), 493-508.

Wilson, W.J. (1987). The truly disadvantaged: The inner city, the underclass, and public policy. Chicago, Illinois, EE.UU.: The University of Chicago Press.

Wirth, L. (2001). Leer la ciudad. Ensayos de antropología urbana: El urbanismo como forma de vida. Revista de Estudios Sociales, 10, 110-115.

Wirth, L. (2002). Urbanism as a way of life. En G. Gmelch \& W.P. Zenner (Eds.), Urban life: Readings in the anthropology of the city (4a. ed.) (pp. 65-82). Prospect Heights, Illinois, EE.UU.: Waveland Press. 
Zárate Martín, A.M. (2003). Madrid, un modelo suprametropolitano de urbanización. Anales de Geografía de la Universidad Complutense, 23, 283-304.

Recuperado el 12 de febrero de 2008 de http://www.ucm.es/BUCM/revistas/ghi/02119803/articulos/AGUC030311028 3A.PDF

Zeiderman, A. (2006, septiembre). Shizophrenia and the slum. Anthropology News. pp. 19-20.

Zenner, W.P. (2002). Beyond urban and rural: Communities in the 21st Century. En G. Gmelch \& W.P. Zenner (Eds.), Urban life: Readings in the anthropology of the city (4a. ed.) (pp. 53-60). Prospect Heights, Illinois, EE.UU.: Waveland Press. 


\section{Glosario}

Desahucio -

Desalojo -

Desplazado(a) -

Eliminación de arrabales -

Expropiación - eviction, en inglés. Es la desposesión legal del residente de una propiedad (Dommouchel, 1975). Abrams (1971) señala que representa el proceso legal para recuperar la propiedad por virtud de derecho supremo reconocido por ley.

implica evacuar o desocupar un lugar, en este caso, una vivienda. Por lo tanto, se entiende que el desahucio y expropiación es un desalojo de la vivienda.

familia, negocio u otro entidad desplazado(a) de un lugar por acción pública.

slum clearance, en inglés. Es definido por Abrams (1971) como la remoción de un arrabal por demolición, alteración o corrección de las condiciones que causan dicho estado. Añade que un arrabal puede ser eliminado por la rehabilitación, proveyendo mejores escuelas y facilidades sociales y removiendo las condiciones de vida. Además, Dummouchel (1975) lo define como la demolición y remoción de los edificios de un arrabal, usualmente bajo las provisiones de un programa de renovación urbana asistido federalmente.

expropriation, en inglés. Ortega Blake (1982: 166) lo define como "la limitación del derecho o propiedad al privar al dueño de una bien mueble o inmueble del mismo, mediante indemnización, en beneficio del interés público. La expropiación puede hacerse por derechos requeridos de dominio, en el caso de compras de empresas o por características patrimoniales, históricas o culturales del inmueble en cuestión". Abrams (1971) señala que expropiación es la acción de estado de tomar o modificar los derechos de propiedad de los individuos a través del ejercicio de la soberanía. Logie (1978) es más específico al definir expropiación, indicando que es la base legal de la adquisición compulsoria de sitios y edificios para la remoción de barrios y para otros propósitos, como la construcción de carreteras. 
Invasión -

Proyecto de renovación urbana - programa específico y oficial llevado a cabo por la

Realojo -

Renovación urbana -

Vivienda pública agencia pública local en el área de renovación urbana para prevenir y eliminar arrabales y puede implicar la eliminación de arrabal y redesarrollo, rehabilitación, conservación o combinación de los anteriores y adquisición de espacios abiertos (Dummouchel, 1975).

movimiento por un grupo o grupos a un área, cambiando el uso de tierra o el tipo de residente (Smith \& Klemanski, 1990).

implica mover un individuo, vivienda, uso o edificio de su lugar original a otra localidad (Moskowitz \& Lindbloom, 1993). Dommouchel (1975) lo define como el proceso en el que la agencia pública cumple con el requisito establecido por ley de hacer disponible viviendas decentes y sanitaria a familias desplazadas por programas públicos. Por otro lado, Abrams (1971) señala que el realojo es el establecimiento de viviendas o negocios en nuevas localidades, particularmente es aplicado a personas desplazadas por acción gubernamental. Añade que los programas de realojo han sido criticados por la insuficiencia de compensación, indisponibilidad de buenas viviendas, alquileres altos y pobre tratamiento a familias por parte de las autoridades, entre otras.

también conocida como rehabilitación urbana, revitalización urbana y redesarrollo urbano. Es definido por Abrams (1971) como el mejoramiento de ambientes urbanos a través de de iniciativa y asistencia pública en la demolición de arrabales, rehabilitación o conservación de estructuras existentes, proveyendo mejores viviendas y edificios comerciales, industriales y públicos. De la misma manera, Dummouchel (1975) lo define como el proceso a través del cual vecindarios deteriorados son mejorados a través de la eliminación o redesarrollo o a través de la rehabilitación e instalación de nuevos o modernizando ya existentes mejoras públicas.

vivienda construida y de propiedad de una agencia pública para las familias elegibles de bajos ingresos (Abrams, 1971). Smith y Klemanski (1990) la define como los domicilios construidos por o para el gobierno para servir principalmente a familias de bajos ingresos y añade que la construcción de 
unidades de vivienda pública usualmente es en forma de apartamentos multifamiliares de alta densidad, llamados proyectos de vivienda y que el primer programa gubernamental en establecer la vivienda pública vino con el Acta de Vivienda de 1937 de los Estados Unidos. 
Anejos 
17 de octubre de 2006

Anejo A

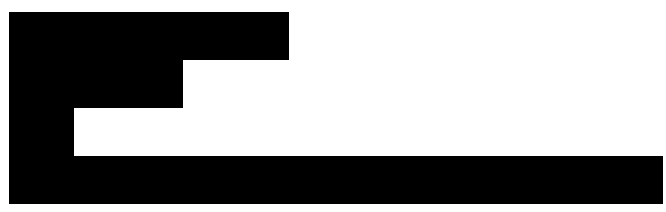

San Juan, Puerto Rico

Estimado señor

Saludos. Estoy realizando una investigación para obtener el Doctorado en Antropología de la Universidad de Salamanca en España, sobre las actitudes de los residentes y las residentes hacia el realojo de vivienda. En algunas comunidades, aledañas al Caño —, me interesa realizar entrevistas y administrar un cuestionario a las personas que ya han sido realojadas y las que serán realojadas en el futuro. De esa manera, podré conocer cuál es la postura que adopta una persona cuando es realojada. El análisis de las actitudes de los residentes y las residentes hacia el realojo contribuiría al desarrollo de políticas públicas adecuadas a sus necesidades particulares, específicamente en el proceso de seleccionar una residencia, abandonar su residencia anterior y reiniciar sus vidas en una vivienda diferente en una área distinta.

Por lo tanto, mis propósitos son informarle mi intención genuina de conocer más sobre las comunidades y solicitar su autorización para asistir a las diferentes actividades que se realicen.

Puede comunicarse conmigo al

Atentamente,

Vivianna De Jesús

Estudiante de Doctorado en Antropología

Universidad de Salamanca

c: Líderes de 


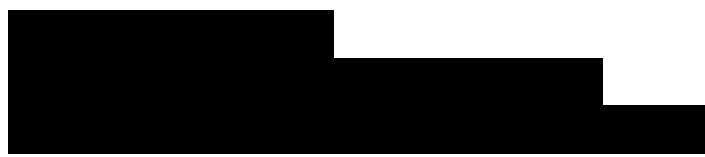

San Juan, Puerto Rico

Estimado señor

Saludos. Según nuestra conversación el viernes, 13 de octubre, estoy realizando una investigación para obtener el grado de Doctora en Antropología de la Universidad de Salamanca en España, sobre las actitudes de los residentes y las residentes hacia el realojo de sus viviendas. Siguiendo su sugerencia, el martes, 17 de octubre, me comuniqué con el Sr. _ , w para acordar un encuentro con los integrantes y las integrantes del para dejarles saber el propósito de mi estudio. Esa reunión se llevó a cabo el lunes, 30 de octubre, donde les expliqué mi intención de hacer el estudio en sus comunidades, además de presentarles los objetivos, metodología y plan de trabajo del proyecto. Al final de mi exposición, los líderes del me autorizaron llevar a cabo mi estudio, además de asistir a los talleres comunitarios del en sus comunidades.

Deseo comenzar el trabajo de campo de mi tesis doctoral a mediados de esta semana. Como acordamos, estoy dispuesta a trabajar como voluntaria en el . Más adelante, le daré más detalles del tiempo que le dedicaré a mi trabajo de campo en la comunidad.

Puede comunicarse conmigo a los siguientes teléfonos:

Atentamente,

Vivianna M. De Jesús 
19 de marzo de 2007

Anejo C

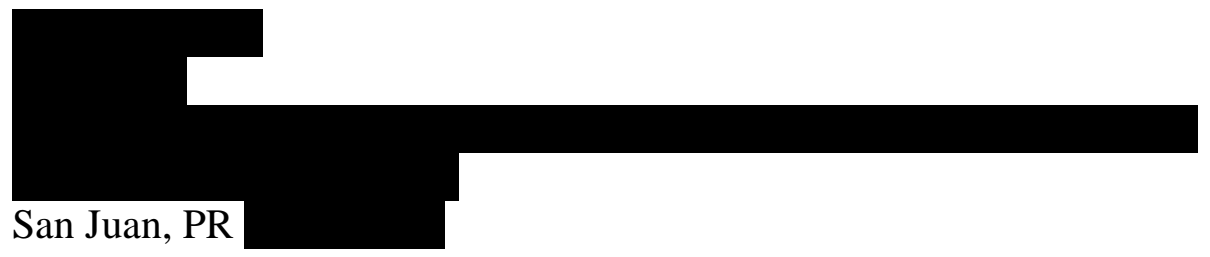

Estimada Sra.

Saludos. Según mi presentación ante el el lunes, 17 de octubre de 2007 en su reunión en la Oficina , estoy realizando mi tesis doctoral sobre las actitudes de los residentes y las residentes hacia el realojo de sus viviendas. En las próximas semanas, en su comunidad realizaré una encuesta y entrevistas a las personas que son jefes o jefas de sus hogares, que han sido realojados(as) o serán realojados(as) en el futuro.

De esa manera, podré conocer más sobre la actitud de una persona cuando es realojada o está próxima a ser realojada. El análisis de los hallazgos de este estudio contribuiría al desarrollo de políticas públicas y programas y servicios adecuados a sus necesidades particulares, específicamente en el proceso de seleccionar una residencia, abandonar su residencia anterior y reiniciar sus vidas en una vivienda diferente en un área distinta.

Por lo tanto, es mi propósito solicitar su autorización y apoyo para coordinar las visitas a las residencias de su comunidad.

Puede comunicarse conmigo al siguiente teléfono:

Atentamente,

Vivianna De Jesús

Estudiante de Doctorado en Antropología

Universidad de Salamanca

Salamanca, España 
de de 2007

Residente

Comunidad

Tesis doctoral: Las actitudes de los residentes y las residentes hacia el realojo en una comunidad urbana pobre en San Juan: 2006-7

Estimado(a) residente:

En la actualidad, estoy realizando una tesis doctoral sobre las actitudes de los residentes y las residentes hacia el realojo de sus viviendas, con el objetivo de obtener el Doctorado en Antropología de la Universidad de Salamanca, en España.

Los hallazgos podrían beneficiar a usted y su comunidad en futuros proyectos, al conocerse su modo de pensar en cuanto al realojo de sus hogares. De esta manera, quienes trabajan en la creación e implementación de los proyectos urbanos y de vivienda en Puerto Rico tendrían más información al momento de tomar decisiones para beneficio de las comunidades.

En esta comunidad, realizaré una encuesta al jefe o jefa del hogar que se encuentre disponible al momento y que desee participar. Para este estudio, seleccionaré 1 de cada 5 casas contiguas (al azar). También, realizaré entrevistas individuales en profundidad a los residentes y las residentes que voluntariamente así lo deseen. Espero estar en su comunidad durante este mes de julio. Es importante recalcar que su participación es voluntaria y estrictamente confidencial.

Si necesita más detalles, puede comunicarse con el personal del

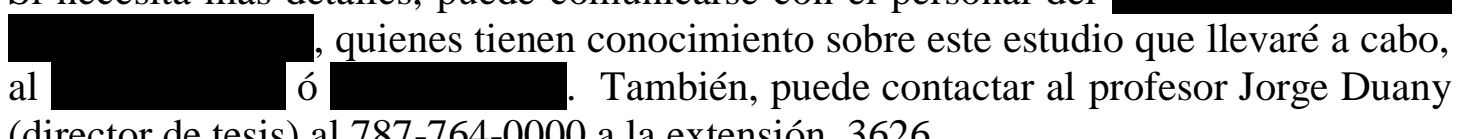

(director de tesis) al 787-764-0000 a la extensión 3626.

Muchas gracias por su atención.

Atentamente,

Vivianna De Jesús

copias:

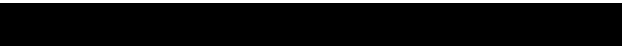


25 de septiembre de 2007

Comunidad

Estimado(a) residente:

Saludos. Mi nombre es Vivianna De Jesús. Soy residente de San Juan y estudiante de la Universidad de Salamanca en España. Para terminar mis estudios, estoy haciendo un proyecto sobre las actitudes de los(as) residentes hacia el realojo de sus viviendas en las 8 comunidades del Caño Entrevistaré a 1 de cada 5 viviendas, por lo que puede ser que salga seleccionado(a), como que no. Es voluntario participar y protegeré su confidencialidad, pues no preguntaré su nombre ni otra información personal.

Estaré en su comunidad el jueves 27, viernes 28, sábado 29 y domingo $\underline{\text { 30 }}$ de septiembre.

Si tiene alguna pregunta o duda, podría comunicarse conmigo al 787-764-0000 x. 3626.

Atentamente, 
Universidad de Salamanca

Anejo E

Facultad de Ciencias Sociales

Departamento de Sociología y Comunicación

Programa de Antropología de Iberoamérica

\section{Tesis doctoral: Las actitudes de los residentes y las residentes hacia el realojo en una comunidad urbana pobre en San Juan: 2006-7}

\section{Carta de presentación}

En la actualidad, estoy realizando una tesis doctoral sobre las actitudes de los residentes y las residentes hacia el realojo de sus viviendas, con el objetivo de obtener el Doctorado en Antropología de la Universidad de Salamanca, en España. Los hallazgos podrían beneficiar a usted y su comunidad en los futuros proyectos, al conocerse su modo de pensar en cuanto al realojo de sus hogares. De esta manera, quienes trabajan en la creación e implementación de los proyectos urbanos y de vivienda en Puerto Rico tendrían más información al momento de tomar decisiones para beneficio de las comunidades. Por otro lado, aportaría a la acumulación de conocimientos en las Ciencias Sociales, sobre todo la Antropología, en cuanto a estudios sobre la vivienda en Puerto Rico. También, actualizaría la literatura disponible sobre los proyectos de realojo que se han dado en Puerto Rico desde hace décadas. En esta comunidad, realizaré una encuesta y entrevistas individuales en profundidad a los residentes y las residentes. La participación en la encuesta y en las entrevistas será anónima y garantizo que mantendré la confidencialidad de sus respuestas, al no divulgar su información ofrecida.

Si necesita más detalles, puede comunicarse con el personal del

, quienes tienen conocimiento sobre este estudio que llevaré a cabo, al ó También, puede contactar al profesor Jorge Duany (director de tesis) al 787-764-0000 a la extensión 3626. 
Universidad de Salamanca

Facultad de Ciencias Sociales

Departamento de Sociología y Comunicación

Programa de Antropología de Iberoamérica

\section{Tesis doctoral: Las actitudes de los residentes y las residentes hacia el realojo en una comunidad urbana pobre en San Juan: 2006-7}

Hoja de consentimiento

Este estudio forma parte de los requisitos para que yo, Vivianna Margarita De Jesús Monge, pueda obtener el Doctorado en Antropología de la Universidad de Salamanca, en España. Su participación en este estudio me permitirá obtener más información relacionada a las actitudes de los residentes y las residentes hacia el realojo de sus viviendas en esta comunidad.

$\mathrm{Su}$ participación en esta investigación es voluntaria y estrictamente confidencial. Toda la información que usted brinde será mantenida de forma anónima y sólo utilizaré los resultados generales para fines educativos y científicos. Si usted decide participar y en algún momento desea suspender la entrevista, es libre de hacerlo en cualquier momento. Los posibles riesgos de daño son mínimos, no mayores a los encontrados en el diario vivir. Además, usted, su familia y comunidad podrían beneficiarse de este estudio porque se conocería más sobre el modo de pensar de $\operatorname{los}$ (as) residentes afectados(as) por el realojo y podría mejorar el proceso del mismo. Para proteger su confidencialidad, le garantizo que soy la única persona autorizada para tener los cuestionarios y la grabación digital de las entrevistas. Estos documentos los guardaré en un lugar seguro. Si le interesa participar en este estudio, debe firmar al final de la página en el lugar señalado. Gracias por su cooperación. Yo, intereso participar voluntariamente en la presente investigación. Entiendo que si durante el transcurso de la entrevista deseo no continuar con la misma, puedo abandonarla en cualquier momento. 
Universidad de Salamanca

Facultad de Ciencias Sociales

Departamento de Sociología y Comunicación

Programa de Antropología de Iberoamérica

\section{Tesis doctoral: Las actitudes de los residentes y las residentes hacia el realojo en una comunidad urbana pobre en San Juan: 2006-7}

Cuestionario a residentes a ser realojados(as)

\section{Comunidad}

Preguntas dirigidas al jefe o la jefa del hogar.

$\underline{\text { Vivienda }}$

1. ¿Es usted el(la) dueño(a) o inquilino(a) de esta vivienda?

Dueño(a)

Inquilino(a)

Otro(a) (especificar)

2. ¿Desde qué año reside en esta vivienda?

3. ¿Desde qué año reside en esta comunidad?

4a. ¿Sus antepasados (generaciones pasadas) han vivido en esta comunidad?

$$
\text { Sí _ No }
$$

4b. Si la respuesta es SÍ, ¿en qué fecha llegaron?

5. ¿Cuáles son los aspectos que le desagradan o molestan de su comunidad?

6. ¿Cuáles son los problemas que predominan en su comunidad (criminalidad, deserción escolar, embarazos en adolescentes, etc.)? 
$\underline{\text { Realojo }}$

7a. ¿Cómo fue informado(a) del posible realojo de su vivienda?

7b. ¿Cuándo fue informado(a)?

7c. ¿Quién le informó?

8. ¿Cuál es el motivo del realojo de su vivienda?

Dragado del caño

Construcción del puente

Arreglos a infraestructura

Proyecto comunitario

Otro

(especificar)

9. ¿Cuál es su mayor preocupación sobre el proceso de realojo? (Marcar sólo una)

Cómo será el proceso de realojo

Valor de la tasación de la vivienda

Los derechos que tiene

Pago por la nueva vivienda

La fecha en que ocurrirá

Otra (especificar)

10. De verse afectado(a) por algún proyecto, ¿cuál sería su preferencia en cuanto al nuevo lugar donde vivir? (¿Cómo es la casa de sus sueños?)

11a. ¿Ha sido realojado(a) anteriormente?

Sí No

11b. Si la respuesta es SÍ, ¿cuándo fue realojado(a)?

11c. Si la respuesta es SÍ, ¿adónde fue realojado(a)?

11d. Si la respuesta es $\mathbf{S} \mathbf{I}$, ¿de dónde fue realojado(a)? 
11e. Si la respuesta es Sí, ¿cómo fue realojado(a)?

11f. Si la respuesta es Sí, ¿por quién fue realojado(a)?

$11 \mathrm{~g}$. Si la respuesta es SÍ, ¿por qué fue realojado(a)?

12a. ¿Ha vivido en otras comunidades en San Juan?

Sí No

12b. Si la respuesta es SÍ, ¿cuáles?

13a. En su comunidad, ¿hay personas que ya fueron realojadas?

Sí No

13b. Si la respuesta es Sí, ¿ha vuelto a tener contacto con ellos(as)?

Sí No

13c. Si la respuesta es Sí, ¿le comentaron sobre la experiencia de vivir en otra comunidad?

Sí No

13d. Si la respuesta es Sí, ¿qué le comentaron?

14a. ¿Tiene sugerencias para mejorar el proceso de realojo?

Sí No

14b. Si la respuesta es SÍ, ¿cuáles son? 
15. ¿Cómo ha sido la comunicación con la organización que está planificando el realojo?

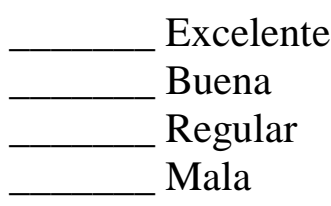

16. ¿Cómo percibe (o valora) los cambios ocurridos en su comunidad?

Excelentes

Buenos

Regulares

Malos

$\underline{\text { Redes sociales (Lazos de parentesco, amistad y compadrazgo) }}$

17a. ¿Tiene parientes que vivan en su comunidad?

Sí No

17b. Si la respuesta es SÍ, ¿cuántos tiene?

17c. Si la respuesta es SÍ, ¿con cuánta frecuencia los(as) ve? $(\mathrm{f} / \mathrm{t})$

17d. Si la respuesta es SÍ, ¿se ayudan mutuamente?

Sí No

18. Si la persona ha estado casada, ¿se ha casado con alguien de su comunidad?

Sí No

19. ¿Conoce personas en su comunidad que se han casado, donde ambas han nacido y/o criado aquí?

Sí No

20a. Si la persona tiene o ha tenido hijos(as), ¿ha asignado a personas de su comunidad como padrinos y/o madrinas de sus hijos(as)?

Sí No

20b. Si la respuesta es Sí, ¿por qué? 
21. ¿Conoce personas de su comunidad que han asignado a personas como padrinos y/o madrinas de sus hijos(as)?

Sí No

22. ¿Hay personas en su comunidad que hayan nacido donde usted nació?

Sí No

23a. ¿Hay ayuda y/o cooperación entre los(as) vecinos(as)?

Sí No

23b. Si la respuesta es Sí, ¿qué tipo de ayuda? ¿En qué consiste?

24a. ¿Viven en la comunidad personas que la fundaron?

Sí No

24b. Si la respuesta es SÍ, ¿quiénes son?

$\underline{\text { Características sociodemográficas }}$

25. ¿Cuál es su edad? (años cumplidos)

26. ¿Cuál es su género (sexo)? Femenino Masculino

27. ¿Cómo describiría su raza?

(Sugerencias: blanco(a), indio(a), jaba(o), negro(a) o trigueño(a)/moreno(a))

28. ¿Cuál es su lugar de nacimiento?

29a. ¿Cuántas personas viven con usted?

(comunidad, ciudad y país)

29b. Favor mencionar el género (sexo), edad y relación con usted.
a. Género
Edad Relación
b. Género Edad Relación
c. Género Edad Relación
d. Género Edad Relación
e. Género Edad Relación
f. Género Edad Relación 
30. ¿Cuál es su estado civil (estado marital)?
i. Casado(a)
ii. Convivencia
iii. Viudo(a)
iv. Divorciado(a)
vi. Nunca casado(a) v. Separado(a)

31. ¿Cuál es su grado escolar o universitario más alto alcanzado? (en años)

32a. ¿Cuál es su estado actual de empleo?
a. Empleada(o)
b. Desempleado(a) (buscando trabajo)
c. Fuera de la fuerza laboral (Retirado(a), encargado(a) del hogar, incapacitado(a)...)

32b. Si la persona está empleada, ¿cuál es la ocupación?

32c. Si la persona está empleada, ¿es a tiempo parcial o completo?

32d. Si la persona está empleada, ¿es temporero o permanente?

32e. Si la persona está desempleada, ¿por qué lo está?

32f. Si la persona está desempleada, ¿desde cuándo?

$$
\text { Meses }
$$

Años

32g. Si la persona está fuera de la fuerza laboral, ¿por qué lo está?

32h. Si la persona está fuera de la fuerza laboral, ¿desde cuándo?

Meses Años

Características económicas

33. ¿Cuáles son sus fuentes de ingresos que recibe regularmente al mes? (Marcar todas las necesarias.)

Salario por empleo
Negocio propio
Renta
Chiripeo (mandados, arreglos, cuido niños(as) ancianos(as), comida)
Pensión (Seguro Social, de retiro, incapacidad)
Ayuda de familiares y/o amistades
Otra

34a. En la actualidad, ¿tiene algún negocio de ventas en su casa (pasteles, alcapurrias, limbers, etc.)?<smiles>[SiH3]N=[No]</smiles>

34b. Si la respuesta es Sí, una vez sea realojado(a) en la nueva comunidad, ¿desearía continuar con el negocio?

Sí No 
34c. Si la respuesta es SÍ, ¿cree que se afectarían las ventas una vez se mude?

Sí No

34d. Si la respuesta es SÍ, ¿cómo?

34e. Si la respuesta es Sí, de mudar el negocio a la otra comunidad, ¿quiénes cree que podrían ser sus clientes en el futuro? ¿Podrían ser los(as) mismos(as) de su comunidad actual?

35a. ¿Recibe ayudas económicas del gobierno?

Sí _ No

35b. Si la respuesta es Sí, ¿cuáles son las ayudas económicas que recibe? (Marcar todas las necesarias.)

Programa de Asistencia Nutricional (PAN)

Desempleo

Plan 8

Subsidio de agua

Subsidio de electricidad

Otra (especificar)

35c. Si la respuesta es Sí, ¿por qué recibe ayudas económicas?

36. ¿Cuál es la cantidad total del ingreso de toda la familia al mes?

37a. ¿Tiene préstamos financieros?

Sí _ No

37b. Si la respuesta es SÍ, ¿qué cantidad de préstamos financieros tiene? 
37c. ¿Por qué solicitó préstamos?

38. ¿A cuál clase social cree que pertenece (baja, media, alta)?

39. ¿Cuáles son sus aspiraciones? (¿Cuáles son sus planes para el futuro?)

40. ¿Cuáles son sus pasatiempos? (¿Qué hace en su tiempo libre?)

41. ¿Pertenece a alguna organización (social, recreativa, deportiva) (club, asociación)?

Sí _ No

\section{Muchas gracias por su atención.}


Universidad de Salamanca

Facultad de Ciencias Sociales

Departamento de Sociología y Comunicación

Programa de Antropología de Iberoamérica

\section{Tesis doctoral: Las actitudes de los residentes y las residentes hacia el realojo en una comunidad urbana pobre en San Juan: 2006-7}

Cuestionario a residentes realojados(as)

Comunidad actual

Comunidad anterior

Preguntas dirigidas al jefe o la jefa del hogar.

\section{$\underline{\text { Vivienda }}$}

1. ¿Es usted el(la) dueño(a) o inquilino(a) de esta vivienda?

Dueño(a)

Inquilino(a)

Otro(a) (especificar)

2. ¿Desde qué año reside en esta vivienda?

3. ¿Desde qué año reside en esta comunidad?

4a. ¿Sus antepasados (generaciones pasadas) han vivido en esta comunidad?

$$
\text { Sí _ No }
$$

4b. Si la respuesta es Sí, ¿en qué fecha llegaron?

5. ¿Cuáles son los aspectos que le desagradan o molestan de su comunidad?

6. ¿Cuáles son los problemas que predominan en su comunidad (criminalidad, deserción escolar, embarazos en adolescentes, etc.)? 
$\underline{\text { Realojo }}$

7a. ¿Cómo fue informado(a) del realojo de su vivienda?

7b. ¿Cuándo fue informado(a)?

7c. ¿Quién le informó?

8. ¿Cuántas veces ha sido realojado(a)?

9. ¿Cuál fue el motivo del realojo de su vivienda?

Dragado del caño

Construcción del puente

Arreglos a infraestructura

Proyecto comunitario

Otro

(especificar)

10a. ¿Cuál era su mayor preocupación sobre el proceso de realojo? (Marcar sólo una)

Cómo será el proceso de realojo

Valor de la tasación de la vivienda

Los derechos que tiene

Pago por la nueva vivienda

La fecha en que ocurrirá

Otra

(especificar)

10b. Durante el proceso de realojo, ¿sintió que esa preocupación desapareció?

Sí No

10c. Si la respuesta es NO, ¿por qué? 
11a. ¿Cuál era su preferencia en cuanto al nuevo lugar donde vivir? (¿Cómo es la casa de sus sueños?)

11b. ¿Pudo satisfacer esa preferencia por el nuevo lugar a vivir?

Sí No

11c. Si la respuesta es NO, ¿por qué?

12a. Además de este realojo, ¿ha sido realojado(a) anteriormente? O sea, ¿ha sido realojado(a) en dos ocasiones o más?

Sí No

12b. Si la respuesta es SÍ, ¿cuándo fue realojado(a)?

12c. Si la respuesta es SÍ, ¿adónde fue realojado(a)?

12d. Si la respuesta es SÍ, ¿de dónde fue realojado(a)?

12e. Si la respuesta es Sí, ¿cómo fue realojado(a)?

12f. Si la respuesta es Sí, ¿por quién fue realojado(a)?

12g. Si la respuesta es SÍ, ¿por qué fue realojado(a)?

13a. ¿Ha vivido en otras comunidades en San Juan?

Sí No

13b. Si la respuesta es SÍ, ¿cuáles?

14a. ¿Ha vuelto a tener contacto con los(as) vecinos(as) de su antigua comunidad?

Sí No 
14b. Si la respuesta es SÍ, ¿qué tipo de contacto tiene?

15a. ¿Tiene sugerencias para mejorar el proceso de realojo?

Sí _ No

15b. Si la respuesta es Sí, ¿cuáles son?

16. ¿Cómo fue la comunicación con la organización que está planificando el realojo?

Excelente

Buena

Regular

Mala

17. ¿Cómo percibe (o valora) los cambios ocurridos en su antigua comunidad?

Excelentes

Buenos

Regulares

Malos

$\underline{\text { Redes sociales (Lazos de parentesco, amistad y compadrazgo) }}$

18a. ¿Tiene parientes que vivan en su comunidad?

Sí No

18b. Si la respuesta es Sí, ¿cuántos tiene?

18c. Si la respuesta es Sí, ¿con cuánta frecuencia los(as) ve? $(\mathrm{f} / \mathrm{t})$

18d. Si la respuesta es Sí, ¿se ayudan mutuamente?

Sí No 
19. Si la persona ha estado casada, ¿se ha casado con alguien de su comunidad?

Sí No

20. ¿Conoce personas en su comunidad que se han casado, donde ambas han nacido y/o criado aquí?

Sí No

21a. Si la persona tiene o ha tenido hijos(as), ¿ha asignado a personas de su comunidad como padrinos y/o madrinas de sus hijos(as)?

Sí No

21b. Si la respuesta es Sí, ¿por qué?

22. ¿Conoce personas de su comunidad que han asignado a personas como padrinos y/o madrinas de sus hijos(as)?

Sí No

23. ¿Hay personas en su comunidad que hayan nacido donde usted nació?

Sí No

24a. ¿Hay ayuda y/o cooperación entre los(as) vecinos(as)?

Sí No

24b. Si la respuesta es Sí, ¿qué tipo de ayuda? ¿En qué consiste?

25a. ¿Viven en la comunidad personas que la fundaron?

Sí No

25b. Si la respuesta es Sí, ¿quiénes son?

$\underline{\text { Características sociodemográficas }}$

26. ¿Cuál es su edad? (años cumplidos) 
27. ¿ Cuál es su género (sexo)?

Femenino

Masculino

28. ¿Cómo describiría su raza?

(Sugerencias: blanco(a), indio(a), jaba(o), negro(a) o trigueño(a)/moreno(a))

29. ¿Cuál es su lugar de nacimiento?

(comunidad, ciudad y país)

30a. ¿Cuántas personas viven con usted?

30b. Favor mencionar el género (sexo), edad y relación con usted.
a. Género
Edad
Relación
b. Género
Edad
Relación
c. Género
Edad
d. Género
Edad
e. Género
Edad
f. Género
Edad
Relación
Relación
Relación
Relación

31. ¿Cuál es su estado civil (estado marital)?
i. Casado(a)
ii. Convivencia
iii. Viudo(a) iv. Divorciado(a) v. Separado(a)
vi. Nunca casado(a)

32. ¿Cuál es su grado escolar o universitario más alto alcanzado? (en años)

33a. ¿Cuál es su estado actual de empleo?
d. Empleada(o)
e. Desempleado(a) (buscando trabajo)
f. Fuera de la fuerza laboral (Retirado(a), encargado(a) del hogar, incapacitado(a)...)

33b. Si la persona está empleada, ¿cuál es la ocupación?

33c. Si la persona está empleada, ¿es a tiempo parcial o completo?

33d. Si la persona está empleada, ¿es temporero o permanente?

33e. Si la persona está desempleada, ¿por qué lo está?

33f. Si la persona está desempleada, ¿desde cuándo?

Meses Años

33g. Si la persona está fuera de la fuerza laboral, ¿por qué lo está? 33h. Si la persona está fuera de la fuerza laboral, ¿desde cuándo?

Meses Años 


\section{$\underline{\text { Características económicas }}$}

34. ¿Cuáles son sus fuentes de ingresos que recibe regularmente al mes? (Marcar todas las necesarias.)

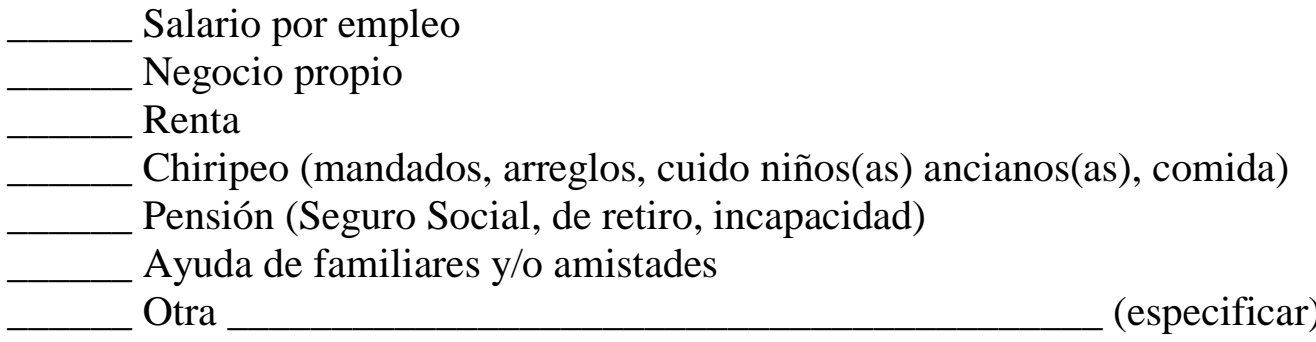

35a. En la actualidad, ¿tiene algún negocio de ventas en su casa (pasteles, alcapurrias, limbers, etc.)?

Sí _ No

35b. Si la respuesta es SÍ, en cuanto a ese negocio, ¿lo tenía en la otra comunidad?

Sí No

35c. Si la respuesta es Sí, ¿cree que las ventas se afectaron con el cambio de comunidad?

Sí No

35d. Si la respuesta es Sí, ¿cómo?

35e. Si la respuesta es SÍ, ¿quiénes son sus clientes en la actualidad? ¿Son los(as) mismos(as) de la otra comunidad?

36a. ¿Recibe ayudas económicas del gobierno?

Sí No 
36b. Si la respuesta es Sí, ¿cuáles son las ayudas económicas que recibe? (Marcar todas las necesarias.)

Programa de Asistencia Nutricional (PAN)
Desempleo
Plan 8
Subsidio de agua
Subsidio de electricidad
Otra
(especificar)

36c. Si la respuesta es SÍ, ¿por qué recibe ayudas económicas?

37. ¿Cuál es la cantidad total del ingreso de toda la familia al mes?

38a. ¿Tiene préstamos financieros?

Sí No

38b. Si la respuesta es SÍ, ¿qué cantidad de préstamos financieros tiene?

38c. ¿Por qué solicitó préstamos?

39. ¿A cuál clase social cree que pertenece (baja, media, alta)?

40. ¿Cuáles son sus aspiraciones? (¿Cuáles son sus planes para el futuro?)

41. ¿Cuáles son sus pasatiempos? (¿Qué hace en su tiempo libre?)

42. ¿Pertenece a alguna organización (social, recreativa, deportiva) (club, asociación)?

Sí No

\section{Muchas gracias por su atención.}


Universidad de Salamanca

Anejo I

Facultad de Ciencias Sociales

Departamento de Sociología y Comunicación

Programa de Antropología de Iberoamérica

Preguntas guías a residentes a ser realojados(as)

Tesis doctoral: Las actitudes de los residentes y las residentes hacia el realojo en una comunidad urbana pobre en San Juan: 2006-7

Vivianna Margarita De Jesús Monge 18 de julio de 2007 


\section{Preguntas}

1. En cuanto a su vivienda, ¿tiene miedos? ¿Cuáles son?

2. En cuanto al proceso de realojo de su vivienda, ¿tiene miedos? ¿Cuáles son?

3. ¿Cómo compara el proceso de realojo con las situaciones vividas en otras comunidades en el pasado y en el presente? (desalojo, expropiación)

4. ¿Cómo se sintió cuando le dijeron que sería realojado(a)?

5. ¿Cómo la comunidad en general reaccionó ante de la noticia del realojo? ¿Se unió?

6. ¿Tienes dudas tiene sobre el proceso de realojo? ¿Cuáles son?

7. ¿Cuán preparado(a) se siente para ser realojado(a)?

8. ¿Cómo ha comenzado el proceso de realojo? ¿Cómo han sido los preparativos? Descríbalo paso a paso.

9. ¿Ha estado involucrado(a) en el proceso de realojo? ¿Cuánto? ¿Ha ido a reuniones?

10. ¿Describiría al realojo como voluntario (había proyecto y opciones presentadas) o forzado (no escogió opciones presentadas)? ¿Por qué?

11. ¿Cómo cree que será ese proceso de adaptación en esta comunidad? ¿Cómo cree que se adaptará?

12. En general, ¿cree que su vida cambiará cuando sea realojado(a)? ¿Cómo?

13. Una vez realojado(a), ¿desearía seguir yendo a los mismo lugares (farmacia, colmado, médicos(as))?

14. Una vez realojado(a), ¿esperaría estar lejos o cerca de familiares y amistades?

15. ¿Cree que adonde será realojado(a) tendrá el mismo sentido de comunidad que ahora tiene ésta?

16. ¿Cree que la nueva comunidad perderá algo en comparación con esta comunidad?

17. ¿Cree que la nueva comunidad ganará algo en comparación con esta comunidad?

18. ¿Le han contado algo de cómo se vive en los nuevos proyectos de vivienda

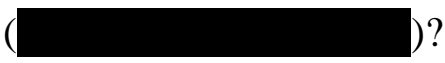

19. ¿Cómo describiría su relación con los(as) vecinos(as)? ¿Cómo espera que sea su relación con los(as) vecinos(as) en la nueva comunidad? 
20. ¿Cómo cree que está cambiando su comunidad? (¿Están llegando nuevas personas (dominicanas)? ¿Qué piensa al respecto? ¿Cómo es su relación con estas personas?)

21. Una vez realojado(a), ¿desearía regresar a esta comunidad?

22. ¿Cómo desea que sea esta nueva comunidad adonde irá vivir? Descríbala.

23. ¿Qué extrañará o echará de menos de esta comunidad?

24. ¿Cómo compara su comunidad con el resto de San Juan? ¿Igual o diferente? ¿Hay más comunidades como ésta?

25. ¿Quiénes son los(as) pobres? ¿Se considera pobre?

26. ¿Cuáles son los problemas sociales que más abundan en la comunidad? (embarazos adolescentes, embarazos fuera del matrimonio, deserción escolar, criminalidad) ¿Hay personas con estos problemas? 
Universidad de Salamanca

Facultad de Ciencias Sociales

Departamento de Sociología y Comunicación

Programa de Antropología de Iberoamérica

Preguntas guías a residentes realojados(as)

Tesis doctoral: Las actitudes de los residentes y las residentes hacia el realojo en una comunidad urbana pobre en San Juan: 2006-7

Vivianna Margarita De Jesús Monge 18 de julio de 2007 


\section{Preguntas}

1. En cuanto a su vivienda pasada, ¿tenía miedos? ¿Cuáles eran? Y, en cuanto a su vivienda actual, ¿tiene miedos? ¿Cuáles son?

2. En cuanto al proceso de realojo de su vivienda, ¿cuáles eran sus miedos?

3. ¿Cómo compara el proceso de realojo con las situaciones vividas en otras comunidades en el pasado y en el presente? (desalojo, expropiación)

4. ¿Cómo se sintió cuando le dijeron que sería realojado(a)?

5. ¿Cómo la comunidad en general reaccionó ante de la noticia del realojo? ¿Se unió?

6. Antes del proceso de realojo, ¿tenía dudas sobre el proceso de realojo? ¿Cuáles eran?

7. ¿Cómo fue el proceso de realojo? ¿Cómo fueron los preparativos? Descríbalo paso a paso.

8. ¿Ha estado involucrado(a) en el proceso de realojo? ¿Cuánto? ¿Ha ido a reuniones?

9. ¿Describiría al realojo como voluntario (había proyecto y opciones presentadas) o forzado (no escogió opciones presentadas)? ¿Por qué?

10. ¿Cómo ha sido ese proceso de adaptación en esta comunidad? ¿Cómo cree que se adaptó?

11. En general, ¿cómo su vida ha cambiado desde que fue realojado(a)?

12. ¿Sigue yendo a los mismo lugares (farmacia, colmado, médicos(as)) de antes? ¿Por qué?

13. En comparación con la otra comunidad donde vivía, ¿cree que ahora está lejos o cerca de familiares y amistades?

14. ¿Cree que ésta tiene el mismo sentido de comunidad que de donde fuera realojado(a)?

15. ¿Cree que esta comunidad perdió algo en comparación con la otra comunidad?

16. ¿Cree que esta comunidad ganó algo en comparación con la otra comunidad?

17. ¿Cómo compara esta comunidad con la anterior, de donde fue realojado(a)?

18. ¿Hay algo que le agrade de esta nueva comunidad? ¿Qué es?

19. ¿Hay algo que le desagrade de esta nueva comunidad? ¿Qué es?

20. ¿Cómo describiría su relación con los(as) vecinos(as) actuales? ¿Mantiene contacto con los(as) vecinos(as) de su antigua comunidad? 
21. Antes de ser realojado(a), ¿cree que había cambiado su comunidad? ¿Cómo? (¿Están llegando nuevas personas (dominicanas)? ¿Qué piensa al respecto? ¿Cómo es su relación con estas personas?)

22. ¿Ha regresado a su antigua comunidad?

23. ¿Qué extraña o echa de menos de su pasada comunidad?

24. ¿Cómo compara su comunidad con el resto de San Juan? ¿Igual o diferente? ¿Hay más comunidades como ésta?

25. ¿Quiénes son los(as) pobres? ¿Se considera pobre?

26. ¿Cuáles son los problemas sociales que más abundan en la comunidad? (embarazos adolescentes, embarazos fuera del matrimonio, deserción escolar, criminalidad) ¿Hay personas con estos problemas? 
Anejo K

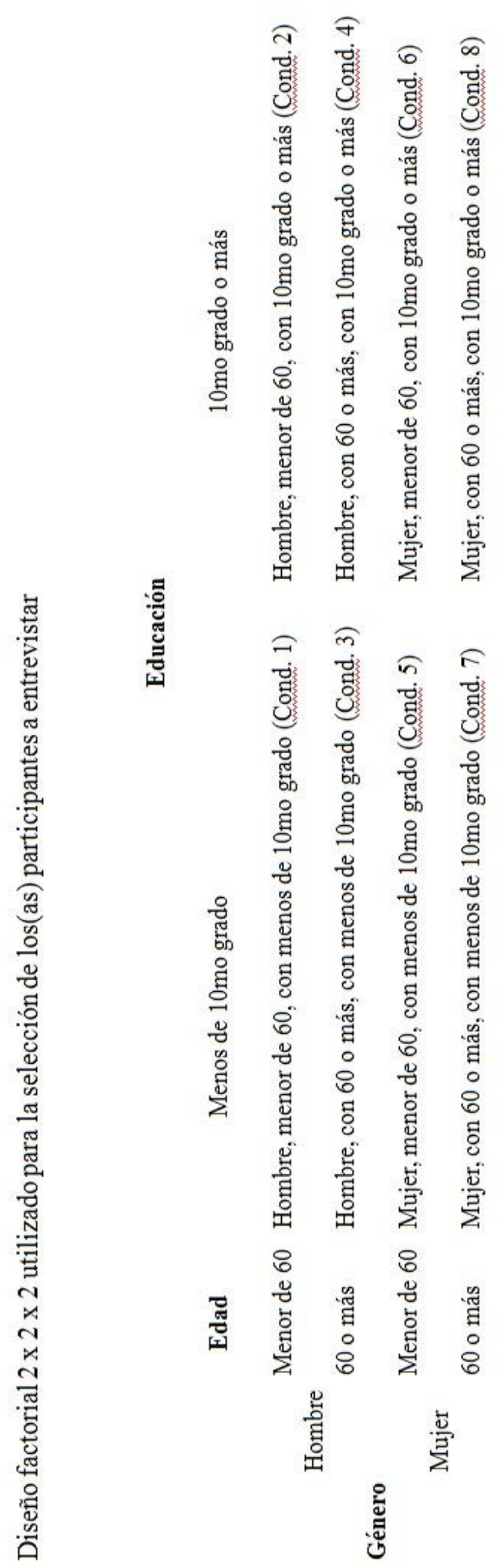


Anejo L

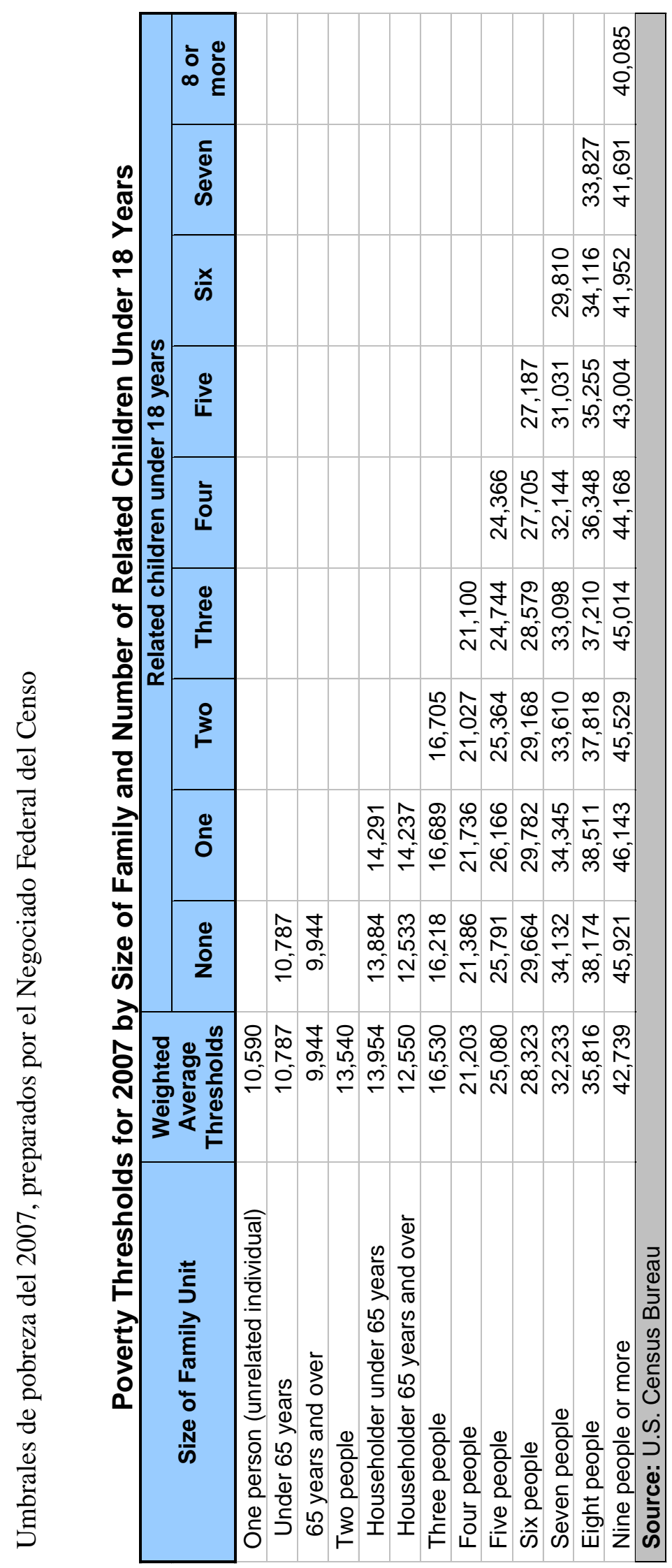

